\title{
Identification of trigger-related phenotypes in sarcoidosis
}

\section{Els Beijer}

5
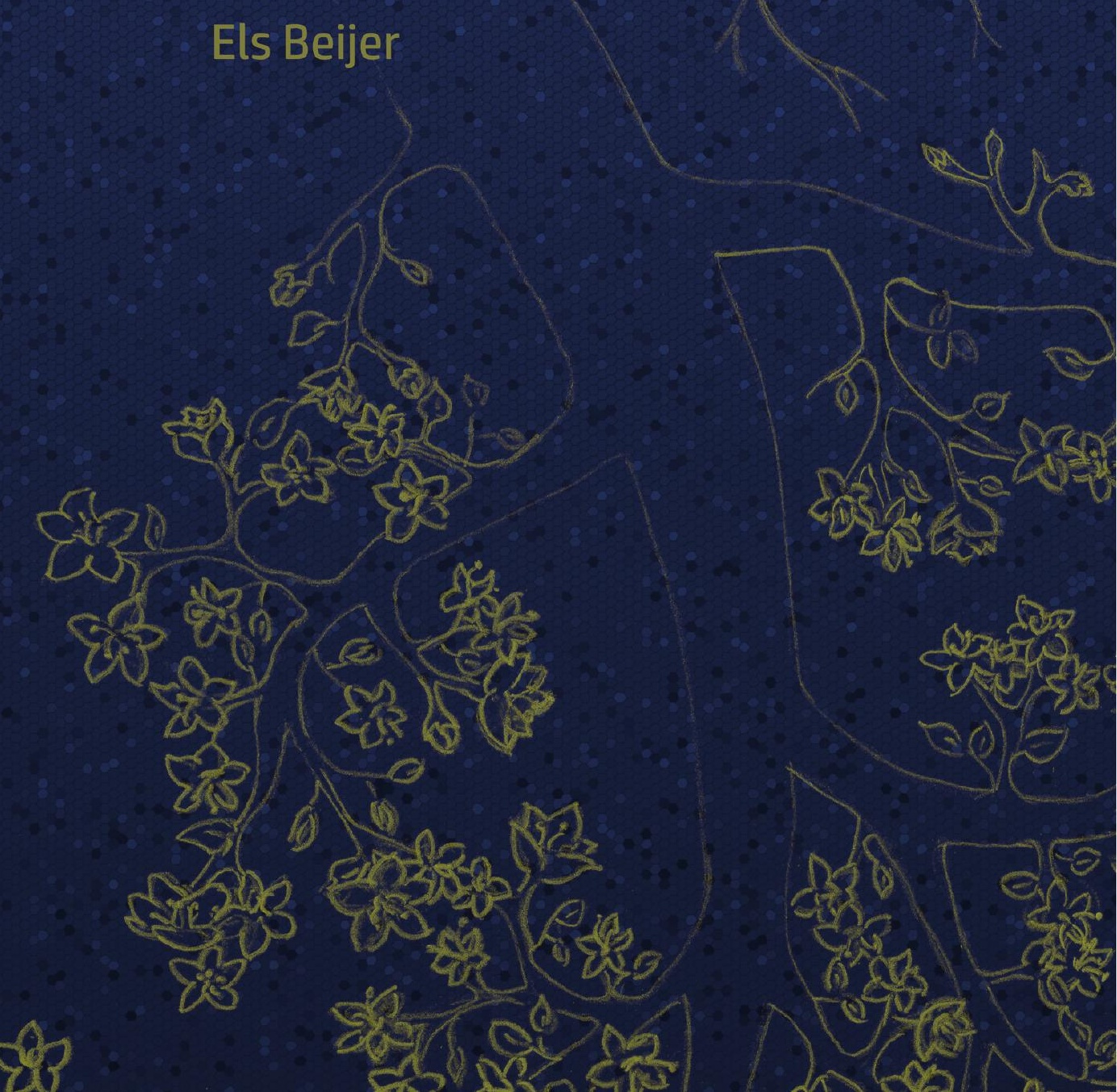


\section{Identification of trigger-related phenotypes in sarcoidosis}


Identification of trigger-related phenotypes in sarcoidosis

Els Beijer

Thesis University of Utrecht

ISBN: 978-90-393-7375-0

DOI: https://doi.org/10.33540/452

Layout and Print: GVO Drukkers en Vormgevers

The research described in this thesis was performed with the TopZorg grant funded by ZonMw and with funding from Sarcoidose.nl

Publication of this thesis was financially supported by St. Antonius Ziekenhuis,

Boehringer Ingelheim, Westfalen Medical BV and Sarcoidose.nl 


\section{Identification of trigger-related phenotypes in sarcoidosis}

Identificatie van trigger-gerelateerde fenotypes in sarcoïdose

(met een samenvatting in het Nederlands)

\section{Proefschrift}

ter verkrijging van de graad van doctor aan de Universiteit Utrecht op gezag van de rector magnificus, prof.dr. H.R.B.M. Kummeling, ingevolge het besluit van het college voor promoties in het openbaar te verdedigen op dinsdag 15 juni 2021 des middags te 2.15 uur

door

Elsje Dinanda Beijer

geboren op 8 mei 1991

te Zutphen 
Promotor:

Copromotoren:
Prof. dr. J.C. Grutters

Dr. M. Veltkamp

Dr. B. Meek 
Paranimfen:

J.J. van der Vis

A.A. van Batenburg

Beoordelingscommissie: Prof. dr. R. Goldschmeding, University Medical Centre Utrecht, Department of pathology

Prof. dr. H.G.M. Heijerman, University Medical Centre Utrecht, Division of Heart and Lungs

Prof. dr. L. Koenderman, University Medical Centre Utrecht, Division of Heart and Lungs

Prof. dr. J. Müller-Quernheim, University of Freiburg, Department of Pneumology

Prof. dr. D.J.J. Heederik, Utrecht University, Institute for Risk Assessment Sciences 




\section{Contents}

$\begin{array}{lll}\text { Chapter } 1 & \mathbf{1} \text { Introduction and outline of the thesis }\end{array}$

Chapter 2 Etiology and immunopathogenesis of sarcoidosis: Novel 23 insights

Chapter 3 Clinical observations: is metal or silica associated sarcoidosis a $\mathbf{5 5}$ new trigger-related phenotype?

Chapter 4 Immunoreactivity to metal and silica associates with 67 sarcoidosis in Dutch patients

Chapter 5 Simultaneous testing of immunological sensitization to multiple antigens in sarcoidosis reveals an association with inorganic antigens specifically related to a fibrotic phenotype

Chapter 6 Latent tuberculosis infection associates with cardiac involvement in patients with sarcoidosis

Chapter 7 Presence of Propionibacterium acnes in granulomas associates 131 with a chronic disease course in Dutch sarcoidosis patients

Chapter 8 Detection of Propionibacterium acnes in granulomas of 151 patients with either hypersensitivity pneumonitis or vasculitis reveals that its presence is not unique for sarcoidosis

Chapter 9 Elevated serum amyloid A levels are not specific for sarcoidosis 163 but associate with a fibrotic pulmonary phenotype

Chapter 10 Summary and general discussion

\section{Appendix}

Nederlandse samenvatting

Affiliations of the authors

Dankwoord

List of publications 

Chapter 1

\section{Introduction and outline of the thesis}
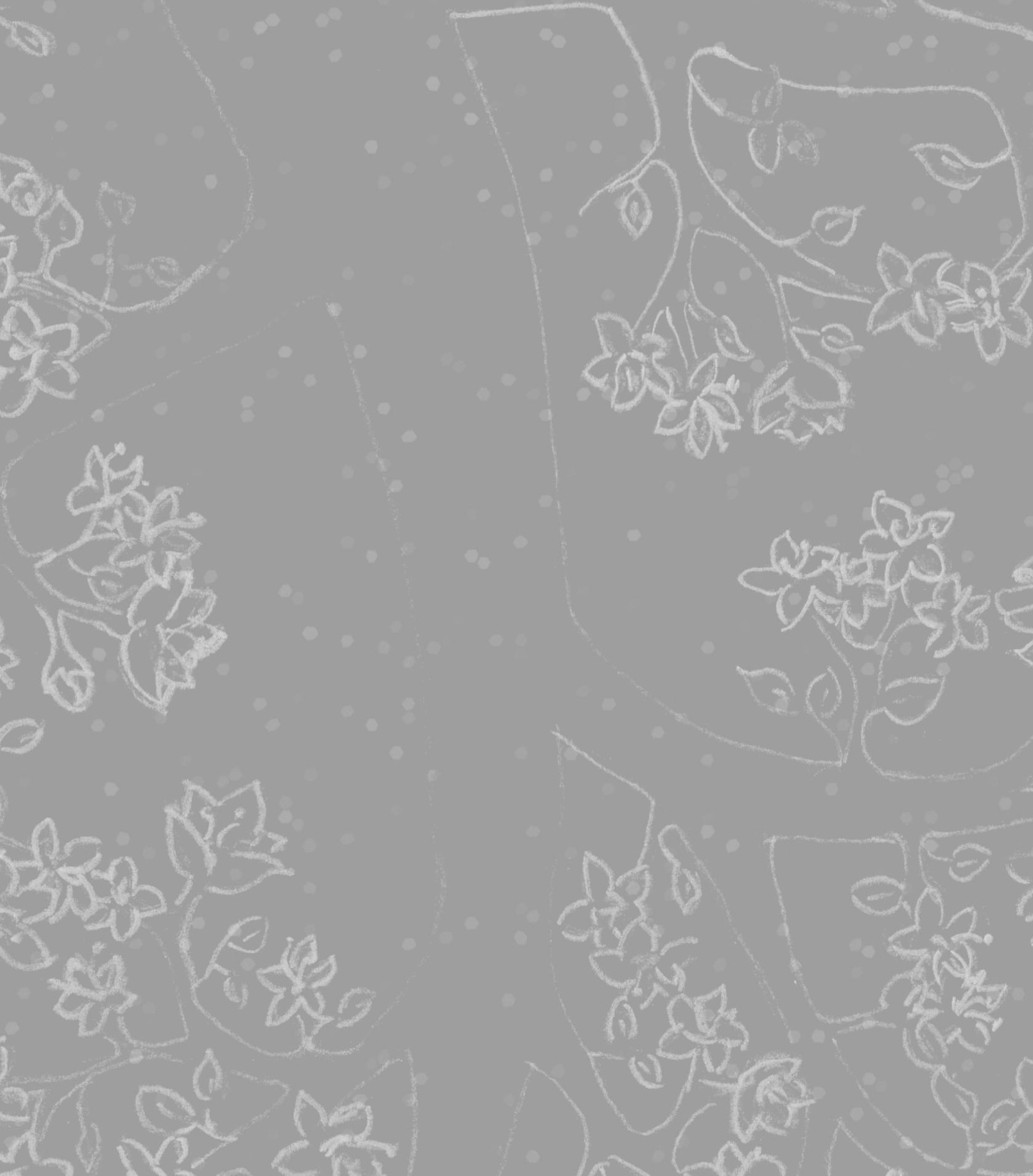



\section{Introduction}

Sarcoidosis is a systemic disease which is characterized by the formation of non-caseating granulomas (1). Virtually any part of the body can be involved, but intrathoracic lymph nodes, the lungs, skin and eyes are most commonly involved (2). Granulomas are compact organized structures of mature macrophages accompanied by other immune cells including lymphocytes and plasma cells. They are thought to be formed in response to inability of phagocytes to destroy certain particles. Granulomas are not specific for sarcoidosis since infectious agents, foreign bodies, many inflammatory and autoimmune conditions coincide with granuloma formation (3). Therefore, a diagnosis of sarcoidosis can only be made when other causes of granuloma formation are excluded (4). Sarcoidosis mainly effects middleaged individuals, with the highest incidence among men between 30 and 50 years of age and women between 40 and 60 years of age (5). The incidence and prevalence of sarcoidosis vary between different regions of the world (6). In the Netherlands the incidence and prevalence of sarcoidosis are estimated to be $10-20$ and 40 per 100.000 respectively (7).

\section{Etiology of sarcoidosis}

The etiology of sarcoidosis is not clear, but both the innate and adaptive immune system are suggested to be involved in its disease pathogenesis (8). A more detailed description of cellular players of our innate and adaptive immune system possible involved in sarcoidosis pathogenesis can be found in chapter 2 . Sarcoidosis is thought to develop due to the interplay between genetic susceptibility, the immune system and exposure to particular etiologic agents. Agents described in relation to sarcoidosis pathogenesis are bacteria (9), inorganic agents $(10,11)$ and auto-antigens $(12,13)$. Those possible "triggers" are reviewed in chapter 2 . The suggestion that inorganic agents are related to sarcoidosis pathogenesis originates from the observation that certain inorganic agents such as metals or silica are able to induce granulomas (14). The most extensively studied metal in the context of granulomatous disease is probably beryllium. Chronic beryllium disease (CBD), a granulomatous disease related to beryllium exposure, can be histopathological and clinical indistinguishable from sarcoidosis (15). Activation of $\mathrm{CD}^{+} \mathrm{T}$-cells by beryllium in genetic susceptible individuals will lead to beryllium sensitization (BeS). BeS can be measured in blood by a lymphocyte proliferation test (LPT), since peripheral blood mononuclear cells (PBMCs) of beryllium sensitized patients show a proliferative response when stimulated in vitro with beryllium (16). The relation between other metals and silica and sarcoidosis have mainly been described in case reports $(17,18)$ or epidemiological studies (19). Examples of clinical observations are described in detail in chapter 3. Sensitization to metals other than beryllium and silica have, however, not been examined in cohorts of sarcoidosis patients and controls. This issue is further addressed in chapter 4. 


\section{Clinical presentation and phenotypes of sarcoidosis}

As mentioned before, the presentation of sarcoidosis can be very heterogeneous and virtually any organ can be affected. The lungs and hilar and mediastinal lymph nodes are the most frequently involved (in about $90 \%$ of cases), followed by involvement of the skin, eyes and liver (2). Moreover, the course of the disease is unpredictable, meaning that the disease can spontaneously resolve, while a chronic disease course can also develop (20). The best known phenotype in sarcoidosis is Löfgren's syndrome, an acute, mainly selflimiting presentation of sarcoidosis. The clinical presentation of Löfgren's syndrome is accompanied by arthritis, erythema nodosum and bilateral hilar lymphadenopathy (21). Some studies already tried to identify other phenotypic subgroups among sarcoidosis patients, for instance by clustering involved organs and disease symptoms in relation to gender, geographic origin and occupational categories or by relating disease course to sex or composition of bronchoalveolar lavage (BAL) fluid (22-24). Since clinical characteristics including organ involvement, Scadding stage and disease course have never been studied in relation to certain etiologic agents in sarcoidosis, in chapter 5 we tried to identify new clinical phenotypes by relating sensitization to organic and inorganic agents to clinical characteristics. An association between sensitization to mycobacterial antigens, one of the identified phenotypes in chapter 5 , was further evaluated in chapter 6 .

\section{The pathological hallmark of sarcoidosis: Non-caseating granulomas}

As mentioned above, the hallmark of sarcoidosis are non-caseating granulomas (25). The diagnosis of sarcoidosis is made based on exclusion of other causes of granulomas since granulomas are observed also in particular infectious diseases, summarized in (4). Moreover, as previously mentioned, several inorganic agents have been found to cause a granulomatous reaction (14). Among sarcoidosis patients, such a granulomatous reaction in response to inorganic agents is observed in tattoos in some cases, probable induced by ink pigments $(26,27)$. Figure 1 shows an example of non-caseating lymph node granulomas including inorganic particles.

Since tuberculosis and sarcoidosis share radiological, clinical and histological similarities (28), mycobacteria have been extensively studied in relation to sarcoidosis pathogenesis (29). Also other bacteria, including Propionibacterium acnes ( $P$. acnes), currently known as Cutibacterium acnes (C. acnes), are able to induce granuloma formation $(30,31)$ and are 
related to sarcoidosis disease pathogenesis mainly by Japanese studies (32). A relation between $P$. acnes and sarcoidosis is difficult to prove, since this bacterium is a commensal of the human skin (33). Some studies have focused on cellular and humoral immune responses to $P$. acnes in sarcoidosis $(34,35)$. However $P$. acnes sensitization to and antibodies against $P$. acnes can also be observed in healthy individuals (36-38). Furthermore, sensitization may be difficult to demonstrate in sarcoidosis patients due to Tcell anergy and exhaustion (39). Another way of examining a relation between $P$. acnes and sarcoidosis is to study its presence in granulomas of patients, which we describe in chapter 7. Although $P$. acnes have previously been related to sarcoidosis pathogenesis, granulomas observed in other interstitial lung diseases (ILDs) have not been studied with regard to presence of $P$. acnes. In chapter $\mathbf{8}$ we examined whether presence of $P$. acnes is limited to granulomas of sarcoidosis patients or that this bacterium can be identified in granulomas of other diseases as well.

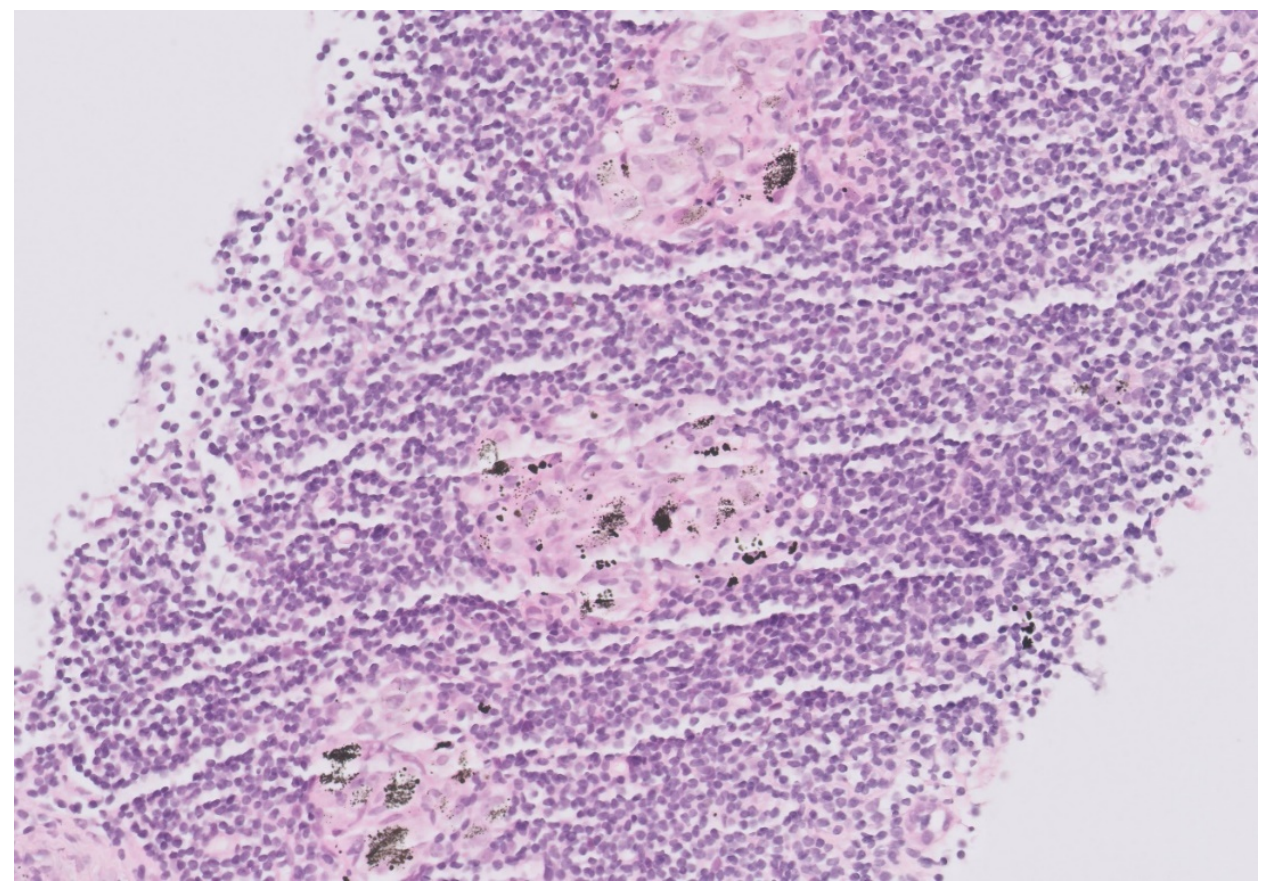

Figure 1. Axillary lymph node of a sarcoidosis patient with large tattoos on both arms, showing ink particles within non-caseating granulomas.

Serum levels of Serum amyloid A (SAA), an acute phase protein (40), have been observed in increased amounts in inflammatory diseases including rheumatoid arthritis, Crohn's disease 
sarcoidosis. The pattern of SAA in granulomas of sarcoidosis was shown to differ from granulomas of Crohn's disease and CBD patients (12). For this reason we investigated in chapter 9 whether SAA levels were higher in serum from patients with granulomatous diseases including sarcoidosis, hypersensitivity pneumonitis and (eosinophilic) granulomatosis with polyangiitis than in controls or patients without granulomatous disease. Furthermore, since the SAA pattern differed between CBD and sarcoidosis patients, we examined whether SAA serum levels differed among sarcoidosis patients sensitized to bacterial antigens, inorganic antigens and self-antigens.

\section{Aim of this thesis}

Sarcoidosis has a very heterogeneous presentation and multiple agents have been related to granuloma formation. It is therefore plausible that sarcoidosis is not a single homogeneous disease but rather a collection of several granulomatous diseases induced by different granuloma stimulating triggers in genetically susceptible individuals. As described above, several possible triggers have already been related to sarcoidosis pathogenesis. However, studies combining multiple possible triggers in the same cohort of patients are lacking. Furthermore, relations between possible triggers and clinical data have not been described before but may lead to the identification of trigger-related phenotypes. This may be clinically relevant as it has the potential to improve the prediction of disease prognosis and a more personized based treatment regime could be explored in subcategories of patients. For example, in sarcoidosis patients with a possible bacterial antigen as cause of the disease the use of antibiotics could be further explored. In patients with an inorganic cause of the disease the focus in clinical management should incorporate the avoidance of further exposure. This thesis therefore aimed to simultaneously study organic as well as inorganic agents in sarcoidosis in order to define trigger-related phenotypes which may allow a more personalized based clinical management in the future. 


\section{Scope and outline of this thesis}

Chapter 2 provides an overview of current knowledge on the etiology and immunopathogenesis of sarcoidosis.

Chapter 3 describes three clinical cases in which sarcoidosis possible developed in response to aluminum, beryllium and silica exposure.

In Chapter 4 metal and silica exposure and sensitization was examined in a Dutch sarcoidosis and control cohort.

Chapter 5 describes peripheral blood responses to organic and inorganic antigens in the same cohort of sarcoidosis patients. Antigen sensitization was linked to clinical characteristics for identification of trigger-related phenotypes.

In Chapter 6 the association between a latent tuberculosis infection (LTBI) and cardiac involvement in sarcoidosis, one of the trigger-related-phenotypes identified in chapter 5 , is further evaluated.

In Chapter 7 the presence of $P$. acnes in granulomas of Dutch sarcoidosis patients was demonstrated with the use of immunohistochemistry. Results of the staining were studied in relation to disease course.

Chapter 8 examines tissue and granulomas of GPA, EGPA and HP patients for presence of $P$. acnes.

Chapter 9 studies SAA levels in serum of sarcoidosis, HP, (E)GPA and IPF patients.

Chapter 10 gives a summary and discusses the main findings of this thesis. 


\section{References}

1. Chopra A, Avadhani V, Tiwari A, Riemer EC, Sica G, Judson MA. Granulomatous lung disease: clinical aspects. Expert Review of Respiratory Medicine. Taylor and Francis Ltd; 2020.

2. Grunewald J, Grutters JC, Arkema E V., Saketkoo LA, Moller DR, Müller-Quernheim J. Sarcoidosis. Nat Rev Dis Prim. 2019 Dec 1;5(1).

3. Pagán AJ, Ramakrishnan L. The Formation and Function of Granulomas. Annu Rev Immunol. 2018 Apr 26;36(1).

4. James DG. A clinicopathological classification of granulomatous disorders. Vol. 76, Postgraduate Medical Journal. Postgrad Med J; 2000. p. 457-65.

5. Polverino F, Balestro E, Spagnolo P. Clinical Presentations, Pathogenesis, and Therapy of Sarcoidosis: State of the Art. J Clin Med. 2020 Jul 24;9(8):2363.

6. Arkema E V., Cozier YC. Sarcoidosis epidemiology: recent estimates of incidence, prevalence and risk factors. Curr Opin Pulm Med. 2020 Sep;26(5):527-34.

7. Mateyo K, Thomeer M. Sarcoidosis around the Globe. Semin Respir Crit Care Med. 2017 Aug 1;38(4):393-403.

8. Cinetto F, Scarpa R, Dell'Edera A, Jones MG. Immunology of sarcoidosis: old companions, new relationships. Curr Opin Pulm Med. 2020 Sep;26(5):535-43.

9. Esteves T, Aparicio G, Garcia-Patos V. Is there any association between Sarcoidosis and infectious agents?: a systematic review and meta-analysis. BMC Pulm Med. 2016 Nov 28;16(1):165.

10. Deubelbeiss U, Gemperli A, Schindler C, Baty F, Brutsche MH. Prevalence of sarcoidosis in Switzerland is associated with environmental factors . Eur Respir J. 2010;35(5):1088-97.

11. Rafnsson V, Ingimarsson O, Hjalmarsson I, Gunnarsdottir H. Association between exposure to crystalline silica and risk of sarcoidosis. Occup Environ Med. 1998;55(10):657-60.

12. Chen ES, Song Z, Willett MH, Heine S, Yung RC, Liu MC, et al. Serum amyloid A regulates granulomatous inflammation in sarcoidosis through Toll-like receptor-2. Am J Respir Crit Care Med. 2010 Feb 15;181(4):360-73.

13. Wahlstrom J, Dengjel J, Persson B, Duyar H, Rammensee HG, Stevanovic S, et al. Identification of HLA-DR-bound peptides presented by human bronchoalveolar lavage cells in sarcoidosis. J Clin Invest. 2007 Nov;117(11):3576-82.

14. Molina-Ruiz AM, Requena L. Foreign Body Granulomas. Vol. 33, Dermatologic Clinics. W.B. Saunders; 2015. p. 497-523.

15. Mayer AS, Hamzeh N, Maier LA. Sarcoidosis and chronic beryllium disease: similarities and differences. Semin Respir Crit Care Med. 2014 Jun;35(3):316-29. 
16. Balmes JR, Abraham JL, Dweik RA, Fireman E, Fontenot AP, Maier LA, et al. An official American Thoracic Society statement: diagnosis and management of beryllium sensitivity and chronic beryllium disease. Am J Respir Crit Care Med. 2014 Nov 15;190(10):e34-59.

17. Werfel U, Schneider J, Rodelsperger K, Kotter J, Popp W, Woitowitz HJ, et al. Sarcoid granulomatosis after zirconium exposure with multiple organ involvement. Eur Respir J. 1998 Sep;12(3):750.

18. Cai HR, Cao M, Meng FQ, Wei JY. Pulmonary sarcoid-like granulomatosis induced by aluminum dust: report of a case and literature review . Chin Med J (Engl). 2007 Sep 5;120(17):1556-60.

19. Judson MA. Environmental Risk Factors for Sarcoidosis. Vol. 11, Frontiers in Immunology. Frontiers Media S.A.; 2020.

20. Prasse A. The Diagnosis, Differential Diagnosis, and Treatment of Sarcoidosis . Dtsch Arztebl Int. 2016 Aug 22;113(33-34):565-74.

21. Karakaya B, Kaiser Y, Van Moorsel CHM, Grunewald J. Löfgren's Syndrome: Diagnosis, Management, and Disease Pathogenesis. Semin Respir Crit Care Med. 2017 Aug 1;38(4):463-76.

22. Schupp JC, Freitag-Wolf S, Bargagli E, Mihailović-Vučinić V, Rottoli P, Grubanovic A, et al. Phenotypes of organ involvement in sarcoidosis. Eur Respir J. 2018 Jan 1;51(1).

23. Castro MDC, Pereira CA de C. Nonlife-Threatening Sarcoidosis. Semin Respir Crit Care Med. 2020 Oct 10;41(05):733-40.

24. Lhote R, Annesi-Maesano I, Nunes H, Launay D, Borie R, Sacré K, et al. Clinical phenotypes of extrapulmonary sarcoidosis: an analysis of a French, multiethnic, multicenter cohort. Eur Respir J. 2020 Oct 22;2001160.

25. Shaikh F, Abtin FG, Lau R, Saggar R, Belperio JA, Lynch JP. Radiographic and Histopathologic Features in Sarcoidosis: A Pictorial Display. Semin Respir Crit Care Med. 2020 Oct 10;41(05):758-84.

26. Leverenz DL, Henderson C, Shah A. Atypical Cutaneous Presentations of Sarcoidosis: Two Case Reports and Review of the Literature. Vol. 18, Current Allergy and Asthma Reports. Current Medicine Group LLC 1; 2018.

27. Lim D, Nantel-Battista M. Sarcoidal Reaction in a Tattoo. N Engl J Med. 2020 Feb 20;382(8):744-744.

28. Agrawal R, Kee AR, Ang L, Tun Hang Y, Gupta V, Kon OM, et al. Tuberculosis or sarcoidosis: Opposite ends of the same disease spectrum? . Tuberculosis (Edinb). 2016;98:21-6.

29. Fang $\mathrm{C}$, Huang $\mathrm{H}, \mathrm{Xu}$ Z. Immunological Evidence for the Role of Mycobacteria in Sarcoidosis: A Meta-Analysis . PLoS One. 2016 Aug 1;11(8):e0154716. 
30. lio K, lio T, Okui $\mathrm{Y}$, Ichikawa $\mathrm{H}$, Tanimoto $\mathrm{Y}$, Miyahara N, et al. Experimental Pulmonary Granuloma Mimicking Sarcoidosis Induced by Propionibacterium Acnes in Mice. Acta Med Okayama. 2010;64(2).

31. Nishiwaki T, Yoneyama H, Eishi Y, Matsuo N, Tatsumi K, Kimura H, et al. Indigenous pulmonary Propionibacterium acnes primes the host in the development of sarcoidlike pulmonary granulomatosis in mice. Am J Pathol. 2004;165(2):631-9.

32. Eishi Y. Etiologic link between sarcoidosis and Propionibacterium acnes . Respir Investig. 2013 Jun;51(2):56-68.

33. Lee, Byun, Kim. Potential Role of the Microbiome in Acne: A Comprehensive Review. J Clin Med. 2019 Jul 7;8(7):987.

34. Furusawa H, Suzuki Y, Miyazaki Y, Inase N, Eishi Y. Th1 and Th17 immune responses to viable Propionibacterium acnes in patients with sarcoidosis. Respir Investig. 2012 Sep;50(3):104-9.

35. Schupp JC, Tchaptchet S, Lutzen N, Engelhard P, Muller-Quernheim J, Freudenberg $\mathrm{MA}$, et al. Immune response to Propionibacterium acnes in patients with sarcoidosis--in vivo and in vitro. BMC Pulm Med. 2015 Jul 24;15:75-7.

36. Wilcox HE, Farrar MD, Cunliffe WJ, Holland KT, Ingham E. Resolution of inflammatory acne vulgaris may involve regulation of CD4+ T-cell responses to Propionibacterium acnes. Br J Dermatol. 2007 Mar;156(3):460-5.

37. Till AE, Goulden V, Cunliffe WJ, Holland KT. The cutaneous microflora of adolescent, persistent and late-onset acne patients does not differ. $\mathrm{Br} J$ Dermatol. 2000;142(5):885-92.

38. Severi G, Shannon BA, Hoang HN, Baglietto L, English DR, Hopper JL, et al. Plasma concentration of Propionibacterium acnes antibodies and prostate cancer risk: Results from an Australian population-based case-control study. Br J Cancer. 2010 Jul 27;103(3):411-5.

39. Loke WSJ, Freeman A, Garthwaite L, Prazakova S, Park M, Hsu K, et al. T-bet and interleukin-27: possible TH1 immunomodulators of sarcoidosis. Inflammopharmacology. 2015 Oct 22;23(5):283-90.

40. Sack GH. Serum amyloid A - A review. Vol. 24, Molecular Medicine. BioMed Central Ltd.; 2018.

41. Zhang $\mathrm{Y}$, Zhang J, Sheng $\mathrm{H}$, Li H, Wang R. Acute phase reactant serum amyloid $\mathrm{A}$ in inflammation and other diseases. In: Advances in Clinical Chemistry. Academic Press Inc.; 2019. p. 25-80.

42. Bargagli E, Magi B, Olivieri C, Bianchi N, Landi C, Rottoli P. Analysis of serum amyloid A in sarcoidosis patients. Respir Med. 2011;105(5):775-80. 




\section{Chapter 2}

\section{Etiology and Immunopathogenesis of Sarcoidosis: Novel Insights}

Els Beijer

Marcel Veltkamp

Bob Meek

David R. Moller

Semin Respir Crit Care Med. 2017 Aug;38(4):404-416 


\begin{abstract}
Sarcoidosis is a disorder of unknown etiology. It is a systemic disease, frequently involving the lungs, skin, eyes and lymph nodes. It is characterized by formation of noncaseating granulomas at the site(s) of disease. Sarcoidosis has a complex disease pathogenesis, with involvement of both the innate and adaptive immune system. Several innate immune system receptors including NLRs and TLRs appear to be involved in the development of sarcoidosis as well as cellular players like DCs and macrophages. Furthermore, lymphocytes from the adaptive immune system including Th1, Th17, Tregs and B-cells are likely to play a role in the sarcoidosis disease pathogenesis as well. Possibly, genetic susceptibility and exposure to particular etiologic agents including mycobacterial and propionibacterial antigens, metals and silica can cause sarcoidosis. Besides exogenous triggers, also selfcompounds such as SAA and vimentin have been found to play a role in the development of sarcoidosis. It is likely that sarcoidosis does not have one single cause but rather is the result of the interplay between different etiologic agents and the immune system in predisposed individuals.
\end{abstract}

Key words: Sarcoidosis, pathogenesis, immune system, Mycobacteria, P. acnes, metals, silica, vimentin, SAA 
Sarcoidosis is a disorder of unknown etiology. It is characterized by formation of noncaseating granuloma mostly affecting the lungs, skin, eyes and lymph nodes. In the last decades, different organic as well as inorganic triggers have been related to sarcoidosis pathogenesis. First, it is suggested that sarcoidosis is the result of an infection, based on overlap found between infectious granulomatous diseases such as tuberculosis and leprosy (1). Secondly, inorganic compounds such as metals may have a role in the onset of sarcoidosis as well (2-5). Furthermore the disease is also considered to be an auto-immune disease due to a possible immune response towards self-antigens (6). The current review describes the role of the innate as well as the adaptive immune system in sarcoidosis disease pathogenesis and the current knowledge on possible etiologic agents.

\section{Innate Immune System}

The innate immune system is an evolutionary-conserved system that provides first-line protection against pathogens. Microorganisms contain a wide range of invariable and highly conserved molecular patterns that differentiate them from eukaryotic cells of the host. These exogenous molecular patterns are called pathogen-associated molecular patterns (PAMPs). Furthermore, endogenous proteins released during tissue injury, such as heat shock protein (HSP), hyaluronan peptide and uric acid crystal can also be recognized by the innate immune system and are known as danger-associated molecular patterns (DAMPs) (7). DAMPs and PAMPs are recognized by the immune system via pattern recognition receptors (PRRs), including Toll-like receptors (TLR), nucleotide-binding oligomerization domain (NOD) like receptors (NLRs), RIG-I like receptors (RLRs), absent in melanoma 2 (AIM2) like receptors and the receptor for advanced glycation end products (RAGE) (8). Upon activation of these receptors an innate immune response is initiated.

\section{NLRs and TLRs}

Studies have investigated the contribution of several of those receptors in the onset of sarcoidosis. Mutations in the NOD2 gene are associated with auto inflammatory diseases, Blau syndrome and early onset sarcoidosis (9). Propionibacterium acnes, a possible causative agent of sarcoidosis, was shown to activate NF-kB via NOD1 and NOD2. Two allelic NOD1 polymorphisms, 796G-haplotype and 796A-haplotype, have been identified in Japanese sarcoidosis patients. The frequency of the latter haplotype was significantly higher among sarcoidosis patients than among the healthy controls. Functional experiments have shown that this polymorphism leads to reduced NOD1 expression and, consequently, to a decreased NF-kB mediated signal transduction in response to $P$. acnes. The altered capacity to recognize PAMPs may lead to increased sarcoidosis susceptibility in the Japanese population (10). Besides NLRs, multiple studies have focused on the contribution of TLRs to 
sarcoidosis. When stimulated with TLR2 and TLR4 ligands, bronchoalveolar lavage (BAL) cells obtained from sarcoidosis patients showed increased cytokine responses to TLR2/1 ligand 19-kDa lipoprotein of Mycobacterium tuberculosis. In addition, in an animal model of sarcoidosis, granuloma formation in response to heat-killed $P$. acnes was attenuated in TLR2 knock out mice compared to the wild-type C57BL/6 ones (11). In one study, it was suggested that sarcoidosis patients with the TLR-2 promotor polymorphism -16934AA have a higher risk of developing a chronic disease course due to a higher production of tumor necrosis factor-alpha (TNF-alpha) (12). The same group identified that the absence of a common haplotype in the TLR10-TLR1-TLR6 gene cluster, all co receptors of TLR2 located in a gene cluster on chromosome 4, increased the risk of developing a chronic disease course as well (13). Also TLR9 has been the topic of investigations as it is involved in every response against microorganisms, and both Mycobacterium tuberculosis and $P$. acnes are potential causative agents of sarcoidosis. A TLR9 polymorphism was found to be more common in chronic sarcoidosis patients than in the control group (14), however these results could not be replicated (15). In addition to the receptors itself, different regulation of TLR and NOD like receptor signaling have been found in sarcoidosis. When ligands bound to TLRs and NLRs, MAPK cascades are activated which leads to phosphorylation of three principal kinases: P38, JNKs and ERKs. Activated P38 is involved in the production of many cytokines including TNF$\alpha$ and interleukin-1 (II-1) which are important factors that contribute to Th1 commitment. MAPKs are inactivated by dephosphorylation trough MAPK phosphatases (MKPs). Interestingly, p38 phosphorylation was sustained in BAL cells from sarcoidosis patients stimulated with NOD-1 and TLR4 agonist. Compared to healthy controls, there was no significant induction of MKP-1 in sarcoidosis BAL cells. This finding points to a yet to explore in more detail regulatory defect in sarcoidosis and may explain the sustained production of Th1 cytokines observed in this disease (16).

\section{Neutrophil Granulocytes}

Neutrophil granulocytes are a type of leukocyte that are the first to move through the endothelium towards the inflammatory site. For this reason they are important contributors in the host defense against invading microorganisms (17). Neutrophils express several receptors that contribute to phagocytosis. Furthermore, they form phagolysosomes containing several proteolytic and antibacterial enzymes capable of microbial killing (18). Although neutrophils are not typically seen within granulomas in sarcoidosis tissues, neutrophils have been found in higher numbers in BAL of sarcoidosis patients compared to healthy controls (19) and the neutrophil percentage in BAL fluid of sarcoidosis patients may very well be related to disease prognosis. A Chinese study found that sarcoidosis patients with higher neutrophil amount in the BAL had more reticular lung changes and lower 
diffusing capacity for carbon monoxide (DLCO) values (20) and Tutor-Ureta and co-workers observed less neutrophils in BAL from radiological stage I sarcoidosis patients compared to stage II and III patients. Löfgren's patients had a significantly lower amount of neutrophils in BAL than non-Löfgren's patients and indeed, patients with a poor disease outcome had a significantly higher amount of neutrophils than patients with a favorable disease course (21). Others have investigated the neutrophil / lymphocyte ratio (NLR) as a marker of disease prognosis in sarcoidosis. Ocal and colleagues observed an increasing NLR with increasing radiological stages in pulmonary sarcoidosis patients (22). Also Dirican et al. found such a relation, by showing that more patients in higher radiological stages had an increased NLR (19). How neutrophil increase leads to a worse disease prognosis is not completely understood, but it may be related to their capacity to secrete matrix proteases that cause collagen destruction and remodeling and, ultimately, promote formation of fibrosis (21) and the development of bronchiectasis and fibrocystic changes.

\section{Dendritic Cells}

Dendritic cells (DCs) are antigen presenting cells and act as messengers between the innate and adaptive immune system (23). In peripheral blood from sarcoidosis patients a decreased number of DCs was observed $(24,25)$. In contrast, in BAL fluid from pulmonary sarcoidosis patients an increased number of DCs can be found compared to healthy controls (26). Probably, peripheral blood DCs are attracted to and maturated DCs have been found to accumulate near the granulomas (25). Moreover, in in vitro co-culture experiments with $\mathrm{CD} 4^{+} \mathrm{T}$-cells, DCs were able to produce more TNF- $\alpha$ when obtained from sarcoidosis patients compared to healthy controls (26). TNF is involved in DC maturation and migration, as well as granuloma formation (26), and TNF inhibitors have successfully been used in the treatment of sarcoidosis, which suggests that DCs are important in the sarcoidosis pathogenesis (27).

\section{Macrophages}

Sarcoidosis is characterized by granuloma formation, a dynamic process in which monocytes are recruited from the circulation and accumulate near already recruited macrophages. Material that is either insoluble or too bulky for phagocytoses may lead to the persistence of the granulomas. Macrophages are the major contributors of the granuloma, suggesting that these cells contribute to the sarcoidosis pathology (28). Kjellin et al. profiled the membrane-associated proteome of alveolar macrophages from sarcoidosis patients and healthy controls to identify proteins and associated signaling pathways possibly involved in sarcoidosis development. They found eighty proteins that were different in abundance between patients and controls. Interestingly, Fcy receptor 
mediated phagocytosis and clathrin mediated endocytosis signaling pathways were upregulated. These are important pathways in pathogen degradation and antigen presentation to memory T-cells (29). The phagocytosis, degradation and clearance of antigens are dependent on several factors including functions of the receptor for Fc fragment for IgG and complement receptors. Significantly higher expression of surface Fcgamma receptors CD16, CD32 and CD64 and complement receptors CD35 on peripheral blood mononuclear cells (PBMCs) of sarcoidosis patients were found in a study by Dubaniewicz and co-workers (30). Once macrophages are activated via PRRs a strong inflammatory response is initiated, not only due to production of cytokines but activated macrophages can be effective antigen presenting cells (APCs), as well thereby serving as the bridge between the innate and adaptive immune response (31).

\section{Adaptive Immune System}

In contrast to the innate immune system, the adaptive immune system is highly specific, and includes APCs, T-cells and antibody producing B-cells. Each T-cell expresses a specific Tcell receptor on its surface, capable of recognizing processed antigens presented in major histocompatibility complex ( $\mathrm{MHC}$ ) molecules on antigen presenting cells. In response to recognized non self-antigens, T-cells will proliferate and produce cytokines, that mediates microbial killing (32). The cytokines that will be produced by the T-cell depends on which effector T-cell type is differentiated from the Th0-lymphocyte. This differentiation is already set at the first contact with the antigen and is dependent on the cytokines present in the surrounding of the T-cell. II-4 produced by mast cells causes differentiation into T-helper-2 cells, II-12 produced by macrophages and dendritic cells and interferon-gamma (IFN- $\gamma$ ) produced by Natural killer (NK) cells leads to differentiation into T-helper-1 cells, while II-1 and II-23 produced by macrophages and dendritic cells cause differentiation into T-helper17 cells. Thus, the kind of response induced by the innate immune system already determines the type of T-cell differentiation in the adaptive immune response (33).

\section{Th1-cells}

Sarcoidosis is considered to be a T-helper-1 (Th1) - cell mediated disease. Due to an ongoing immune stimulation, T-cells accumulate around granulomas (34). So far it is not known why the hyperactive Th1-cell response occurs in sarcoidosis. It might be that the immune system of a predisposed host reacts to specific antigens without a normally occurring negative feedback signal, leading to an enhanced and ongoing immune response (35). Sarcoidosis patients generally have more Th1 cytokine production, including II-2 and IFN- $\gamma$, than healthy controls (36). Also II-12 and II-18 are important cytokines in the Th1 immune response, since they stimulate IFN- $\gamma$ production. In addition, as mentioned above, II-12 stimulates the 
differentiation from Th0-cells into Th1-cells. Importantly, II-12 (37) and II-18 (38) were found to be increased in BAL fluid from sarcoidosis patients compared to healthy controls. Furthermore, these cytokines were able to induce higher IFN- $\gamma$ production by cells present in sarcoid BAL from sarcoidosis patients (38). Th1-cells present in sarcoidosis lung patients express the chemokine receptor CXCR-3. Expression of this receptor on CD4 T-cells is controlled by T-bet, a Th1 transcription factor, along with typical cytokines such as IFN- $\gamma$. It was found that T-bet expression levels are higher in sarcoidosis BAL cells compared to healthy controls cells, positively correlated with IFN- $\gamma$ and CXCR-3 expression levels in sarcoidosis patients (39). In Scandinavian sarcoidosis patients it was found that HLADRB1*0301 positive patients had lower Th1 IFN- $\gamma$ expression in peripheral blood Th- cells and a tendency towards lower IFN- $\gamma$ expression in BALF Th1 cells. In this population, expression of HLA-DRB1*0301 is associated with more acute onset of the disease and a better prognosis (40). This could indicate that HLA-DRB1*0301 positive patients have a less pronounced Th1 response that may result in better disease prognosis, considering the role of IFN- $\gamma$ in driving granulomatous inflammation (41).

\section{PD-1}

Programmed cell death protein 1 (PD-1) is a receptor expressed on T-cells and inhibits T-cell effector functions, by blocking cytokine production, T-cell proliferation and impairing T-cell survival. For this reason, this receptor is important in auto-immunity and self-tolerance, and it is regarded as an immune checkpoint $(42,43)$. The dysregulation of cellular immunity could play a role in sarcoidosis trough $\mathrm{T}$-cell mediated responses to so far unknown antigens (44). It has been found that PD-1 pathway blockade restores T-cell function in chronic beryllium disease (CBD) (45). Interestingly, this has also been found in sarcoidosis. Sarcoidosis CD4+ T-cells have increased PD-1 expression and reduced proliferation capacity, which was restored upon blockage of the PD-1 pathway $(46,47)$. In addition, patients with resolving disease were found to have reduced PD-1 expressing CD4+ T-cells and normal proliferative capacity compared to the patients with progressive disease (48). P13K and Akt are part of the signaling pathway that is critical for cell proliferation. Signaling trough PD-1 disturbs the phosphorylation of $\mathrm{P} 13 \mathrm{~K}$, which has a negative impact on cell proliferation. Besides increased PD-1 expression on sarcoidosis T-cells, also reduced expression of the P13/Akt pathway was found. Those expression levels were restored to levels found in healthy controls when the PD-1 pathway was blocked. In response to foreign antigens Tcells undergo proliferation and differentiation to facilitate antigen clearance, loss of T-cell proliferation might therefore lead to antigen persistence. Impaired T-cell proliferation possibly leads to disease progression in some sarcoidosis cases (47) as sarcoidosis might be caused by an intracellular infection in which the cellular immune response is the most 
important defense mechanism. Those studies indicate that blocking PD-1 pathways could be a new therapeutic option in sarcoidosis patients. However, given the lack of microbiologic or pathologic evidence that sarcoidosis is associated with an active infection, PD-1 blockade may be counterproductive if not toxic to sarcoidosis patients if as in the example of chronic beryllium disease, PD-1 is upregulated to control the adaptive immune response to persistent tissue antigens that the patient is unable to clear (45). Furthermore, there are several cases described where blockage of PD-1 led to the occurrence of sarcoidosis symptoms. A refractory stage IV Hodgkin lymphoma patient treated with pembrolizumab, a human antibody targeting PD-1, developed a flare of her sarcoidosis (49). In addition, a lung adenocarcinoma patient with a combined treatment of ipilimumab (a CTLA-4 inhibitor) and nivolumab (a PD-1 inhibitor), developed sarcoidosis as an immune related adverse event (44). Finally, two patients diagnosed with metastatic melanoma treated with nivolumab alone developed a sarcoid like reaction $(50,51)$. Remarkably, the same phenomenon has been observed in patients treated with TNF- $\alpha$ inhibitors. The use of TNF-alpha blockers is a well-established and effective treatment in patients with severe and refractory sarcoidosis (52). However new onset sarcoidosis cases are observed in rheumatoid arthritis patients and a psoriatic arthritis patient receiving TNF- $\alpha$ inhibitors $(53,54)$. Those cases point to the complex immunopathogenesis in sarcoidosis.

\section{Th17-cells}

Th17-cells produce the pro-inflammatory cytokine II-17, which is involved in the immune response towards extracellular and intracellular pathogens, including Listeria monocytogenes, Salmonella enterica as well as Mycobacterium tuberculosis (55). For this reason, this cell type has been related to sarcoidosis and it was found to induce granuloma formation (56). II-17 expressing cells were found in granuloma containing lung biopsies of sarcoidosis patients. The II-17 positive cells were mainly present in and surrounding the granulomas (57). The number of CD4+ II-17 producing cells was higher in both blood and BAL of sarcoidosis patients with active disease compared to patients with inactive disease (56). As mentioned before, mycobacterial antigens are suggested to play a role in the etiology of sarcoidosis. Richmond and colleagues report mycobacterial specific Th17 responses in blood and BALF of sarcoidosis patients, which were not observed in healthy controls (58). Ostadkarampour and colleagues found that when BAL cells from either Lofgren or non-Lofgren patients were stimulated with the candidate mycobacterial pathogenic antigen $\mathrm{mKatG}$, Th1 cells (defined by release of INF- $\gamma$ ) were more than twice as prevalent than Th17 cells (defined by release of IL17) suggesting Th1 responses may dominate sarcoidosis specific immunity at sites of disease when directly compared (59). Next to Th1 cells, also Th17 cells produce IFN- $\gamma$. This subtype of IFN- $\gamma$ producing Th17-cells 
are known as Th17.1-cells (60). The fraction of IFN- $\gamma$ producing Th17-cells was found to be two times higher in sarcoidosis BALF than in controls. In addition, the percentage of Th17.1cells correlated positively with the radiological score for staging sarcoidosis (61). Ramstein et al. suggest that IFN- $\gamma$ producing cells may have been misclassified as Th1-cells in the past. IFN- $\gamma$ and II-17A cytokine measurement has mostly been used to define Th1 and Th17-cells respectively, IFN- $\gamma$ producing Th17-cells would have been missed in this way (60). Lexberg and co-workers (62) have shown that Th17-cells can be transformed to Th17.1-cells following incubation with the Th1 cytokines II-12 and IFN- $\gamma$. In conclusion, IFN- $\gamma$ producing CD4 T-helper-cells are observed in higher numbers in sarcoidosis. Th1 as well as Th17-cells are capable of IFN- $\nu$ production and Th1 cytokines have been shown to skew Th17 cells into Th17.1 producing IFN- $\gamma$ cells. Therefore, sarcoidosis can be considered as an Th1 as well as Th17 mediated disease, but fundamentally these studies confirm that sarcoidosis is an INF$\gamma$ (and likely T-bet) driven disorder.

\section{Regulatory T-cells}

Regulatory T-cells (Tregs) are essential for maintenance of immune tolerance and prevent development of auto-immune diseases. Immune homeostasis is established by production of immune suppressive cytokines such as II-10 and transforming growth factor-beta (TGF $\beta$ ) $(63,64)$. As sarcoidosis has many elements resembling a deregulated immune response, impaired function of Tregs may be a possible contribution factor to the response seen in sarcoidosis. Indeed, an impaired suppressive function of peripheral Tregs from sarcoidosis patients has been observed in several studies $(48,65,66)$. Broos et al. found increased levels of peripheral Tregs in patients developing chronic disease compared to healthy controls. However, Treg mediated suppression of pro-inflammatory cytokine production and proliferation of Th-cells was significantly impaired in the sarcoidosis patients. Furthermore, Tregs obtained from pulmonary sarcoidosis patients suffered from impaired survival and increased apoptosis (67). Moreover, restoration of Treg function was associated with disease remission (48). Taflin and colleagues have suggested that Tregs may be able to prevent sarcoidosis development, but cannot reverse the granuloma process. This was supported by the observation that [1] healthy Tregs prevent granuloma formation in vitro whereas sarcoidosis Tregs do not, and [2] Tregs are found to accumulate and proliferate within sarcoidosis granulomas, but are clearly not able to reduce their growth (68).

\section{B-cells}

Next to innate and cellular immune factors in sarcoidosis, also the humoral immune response is thought to contribute to the sarcoidosis disease process. Sarcoidosis patients with active disease were found to have a higher frequency of naive B-cells and II-10 
producing regulatory B-cells in blood than healthy controls (69) and B-cells were found within and near granulomas. Differences in immunoglobulin producing capacities of B-cell blasts were not found between sarcoidosis patients and healthy controls (70). B-cell activating factor from the TNF family (BAFF) plays a role in the survival and maturation of B-cells. Increased BAFF levels have been found in sarcoidosis patients with active disease $(68,71)$. It is suggested that BAFF overexpression can lead to severe auto-immune disease by rescuing self-reactive $B$-cells from deletion (71). A study among chronic sarcoidosis patients showed indeed disturbed B-cell homeostasis (72). There are some case reports describing the successful treatment of sarcoidosis with rituximab, an antibody against CD20 (73). CD20 is a non-glycosylated phosphoprotein present on all B-cells, except on plasma cells (74). The fact that rituximab is an effective treatment in some sarcoidosis patients $(73,75-77)$ points towards the possible involvement of B-cells in the pathology of the disease.

\section{Etiologic agents}

Although sarcoidosis is a systemic disease, the intrathoracic lymph nodes and lungs are the most frequent involved organs. This has led to the hypothesis that the etiologic agent of this disease must be airborne (78). Both exogenous organic (79) and inorganic components (80-82) can be involved in sarcoidosis, of which the exposure to the inorganic components is often related to particular professions (5). More recent data suggest that also selfantigens can be at least involved in the sarcoidosis process (6).

\section{Mycobacteria}

In clinical, radiological as well as immunological features, there is similarity between sarcoidosis and tuberculosis (78), leading to the suggestion of mycobacteria as etiologic agent in sarcoidosis (83). Several studies have described a role of mycobacteria in the involvement of sarcoidosis. Gupta and colleagues wrote a meta-analysis of 31 studies published between 1980 and 2006 that have used molecular techniques to determine the histological as well as the cellular presence of mycobacteria in sarcoidosis. The odds ratio to identify mycobacterial DNA in sarcoidosis samples versus control samples was calculated to be 9.67 and it was estimated that a mycobacterial signature was present in granulomatous tissue of almost $30 \%$ of sarcoidosis patients (84). A recently published metaanalysis by Fang et al. showed a significantly higher frequency of immune responses towards mycobacteria among sarcoidosis patients than controls (85). The presence of an immune response against antigens at least indicates past exposure that has resulted in induction of immunological memory, which can also be accessed in vitro in the absence of an active infection. For this reason, immune assays are a powerful tool to study involvement 
of particular antigens in sarcoidosis (86). To identify specific antigens involved in the granuloma formation in sarcoidosis, Song et al. used a proteomic approach and identified protein aggregates containing mycobacterial catalase-peroxidase (mKatG) in tissue biopsies of a subset of sarcoidosis patients. KatG is found in most mycobacterial species and is an important virulence factor that provides protection from peroxide, which leads to the survival of the organism in macrophages. Mycobacterial organisms may trigger sarcoidosis in a subset of patients, in which mKatG possibly serves as a target antigen (87). Chen et al. investigated the T-cell response against $\mathrm{mKatG}$ in a cohort of Swedish as well as American sarcoidosis patients. In this cohort of 150 patients, $50 \%$ had an increased IFN- $\gamma$ response against $\mathrm{mKatG}$ compared to no responses in the group of healthy volunteers (88). Studies by Oswald-Richter et al. and Drake et al. demonstrated significantly increased IFN- $\gamma$ responses towards mKatG and ESAT- 6 in BAL and PBMCs respectively, from sarcoidosis patients compared to controls $(89,90)$. Those results were confirmed in a latter study of Oswald-Richter and colleagues, where $70 \%(n=31)$ BAL samples of sarcoidosis patients produced a CD4+ T-cell response to at least one of the mycobacterial epitopes of KatG, ESAT-6, Ag85A, sodA or Heat shock protein (HSP). ESAT-6 was the most frequently recognized antigen by sarcoidosis patients in this study (91). Although immune responses to HSP were not different in the above mentioned study, Dubaiewicz et al. did show significant differences between sarcoidosis patients and controls in TNF- $\alpha$ and II-6 responses upon in vitro stimulation using mycobacteria hsp (92). Next to Oswald-Richter and colleagues, also Carlisle et al. observed significantly more sarcoidosis patients responding to the virulence factor sodA compared to PPD- controls (93). An overview of different mycobacterial antigens studied in sarcoidosis is given in Table 1.

If mycobacteria play a role in disease pathogenesis a key question is why some patients develop tuberculosis while others develop sarcoidosis. One could speculate that there is a different immune reaction in patients against the same pathogen. Interestingly, such a phenomenon has already been observed in patients infected with Mycobacterium leprae (94). In leprosy there is a type I as well as a type II reaction based on variety in strength of the cellular immune response. The type I reaction, also called the reversal reaction, might result from an exacerbated Th1 reaction in response to increased release of mycobacterial antigens (95). The type II reaction, also called erythema nodosum leprosum, is a more immunocomplex-mediated disease and involves Th1 as well as Th2 cells (96). Different immune reactions to the same pathogen lead to different clinical manifestations and outcomes in patients with leprosy (97). 
Table 1. Overview of mycobacterial antigens recognized by the immune system of sarcoidosis patients

\begin{tabular}{|c|c|}
\hline Mycobacterial antigen & Studies showing immune response \\
\hline AG85A & Oswald-Richter et al., 2010 (91) \\
\hline \multirow[t]{4}{*}{ ESAT-6 } & Carlisle et al., 2007 (93) \\
\hline & Drake et al., 2007 (90) \\
\hline & Oswald-Richter et al., 2009 (89) \\
\hline & Oswald-Richter et al., 2010 (91) \\
\hline HSP & Dubaniewicz et al., 2007 (92) \\
\hline \multirow[t]{5}{*}{ KatG } & Carlisle et al., 2007 (93) \\
\hline & Chen et al., 2008 (88) \\
\hline & Drake et al., 2007 (90) \\
\hline & Oswald-Richter et al., 2009 (89) \\
\hline & Oswald-Richter et al., 2010 (91) \\
\hline \multirow[t]{2}{*}{ sodA } & Carlisle et al., 2007 (93) \\
\hline & Oswald-Richter et al., 2010 (91) \\
\hline
\end{tabular}

AG85A = Antigen 85A, ESAT-6 = early secreted antigenic target of $6 \mathrm{kDa}, \mathrm{HSP}=$ Heat shock protein, KatG $=$ catalase-peroxidase, soda $=$ superoxide dismutase $A$.

Based on possible involvement of mycobacteria in sarcoidosis pathogenesis, Drake et al. investigated the use of levofloxacin, ethambutol, azithromycin, and rifampin (CLEAR) therapy in patients with pulmonary and cutaneous sarcoidosis. In the first pilot study of 15 sarcoidosis patients with pulmonary sarcoidosis, a significant increase of forced vital capacity (FVC) was seen after treatment with the CLEAR regimen. Interestingly, the highest increase of FVC was seen in patients with a positive IFN-y response to ESAT-6 (98). The second trial was a RCT of CLEAR versus placebo in sarcoidosis patients with cutaneous localization. A significant decrease in lesion diameter was seen in the CLEAR group compared to the placebo group after 8 weeks of treatment (99). In both studies, the authors acknowledged the lack of evidence for an active mycobacterial infection in either the lung or skin, but rather suggested this antibiotic combination had significant anti-inflammatory effects, suppressing NFkB and related pathways. In summary, histological and cellular presence of mycobacteria in sarcoidosis lesions, immune response towards mycobacterial antigens and beneficial effects of anti-mycobacterial therapy in sarcoidosis patients suggest an etiological link between mycobacteria and sarcoidosis. However, regarding the role of mycobacteria, there is a lack of consensus on whether an active replicating mycobacterial infection is the cause of chronic sarcoidosis or an ongoing immune response to persistent mycobacterial antigens in the absence of an active infection. The challenge for those who 
propose chronic sarcoidosis is caused by an active infection is to explain the lack of clinical, microbiologic and pathologic evidence for an active infection in sarcoidosis patients throughout their course, despite treatment with corticosteroid, immunosuppressive or anti-TNF therapies for many years. There is no credible evidence that directly supports the concept of an active replicating infection despite this hypothesis being formulated after the initial description of the disease over 100 years ago.

\section{Propionibacteria}

Mycobacteria and propionibacteria have several features in common. The most important shared feature in the context of sarcoidosis is that both bacteria are intracellular pathogens, which persist in macrophages (100). Propionibacterium acnes ( $P$. acnes) has been cultured from lymph nodes of sarcoidosis patients, and DNA of this bacterium was found in BAL from sarcoidosis patients as well (101-103), though widespread clinical experience suggests this is a rare finding during routine clinical biopsies or BAL procedures. In a study by Zhou et al. ribosomal RNA (rRNA) of $P$. acnes and $P$. granulosum was measured by RT-PCR in lymph node tissue from Chinese sarcoidosis patients, which is considered proof for the presence of viable bacteria. They found that the proportion of samples positive for $P$. acnes and $P$. granulosum rRNA was significantly higher in sarcoidosis patients compared with tuberculosis patients or controls with other diseases. In addition, the copy number of rRNA from both the bacteria was also higher in sarcoidosis patients compared to the two control groups. These results indicate that Propionibacteria are associated with the development of sarcoidosis (104). Ebe et al. screened a genomic DNA expression library of $P$. acnes with sera of sarcoidosis patients. Using this methodology, they identified RP35, the c-terminal region of the trigger factor of $P$. acnes as a potential antigen involved in the sarcoidosis disease process. They demonstrated that RP35 caused proliferation of the mononuclear cells in $18 \%$ of the sarcoidosis patients investigated compared to none in healthy controls (105). Minami et al. investigated whether RP35 was able to induce granulomas in a mouse model. They found a strong immune response and pulmonary granuloma forming in mice sensitized with RP35 in CFA (106). Interestingly, administration of antibiotics before and during the experiment prevented granuloma formation in this experimental model of sarcoidosis. In a study using immunoblotting, Yorozu et al. identified $P$. acnes catalaseperoxidase (KAT) as a one of the immunogenic antigens in sarcoidosis. The identified $P$. acnes KAT antigen showed increased peripheral blood mononuclear cell (PBMC) IFN- $\gamma$ responses in sarcoidosis patients compared to patients with other interstitial lung diseases and healthy controls (107). Schupp et al. also demonstrated the link between sarcoidosis and $P$. acnes in Caucasian sarcoidosis patients. In this study BAL cells were exposed to heat- 
killed $P$. acnes which resulted in significantly higher production of IFN- $\gamma$ and granulocyte macrophage-colony stimulating factor (GM-CSF) in case of sarcoidosis patients. Furthermore, a higher concentration of $P$. acnes-IgGs antibodies was found in BALF from sarcoidosis patients as well (100). The above mentioned studies suggest different antigens of $P$. acnes as possible causative agents in some sarcoidosis patients. A key question related to $P$. acnes is why some patients develop sarcoidosis as a reaction to this human commensal. In an excellent review by Eishi, it is hypothesized that $P$. acnes, just as mycobacteria, can be present as a latent infection in the form of Hamazaki-Wesenberg bodies. Intracellular proliferation of latent $P$. acnes in macrophages triggers granuloma formation in patients with a hypersensitivity to this bacterium (Figure 1) (108).

A case report successfully using clarithromycin in the treatment of a sarcoidosis patient further strengthens the link between $P$. acnes and sarcoidosis pathogenesis (109), though, in contrast, it is the widespread clinical experience that antimicrobial therapy including antibiotics effective against $P$. acnes, is not effective in the vast majority of sarcoidosis patients.

In conclusion, culturing of $P$. acnes from sarcoid lymph nodes in rare cases, the presence of $P$. acnes rRNA in lymph nodes of sarcoidosis patients and immunological responses towards P. acnes antigens suggest that propionibacteria are associated with the development of sarcoidosis. As for a mycobacterial link to sarcoidosis, there is a lack of consensus as to whether an active, replicating $P$. acnes infection is central to chronic sarcoidosis. In experimental models of allergic diseases using immunization with self-antigens such as thyroglobulin (thyroiditis) or myelin basic protein (encephalomyelitis) autoimmune inflammatory lesions could only be induced in the organs from which these self-antigens originated $(110,111)$. In theory, when sarcoidosis is seen as an autoimmune disease, one could speculate that in the absence of an active infection $P$. acnes serves as a self-antigen in some patients where this bacterium is a commensal of the lungs. 

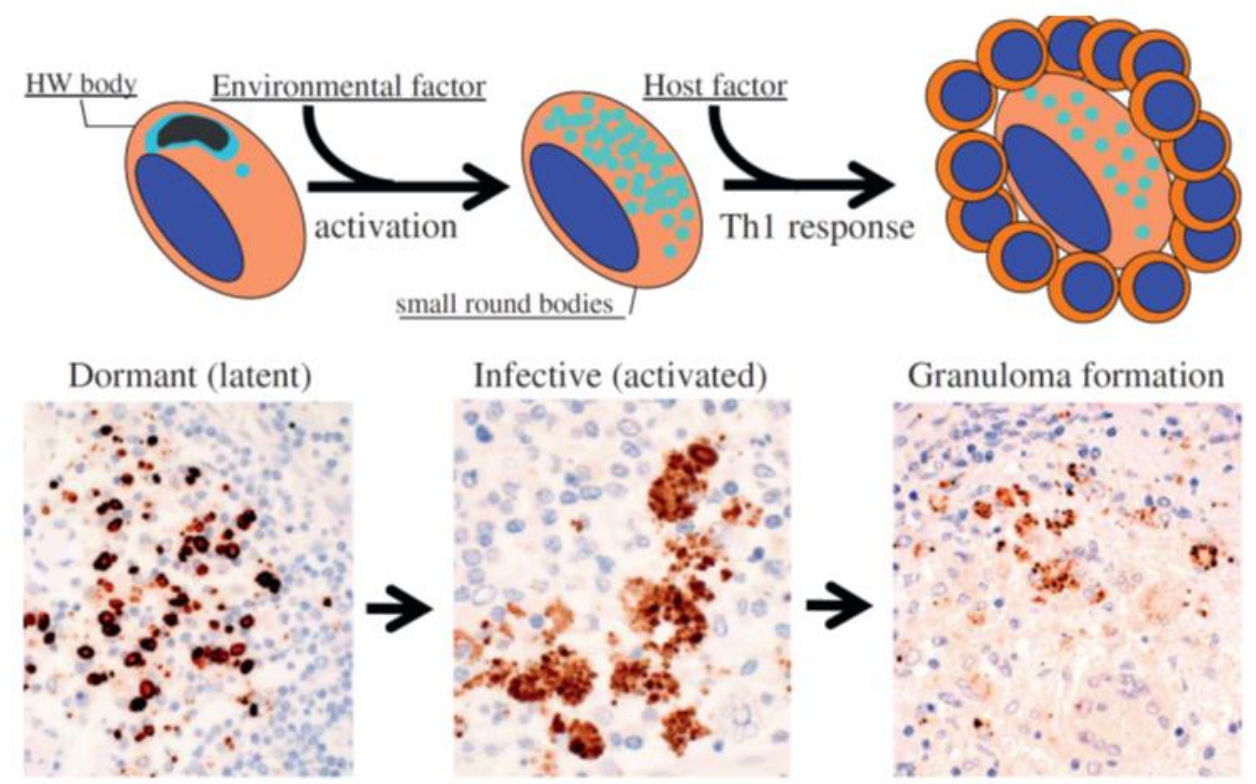

Figure 1. Dormant and cell-wall deficient forms of $P$.acnes may be present as Hamazaki-Wesenberg bodies and can be activated under certain conditions, which lead to proliferation of the bacteria in cells at latent infection sites. Infective proliferating forms of the bacteria may be present in macrophages as small round bodies. When macrophages release those small round bodies they can infect other cells and organs via the lymph and blood stream. To prevent this spread, granulomas are formed as a host defense mechanism in patients having a hypersensitive immune response towards this bacterium. (Adapted with permission from Eishi Y. Etiologic link between sarcoidosis and Propionibacterium acnes . Respir Investig. 2013 Jun;51(2):56-68. ${ }^{108}$ )

\section{Metals}

The inhalation of metal dust has been related to lung diseases for several years and has been proposed as a cause of sarcoidosis. Chronic beryllium disease (CBD) and sarcoidosis can present with the same clinical findings in the lung. The only way to distinguish between $\mathrm{CBD}$ and isolated pulmonary sarcoidosis is by an occupational history that shows beryllium exposure, in combination with a positive in vitro T-cell proliferation test in which beryllium is included (112). Many investigators do not believe CBD or other metals should be included under the disease classification of sarcoidosis (but rather "sarcoidosis -like") because of the clinical differences in organ involvement with only rare cases of metal induced granulomatous pneumonitis having extra-pulmonary involvement. Chronic beryllium disease can be misdiagnosed by sarcoidosis when exposure is not examined properly and a beryllium proliferation test is not performed. In a well-designed cohort of 536 sarcoidosis 
patients, Müller-Quernheim and colleagues identified 34 patients who were exposed to beryllium and had a positive result in the beryllium lymphocyte proliferation test. Therefore, almost $6 \%$ of this cohort could be diagnosed as CBD instead of sarcoidosis (113). Genetic susceptibility towards CBD is found in patients expressing HLA-DPB1 alleles that are characterized by the presence of a glutamic acid at position 69 of the beta chain (114-116). Also other metals like aluminum and zirconium have been linked to sarcoidosis onset in different case reports (4,117-120). Furthermore, a study in Switzerland found an association between the regional frequency of sarcoidosis and the distribution of different sub-branches of the metal industry (121). How metals activate lymphocytes via T-cell receptors to induce an immune reaction is still not completely clear. A possible mechanism is that non-proteinaceous compounds like metals can function as haptens (122). Haptens are molecules not immunogenic themselves but only when bound to a carrier protein (123). Another mechanism has been recently identified upon detailed analysis of T-cell proliferation process mediated by beryllium. The T-cell receptor does not interact with beryllium directly. Rather, the Be ion non-covalently interacts with the peptide binding pocket of HLA-DP, thereby altering the position of peptides that are presented by HLA-DP. Under non-infectious condition, a self-peptide will be present in the peptide binding proof of HLA-DP, against which T-cell are trained not to respond. Due to the presence of beryllium in the pocket, the self-peptide gets displaced and is seen as foreign by HLA-DP specific CD4 T-cells $(124,125)$. Peptides of the plexin A protein may be the potential source of the displaced self-peptide (126). Plexins are proteins involved in cell movement and response (127). Expression of plexin A was found in BAL and lung tissue from CBD patients (126), strongly supporting the role of plexin $A$ as possible endogenous antigen in this disease.

\section{Silica}

Silicon ( $\mathrm{Si}$ ) is one of the most abundant elements on the earth and the combination of two oxygen atoms is well known as silicon oxide or silica $\left(\mathrm{siO}_{2}\right)(128)$. Silica is abundantly present in nature and several industrial products like glass, ceramics and cement contain silica (129). Silica exposure is known to cause a fibrotic and sometimes progressive lung disease called silicosis (130) however, a relation with rheumatoid arthritis, systemic lupus erythematosus as well as sarcoidosis pathogenesis has been suggested (131). For example, sarcoidosis was found to be more common among an Iceland's cohort exposed to crystalline silica in the form of cristobalite, resulting in an increased odds ratio in case of exposure (81). Furthermore, a few case reports have described occupational as well as non-occupational silica exposure as possible causes of sarcoidosis (132-135). In a pilot study by Fireman et al. a teacher and a dental technician diagnosed with sarcoidosis showed a positive lymphocyte proliferation response towards silica and metals, determined by the MELISA test. This is a 
memory lymphocyte immuno-stimulation assay used to identify sensitization towards metals and silica (136). To induce granulomatous inflammation, silica must be able to react with the immune system. This process is proposed as follows: silica particles are inhaled and reach the alveolar space. Here it is covered by proteins and surfactants and reacts with endogenous antioxidants (129). By binding to proteins, silica possibly cause antibody formation in a hapten like manner. Alveolar macrophages will ingest silica particles and try to clear it from the lungs. Modified silica particles could end up in $\mathrm{MHC}$ I or II, which leads to a cellular immune response. When the clearance process is not successful, macrophages are activated and will release chemotactic factors, pro-inflammatory- and pro-fibrotic mediators. In addition, macrophages will be physically damaged by the silica particles which eventually results in cell death, and activation of DAMPs (129). This might eventually result in auto-immune disease or sarcoidosis. Silica-containing macrophages together with surrounding lymphocytes will release macrophage attracting chemokines which lead to the attraction of other macrophages which eventually could lead to granuloma formation (137). As in $\mathrm{CBD}$, the lack of extra pulmonary or multiorgan involvement makes inclusion of this exposure as a cause of sarcoidosis uncertain to many investigators.

\section{SAA}

Serum amyloid $A(S A A)$ is produced by the liver during the acute phase reaction (APR). The acute phase reaction serves to eliminate foreign pathogens. In inflammatory conditions, macrophages are a major source of SAA. Elevated SAA levels have been found in several inflammatory diseases including rheumatoid arthritis, diabetes type II and Crohn's disease (138). Significantly higher SAA levels in serum and BAL fluid were observed in sarcoidosis as well (139-142). SAA levels are elevated during infection and inflammation, and this APR protein can activate cells via several mechanisms and receptors including TLR2, TLR4 and RAGE (138). Chen et al. have studied the role of SAA in the regulation of granulomatous inflammation in sarcoidosis. SAA expression was found in granulomas of sarcoidosis patients. This SAA expression in granulomas seemed to be sarcoidosis specific, because SAA expression was both quantitatively as well as qualitatively different in other granulomatous disorders including chronic beryllium disease, Wegener granulomatosis, Crohn's disease and tuberculosis. The authors observed in vitro that SAA can signal via TLR2, since SAA mediated activation of NF-kB signaling was inhibited by antibody mediated blockage of TLR2 in a human cell line. Furthermore, it was found that SAA induced higher TNF, II-10 and II-18 cytokine production in BAL cells from sarcoidosis patients compared to healthy control cells. This coincided with higher TLR2 expression on BAL macrophages from these sarcoidosis patients. When TLR2 was blocked, cytokine production was inhibited. To summarize, the results suggest that SAA is involved in the sarcoidosis disease pathogenesis in a TLR2 
dependent way (142). Chen and colleagues proposed a model of the contribution of SAA in sarcoidosis $(143,144)$ (Figure 2).

In a (myco)bacterial infection, SAA is produced as part of acute phase response. Due to genetic and environmental factors, a Th1 dominated response is induced towards microbial antigens. The intensity of the immune response results in overproduction of SAA, resulting in misfolding or aggregation of SAA. These SAA aggregates form complexes with other matrix proteins, leading to granuloma formation and entrapment of microbial antigens or autoantigens. Being a TLR2 ligand, SAA functions as a feed forward loop to conserve granuloma formation. Granulomas are only resolved when both SAA as well as the other (microbial) antigens are cleared (143). Therefore, SAA serum levels may be helpful in order to determine sarcoidosis activity. In a study by Gungor et al. disease activity was determined by clinical findings, pulmonary function tests and radiological findings. They observed that SAA serum levels were significantly higher in sarcoidosis patients with active disease (140), which was confirmed by Salazar et al. (145).

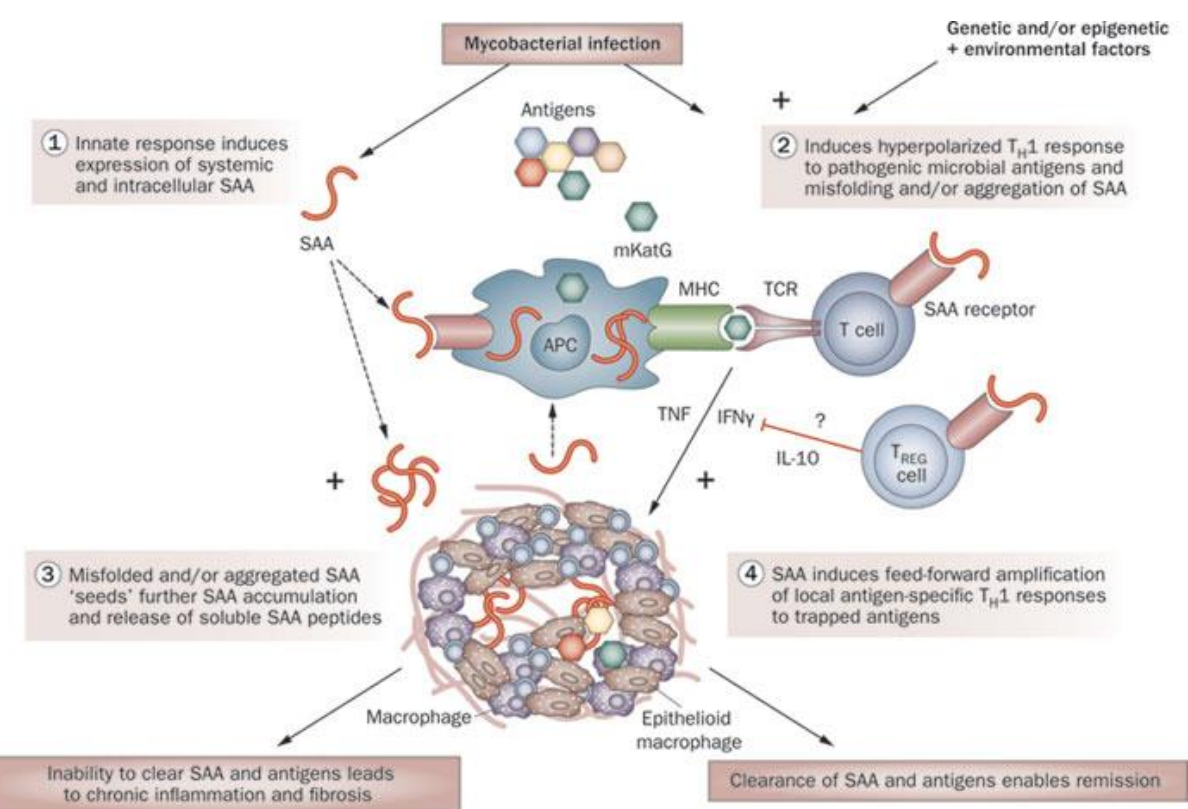

Figure 2. Hypothesized contribution of SAA in the pathogenesis of sarcoidosis. SAA released from granulomas reacts with receptors including TLR2, which leads to the feed-forward stimulation of macrophages and Th1 cells. In combination with uncleared microbial antigens, granulomas will persist. (With permission from Chen ES, Moller DR. Sarcoidosis--scientific progress and clinical challenges . Nat Rev. 2011 Jul 12;7(8):457-67 (144)) 


\section{Vimentin}

Vimentin is a filament protein present in the cell cytoskeleton. Mesenchymal cells, including endothelial cells, express vimentin. It is also expressed in cells that experience physiological and pathological changes, such as wound healing and metastasis. In addition, vimentin might be involved in the host defense to clear microbial infections (146). By immunestaining, asteroid bodies in granulomas of sarcoidosis patients were found to contain vimentin (147). Wahlström and colleagues identified peptides extracted from HLADRB1*0301 molecules on BAL cells to be derived from vimentin, along with $\beta$-actin, lysyltRNA synthase, ATP synthase and kininogen (148). In continuation on this study, antigenic capacity of those peptides was investigated by ELISPOT tests. Significantly higher IFN-y ELISPOT responses against vimentin were observed in the HLA-DRB1*0301 positive group compared to the HLA-DRB1*0301 negative group. In 4 recovered HLA-DRB1*0301 subjects, no strong responses against vimentin were seen (149). Furthermore, Grunewald and colleagues identified highly clonal T-cells expressing $V \alpha 2.3 / \mathrm{V} \beta 22$ receptors in the lungs of HLADRB1*03 positive patients. The expression of specific $V \alpha$ and $V \beta$ genes suggest clonal expansion due to abundant availability of cognate peptide - MHC class II combination. Using in silico modeling, they made very plausible that the combination of vimentin peptide bound to HLA matches with the T-cell receptor (150). Recently, Eberhardt et al. identified vimentin as a Kveim specific protein. Stimulation with vimentin could induce a specific proinflammatory cytokine response only in patients with sarcoidosis (151). These data further strengthen the role of vimentin as a possible autoantigen in sarcoidosis pathogenesis. Given the lack of immune responses to vimentin in all patients, it is likely other autoantigens may be involved in disease pathogenesis. A hypothesis that combines a central role for SAA driving persistent Th1 immunity to tissue autoantigens such as vimentin is consistent with the known clinical biology of chronic sarcoidosis.

\section{Conclusion}

Sarcoidosis is a complex disease and seems an interplay between genetic susceptibility, cellular function of both innate as well as adaptive immunity, and several exogenous and endogenous triggers. Studies addressing both the innate and adaptive immune response can result in successfully targeting specific mediators such as been demonstrated by blocking TNF-alpha. Elucidating possible triggers in sarcoidosis can help in development of a more personalized-based treatment regime such as use of anti-mycobacterial or antipropionibacterial drugs. Increasing knowledge of exposure to metals or silica helps to identify sarcoidosis patients which could benefit more from exposure prevention rather than increasing the amount of immune suppression. Further studies are therefore eagerly awaited to definitely confirm the link between possible triggers and sarcoidosis etiology. 


\section{References}

1. Chen ES, Moller DR. Etiologic role of infectious agents. Semin Respir Crit Care Med. 2014 Jun;35(3):285-95.

2. Costabel U, Hunninghake GW. ATS/ERS/WASOG statement on sarcoidosis. Sarcoidosis Statement Committee. American Thoracic Society. European Respiratory Society. World Association for Sarcoidosis and Other Granulomatous Disorders. Eur Respir J. 1999;14(4):735-7.

3. De Vuyst $P$, Dumortier $P$, Schandene L, Estenne $M$, Verhest A, Yernault JC. Sarcoidlike lung granulomatosis induced by aluminum dusts. Am Rev Respir Dis. 1987 Feb;135(2):493-7.

4. Werfel U, Schneider J, Rodelsperger K, Kotter J, Popp W, Woitowitz HJ, et al. Sarcoid granulomatosis after zirconium exposure with multiple organ involvement. Eur Respir J. 1998 Sep;12(3):750.

5. Newman KL, Newman LS. Occupational causes of sarcoidosis. Curr Opin Allergy Clin Immunol. 2012 Apr;12(2):145-50.

6. Zissel G, Muller-Quernheim J. Specific antigen(s) in sarcoidosis: a link to autoimmunity? . Eur Respir J. 2016;47(3):707-9.

7. Tanabe $T$, Yamaguchi N, Okuda M, Ishimaru $Y$, Takahashi H. Immune System Reaction against Environmental Pollutants. Nihon eiseigaku zasshiJapanese J Hyg. 2015;70(2):115-9.

8. Tang D, Kang R, Coyne CB, Zeh HJ, Lotze MT. PAMPs and DAMPs: signal Os that spur autophagy and immunity. Immunol Rev. 2012;249(1):158-75.

9. Iwasaki T, Kaneko N, Ito Y, Takeda H, Sawasaki T, Heike T, et al. Nod2-Nodosome in a Cell-Free System: Implications in Pathogenesis and Drug Discovery for Blau Syndrome and Early-Onset Sarcoidosis . ScientificWorldJournal. 2016;2016:2597376.

10. Tanabe T, Ishige I, Suzuki Y, Aita Y, Furukawa A, Ishige Y, et al. Sarcoidosis and NOD1 variation with impaired recognition of intracellular Propionibacterium acnes. Biochim Biophys Acta - Mol Basis Dis. 2006;1762(9):794-801.

11. Gabrilovich MI, Walrath J, van Lunteren J, Nethery D, Seifu M, Kern JA, et al. Disordered Toll-like receptor 2 responses in the pathogenesis of pulmonary sarcoidosis . Clin Exp Immunol. 2013 Sep;173(3):512-22.

12. Veltkamp M, Wijnen PA, van Moorsel CH, Rijkers GT, Ruven HJ, Heron M, et al. Linkage between Toll-like receptor (TLR) 2 promotor and intron polymorphisms: functional effects and relevance to sarcoidosis. Clin Exp Immunol. 2007 Sep;149(3):453-62.

13. Veltkamp M, van Moorsel CH, Rijkers GT, Ruven HJ, Grutters JC. Genetic variation in 
the Toll-like receptor gene cluster (TLR10-TLR1-TLR6) influences disease course in sarcoidosis . Tissue Antigens. 2012 Jan;79(1):25-32.

14. Pabst S, Bradler O, Gillissen A, Nickenig G, Skowasch D, Grohe C. Toll-like receptor9 polymorphisms in sarcoidosis and chronic obstructive pulmonary disease. Adv Exp Med Biol. 2013;756:239-45.

15. Veltkamp M, Van Moorsel CH, Rijkers GT, Ruven HJ, Van Den Bosch JM, Grutters JC. Toll-like receptor (TLR)-9 genetics and function in sarcoidosis. Clin Exp Immunol. 2010;162(1):68-74.

16. Rastogi R, Du W, Ju D, Pirockinaite G, Liu Y, Nunez G, et al. Dysregulation of $p 38$ and MKP-1 in response to NOD1/TLR4 stimulation in sarcoid bronchoalveolar cells. Am J Respir Crit Care Med. 2011 Feb 15;183(4):500-10.

17. Witko-Sarsat V, Rieu P, Descamps-Latscha B, Lesavre P, Halbwachs-Mecarelli L. Neutrophils: molecules, functions and pathophysiological aspects . Lab Invest. 2000;80(5):617-53.

18. Hickey MJ, Kubes P. Intravascular immunity: the host-pathogen encounter in blood vessels . Nat Rev. 2009;9(5):364-75.

19. Dirican N, Anar C, Kaya S, Bircan HA, Colar HH, Cakir M. The clinical significance of hematologic parameters in patients with sarcoidosis . Clin Respir J. 2016 Jan;10(1):32-9.

20. Ding YL, Sun YC, Shen N, Chen YH, Yao WZ. The clinical significance of increased neutrophils in bronchoalveolar lavage fluid in sarcoidosis. Zhonghua Jie $\mathrm{He} \mathrm{He} \mathrm{Hu}$ Xi Za Zhi. 2016 Dec 12;39(12):934-8.

21. Tutor-Ureta P, Citores MJ, Castejon R, Mellor-Pita S, Yebra-Bango M, Romero Y, et al. Prognostic value of neutrophils and NK cells in bronchoalveolar lavage of sarcoidosis . Cytom B, Clin Cytom. 2006 Nov 15;70(6):416-22.

22. Ocal N, Dogan D, Ocal R, Tozkoparan E, Deniz O, Ucar E, et al. Effects of radiological extent on neutrophil/lymphocyte ratio in pulmonary sarcoidosis . Eur Rev Med Pharmacol Sci. 2016;20(4):709-14.

23. McKenna K, Beignon AS, Bhardwaj N. Plasmacytoid dendritic cells: linking innate and adaptive immunity . J Virol. 2005 Jan;79(1):17-27.

24. Hayashi Y, Ishii Y, Hata-Suzuki M, Arai R, Chibana K, Takemasa A, et al. Comparative analysis of circulating dendritic cell subsets in patients with atopic diseases and sarcoidosis . Respir Res. 2013;14:29.

25. Ota M, Amakawa R, Uehira K, Ito T, Yagi Y, Oshiro A, et al. Involvement of dendritic cells in sarcoidosis. Thorax. 2004;59(5):408-13.

26. Ten Berge B, Kleinjan A, Muskens F, Hammad H, Hoogsteden HC, Hendriks RW, et al. Evidence for local dendritic cell activation in pulmonary sarcoidosis . Respir Res. 
2012 Apr 18;13:33.

27. Zaba LC, Smith GP, Sanchez M, Prystowsky SD. Dendritic cells in the pathogenesis of sarcoidosis . Am J Respir Cell Mol Biol. 2010 Jan;42(1):32-9.

28. Chen ES. Innate immunity in sarcoidosis pathobiology . Curr Opin Pulm Med. 2016 Sep;22(5):469-75.

29. Kjellin H, Silva E, Branca RM, Eklund A, Jakobsson PJ, Grunewald J, et al. Alterations in the membrane-associated proteome fraction of alveolar macrophages in sarcoidosis . Sarcoidosis, Vasc Diffus lung Dis Off J WASOG. 2016;33(1):17-28.

30. Dubaniewicz A, Typiak M, Wybieralska M, Szadurska M, Nowakowski S, StaniewiczPanasik $A$, et al. Changed phagocytic activity and pattern of Fcy and complement receptors on blood monocytes in sarcoidosis. Hum Immunol. 2012;73(8):788-94.

31. Zissel G, Muller-Quernheim J. Cellular Players in the Immunopathogenesis of Sarcoidosis . Clin Chest Med. 2015 Dec;36(4):549-60.

32. den Haan JM, Arens R, van Zelm MC. The activation of the adaptive immune system: cross-talk between antigen-presenting cells, T cells and B cells . Immunol Lett. 2014 Dec;162(2 Pt B):103-12.

33. Ottenhof THM. Cellulaire immuniteit. In: Rijkers TG, Kroese FGM, Kallenberg CGM, Derksen RHWM, editors. Immunologie. Houten: Bohn Stafleu Van Loghum; 2009. p. 132-3.

34. Mortaz Rezayat, F., Amani, D., Kiani, A., Garssen, J., Adcock, I., Velayati,A. E. The Roles of T Helper 1, T Helper 17 and Regulatory T Cells in the Pathogenesis of Sarcoidosis. Iran J Allergy, Asthma Immunol. 2016;15(4).

35. Ho L-P, Urban BC, Thickett DR, Davies RJO, McMichael AJ. Deficiency of a subset of T-cells with immunoregulatory properties in sarcoidosis. Lancet. 2005;365(9464):1062-72.

36. Wahlstrom J, Katchar K, Wigzell H, Olerup O, Eklund A, Grunewald J. Analysis of intracellular cytokines in CD4+ and CD8+ lung and blood T cells in sarcoidosis . Am J Respir Crit Care Med. 2001 Jan;163(1):115-21.

37. Moller DR, Forman JD, Liu MC, Noble PW, Greenlee BM, Vyas P, et al. Enhanced expression of IL-12 associated with Th1 cytokine profiles in active pulmonary sarcoidosis . J Immunol (Baltimore, Md 1950). 1996 Jun 15;156(12):4952-60.

38. Shigehara K, Shijubo N, Ohmichi M, Takahashi R, Kon S, Okamura H, et al. IL-12 and IL-18 are increased and stimulate IFN-gamma production in sarcoid lungs . J Immunol (Baltimore, Md 1950). 2001 Jan 1;166(1):642-9.

39. Kriegova E, Fillerova R, Tomankova T, Hutyrova B, Mrazek F, Tichy $T$, et al. T-helper cell type-1 transcription factor T-bet is upregulated in pulmonary sarcoidosis . Eur Respir J. 2011 Nov;38(5):1136-44. 
40. Berlin M, Fogdell-Hahn A, Olerup O, Eklund A, Grunewald J. HLA-DR predicts the prognosis in Scandinavian patients with pulmonary sarcoidosis . Am J Respir Crit Care Med. 1997 Nov;156(5):1601-5.

41. Idali F, Wiken $M$, Wahlstrom J, Mellstedt $\mathrm{H}$, Eklund A, Rabbani $\mathrm{H}$, et al. Reduced Th1 response in the lungs of HLA-DRB1*0301 patients with pulmonary sarcoidosis . Eur Respir J. 2006;27(3):451-9.

42. Francisco LM, Sage PT, Sharpe AH. The PD-1 pathway in tolerance and autoimmunity . Immunol Rev. 2010 Jul;236:219-42.

43. Fife BT, Pauken KE. The role of the PD-1 pathway in autoimmunity and peripheral tolerance. Ann N Y Acad Sci. 2011 Jan;1217:45-59.

44. Suozzi KC, Stahl M, Ko CJ, Chiang A, Gettinger SN, Siegel MD, et al. Immune-related sarcoidosis observed in combination ipilimumab and nivolumab therapy. JAAD case reports. 2016 Jul 14;2(3):264-8.

45. Palmer BE, Mack DG, Martin AK, Gillespie M, Mroz MM, Maier LA, et al. Upregulation of programmed death-1 expression on beryllium-specific CD4+ T cells in chronic beryllium disease . J Immunol (Baltimore, Md 1950). 2008 Feb 15;180(4):2704-12.

46. Braun NA, Celada LJ, Herazo-Maya JD, Abraham S, Shaginurova G, Sevin CM, et al. Blockade of the programmed death-1 pathway restores sarcoidosis CD4(+) T-cell proliferative capacity . Am J Respir Crit Care Med. 2014 Sep 1;190(5):560-71.

47. Celada L, Rotsinger JE, Young A, Shaginurova G, Shelton D, Hawkins C, et al. Programmed Death-1 Inhibition of PI3K/AKT/mTOR Signaling Impairs Sarcoidosis CD4+ T Cell Proliferation. Am J Respir Cell Mol Biol. 2016 Aug 26;

48. Oswald-Richter KA, Richmond BW, Braun NA, Isom J, Abraham S, Taylor TR, et al. Reversal of global CD4+ subset dysfunction is associated with spontaneous clinical resolution of pulmonary sarcoidosis . J Immunol (Baltimore, Md 1950). 2013 Jun 1;190(11):5446-53.

49. Cotliar J, Querfeld C, Boswell WJ, Raja N, Raz D, Chen R. Pembrolizumab-associated sarcoidosis . JAAD case reports. 2016 Jul 27;2(4):290-3.

50. Montaudie H, Pradelli J, Passeron T, Lacour JP, Leroy S. Pulmonary sarcoid-like granulomatosis induced by nivolumab. Br J Dermatol. 2016 Jun 13;

51. Danlos F-X, Pagès C, Baroudjian B, Vercellino L, Battistella M, Mimoun $M$, et al. Nivolumab-Induced Sarcoid-Like Granulomatous Reaction in a Patient With Advanced Melanoma. Chest. 2016;149(5):e133-6.

52. Vorselaars AD, Crommelin HA, Deneer VH, Meek B, Claessen AM, Keijsers RG, et al. Effectiveness of infliximab in refractory FDG PET-positive sarcoidosis. Eur Respir J. 2015 Jul;46(1):175-85. 
53. Tong D, Manolios N, Howe G, Spencer D. New onset sarcoid-like granulomatosis developing during anti-TNF therapy: an under-recognised complication . Intern Med J. 2012 Jan;42(1):89-94.

54. Christoforidou A, Goudakos J, Bobos M, Lefkaditis E, Vital V, Markou K. Sarcoidosislike granulomatosis of the hypopharynx as a complication of anti-TNF therapy . Am J Otolaryngol. 2013;34(3):268-72.

55. Curtis MM, Way SS. Interleukin-17 in host defence against bacterial, mycobacterial and fungal pathogens. Immunology. 2009 Feb;126(2):177-85.

56. Facco M, Cabrelle A, Teramo A, Olivieri V, Gnoato M, Teolato S, et al. Sarcoidosis is a Th1/Th17 multisystem disorder . Thorax. 2011 Feb;66(2):144-50.

57. Ten Berge B, Paats MS, Bergen IM, van den Blink B, Hoogsteden HC, Lambrecht BN, et al. Increased IL-17A expression in granulomas and in circulating memory $T$ cells in sarcoidosis . Rheumatology (Oxford). 2012 Jan;51(1):37-46.

58. Richmond BW, Ploetze K, Isom J, Chambers-Harris I, Braun NA, Taylor T, et al. Sarcoidosis Th17 cells are ESAT- 6 antigen specific but demonstrate reduced IFNgamma expression . J Clin Immunol. 2013 Feb;33(2):446-55.

59. Ostadkarampour M, Eklund A, Moller D, Glader P, Olgart Hoglund C, Linden A, et al. Higher levels of interleukin IL-17 and antigen-specific IL-17 responses in pulmonary sarcoidosis patients with Lofgren's syndrome . Clin Exp Immunol. 2014 Nov;178(2):342-52.

60. Ramstein J, Broos CE, Simpson LJ, Ansel KM, Sun SA, Ho ME, et al. IFN- $\gamma$-Producing T-Helper 17.1 Cells Are Increased in Sarcoidosis and Are More Prevalent than THelper Type 1 Cells. Am J Respir Crit Care Med. 2016;193(11):1281-91.

61. Tondell A, Moen T, Borset M, Salvesen O, Ro AD, Sue-Chu M. Bronchoalveolar lavage fluid IFN-gamma+ Th17 cells and regulatory T cells in pulmonary sarcoidosis . Mediators Inflamm. 2014;2014:438070.

62. Lexberg MH, Taubner A, Albrecht I, Lepenies I, Richter A, Kamradt T, et al. IFN-? and IL-12 synergize to convert in vivo generated Th17 into Th1/Th17 cells. Eur J Immunol. 2010;40(11):3017-27.

63. Li P, Liu C, Yu Z, Wu M. New Insights into Regulatory T Cells: Exosome- and NonCoding RNA-Mediated Regulation of Homeostasis and Resident Treg Cells . Front Immunol. 2016 Dec 6;7:574.

64. Bettelli E, Carrier Y, Gao W, Korn T, Strom TB, Oukka M, et al. Reciprocal developmental pathways for the generation of pathogenic effector TH17 and regulatory T cells . Nature. 2006;441(7090):235-8.

65. Rappl G, Pabst S, Riemann D, Schmidt A, Wickenhauser C, Schutte W, et al. Regulatory $\mathrm{T}$ cells with reduced repressor capacities are extensively amplified in 
pulmonary sarcoid lesions and sustain granuloma formation . Clin Immunol. 2011 Jul;140(1):71-83.

66. Miyara M, Amoura Z, Parizot C, Badoual C, Dorgham K, Trad S, et al. The immune paradox of sarcoidosis and regulatory T cells . J Exp Med. 2006 Feb 20;203(2):35970.

67. Broos CE, van Nimwegen M, Kleinjan A, ten Berge B, Muskens F, in 't Veen JC, et al. Impaired survival of regulatory T cells in pulmonary sarcoidosis . Respir Res. 2015 Sep 16;16:108.

68. Taflin C, Miyara M, Nochy D, Valeyre D, Naccache JM, Altare F, et al. FoxP3+ regulatory $T$ cells suppress early stages of granuloma formation but have little impact on sarcoidosis lesions. Am J Pathol. 2009 Feb;174(2):497-508.

69. Saussine A, Tazi A, Feuillet S, Rybojad M, Juillard C, Bergeron A, et al. Active chronic sarcoidosis is characterized by increased transitional blood $B$ cells, increased IL-10producing regulatory B cells and high BAFF levels. PLoS One. 2012;7(8):e43588.

70. Kamphuis LS, van Zelm MC, Lam KH, Rimmelzwaan GF, Baarsma GS, Dik WA, et al. Perigranuloma localization and abnormal maturation of $B$ cells: emerging key players in sarcoidosis? . Am J Respir Crit Care Med. 2013 Feb 15;187(4):406-16.

71. Ueda-Hayakawa I, Tanimura H, Osawa M, Iwasaka H, Ohe S, Yamazaki F, et al. Elevated serum BAFF levels in patients with sarcoidosis: association with disease activity . Rheumatology (Oxford). 2013 Sep;52(9):1658-66.

72. Lee NS, Barber L, Akula SM, Sigounas G, Kataria YP, Arce S. Disturbed homeostasis and multiple signaling defects in the peripheral blood B-cell compartment of patients with severe chronic sarcoidosis . Clin Vaccine Immunol. 2011 Aug;18(8):1306-16.

73. Cinetto F, Compagno N, Scarpa R, Malipiero G, Agostini C. Rituximab in refractory sarcoidosis: a single centre experience . Clin Mol Allergy. 2015 Sep 1;13(1):19-0150025-9. eCollection 2015.

74. Cragg MS, Walshe CA, Ivanov AO, Glennie MJ. The biology of CD20 and its potential as a target for mAb therapy . Curr Dir Autoimmun. 2005;8:140-74.

75. Krause ML, Cooper LT, Chareonthaitawee P, Amin S. Successful use of rituximab in refractory cardiac sarcoidosis . Rheumatology (Oxford). 2016 Jan;55(1):189-91.

76. Beccastrini E, Vannozzi L, Bacherini D, Squatrito D, Emmi L. Successful treatment of ocular sarcoidosis with rituximab. Ocul Immunol Inflamm. 2013 Jun;21(3):244-6.

77. Belkhou A, Younsi R, El Bouchti I, El Hassani S. Rituximab as a treatment alternative in sarcoidosis . Joint Bone Spine. 2008 Jul;75(4):511-2.

78. Agrawal R, Kee AR, Ang L, Tun Hang Y, Gupta V, Kon OM, et al. Tuberculosis or sarcoidosis: Opposite ends of the same disease spectrum? . Tuberculosis (Edinb). 
2016;98:21-6.

79. Esteves T, Aparicio G, Garcia-Patos V. Is there any association between Sarcoidosis and infectious agents?: a systematic review and meta-analysis. BMC Pulm Med. 2016 Nov 28;16(1):165.

80. Newman LS. Metals that cause sarcoidosis . Semin Respir Infect. 1998 Sep;13(3):212-20.

81. Rafnsson V, Ingimarsson O, Hjalmarsson I, Gunnarsdottir H. Association between exposure to crystalline silica and risk of sarcoidosis. Occup Environ Med. 1998;55(10):657-60.

82. Drent M, Bomans PH, Van Suylen RJ, Lamers RJ, Bast A, Wouters EF. Association of man-made mineral fibre exposure and sarcoidlike granulomas . Respir Med. 2000 Aug;94(8):815-20.

83. Mortaz E, Adcock IM, Barnes PJ. Sarcoidosis: Role of non-tuberculosis mycobacteria and Mycobacterium tuberculosis. Int J mycobacteriology. 2014 Dec;3(4):225-9.

84. Gupta D, Agarwal R, Aggarwal AN, Jindal SK. Molecular evidence for the role of mycobacteria in sarcoidosis: a meta-analysis . Eur Respir J. 2007 Sep;30(3):508-16.

85. Fang $\mathrm{C}$, Huang $\mathrm{H}, \mathrm{Xu} \mathrm{Z}$. Immunological Evidence for the Role of Mycobacteria in Sarcoidosis: A Meta-Analysis . PLoS One. 2016 Aug 1;11(8):e0154716.

86. Brownell I, Ramirez-Valle F, Sanchez M, Prystowsky S. Evidence for mycobacteria in sarcoidosis. Am J Respir Cell Mol Biol. 2011 Nov;45(5):899-905.

87. Song Z, Marzilli L, Greenlee BM, Chen ES, Silver RF, Askin FB, et al. Mycobacterial catalase-peroxidase is a tissue antigen and target of the adaptive immune response in systemic sarcoidosis. J Exp Med. 2005;201(5):755-67.

88. Chen ES, Wahlstrom J, Song Z, Willett MH, Wiken M, Yung RC, et al. T cell responses to mycobacterial catalase-peroxidase profile a pathogenic antigen in systemic sarcoidosis. J Immunol (Baltimore, Md 1950). 2008 Dec 15;181(12):8784-96.

89. Oswald-Richter KA, Culver DA, Hawkins C, Hajizadeh R, Abraham S, Shepherd BE, et al. Cellular responses to mycobacterial antigens are present in bronchoalveolar lavage fluid used in the diagnosis of sarcoidosis. Infect Immun. 2009 Sep;77(9):3740-8.

90. Drake WP, Dhason MS, Nadaf M, Shepherd BE, Vadivelu S, Hajizadeh R, et al. Cellular recognition of Mycobacterium tuberculosis ESAT-6 and KatG peptides in systemic sarcoidosis. Infect Immun. 2007 Jan;75(1):527-30.

91. Oswald-Richter KA, Beachboard DC, Zhan X, Gaskill CF, Abraham S, Jenkins C, et al. Multiple mycobacterial antigens are targets of the adaptive immune response in pulmonary sarcoidosis. Respir Res. 2010 Nov 23;11:161.

92. Dubaniewicz A, Trzonkowski P, Dubaniewicz-Wybieralska M, Dubaniewicz A, Singh 
M, Mysliwski A. Mycobacterial heat shock protein-induced blood T lymphocytes subsets and cytokine pattern: comparison of sarcoidosis with tuberculosis and healthy controls. Respirology. 2007;12(3):346-54.

93. Carlisle J, Evans W, Hajizadeh R, Nadaf M, Shepherd B, Ott RD, et al. Multiple Mycobacterium antigens induce interferon-gamma production from sarcoidosis peripheral blood mononuclear cells. Clin Exp Immunol. 2007 Dec;150(3):460-8.

94. Vieira AP, Trindade MA, Pagliari C, Avancini J, Sakai-Valente NY, Duarte AJ, et al. Development of Type 2, But Not Type 1, Leprosy Reactions is Associated with a Severe Reduction of Circulating and In situ Regulatory T-Cells . Am J Trop Med Hyg. 2016 Apr;94(4):721-7.

95. Walker SL, Lockwood DN. Leprosy type 1 (reversal) reactions and their management . Lepr Rev. 2008 Dec;79(4):372-86.

96. Kahawita IP, Lockwood DN. Towards understanding the pathology of erythema nodosum leprosum . Trans R Soc Trop Med Hyg. 2008 Apr;102(4):329-37.

97. Fonseca AB, Simon MD, Cazzaniga RA, de Moura TR, de Almeida RP, Duthie MS, et al. The influence of innate and adaptative immune responses on the differential clinical outcomes of leprosy . Infect Dis poverty. 2017 Feb 6;6(1):3-5.

98. Drake WP, Richmond BW, Oswald-Richter K, Yu C, Isom JM, Worrell JA, et al. Effects of broad-spectrum antimycobacterial therapy on chronic pulmonary sarcoidosis . Sarcoidosis, Vasc Diffus lung Dis Off J WASOG. 2013 Nov 25;30(3):201-11.

99. Drake WP, Oswald-Richter K, Richmond BW, Isom J, Burke VE, Algood H, et al. Oral antimycobacterial therapy in chronic cutaneous sarcoidosis: a randomized, singlemasked, placebo-controlled study . JAMA dermatology. 2013 Sep;149(9):1040-9.

100. Schupp JC, Tchaptchet S, Lutzen N, Engelhard P, Muller-Quernheim J, Freudenberg $\mathrm{MA}$, et al. Immune response to Propionibacterium acnes in patients with sarcoidosis--in vivo and in vitro. BMC Pulm Med. 2015 Jul 24;15:75-7.

101. Hiramatsu J, Kataoka M, Nakata Y, Okazaki K, Tada S, Tanimoto M, et al. Propionibacterium acnes DNA detected in bronchoalveolar lavage cells from patients with sarcoidosis. Sarcoidosis, Vasc Diffus lung Dis Off J WASOG. 2003;20(3):197-203.

102. Abe C, Iwai K, Mikami R, Hosoda Y. Frequent isolation of Propionibacterium acnes from sarcoidosis lymph nodes. Zentralblatt fur Bakteriol Mikrobiol und Hyg A, Med Microbiol Infect Dis Virol Parasitol. 1984 Apr;256(4):541-7.

103. de Brouwer B, Veltkamp M, Wauters CA, Grutters JC, Janssen R. Propionibacterium acnes isolated from lymph nodes of patients with sarcoidosis . Sarcoidosis, Vasc Diffus lung Dis Off J WASOG. 2015 Sep 14;32(3):271-4.

104. Zhou Y, Wei YR, Zhang Y, Du SS, Baughman RP, Li HP. Real-time quantitative reverse 
transcription-polymerase chain reaction to detect propionibacterial ribosomal RNA in the lymph nodes of Chinese patients with sarcoidosis. Clin Exp Immunol. 2015 Sep;181(3):511-7.

105. Ebe Y, Ikushima S, Yamaguchi T, Kohno K, Azuma A, Sato K, et al. Proliferative response of peripheral blood mononuclear cells and levels of antibody to recombinant protein from Propionibacterium acnes DNA expression library in Japanese patients with sarcoidosis. Sarcoidosis Vasc Diffuse Lung Dis. 2000;17(3):256-65.

106. Minami J, Eishi Y, Ishige Y, Kobayashi I, Ishige I, Kobayashi D, et al. Pulmonary granulomas caused experimentally in mice by a recombinant trigger-factor protein of Propionibacterium acnes. J Med Dent Sci. 2003 Dec;50(4):265-74.

107. Yorozu P, Furukawa A, Uchida K, Akashi T, Kakegawa T, Ogawa T, et al. Propionibacterium acnes catalase induces increased Th1 immune response in sarcoidosis patients. Respir Investig. 2015 Jul;53(4):161-9.

108. Eishi Y. Etiologic link between sarcoidosis and Propionibacterium acnes . Respir Investig. 2013 Jun;51(2):56-68.

109. Takemori N, Nakamura M, Kojima M, Eishi Y. Successful treatment in a case of Propionibacterium acnes-associated sarcoidosis with clarithromycin administration: a case report. J Med Case Rep. 2014 Jan 15;8:15.

110. Goulvestre C, Batteux F, Charreire J. Chemokines modulate experimental autoimmune thyroiditis through attraction of autoreactive or regulatory $T$ cells . Eur J Immunol. 2002 Dec;32(12):3435-42.

111. Swanborg RH. Experimental autoimmune encephalomyelitis in the rat: lessons in Tcell immunology and autoreactivity . Immunol Rev. 2001 Dec;184:129-35.

112. Balmes JR, Abraham JL, Dweik RA, Fireman E, Fontenot AP, Maier LA, et al. An official American Thoracic Society statement: diagnosis and management of beryllium sensitivity and chronic beryllium disease. Am J Respir Crit Care Med. 2014 Nov 15;190(10):e34-59.

113. Muller-Quernheim J, Gaede KI, Fireman E, Zissel G. Diagnoses of chronic beryllium disease within cohorts of sarcoidosis patients . Eur Respir J. 2006 Jun;27(6):1190-5.

114. Bill JR, Mack DG, Falta MT, Maier LA, Sullivan AK, Joslin FG, et al. Beryllium presentation to $C D 4+T$ cells is dependent on a single amino acid residue of the $\mathrm{MHC}$ class II beta-chain . J Immunol (Baltimore, Md 1950). 2005 Nov 15;175(10):702937.

115. McCanlies EC, Ensey JS, Schuler CR, Kreiss K, Weston A. The association between HLA-DPB1Glu69 and chronic beryllium disease and beryllium sensitization. Am J Ind Med. 2004 Aug;46(2):95-103. 
116. McCanlies EC, Kreiss K, Andrew M, Weston A. HLA-DPB1 and chronic beryllium disease: a HuGE review . Am J Epidemiol. 2003;157(5):388-98.

117. Kelleher P, Pacheco K, Newman LS. Inorganic dust pneumonias: the metal-related parenchymal disorders . Environ Health Perspect. 2000 Aug;108 Suppl:685-96.

118. Cao M, Cai HR, Meng FQ, Wei JY. Pulmonary sarcoidlike granulomatosis induced by aluminum dust: a case report and literature review . Zhonghua Jie He He Hu Xi Za Zhi. 2008 Jun;31(6):406-9.

119. Chen WJ, Monnat Jr RJ, Chen M, Mottet NK. Aluminum induced pulmonary granulomatosis . Hum Pathol. 1978 Nov;9(6):705-11.

120. Tomioka H, Kaneda T, Katsuyama E, Kitaichi M, Moriyama H, Suzuki E. Elemental analysis of occupational granulomatous lung disease by electron probe microanalyzer with wavelength dispersive spectrometer: Two case reports . Respir Med case reports. 2016 Apr 26;18:66-72.

121. Deubelbeiss U, Gemperli A, Schindler C, Baty F, Brutsche MH. Prevalence of sarcoidosis in Switzerland is associated with environmental factors . Eur Respir J. 2010;35(5):1088-97.

122. Schmidt M, Goebeler M. Immunology of metal allergies . J Dtsch Dermatol Ges. 2015 Jul;13(7):653-60.

123. Yun J, Cai F, Lee FJ, Pichler WJ. T-cell-mediated drug hypersensitivity: immune mechanisms and their clinical relevance. Asia Pac Allergy. 2016 Apr;6(2):77-89.

124. Clayton GM, Wang Y, Crawford F, Novikov A, Wimberly BT, Kieft JS, et al. Structural basis of chronic beryllium disease: linking allergic hypersensitivity and autoimmunity . Cell. 2014 Jul 3;158(1):132-42.

125. Petukh M, Wu B, Stefl S, Smith N, Hyde-Volpe D, Wang L, et al. Chronic Beryllium Disease: revealing the role of beryllium ion and small peptides binding to HLA-DP2 . PLoS One. 2014 Nov 4;9(11):e111604.

126. Falta MT, Pinilla C, Mack DG, Tinega AN, Crawford F, Giulianotti M, et al. Identification of beryllium-dependent peptides recognized by CD4+ $T$ cells in chronic beryllium disease . J Exp Med. 2013 Jul 1;210(7):1403-18.

127. Roney K, Holl E, Ting J. Immune plexins and semaphorins: old proteins, new immune functions . Protein Cell. 2013 Jan;4(1):17-26.

128. Hamilton Jr RF, Thakur SA, Holian A. Silica binding and toxicity in alveolar macrophages . Free Radic Biol Med. 2008 Apr 1;44(7):1246-58.

129. Pavan C, Fubini B. Unveiling the Variability of "Quartz Hazard" in Light of Recent Toxicological Findings . Chem Res Toxicol. 2016 Dec 19;

130. Leung CC, Yu IT, Chen W. Silicosis . Lancet (London, England). 2012;379(9830):200818. 
131. Calvert GM, Rice FL, Boiano JM, Sheehy JW, Sanderson WT. Occupational silica exposure and risk of various diseases: an analysis using death certificates from 27 states of the United States . Occup Environ Med. 2003 Feb;60(2):122-9.

132. Checchi L, Nucci MC, Gatti AM, Mattia D, Violante FS. Sarcoidosis in a dental surgeon: a case report. J Med Case Rep. 2010 Aug 10;4:259.

133. Kawano-Dourado LB, Carvalho CR, Santos UP, Canzian M, Coletta EN, Pereira CA, et al. Tunnel excavation triggering pulmonary sarcoidosis. Am J Ind Med. 2012 Apr;55(4):390-4.

134. Drent M, Wijnen PA, Boots AW, Bast A. Cat litter is a possible trigger for sarcoidosis . Eur Respir J. 2012 Jan;39(1):221-2.

135. Sola R, Boj M, Hernandez-Flix S, Camprubi M. Silica in oral drugs as a possible sarcoidosis-inducing antigen . Lancet (London, England). 2009 Jun 6;373(9679):1943-4.

136. Fireman E, Shai AB, Alcalay Y, Ophir N, Kivity S, Stejskal V. Identification of metal sensitization in sarcoid-like metal-exposed patients by the MELISA(R) lymphocyte proliferation test - a pilot study . J Occup Med Toxicol. 2016 Apr 12;11:18-016-01011. eCollection 2016.

137. Friedetzky A, Garn H, Kirchner A, Gemsa D. Histopathological changes in enlarged thoracic lymph nodes during the development of silicosis in rats . Immunobiology. 1998 Jul;199(1):119-32.

138. Ye RD, Sun L. Emerging functions of serum amyloid A in inflammation. J Leukoc Biol. 2015 Dec;98(6):923-9.

139. Ivanisevic J, Kotur-Stevuljevic J, Stefanovic A, Spasic S, Vucinic Mihailovic V, Videnovic Ivanov $J$, et al. Association of serum amyloid $A$ and oxidative stress with paraoxonase 1 in sarcoidosis patients . Eur J Clin Invest. 2016;46(5):418-24.

140. Gungor S, Ozseker F, Yalcinsoy M, Akkaya E, Can G, Eroglu H, et al. Conventional markers in determination of activity of sarcoidosis. Int Immunopharmacol. 2015;25(1):174-9.

141. Bargagli E, Magi B, Olivieri C, Bianchi N, Landi C, Rottoli P. Analysis of serum amyloid A in sarcoidosis patients. Respir Med. 2011;105(5):775-80.

142. Chen ES, Song Z, Willett MH, Heine S, Yung RC, Liu MC, et al. Serum amyloid A regulates granulomatous inflammation in sarcoidosis through Toll-like receptor-2. Am J Respir Crit Care Med. 2010 Feb 15;181(4):360-73.

143. Chen ES, Moller DR. Etiologies of Sarcoidosis. Clin Rev Allergy Immunol. 2015 Aug;49(1):6-18.

144. Chen ES, Moller DR. Sarcoidosis--scientific progress and clinical challenges . Nat Rev. 2011 Jul 12;7(8):457-67. 
145. Salazar A, Mana J, Fiol C, Hurtado I, Argimon JM, Pujol R, et al. Influence of serum amyloid $A$ on the decrease of high density lipoprotein-cholesterol in active sarcoidosis . Atherosclerosis. 2000;152(2):497-502.

146. Mak TN, Bruggemann H. Vimentin in Bacterial Infections. Cells. $2016 \mathrm{Apr}$ 18;5(2):10.3390/cells5020018.

147. Cain H, Kraus B. Immunofluorescence microscopic demonstration of vimentin filaments in asteroid bodies of sarcoidosis. A comparison with electron microscopic findings. Virchows Arch Cell Pathol Incl Mol Pathol. 1983;42(2):213-26.

148. Wahlstrom J, Dengjel J, Persson B, Duyar H, Rammensee HG, Stevanovic S, et al. Identification of HLA-DR-bound peptides presented by human bronchoalveolar lavage cells in sarcoidosis. J Clin Invest. 2007 Nov;117(11):3576-82.

149. Wahlstrom J, Dengjel J, Winqvist O, Targoff I, Persson B, Duyar H, et al. Autoimmune $T$ cell responses to antigenic peptides presented by bronchoalveolar lavage cell HLADR molecules in sarcoidosis. Clin Immunol. 2009 Dec;133(3):353-63.

150. Grunewald J, Kaiser Y, Ostadkarampour M, Rivera N V, Vezzi F, Lotstedt B, et al. Tcell receptor-HLA-DRB1 associations suggest specific antigens in pulmonary sarcoidosis . Eur Respir J. 2016;47(3):898-909.

151. Eberhardt C, Thillai M, Parker R, Siddiqui N, Potiphar L, Goldin R, et al. Proteomic Analysis of Kveim Reagent Identifies Targets of Cellular Immunity in Sarcoidosis . PLoS One. 2017 Jan 23;12(1):e0170285. 


\section{Chapter 3}

\section{Clinical observations: is metal or silica associated sarcoidosis a new trigger-related phenotype?}

Els Beijer

Raisa Kraaijvanger

Bob Meek

Hans Kromhout

Wouter H. van Es

Kees A. Seldenrijk

Marjolein Drent

Jos M. Rooijackers

Marcel Veltkamp

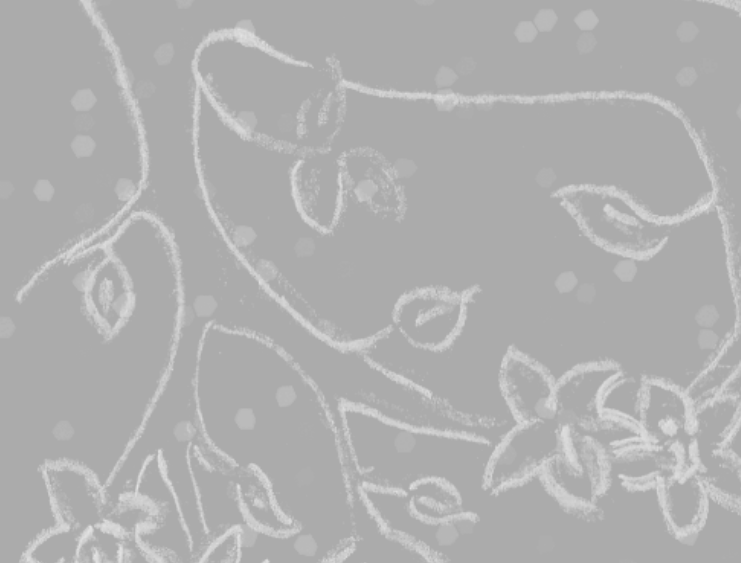

Case 3 of this chapter was published as a case report in Respir Med Case Reports. 2019 Jan;28:100906 


\section{Introduction}

Sarcoidosis is a systemic disorder of unknown etiology, although initiating inorganic triggers such as metals or silica have previously been suggested to play a role (1-4). Interestingly, some epidemiological studies have even demonstrated an elevated risk of sarcoidosis among occupationally silica-exposed individuals $(5,6)$ and patients with chronic beryllium disease (CBD) have been found among cohorts of sarcoidosis patients (7). In this chapter, 3 patients with a biopsy proven diagnosis of sarcoidosis are described in which exposure to metals or silica may have contributed in the development of the disease.

\section{Case 1: Beryllium}

The clinical presentation of CBD and sarcoidosis can be identical (8), and the only way to distinguish between both diseases is to assess beryllium sensitization using a lymphocyte proliferation test (LPT) on beryllium (9). An LPT examines the presence of sensitized lymphocytes or memory lymphocytes, for a specific antigen. If memory/sensitized T-cells are present, proliferation of these cells will be observed after stimulation of these cells in vitro by the particular antigen. The degree of proliferation is expressed as stimulation index (SI), where an SI between 2 and 3 is defined as a weak positive response and an $\mathrm{SI}>3$ as a positive response (10).

A 53 year old man was referred to our hospital because of persistent complaints of cough and dyspnea. He first experienced dyspnea while working as a smelter in a foundry about 25 years ago. In this period, fever and dyspnea particular presented during the evening. He was diagnosed with metal fume fever and therefore changed his job. He improved, although the complaints did not completely disappear over the years. At presentation in our ILD clinic, his dyspnea had progressed over the last couple of months. Upon physical examination the patient had a normal breathing rate with an oxygen saturation of $92 \%$ at room air. During auscultation of the lung, dorsobasal inspiratory crackles were heard and digital clubbing was seen. His pulmonary function demonstrated a restrictive pattern with a significant reduced diffusion capacity of $33 \%$ of predicted. A High-resolution computed tomography (HRCT) scan of the thorax showed bilateral hilar and mediastinal lymphadenopathy with extensive peribronchovascular located ground glass densities present at both lungs. Furthermore, small areas of air trapping and fibrotic abnormalities were seen at both lungs without the presence of honeycombing (Figure 1). 


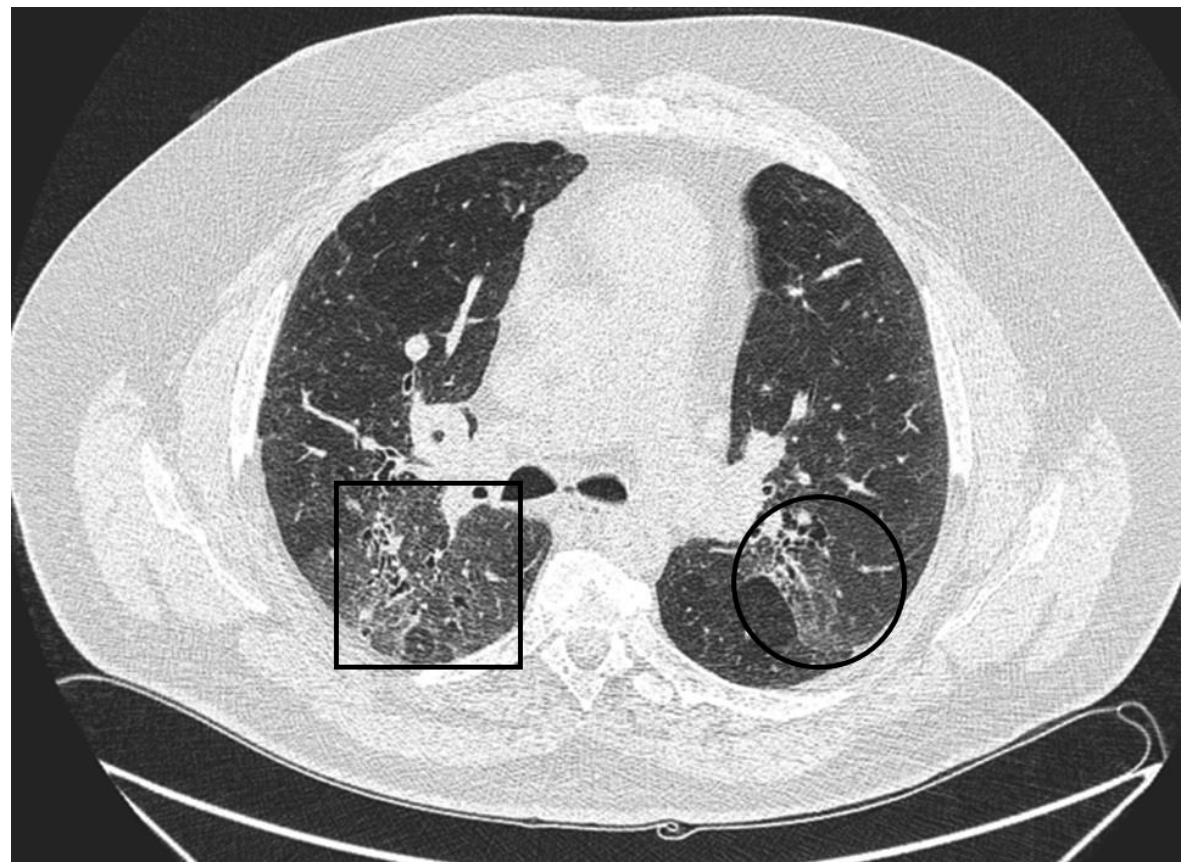

Figure 1. HRCT scan of the thorax which shows ground glass areas in the left lung (circle) and areas of fibrosis (square) in the right lung.

In order to make a diagnosis, an Endoscopic Ultra Sound (EUS) guided puncture of the subcarinal lymph node was performed revealing non-caseating granulomas. Culture for bacteria such as mycobacteria was negative and a diagnosis of pulmonary sarcoidosis was made. However, due to his occupational history, presence of pulmonary fibrosis and clubbing, it was decided to perform an LPT on aluminum, beryllium and zirconium. A positive LPT for beryllium, with an SI of 24.5, was observed indicating beryllium sensitization. Based on exposure to metals, presence of non-caseating granulomas and sensitization for beryllium, the diagnosis was changed into CBD according to the current guideline (9). Due to the disease progression of this patient, treatment with methotrexate and later with infliximab was initiated, both with only a marginal effect. Although the patient already quitted his occupational activities in the foundry, he was advised to avoid further exposure to beryllium, for example in hobby related activities. 


\section{Case 2: Aluminum}

A 31 old man without relevant medical history, was referred to our hospital because of complaints of dyspnea. He had been working for 12 years as a logistic employee in the dock of a steel factory, with direct exposure to lignite, coal and iron ores.

During physical examination the patient had a normal breathing rate with an oxygen saturation of $96 \%$ at room air. On auscultation, inspiratory crackles were heard in the basal fields of both lungs and presence of digital clubbing was observed. Pulmonary function tests showed a minimal restricted pattern and a moderate to severe impairment of diffusion capacity (52\% of predicted) An HRCT scan of the thorax showed ground glass densities with mosaic attenuation in both lungs. Lymphadenopathy or fibrosis were not observed (Figure 2).

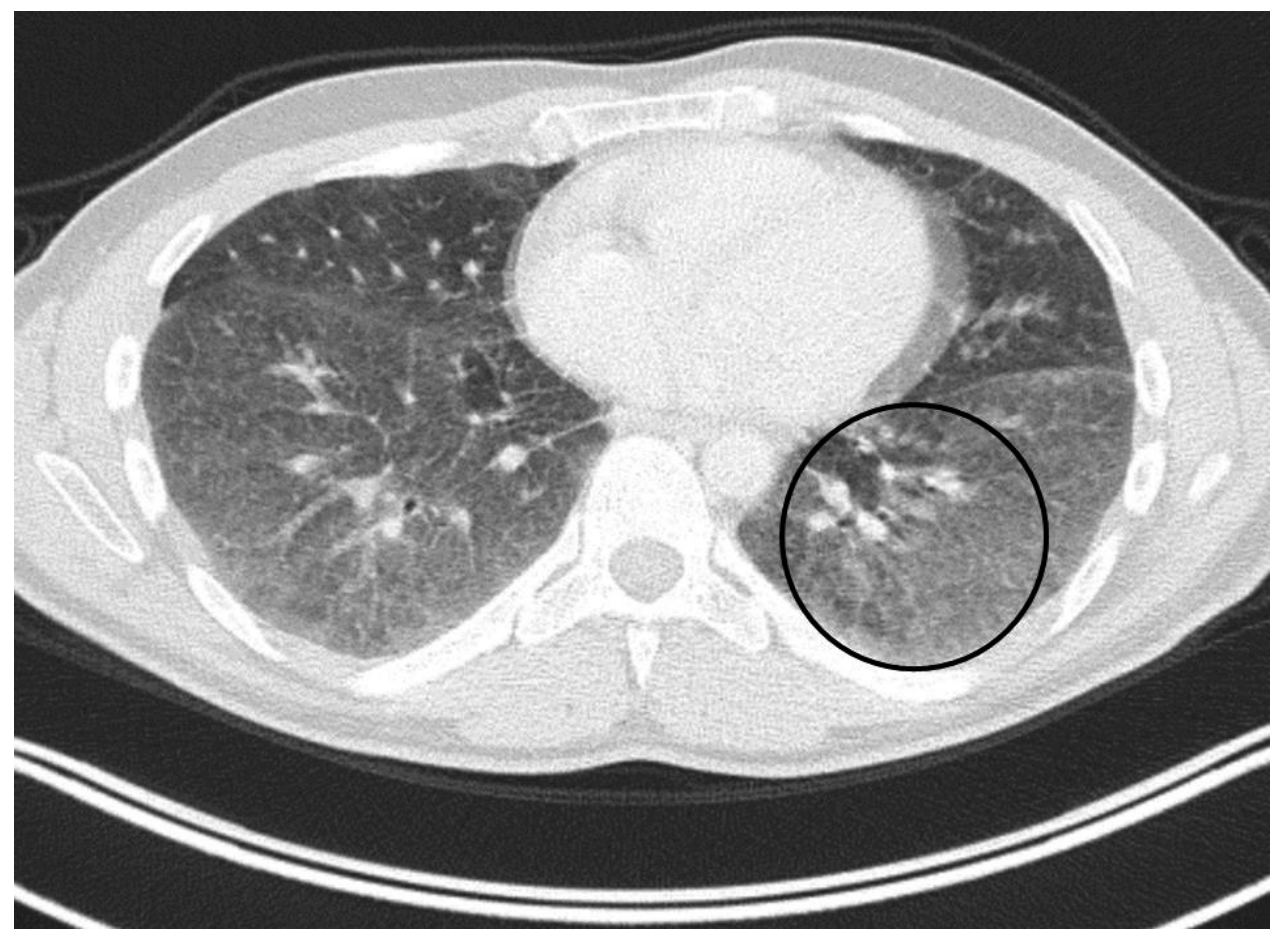

Figure 2. HRCT scan of the thorax. An extensive reticulonodular interstitial pattern was observed with ground glass areas and mosaic attenuation (circle) at both lungs.

The differential diagnosis included pneumoconiosis or an atypical presentation of sarcoidosis. To make a definite diagnosis, an open lung biopsy was performed revealing mature non-caseating granulomas, suggesting a diagnosis of sarcoidosis instead of pneumoconiosis. Besides granulomas, however, presence of birefringent material was 
found in the lung biopsy. An Energy-dispersive X-ray spectroscopy analysis (EDXA) to determine the origin of the birefringent material failed due to technical reasons. Based on his exposure to metals, the extensive ground glass on HRCT and findings on physical examination suggesting pulmonary fibrosis, an LPT was performed on aluminum, beryllium and zirconium. A weakly positive response for aluminum ( $\mathrm{SI}$ 2.7) was found. For this reason, the patient was advised to avoid further metal exposure. Exposure avoidance combined with prednisone treatment resulted in the decrease of dyspnea complaints as well as an improvement in the patient's radiological picture.

\section{Case 3: Silica}

Silicosis is caused by the inhalation of crystalline silicon dioxide, or silica, and is one of the most important occupational diseases worldwide (11). A diagnosis of silicosis is made based on exposure and typical radiological findings, according to the ILO's International Classification of Radiographs of Pneumoconiosis (12). In addition, competing diagnoses such as miliary tuberculosis or sarcoidosis should be excluded, as radiologic patterns of these diseases can be similar (11).

A 49-year-old male who had worked as a plasterer for 30 years presented with complaints of fatigue and progressive dyspnea, and was diagnosed as having silicosis. The patient was referred to our hospital because of deterioration, and to confirm the diagnosis. Occupational history was taken by an occupational hygienist and did indeed show exposure to construction dust including both crystalline and amorphous silica. HRCT showed mediastinal and bilateral hilar lymphadenopathy, subpleural nodules, consolidations, bronchiectasis and fibrotic lesions (Figure 3).

The radiology findings did not allow a diagnostic distinction to be made between silicosis and sarcoidosis. Hence, an open lung biopsy was performed, which showed inflammatory infiltration in the pleura, non-necrotizing granulomas including multinucleated giant cells with hyalinization, and birefringent material in the lung parenchyma (Figure 4).

Since yeast, mycobacterial and fungus cultures were negative and malignancy was excluded as well, the biopsy fitted within a diagnosis of sarcoidosis. In view of the presence of birefringent material in the tissue, most likely deposited as a result of the patient's masonry and plasterwork, an EDXA was performed. This revealed aluminum, silicon and titanium, elements that are all present in cement. An LPT was used to test whether the patient showed immunoreactivity to any of these compounds. Since beryllium is known to be capable of inducing a granulomatous reaction (9), the LPT was performed for beryllium as well. The stimulation indexes for the metals tested were all below 2.0. Interestingly, a positive stimulation index of 3.2 was found for silica, indicating sensitization. 


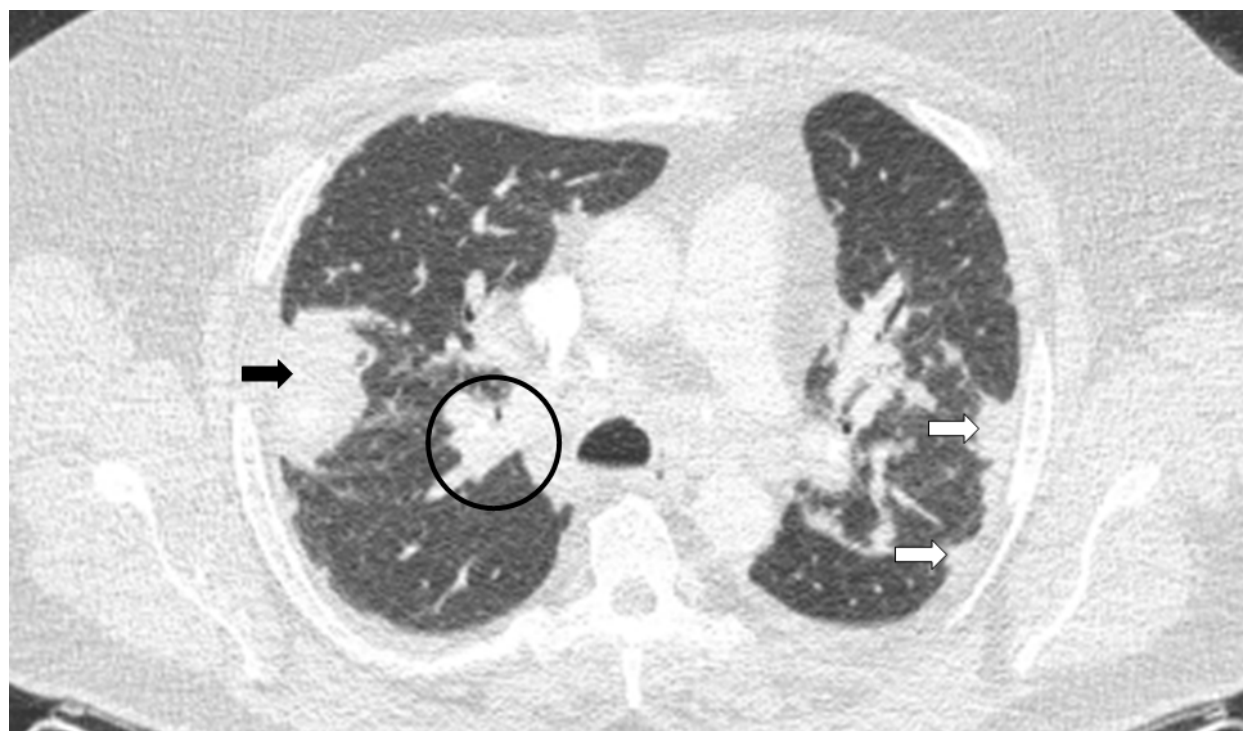

Figure 3. HRCT scan of the thorax showed bilateral hilar and mediastinal lymphadenopathy (circle) with sub pleural nodules (white arrows) and consolidations (black arrow).

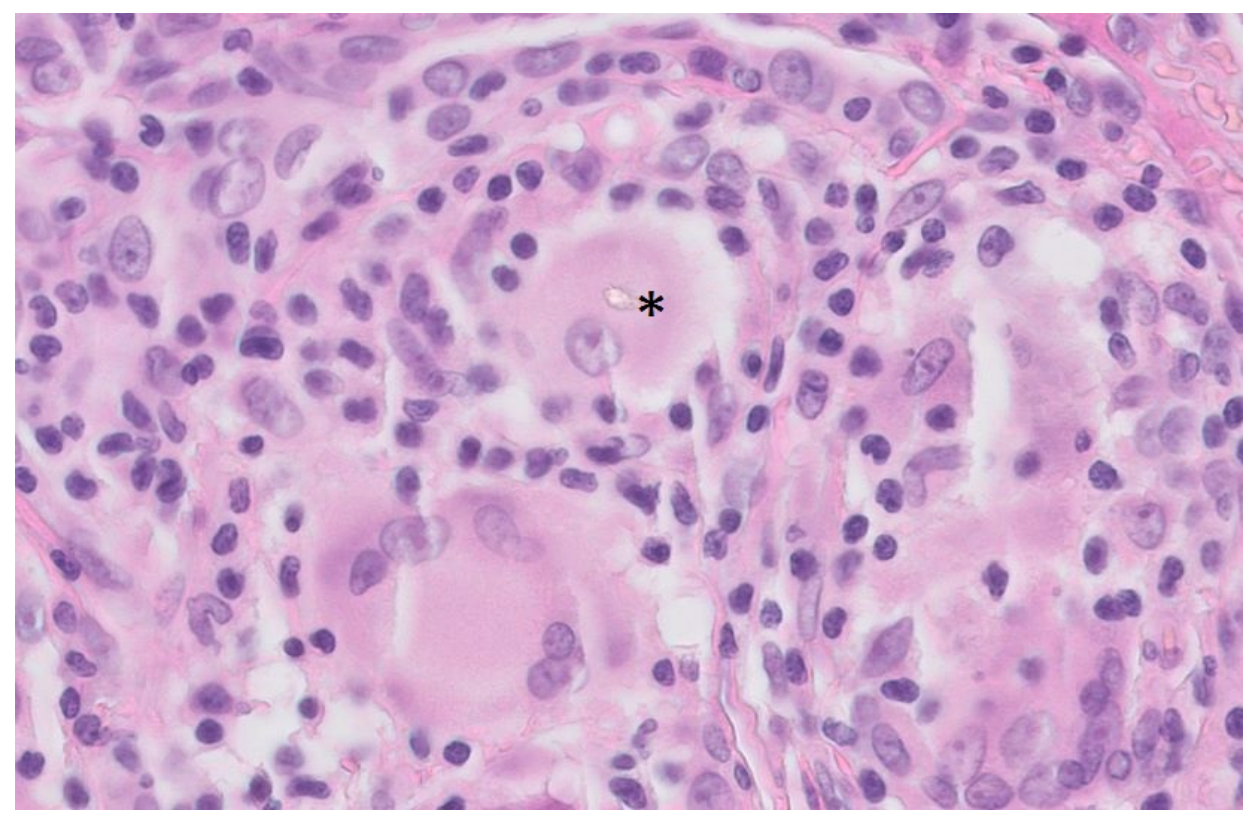

Figure 4. Open lung biopsy tissue demonstrating non-necrotizing granulomas including birefringent material, as indicated by the asterisk. 
While being treated with a combination of prednisone and azathioprine, the patient deteriorated further, with increased dyspnea and pulmonary consolidations and worsening of the pulmonary function tests. In view of the final diagnosis of sarcoidosis instead of silicosis, treatment with infliximab was started. After 7 months of treatment with this agent, the patient's pulmonary function test had improved and pulmonary consolidations on HRCT as well as the inflammatory activity measured by ${ }^{18} \mathrm{~F}$-luorodeoxyglucose by positron emission tomography/computed tomography ( ${ }^{18}$ F-FDG PET/CT) had decreased (Figure 5). Forced Vital Capacity (FVC) rose from $1.97 \mathrm{~L}$ to $2.35 \mathrm{~L}$ (44 and 53 percent of predicted, respectively) and the diffusing capacity of the lung for carbon monoxide (DLCO) rose from $5.46 \mathrm{mmol} /(\mathrm{min} * \mathrm{kPa}$ ) (54 percent of predicted) to $6.26 \mathrm{mmol} /(\mathrm{min} * \mathrm{kPa})$ (62 percent of predicted). carbon monoxide (DLCO) rose from $5.46 \mathrm{mmol} /(\mathrm{min} * \mathrm{kPa})$ (54 percent of predicted) to $6.26 \mathrm{mmol} /(\mathrm{min} * \mathrm{kPa})(62$ percent of predicted).

\section{Discussion}

The patients described in this chapter highlight an interesting clinical problem in the differential diagnosis of pneumoconiosis versus sarcoidosis. The appearance of noncaseating granulomas in the biopsies of these patients pointed towards a diagnosis of sarcoidosis and not pneumoconiosis, where more sclerotic nodules are found (13). However, demonstration of sensitization to metals or silica in these patients makes it difficult to apply the criterion "per exclusionem" for diagnosis of sarcoidosis in the last two of these patients. In the first patient, the diagnosis of sarcoidosis could be changed to CBD according the current guideline (9). The patient had exposure to beryllium, presence of noncaseating granulomas and proven immunological sensitization for beryllium. It is well known that the non-necrotizing granulomas found in CBD are identical to the granulomas found in sarcoidosis, so one could speculate that CBD can be seen as a form of berylliuminduced sarcoidosis $(14,15)$. A current guideline for diagnosing aluminum or silica induced granulomatous pulmonary disease is lacking. Keeping in mind the above mentioned criteria to diagnose CBD, and applying them to aluminum and silica, a diagnosis of sarcoidosis associated with aluminum or silica exposure seems reasonable in our opinion for the last 2 patients. In the future, we could perhaps use the diagnosis of "chronic aluminum disease (CAD)" or "chronic silica disease (CSD)" when we demonstrate immunological sensitization against the above mentioned antigens in patients with biopsy proven sarcoidosis. 


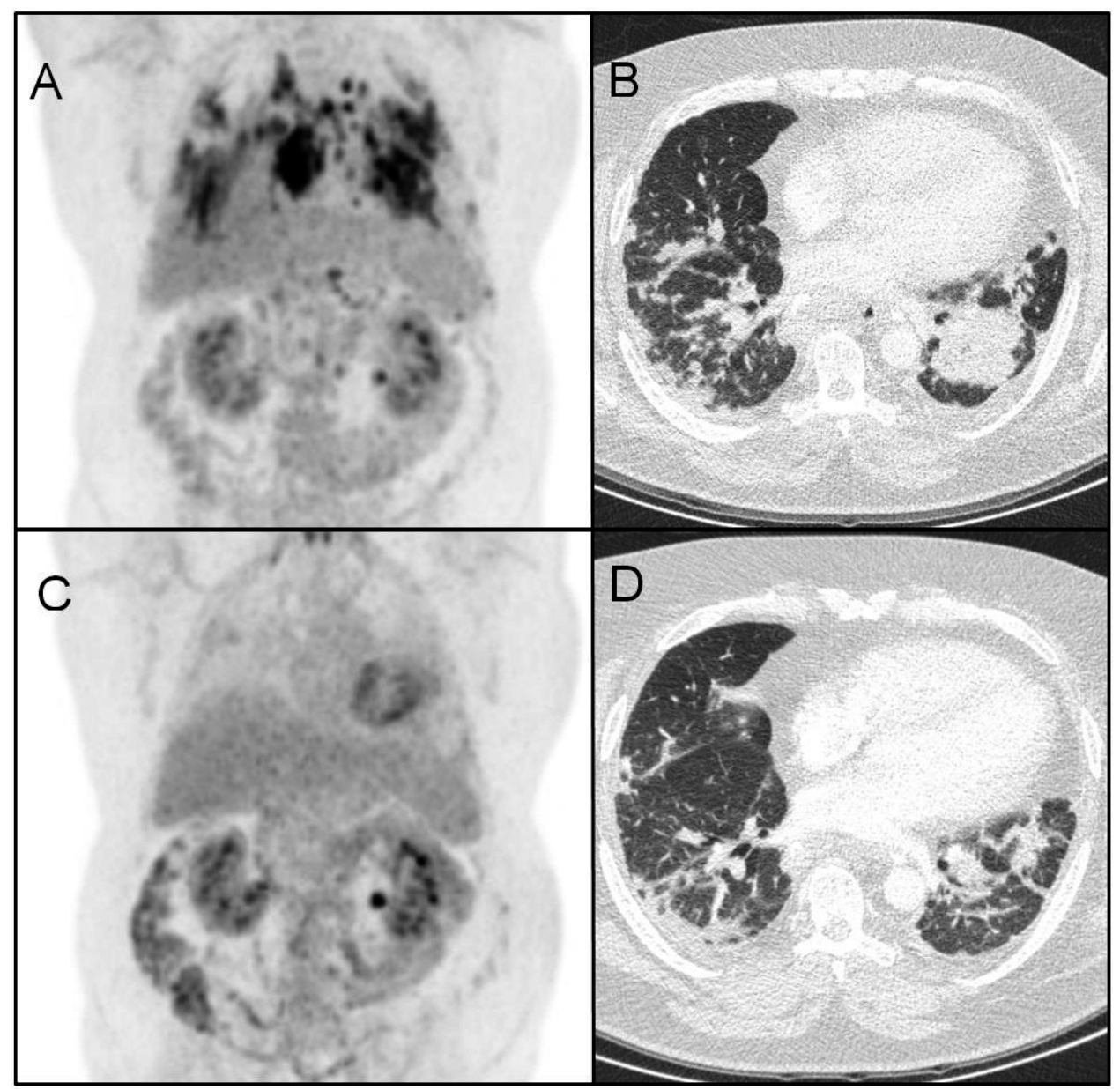

Figure 5. PET and HRCT scans before and after 7 months of infliximab therapy. Upper part: PET (A) and HRCT scan (B) 2 months prior to the start of infliximab. At this time, the patient had been on azathioprine therapy for 8 months, and prednisone therapy had been stopped 14 months ago. Lower part: PET (C) and HRCT Scans (D) after 7 months of infliximab therapy, showing decreased consolidations.

The clinical, radiological as well as histological presentation of these 3 patients can provide some clinical guidance. Indications of pulmonary crackles on auscultation (case 1 and 2) are not typical findings in sarcoidosis patients, and might point to the development of pulmonary fibrosis. Furthermore, also diffuse ground glass abnormalities were observed in patient 1 and 2, which are not common in the presentation of sarcoidosis either. Last, birefringent material in biopsies are neither frequently seen in sarcoidosis patients. 
Therefore, when above mentioned features are observed in a patient suspected for sarcoidosis, the clinician should assess the occupational history in more detail and assess the possible presence of an inorganic inducing agent. This could be done by the performance of an EDXA in case of presence of birefringent material in biopsy. However, beryllium has proven to be too small to be detected by EDXA. For this reason, patients with $\mathrm{CBD}$ will be missed when only the biopsy is analyzed for presence of inorganic agents while an LPT is not performed. It could therefore be important to carefully examine occupational and exposure history of patients suspected for sarcoidosis and to perform an LPT.

In conclusion, it can be difficult to distinguish between pneumoconiosis and sarcoidosis based on only exposure, radiological or histological patterns. Sensitization to metals and silica could be involved in an underlying immunological mechanism resulting in sarcoidosis, explaining why people with metal or silica exposure have an elevated risk of developing sarcoidosis $(5,16)$. Future studies in larger patients groups should be initiated to address the possible causality of metal and silica exposure and the development of sarcoidosis, and clarify the underlying immunological mechanisms in more detail. 


\section{References}

1. Werfel U, Schneider J, Rodelsperger K, Kotter J, Popp W, Woitowitz HJ, et al. Sarcoid granulomatosis after zirconium exposure with multiple organ involvement. Eur Respir J. 1998 Sep;12(3):750.

2. Cao M, Cai HR, Meng FQ, Wei JY. Pulmonary sarcoidlike granulomatosis induced by aluminum dust: a case report and literature review . Zhonghua Jie He He Hu Xi Za Zhi. 2008 Jun;31(6):406-9.

3. Sola R, Boj M, Hernandez-Flix S, Camprubi M. Silica in oral drugs as a possible sarcoidosis-inducing antigen . Lancet (London, England). 2009 Jun 6;373(9679):1943-4.

4. Drent M, Wijnen PA, Boots AW, Bast A. Cat litter is a possible trigger for sarcoidosis . Eur Respir J. 2012 Jan;39(1):221-2.

5. Rafnsson V, Ingimarsson O, Hjalmarsson I, Gunnarsdottir H. Association between exposure to crystalline silica and risk of sarcoidosis . Occup Environ Med. 1998;55(10):657-60.

6. Vihlborg P, Bryngelsson IL, Andersson L, Graff P. Risk of sarcoidosis and seropositive rheumatoid arthritis from occupational silica exposure in Swedish iron foundries: a retrospective cohort study. BMJ Open. 2017 Jul 20;7(7):e016839-2017-016839.

7. Muller-Quernheim J, Gaede KI, Fireman E, Zissel G. Diagnoses of chronic beryllium disease within cohorts of sarcoidosis patients . Eur Respir J. 2006 Jun;27(6):1190-5.

8. Mayer AS, Hamzeh N, Maier LA. Sarcoidosis and chronic beryllium disease: similarities and differences. Semin Respir Crit Care Med. 2014 Jun;35(3):316-29.

9. Balmes JR, Abraham JL, Dweik RA, Fireman E, Fontenot AP, Maier LA, et al. An official American Thoracic Society statement: diagnosis and management of beryllium sensitivity and chronic beryllium disease. Am J Respir Crit Care Med. 2014 Nov 15;190(10):e34-59.

10. Stejskal VD, Cederbrant K, Lindvall A, Forsbeck M. MELISA-an in vitro tool for the study of metal allergy . Toxicol In Vitro. 1994;8(5):991-1000.

11. Greenberg MI, Waksman J, Curtis J. Silicosis: a review . Dis Mon. 2007 Aug;53(8):394-416.

12. Muszynska-Graca M, Dabkowska B, Brewczynski PZ. Guidelines for the use of the International Classification of Radiographs of Pneumoconioses of the International Labour Office (ILO): Substantial changes in the currrent edition . Med Pr. 2016 Dec $22 ; 67(6): 833-7$.

13. Chong S, Lee KS, Chung MJ, Han J, Kwon OJ, Kim TS. Pneumoconiosis: Comparison of imaging and pathologic findings. Vol. 26, Radiographics. Radiological Society of North America ; 2006. p. 59-77. 
14. Rossman MD, Kreider ME. Is chronic beryllium disease sarcoidosis of known etiology? . Sarcoidosis, Vasc Diffus lung Dis Off J WASOG. 2003 Jun;20(2):104-9.

15. Richeldi L. Chronic beryllium disease: a model for pulmonary sarcoidosis? . Acta Biomed. 2005;76 Suppl 2:11-4.

16. Deubelbeiss U, Gemperli A, Schindler C, Baty F, Brutsche MH. Prevalence of sarcoidosis in Switzerland is associated with environmental factors . Eur Respir J. 2010;35(5):1088-97. 

Chapter 4

\section{Immunoreactivity to metal and silica associates with sarcoidosis in Dutch patients}

Els Beijer

Bob Meek

Xavier Bossuyt

Susan Peters

Roel C.H. Vermeulen

Hans Kromhout

Marcel Veltkamp

Respir Res. 2020 Jun 8;21(1):141.

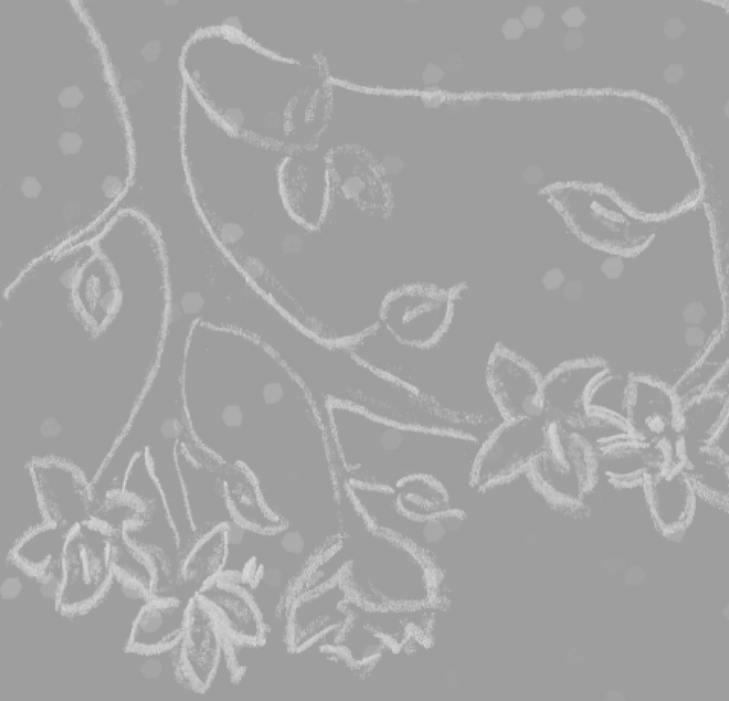




\begin{abstract}
Involvement of metals or silica in the pathogenesis of sarcoidosis has been suggested by several case reports and specific epidemiological studies. However, the combination of occupational exposure and an immunological reaction has not been studied before in a group of sarcoidosis patients and non-sarcoidosis controls.

In 256 sarcoidosis patients and 73 control patients with obstructive sleep apnea, exposure to metal and silica was assessed using a questionnaire consisting of a complete occupational history subsequently linked to job-exposure matrices. Next, immunoreactivity to aluminum, beryllium, zirconium and silica was determined in 33 sarcoidosis and 19 control patients using a lymphocyte proliferation test.

In sarcoidosis, 83 out 256 patients (32.4\%) had occupational exposure to metals or silica, compared to $24.7 \%$ in the control group $(P=0.21)$. A significantly higher percentage of the sarcoidosis patients tested showed immunoreactivity to metals or silica compared to the control group $(21.2 \%$ and $0 \%$ respectively, $\mathrm{P}=0.039)$.

Immunoreactivity to silica and metals only found in sarcoidosis patients, supporting the hypothesis that these antigens may be involved in the pathogenesis of a distinct subgroup of sarcoidosis patients. This indicates that when searching for causative agents in sarcoidosis patients, besides beryllium, zirconium, aluminum and silica also deserve clinical investigation.
\end{abstract}

Keywords: Sarcoidosis, aluminum, beryllium, zirconium, metals, silica 


\section{Introduction}

Sarcoidosis is a systemic disease characterized by the formation of noncaseating granuloma, mostly affecting the lungs, skin, eyes and lymph nodes (1). The etiology of sarcoidosis remains unclear to date and possible etiologic factors such as metals or silica are not included in the current work-up of sarcoidosis. When beryllium exposure is clinically suspected in patients with sarcoidosis, chronic beryllium disease (CBD) can be excluded by testing for beryllium immunoreactivity using a Lymphocyte Proliferation Test (LPT). This is important since CBD can be histopathological and clinical indistinguishable from sarcoidosis (2). Also other antigens such as aluminum, zirconium and silica are suggested to play a role in the pathogenesis of sarcoidosis (3-7). At present, however, a causal relationship between these antigens and sarcoidosis has not been established. First because studies using a control group are lacking and second because exposure is difficult to assess. Identification of possible etiologic antigens in sarcoidosis is important since it may lead to a more personalized treatment regime. Retrospective studies on CBD showed that termination of beryllium exposure could lead to disease reversal $(8,9)$. Avoiding exposure might therefore be the first step in the treatment of sarcoidosis patients in whom metal or silica might be involved in the disease pathogenesis.

Although involvement of metals and silica in sarcoidosis pathogenesis has been suggested by several case reports and epidemiological studies, it has not been systematically studied in a larger group of sarcoidosis patients. The aim of this study was to characterize both occupational exposure and immunoreactivity to metals and silica in a group of sarcoidosis patients and controls. Since sarcoidosis is a very heterogeneous disease, we hypothesize that metals or silica are involved in the pathogenesis of the disease in only a subgroup of patients. Therefore, we have investigated whether occupational history linked to a job exposure matrix (JEM) can be an appropriate tool to identify which sarcoidosis patients have to be further tested for metal and silica immunoreactivity.

\section{Material and methods}

\section{Study subjects}

Sarcoidosis patients visiting the Interstitial Lung Disease (ILD) outpatient clinic of St. Antonius Hospital (Nieuwegein, The Netherlands) received an invitation letter to participate in the study. The diagnosis of sarcoidosis had been established according to the criteria of the American Thoracic Society/European Respiratory Society (10). The characteristics of the sarcoidosis patients, including age at diagnosis and inclusion, Scadding stage at diagnosis and inclusion, organ involvement and the use of immunosuppressive medication, were collected from medical records. As a control group, patients with obstructive sleep apnea (OSA) visiting the Pulmonary outpatient clinic of the St. Antonius Hospital were asked to 
participate. Patients diagnosed with OSA were used as controls based on the fact that there is no relationship between environmental triggers and development of OSA (11). This study was approved by the Medical research Ethics Committees United (MEC-U) of the St. Antonius Hospital (R14.023) and written informed consent was obtained from all participants.

\section{Assessment of metal and silica exposure}

Sarcoidosis and control patients received an online questionnaire asking for a complete occupational history. The patients' job histories were coded using the International Standard Classification of Occupations 1968 (ISCO-68) (12). This classification system consists of seven major groups, which are subdivided into several minor groups. These minor groups are further divided into unit groups, and eventually into single jobs. Every single job has a unique 5-digit code. This allows jobs to be organized into clearly defined sets according to the tasks and duties undertaken in the job. The complete job history, until the diagnosis of sarcoidosis, was taken into account. Occupational exposure to silica, and the metals nickel and chromium was assigned through the DOM-JEM developed by experts in the Netherlands for application in general population studies (13). Occupational exposure to metals in general was assigned through the ALOHA + JEM, developed by the same experts (14). Because this JEM needs jobs coded into ISCO-88 (15), initial ISCO-68 job codes were recoded into ISCO-88 codes.

\section{Lymphocyte proliferation tests to determine metal and silica immunoreactivity}

\section{Patient selection}

A random selection of 45 sarcoidosis patients with occupational exposure to silica or metals were asked to donate a blood sample for an LPT on beryllium, aluminum, zirconium and silica. From the group of sarcoidosis patients without exposure, 10 patients who had an appointment in the near future were asked for the LPT as well. Those patients were selected in such way that age and sex did not differ from the exposed sarcoidosis patients invited for the LPT. The first 20 control patients included were also asked to donate a blood sample.

\section{MELISA $^{\circledR}$}

Blood was drawn in citrate tubes and sent within 24 hours to Prohealth Medical, Nederweert, The Netherlands, where the memory lymphocyte immunostimulation assay $\left(\right.$ MELISA $^{\circledR}$ ) LPT was performed. MELISA ${ }^{\circledR}$ is a clinically validated blood test that detects typeIV allergy (sensitization) to multiple metals $(16,17)$. Furthermore, it can also be used to determine sensitization for silica (18). Lymphocytes were isolated from citrated blood, and $1 * 10^{6}$ cells were incubated for 5 days in HEPES-buffered media containing at least two 
consecutive dilutions of an antigen: aluminum nitrate, beryllium sulfate, silicon dioxide or zirconium dioxide. After cultivating for 5 days, proliferation was measured by incorporation of $\mathrm{H}^{3}$-labelled thymidine. Radioactivity was measured with a scintillation counter (Microbeta, Perkin Elmer). Stimulation indexes (SI) were calculated by dividing the antigen specific counts per minute by the mean counts per minute of the basal controls. SI of $\geq 3.0$ were considered as a positive test results, based on the MELISA ${ }^{\circledR}$ guidelines (16).

\section{Beryllium LPT}

Patients with an SI of $\geq 3.0$ for beryllium were invited to donate a second blood sample, which was sent to the department of Laboratory Medicine, University Hospitals Leuven, Belgium, where a second beryllium LPT was performed according to the protocol described in the ATS official statement on diagnosis and management of beryllium sensitivity and chronic beryllium disease (19). Briefly, $1.8 * 10^{5}$ PBMCs $/ 200 \mu \mathrm{L}$ were incubated for 6 days in medium (RPMI-1640 GlutaMax supplemented with 5\% autologous plasma and penicillin/streptomycin) containing concentrations of $10^{-4} \mathrm{M}$ till $10^{-10} \mathrm{M} \mathrm{BeSO}_{4}$. Cell proliferation was measured by incorporation of $\mathrm{H}^{3}$-labelled thymidine. An $\mathrm{SI}$ of $\geq 3.0$ was considered positive. The highest SI measured for each sample was used in the analysis. For calculating the correlation between the SI for beryllium obtained by MELISA ${ }^{\circledR}$ and obtained in Leuven, one additional patient, who had already performed both test for clinical evaluation, was included.

\section{Statistical analysis}

Study data were collected and managed using REDCap electronic data capture tools hosted at St. Antonius hospital. Data were analyzed using IBM SPSS statistics version 24. An unpaired T-test was used to compare numerical data between the sarcoidosis and control group. Non-parametric tests were used for non-normally distributed data (Mann-Whitney $\mathrm{U}$ test). Categorical data were compared between the sarcoidosis and control group using the Chi-squared test. If expected cell frequencies were below 5, Fisher's exact test was used for categorical data up to two categories. Odds ratios were estimated for sarcoidosis and occupational metal and silica exposure. Correlation between the MELISA ${ }^{\circledR}$ LPT and validated beryllium LPT was determined with Spearman's rho correlation. P-values $<0.05$ were considered significant. 


\section{Results}

\section{Patient characteristics}

A total of 590 patients were invited to participate in the study, of whom 314 responded and were willing to fill out the questionnaire. Finally, 256 sarcoidosis patients completed the occupational history and were included in the study. Seventy-three patients with OSA were included to serve as a control group. Demographics of all sarcoidosis and control patients are presented in Table 1. No difference in age at inclusion, sex or ethnicity was observed between the sarcoidosis and control patients. Only smoking status was significantly different between the sarcoidosis and control patients, with a higher proportion of never smokers in the sarcoidosis group.

Table 1. Demographics of sarcoidosis and control patients

\begin{tabular}{llll}
\hline & $\begin{array}{l}\text { Controls (\%) } \\
(\mathbf{n = 7 3 )}\end{array}$ & $\begin{array}{l}\text { Sarcoidosis (\%) } \\
(\mathbf{n = 2 5 6 )}\end{array}$ & P* \\
\hline Male / Female & $64.4 / 35.6$ & $63.7 / 36.3$ & 0.91 \\
\hline Age at diagnosis (Y) & $\mathrm{N} / \mathrm{A}$ & $43.57 \pm 10.63$ & - \\
\hline Age at inclusion (Y) & $55.42 \pm 14.37$ & $54.50 \pm 10.83$ & 0.61 \\
\hline Ethnicity (W/B/O) & $93.2 / 2.7 /$ & $93.4 / 3.5 / 3.1$ & 0.88 \\
\hline $\begin{array}{l}\text { Smoking status } \\
\text { (Never/former or current) }\end{array}$ & 34.1 & & $<0.001$ \\
\hline $\begin{array}{l}\text { Scadding stage at } \\
\text { inclusion (0/I/II/III/IV/ }\end{array}$ & N/A & $57.7 / 42.3$ & \\
$\begin{array}{l}\text { unknown) } \\
\text { Extra pulmonary }\end{array}$ & N/A & $30.1 / 9.8 / 18.4 / 12.9 / 26.2 /$ & \\
involvement & & 2.7 & \\
\hline
\end{tabular}

Age at diagnosis and age at inclusion are shown as means \pm std. deviation. Scadding stages were determined by chest X-ray. If Scadding stages at the time of inclusion were not available, Scadding stage was determined from the last obtained chest $\mathrm{X}$-ray before the inclusion date. $0=$ Normal chest radiograph; $\mathrm{I}=$ Bilateral hilar Iymphadenopathy (BHL); II = BHL with pulmonary infiltrates; III = pulmonary infiltrates without BHL; IV = fibrosis. B: Black; O: Other; W: White

a Smoking status was not available from 8 sarcoidosis patients. *Statistical differences for sex, ethnicity and smoking status were accessed using Pearson Chi-Square, statistical differences for age were calculated using an unpaired T-test. 


\section{No differences in occupational history and exposure between sarcoidosis patients and controls}

The distribution of sarcoidosis patients and controls over the major occupational groups is shown in Table 2. Almost all occupations classified by the JEMs as involving exposure to metals or silica, were jobs in major group 7/8/9 (Production and Related Workers, Transport Operators and laborers). Hence we compared the distribution of sarcoidosis and controls patients also over the minor groups belonging to major group 7/8/9 (Table 2). No significant differences between sarcoidosis patients and controls were observed for any of these major or minor group. Occupational metal or silica exposure was assigned to 83 sarcoidosis patients (32.4\%) and 18 control patients (24.7\%) $(P=0.21)(O R=1.47 ; 95 \% \mathrm{Cl} 0.81$ to 2.97, Table 3). No significant differences were observed in occupational metal or silica exposure between the sarcoidosis and control group (Table 4).

\section{Immunoreactivity to metals and silica was only observed in sarcoidosis patients}

Forty-five patients occupationally exposed to metals or silica were invited for the LPT, of whom 37 were willing to donate a blood sample. Unfortunately, LPTs on 11 samples could not be performed due to an insufficient number of lymphocytes. Ten sarcoidosis patients who had no exposure based on the JEMs were invited for the LPT as well. Of those 10 samples, 3 patients also had an insufficient number of lymphocytes. Of the 14 patients in whom the lymphocyte count was insufficient, 8 were on immunosuppressive medication and 6 were not. In total, an LPT was performed on samples of 33 sarcoidosis patients, of whom 26 had JEM assigned exposure and 7 had no JEM assigned exposure to either metals or silica. Of the 20 blood samples from control patients, 1 sample could not be analyzed for technical reasons. Three of those 19 control patients had JEM assigned exposure to either metals or silica. No significant differences regarding ethnicity, age at time of the LPT, sex or smoking were observed between the sarcoidosis and control patients of whom an LPT was performed. We found that $45.5 \%$ of the sarcoidosis patients, compared to none of the controls, were on immunosuppressive drugs at the time of the LPT $(P<0.01)$ (Table 5). 
Table 2. Percentage of patients within ISCO-68 major groups and in minor groups of major group 7/8/9.

\begin{tabular}{lll}
\hline Major occupational group & $\begin{array}{l}\text { Sarcoidosis (\%) } \\
\text { (n=256) }\end{array}$ & $\begin{array}{l}\text { Controls (\%) } \\
\text { (n=73) }\end{array}$ \\
\hline $\begin{array}{l}\text { 0/1. Professional, Technical and Related } \\
\text { Workers }\end{array}$ & 34.8 & 30.1 \\
\hline 2. Administrative and Managerial Workers. & 11.7 & 11.0 \\
\hline 3. Clerical and Related Workers & 23.0 & 27.4 \\
\hline $\begin{array}{l}\text { 4. Sales Workers } \\
\text { 5. Service Workers }\end{array}$ & 9.8 & 15.1 \\
\hline $\begin{array}{l}\text { 6. Agricultural, Animal Husbandry and } \\
\text { Forestry Workers, Fishermen and Hunters }\end{array}$ & 13.3 & 16.4 \\
\hline $\begin{array}{l}\text { 7/8/9. Production and Related Workers, } \\
\text { Transport Operators and Laborers }\end{array}$ & 41.5 & 2.7 \\
\hline
\end{tabular}

Minor occupational groups of major group

$7 / 8 / 9$

70. Production Supervisors and General

3.5

4.1

Foremen

71. Miners, Quarrymen, Well Drillers and

0.4

0.0

Related Workers

\begin{tabular}{lll} 
72. Metal Processers & 2.7 & 0.0 \\
\hline 73. Wood Preparation Workers and Paper & 0.8 & 0.0
\end{tabular}

Makers

\begin{tabular}{|c|c|c|}
\hline 77. Food and Beverage Processers & 3.1 & 4.1 \\
\hline $\begin{array}{l}\text { 79. Tailors, Dressmakers, Sewers, } \\
\text { Upholsterers and Related Workers }\end{array}$ & 1.2 & 1.4 \\
\hline $\begin{array}{l}\text { 81. Cabinetmakers and Related } \\
\text { Woodworkers }\end{array}$ & 0.4 & 0 \\
\hline $\begin{array}{l}\text { 83. Blacksmiths, Toolmakers and Machine- } \\
\text { Tool Operators }\end{array}$ & 3.1 & 6.8 \\
\hline $\begin{array}{l}\text { 84. Machinery Fitters, Machine Assemblers } \\
\text { and Precision Instrument Makers (except } \\
\text { Electrical) }\end{array}$ & 9.4 & 8.2 \\
\hline $\begin{array}{l}\text { 85. Electrical Fitters and Related Electrical } \\
\text { and Electronics Workers }\end{array}$ & 10.9 & 9.6 \\
\hline $\begin{array}{l}\text { 87. Plumbers, Welders, Sheet Metal and } \\
\text { Structural Metal Preparers and Erectors }\end{array}$ & 7.4 & 2.7 \\
\hline
\end{tabular}




\begin{tabular}{|c|c|c|}
\hline 88. Jewelry and Precious Metal Workers & 0.8 & 0.0 \\
\hline 90. Rubber and Plastics Product Makers & 0.4 & 0.0 \\
\hline 91. Paper and Paperboard Products Makers & 0.0 & 1.4 \\
\hline 92. Printers and Related Workers & 0.4 & 0.0 \\
\hline 93. Painters & 1.6 & 1.4 \\
\hline $\begin{array}{l}\text { 94. Production and Related Workers Not } \\
\text { Elsewhere Classified }\end{array}$ & 1.6 & 0.0 \\
\hline $\begin{array}{l}\text { 95. Bricklayers, Carpenters and Other } \\
\text { Construction Workers }\end{array}$ & 4.7 & 8.2 \\
\hline $\begin{array}{l}\text { 97. Material-Handling and Related } \\
\text { Equipment Operators, Dockers and Freight } \\
\text { Handlers }\end{array}$ & 3.5 & 4.1 \\
\hline 98. Transport Equipment Operators & 6.3 & 8.2 \\
\hline 99. laborers Not Elsewhere Classified & 0.8 & 1.4 \\
\hline
\end{tabular}

Table 3. Estimated odds ratios for sarcoidosis and JEM assigned exposure

\begin{tabular}{lllll}
\hline Exposure & $\begin{array}{l}\text { Controls (\%) } \\
(\mathbf{n = 7 3 )}\end{array}$ & $\begin{array}{l}\text { Sarcoidosis (\%) } \\
(\mathrm{n}=\mathbf{2 5 6})\end{array}$ & OR (95\% CI) & $\begin{array}{l}\text { OR (95\% Cl) } \\
\text { Adjusted* }\end{array}$ \\
\hline $\begin{array}{l}\text { Silica } \\
\text { and/or } \\
\text { metals }\end{array}$ & 24.7 & 32.4 & $1.47(0.81,2.65)$ & $1.62(0.88,2.97)$ \\
\hline Silica & 5.5 & 7.4 & $1.38(0.46,4.20)$ & $1.52(0.49,4.70)$ \\
\hline Metals & 23.3 & 29.3 & $1.37(0.75,2.50)$ & $1.48(0.80,2.76)$ \\
\hline
\end{tabular}

*adjusted for smoking 
Chapter 4. Immunoreactivity to metal and silica associates with sarcoidosis

Table 4. JEM assigned exposure of sarcoidosis patients and controls

\begin{tabular}{llll}
\hline JEM Exposure & Controls $(\mathbf{n}=\mathbf{7 3})$ & Sarcoidosis $(\mathbf{n}=\mathbf{2 5 6})$ & $\mathbf{P} *$ \\
\hline Silica & $4(5.5)$ & $19(7.4)$ & 0.57 \\
\hline Metals & $17(23.3)$ & $75(29.3)$ & 0.31 \\
\hline Chromium & $6(8.2)$ & $35(13.7)$ & 0.21 \\
\hline Nickel & $6(8.2)$ & $31(12.1)$ & 0.35 \\
\hline Silica and/or metal & $18(24.7)$ & $83(32.4)$ & 0.21 \\
\hline
\end{tabular}

Values are shown as absolute numbers with percentages in brackets.

* Statistical differences were accessed using Pearson Chi-Square

Table 5. Demographics of the sarcoidosis and control patients who had an LPT performed

\begin{tabular}{llll}
\hline & $\begin{array}{l}\text { Controls (\%) } \\
(\mathbf{n = 1 9 )}\end{array}$ & $\begin{array}{l}\text { Sarcoidosis (\%) } \\
(\mathbf{n = 3 3 )}\end{array}$ & P* \\
\hline Male / Female & $68.4 / 31.6$ & $90.9 / 9.1$ & 0.06 \\
\hline Age at inclusion (Y) & $60.53 \pm 14.21$ & $54.36 \pm 11.18$ & 0.09 \\
\hline Ethnicity (W/B/O) & $94.7 / 0 / 5.3$ & $97.0 / 3.0 / 0$ & 0.31 \\
\hline $\begin{array}{l}\text { Smoking status }{ }^{\text {a }} \text { (Never/Former } \\
\text { or current) }\end{array}$ & $47.4 / 52.6$ & $62.5 / 37.5$ & 0.29 \\
\hline $\begin{array}{l}\text { Using immunosuppressive } \\
\text { medication }\end{array}$ & 0 & & $<0.01$ \\
\hline
\end{tabular}

Age at inclusion is shown as means \pm std. deviation.. B: Black; O: Other; W: White.

a Smoking status was not available from 1 sarcoidosis patient * Statistical differences for sex was accessed using Fisher's Exact Test, P-values of ethnicity, smoking status and use of medication were calculated using Pearson Chi-Square and statistical differences for age were calculated using an unpaired T-test.

Immunoreactivity was only observed within the sarcoidosis group. Seven $(21.2 \%)$ sarcoidosis patients had a positive LPT for at least one of the antigens tested, compared to none of the controls (Figure $1, P=0.039$ ). One sarcoidosis patient had a positive LPT for multiple antigens, namely zirconium and beryllium. In total, 3 sarcoidosis patients had an SI of $\geq 3.0$ for beryllium and were invited for a second beryllium LPT using the ATS protocol. The highest SI values obtained by MELISA ${ }^{\circledR}$ for those three patients and the additional clinical patient were 3.96, 4.94, 9.05 and 24.48. The highest SI values of the second beryllium LPT following the ATS protocol for these patients were 1.27, 3.42, 5.93 and 379, 
respectively. When the results of those 4 patients were combined, a strong correlation of $1.00(P<0.01)$ was found between the beryllium SI of the MELISA ${ }^{\circledR}$ and LPT using the ATS protocol.

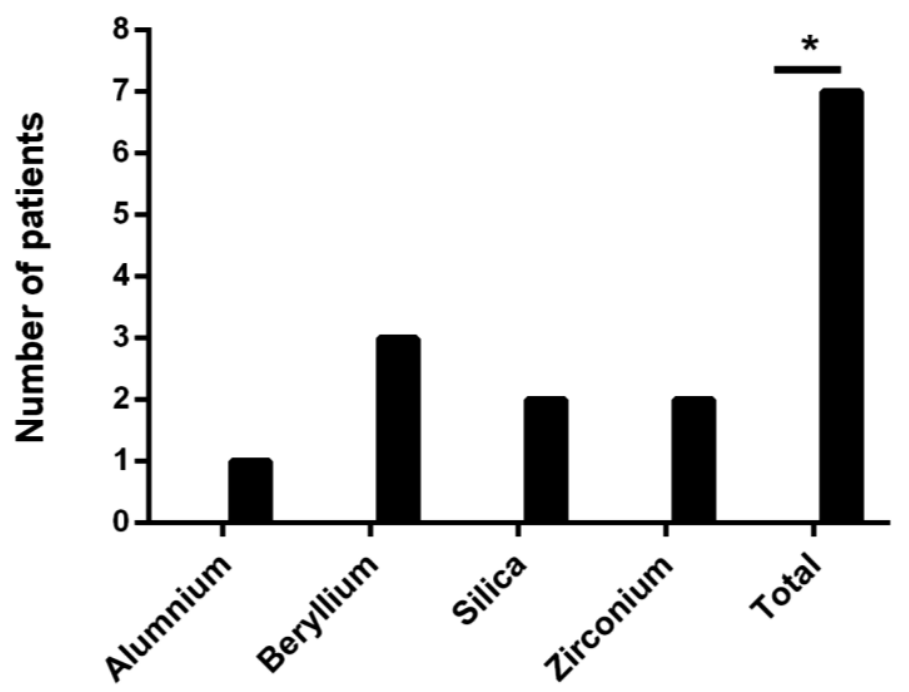

Figure 1. Number of sarcoidosis patients and controls with a positive LPT to the antigens tested. None of the control patients had a positive LPT for aluminum, silica, zirconium or beryllium. The difference between sarcoidosis patients and controls with a positive LPT to any of the antigens was significant $(P=0.039)$. An LPT was considered positive when the stimulation index was $\geq 3.0$. .

\section{Occupational exposure does not predict immunoreactivity}

Occupational exposure as assigned by JEMs was compared with LPT results. Four of the 26 sarcoidosis patients (15.4\%) with metal or silica exposure showed immunoreactivity to at least one of the antigens tested. Among the 7 sarcoidosis patients without JEM assigned exposure, 3 (42.9\%) had a positive LPT for the antigens tested (Table 6). The difference in percentage positive LPTs between patients with and without JEM assigned exposure was not significant $(P=0.145)$. 
Table 6. JEM assigned exposure of LPT positive sarcoidosis and control patients

\begin{tabular}{llll}
\hline $\begin{array}{l}\text { Sarcoidosis or } \\
\text { control }\end{array}$ & LPT positive for & SI & $\begin{array}{l}\text { JEM assigned } \\
\text { exposure }\end{array}$ \\
\hline Sarcoidosis & Al & 13.62 & - \\
\hline Sarcoidosis & $\mathrm{Be}$ & 4.94 & - \\
\hline Sarcoidosis & $\mathrm{Be}$, Zir & $9.05,3.51$ & - \\
\hline Sarcoidosis & $\mathrm{Be}$ & 3.96 & Silica \\
\hline Sarcoidosis & $\mathrm{Si}$ & 3.20 & Silica \\
\hline Sarcoidosis & $\mathrm{Si}$ & 6.90 & Metals \\
\hline Sarcoidosis & Zir & 3.01 & Metals \\
\hline
\end{tabular}

Al: aluminum; Be: Beryllium; Si: Silica; Zir: zirconium; SI: Stimulation index

\section{Clinical phenotypes of LPT-positive sarcoidosis and LPT-negative sarcoidosis patients}

Clinical characteristics of LPT-positive sarcoidosis patients and LPT-negative sarcoidosis patients are shown in Table 7. We also determined the clinical outcome status (COS), and divided it into three groups: resolved and minimal disease ( $\operatorname{COS} 1,2,3,4)$, persistent disease without therapy $(\operatorname{COS} 5,6)$ and persistent disease with need for therapy ( $\operatorname{COS} 7,8,9)$. No differences between the two groups were observed for any of the clinical characteristics or cos.

\section{Discussion}

This study is to our knowledge the first to combine both exposure analysis and lymphocyte proliferations tests for multiple inorganic antigens in patients with sarcoidosis and controls. We found immunoreactivity to metals and silica only in patients with sarcoidosis. Although a large group of patients with sarcoidosis was included, no differences in occupational exposure to metals and silica with the OSA control group was observed. Previous studies addressing such questions were either large epidemiological studies without immunological data, or smaller studies and case reports describing only one specific antigen $(3,7,20,21)$. 
Table 7. Clinical features of LPT-positive and LPT-negative sarcoidosis patients

\begin{tabular}{|c|c|c|c|}
\hline & $\begin{array}{l}\text { LPT-negative (\%) } \\
(n=26)\end{array}$ & $\begin{array}{l}\text { LPT-positive (\%) } \\
\text { (n=7) }\end{array}$ & P* \\
\hline Male / Female & $92.3 / 7.7$ & $85.7 / 14.3$ & 0.52 \\
\hline Age at diagnosis (Y) & $43.46 \pm 11.61$ & $41.40 \pm 7.97$ & 0.66 \\
\hline Time after diagnosis $(\mathrm{Y})$ & $13.65 \pm 12.39$ & $9.21 \pm 8.21$ & 0.36 \\
\hline Medication & 46.2 & 42.9 & 1.00 \\
\hline $\begin{array}{l}\text { Scadding stage at } \\
\text { diagnosis (0/I/II/III/IV/ } \\
\text { unknown) }\end{array}$ & $\begin{array}{l}11.5 / 26.9 / 42.3 / 3.8 / 0 / \\
15.4\end{array}$ & $\begin{array}{l}0 / 42.9 / 28.6 / 0 / 14.3 / \\
14.3\end{array}$ & 0.36 \\
\hline $\begin{array}{l}\text { Scadding stage at } \\
\text { inclusion (0/1/II/III/IV/ } \\
\text { unknown) }\end{array}$ & $\begin{array}{l}38.5 / 7.7 / 11.5 / 11.5 / 30.8 \\
/ 0\end{array}$ & $\begin{array}{l}28.6 / 14.3 / 14.3 / 0 / 28.6 \\
/ 14.3\end{array}$ & 0.42 \\
\hline $\begin{array}{l}\text { Extra pulmonary } \\
\text { involvement }\end{array}$ & 57.7 & 57.1 & 1.00 \\
\hline $\cos$ & $n=21$ & $n=5$ & \\
\hline $\begin{array}{l}\text { Resolved \& minimal } \\
\text { disease }\end{array}$ & 4.8 & 40 & 0.09 \\
\hline $\begin{array}{l}\text { Persistent disease } \\
\text { without therapy }\end{array}$ & 33.3 & 20 & 1.00 \\
\hline $\begin{array}{l}\text { Persistent disease with } \\
\text { need for therapy }\end{array}$ & 61.9 & 40 & 0.62 \\
\hline
\end{tabular}

Age at diagnosis and time after diagnosis are shown as means \pm std. deviation. COS: Clinical outcome status. COS was defined 5 years after diagnosis. Information to determine COS was missing for 7 patients (5 LPTnegative and 2 LPT positive patients).

* Statistical differences for sex, medication, COS groups, extra pulmonary involvement, was accessed using Fisher's Exact Test, P-values for scadding stages were calculated using Pearson Chi-Square. Statistical differences for age at diagnosis were calculated using an unpaired T-test and statistical differences for time after diagnosis was calculated using Mann-Whitney $U$ test.

The fact that only patients within the sarcoidosis group demonstrated immunoreactivity for different antigens supports the concept of metals and silica involvement in the disease pathogenesis of a distinct subgroup of sarcoidosis patients. Different epidemiological studies have demonstrated a higher risk of sarcoidosis among persons occupationally exposed to silica $(4,22)$. Immunoreactivity to silica in some sarcoidosis patients, suggests an underlying immunological mechanism that could explain these epidemiological observations. Regarding the role of zirconium and aluminum in sarcoidosis pathogenesis, 
no other studies than case-reports exist $(3,7,23)$. Müller-Quernheim and colleagues (20) established that in a well-defined cohort of biopsy-proven sarcoidosis patients, over $6 \%$ should be diagnosed with CBD based on the diagnostic criteria for this disease, which includes presence of non-caseating granulomas in lung or lymph node biopsies, beryllium exposure and sensitization (19). In our cohort, 3 out of 256 sarcoidosis patients (1.2\%) had a positive LPT for beryllium defined by MELISA ${ }^{\circledR}$, of which two also had elevated SI values on the beryllium LPT using the ATS guideline protocol (19). These results demonstrate that also in the Netherlands, patients with CBD can be identified within a group of biopsy proven sarcoidosis patients. This is a clinically relevant finding since termination of exposure to beryllium may be the first step in the treatment of CBD to prevent progression of the disease in these patients. In light of diagnostic criteria for CBD, it is tempting to speculate that patients with a positive LPT to zirconium, aluminum or silica, have a disease etiology clinically comparable to that of CBD. In CBD, genetic susceptibility has been demonstrated, since a Glu at position 69 in the HLA-DPB1 gene is found in approximately $90 \%$ of patients compared to about $40 \%$ of healthy controls. The presence of this genetic variant has proven to be an important contributing factor to the development of CBD $(24,25)$. Since immunoreactivity, but not occupational exposure, differed between patients and controls, genetic variants may very well be involved in the ability to respond to the metals and silica addressed in this study.

Another important conclusion from our study is that our screening method, including the questionnaire linked to the JEMs, appears unable to predict immunoreactivity. Almost half of our patients with a positive LPT were classified by JEMs as unexposed. The JEMs are designed to be very specific (i.e. high probability of exposure within a certain job) and will, by definition, not capture individuals experiencing coincidental high risk exposure while carrying out otherwise low-risk jobs (26). It is important to state that even very low occasional exposures can be relevant, as suggested by the work of Infante et al. (27), who described that bystander beryllium exposure can lead to CBD. Perhaps a simple occupational history is not detailed enough, and additional (job-specific) questionnaires will be required to identify occasional/recreational exposures that can be sufficient to initiate sarcoidosis or a sarcoid-like disease. However, the addition of more detailed methods to establish exposure will also lead to less specificity, i.e. there will be a higher number of exposure assigned patients who may not show immunoreactivity. Furthermore, since even low non-occupational exposures (28) can be of relevance in light of immunoreactivity, it will be difficult to distinguish between meaningful and negligible exposures. Therefore, testing all sarcoidosis patients for immunoreactivity to metals and silica in future studies, irrespective of exposure, will probably be more convenient to address this issue. 
A limitation of the study is that the group for whom an LPT has been performed was quite small. The LPT could not be performed on blood samples of some sarcoidosis patients, due to insufficient lymphocyte counts. Lymphocytopenia is a common observation in sarcoidosis patients (29), not related to immunosuppressive medication (30). As a consequence, less LPTs were performed than anticipated. LPT subgroups proved to be too small to detect differences in clinical phenotype between the LPT-positive and LPT-negative sarcoidosis patients. Further studies are needed to indicate whether metal and silica immunoreactive patients have a distinct disease phenotype or particular genetic variants comparable to the Glu at position 69 in HLA-DPB1 in CBD. For beryllium, it has already been discovered that the $\mathrm{Be}^{2+}$ cation induces a conformational change in the HLA-DP2/peptide complex. Immunoreactivity develops when $T$ lymphocytes regard the displaced peptide as foreign (non-self) and become activated(31). Possibly, other metals, including aluminum and zirconium, may induce similar conformational changes in the MHCll-peptide binding complex. Therefore, future studies are warranted as well to clarify these underlying immunological mechanisms leading to aluminum, silica and zirconium immunoreactivity. Another study limitation may be the sensitivity of the assays performed. For beryllium LPTs, about $1 \%$ false positive and $30 \%$ false negative results are observed. The specificity of this assay is quite high (0.969) although the sensitivity is determined to be lower (0.686) (32). Data on sensitivity and specificity regarding aluminum, zirconium and silica LPTs are lacking but probably comparable. The MELISA ${ }^{\circledR}$ test is using a higher number of lymphocytes per test suggesting that the sensitivity could be slightly higher than the classical LPT (17). Due to the low sensitivity observed for the beryllium LPT, it is possible that the number of sarcoidosis patients with metal/silica immunoreactivity we observed is an underestimation, and the real number of patients with a positive LPT may actually be higher.

In conclusion, immunoreactivity to silica and metals found in sarcoidosis patients only, supports the hypothesis that these antigens may be involved in the disease pathogenesis of a distinct subgroup of sarcoidosis patients. Since job history with assigned exposure did not differ between sarcoidosis patients and controls, our data indicate that even very low incidence or occasional exposures could be relevant in sarcoidosis patients. Future studies may consider testing all sarcoidosis patients for immunoreactivity without screening them on exposure beforehand. Finally, the data presented in this paper suggests that besides beryllium, also zirconium, aluminum and silica can be considered as possible antigens in this heterogeneous disease. Future studies should however be initiated to clarify underlying immunological pathways and mechanisms in order to establish a more definitive role for these antigens in sarcoidosis. 


\section{References}

1. Baughman RP, Teirstein AS, Judson MA, Rossman MD, Yeager Jr H, Bresnitz EA, et al. Clinical characteristics of patients in a case control study of sarcoidosis. Am J Respir Crit Care Med. 2001 Nov 15;164(10 Pt 1):1885-9.

2. Mayer AS, Hamzeh N, Maier LA. Sarcoidosis and chronic beryllium disease: similarities and differences. Semin Respir Crit Care Med. 2014 Jun;35(3):316-29.

3. Werfel U, Schneider J, Rodelsperger K, Kotter J, Popp W, Woitowitz HJ, et al. Sarcoid granulomatosis after zirconium exposure with multiple organ involvement. Eur Respir J. 1998 Sep;12(3):750.

4. Rafnsson V, Ingimarsson O, Hjalmarsson I, Gunnarsdottir H. Association between exposure to crystalline silica and risk of sarcoidosis. Occup Environ Med. 1998;55(10):657-60.

5. Tomioka H, Kaneda T, Katsuyama E, Kitaichi M, Moriyama H, Suzuki E. Elemental analysis of occupational granulomatous lung disease by electron probe microanalyzer with wavelength dispersive spectrometer: Two case reports . Respir Med case reports. 2016 Apr 26;18:66-72.

6. Drent M, Bomans PH, Van Suylen RJ, Lamers RJ, Bast A, Wouters EF. Association of man-made mineral fibre exposure and sarcoidlike granulomas . Respir Med. 2000 Aug;94(8):815-20.

7. Cao M, Cai HR, Meng FQ, Wei JY. Pulmonary sarcoidlike granulomatosis induced by aluminum dust: a case report and literature review. Zhonghua Jie $\mathrm{He} \mathrm{He} \mathrm{Hu} \mathrm{Xi} \mathrm{Za}$ Zhi. 2008 Jun;31(6):406-9.

8. Sood A, Beckett WS, Cullen MR. Variable response to long-term corticosteroid therapy in chronic beryllium disease . Chest. 2004 Dec;126(6):2000-7.

9. Sprince NL, Kanarek DJ, Weber AL, Chamberlin RI, Kazemi H. Reversible respiratory disease in beryllium workers . Am Rev Respir Dis. 1978 Jun;117(6):1011-7.

10. Costabel U, Hunninghake GW. ATS/ERS/WASOG statement on sarcoidosis. Sarcoidosis Statement Committee. American Thoracic Society. European Respiratory Society. World Association for Sarcoidosis and Other Granulomatous Disorders. Eur Respir J. 1999;14(4):735-7.

11. Maspero C, Giannini L, Galbiati G, Rosso G, Farronato G. Obstructive sleep apnea syndrome: a literature review. Minerva Stomatol. 2015;64(2):97-109.

12. International Labour Office; Geneva. International Standard Classification of Occupations. Revised edition 1968. International Labor Office, Washington Branch, 917 15th Street, N.W., Washington, D.C. 20005 (\$5.00); 1969. 362 p.

13. Peters S, Vermeulen R, Cassidy A, Mannetje A, van Tongeren M, Boffetta P, et al. Comparison of exposure assessment methods for occupational carcinogens in a 
multi-centre lung cancer case-control study . Occup Environ Med. 2011 Feb;68(2):148-53.

14. SUNYER J, KOGEVINAS M, KROMHOUT H, ANTÓ JM, ROCA J, TOBIAS A, et al. Pulmonary Ventilatory Defects and Occupational Exposures in a Population-based Study in Spain. Am J Respir Crit Care Med. 1998 Feb 14;157(2):512-7.

15. International Labour Office. International standard classification of occupations: ISCO-88. Geneva: International Labour Organization; 1990.

16. Stejskal VD, Cederbrant K, Lindvall A, Forsbeck M. MELISA-an in vitro tool for the study of metal allergy . Toxicol In Vitro. 1994;8(5):991-1000.

17. Valentine-Thon E, Schiwara H-W. Validity of MELISA for metal sensitivity testing. Neuro Endocrinol Lett. 24(1-2):57-64.

18. Fireman E, Shai AB, Alcalay $Y$, Ophir N, Kivity S, Stejskal V. Identification of metal sensitization in sarcoid-like metal-exposed patients by the MELISA(R) lymphocyte proliferation test - a pilot study . J Occup Med Toxicol. 2016 Apr 12;11:18-016-01011. eCollection 2016.

19. Balmes JR, Abraham JL, Dweik RA, Fireman E, Fontenot AP, Maier LA, et al. An official American Thoracic Society statement: diagnosis and management of beryllium sensitivity and chronic beryllium disease. Am J Respir Crit Care Med. 2014 Nov 15;190(10):e34-59.

20. Muller-Quernheim J, Gaede KI, Fireman E, Zissel G. Diagnoses of chronic beryllium disease within cohorts of sarcoidosis patients . Eur Respir J. 2006 Jun;27(6):1190-5.

21. Barnard J, Rose C, Newman L, Canner M, Martyny J, McCammon C, et al. Job and industry classifications associated with sarcoidosis in A Case-Control Etiologic Study of Sarcoidosis (ACCESS) . J Occup Environ Med. 2005;47(3):226-34.

22. Vihlborg P, Bryngelsson IL, Andersson L, Graff P. Risk of sarcoidosis and seropositive rheumatoid arthritis from occupational silica exposure in Swedish iron foundries: a retrospective cohort study. BMJ Open. 2017 Jul 20;7(7):e016839-2017-016839.

23. De Vuyst $P$, Dumortier $P$, Schandene $L$, Estenne $M$, Verhest A, Yernault JC. Sarcoidlike lung granulomatosis induced by aluminum dusts. Am Rev Respir Dis. 1987 Feb;135(2):493-7.

24. Richeldi L, Sorrentino R, Saltini C. HLA-DPB1 glutamate 69: a genetic marker of beryllium disease. Science. 1993;262(5131):242-4.

25. McCanlies EC, Kreiss K, Andrew M, Weston A. HLA-DPB1 and chronic beryllium disease: a HuGE review. Am J Epidemiol. 2003;157(5):388-98.

26. Kromhout $\mathrm{H}$, Vermeulen R. Application of job-exposure matrices in studies of the general population: some clues to their performance. Eur Respir Rev. 2001;11:8090. 
27. Infante PF, Newman LS. Beryllium exposure and chronic beryllium disease . Lancet (London, England). 2004 Feb 7;363(9407):415-6.

28. Newman LS, Kreiss K. Nonoccupational beryllium disease masquerading as sarcoidosis: identification by blood lymphocyte proliferative response to beryllium . Am Rev Respir Dis. 1992;145(5):1212-4.

29. Lower EE, Smith JT, Martelo OJ, Baughman RP. The anemia of sarcoidosis . Sarcoidosis. 1988;5(1):51-5.

30. Sweiss NJ, Salloum R, Gandhi S, Alegre ML, Sawaqed R, Badaracco M, et al. Significant CD4, CD8, and CD19 lymphopenia in peripheral blood of sarcoidosis patients correlates with severe disease manifestations. PLoS One. 2010 Feb 5;5(2):e9088.

31. Clayton GM, Wang Y, Crawford F, Novikov A, Wimberly BT, Kieft JS, et al. Structural basis of chronic beryllium disease: linking allergic hypersensitivity and autoimmunity . Cell. 2014 Jul 3;158(1):132-42.

32. Stange AW, Furman FJ, Hilmas DE. The beryllium lymphocyte proliferation test: Relevant issues in beryllium health surveillance. Am J Ind Med. 2004 Nov;46(5):45362. 


Chapter 5

\section{Simultaneous testing of immunological sensitization to multiple antigens in sarcoidosis reveals an association with inorganic antigens specifically related to a fibrotic phenotype}

Els Beijer

Raisa Kraaijvanger

Claudia Roodenburg

Jan C. Grutters

Bob Meek

Marcel Veltkamp

Clin Exp Immunol. 2020 Sep 17;cei.13519 


\begin{abstract}
Organic and inorganic antigens were studied simultaneously in the same cohort of sarcoidosis patients, to investigate whether correlations between clinical characteristics and immunological sensitization could reveal new phenotypes.

Sensitization to antigens of mycobacteria, $P$. acnes catalase and vimentin was investigated in 201 sarcoidosis and 51 obstructive sleep apnea patients, serving as control group. Sensitization to aluminum, beryllium, silica and zirconium was also studied in 105 of the sarcoidosis patients and in 24 of the controls.

A significantly higher percentage of sarcoidosis patients (27.6\%) than controls (4.2\%) had an immunological response to metals or silica $(P=0.014)$. A higher percentage of these sarcoidosis patients showed fibrosis on chest $X$-ray 5 years after the diagnosis $(69.2 \%$ vs. $30.3 \%, P=0.016)$. No significant differences in mycobacterial or vimentin elispot assay results were observed between sarcoidosis and control patients. A significantly lower percentage of sarcoidosis patients (3.5\%) than control patients $(15.7 \%)$ had a positive elispot for $P$. acnes catalase $(P=0.003)$. However, sarcoidosis patients sensitized to $P$. acnes catalase were more likely to have skin involvement, while sarcoidosis patients sensitized to mycobacterial antigens were more likely to have cardiac involvement.

Our study suggests a more prominent role for inorganic triggers in sarcoidosis pathogenesis than previously thought. Immunological sensitization to inorganic antigens was associated with development of fibrotic sarcoidosis. No association was found between sensitization to bacterial antigens or vimentin and sarcoidosis in Dutch patients. However, our data does suggest that trigger-related phenotypes can exist in the heterogeneous population of sarcoidosis patients.
\end{abstract}

Key words: Sarcoidosis, triggers, metals, silica, P. acnes 


\section{Introduction}

Sarcoidosis is a systemic disease characterized by formation of noncaseating granulomas, mostly affecting the lungs, skin, eyes and lymph nodes (1). The course of the disease is unpredictable, meaning that the disease can spontaneously resolve, while a chronic disease course can also develop (2). Currently, no curative treatment exists for sarcoidosis patients. Patients with symptomatic organ involvement or at risk of permanent damage are treated with immunosuppressive drugs. This kind of treatment is associated with several side effects, and approximately $10 \%$ of patients still develop progressive disease while receiving immunosuppressives (2).

Considerable research effort has focused on identification of triggers of sarcoidosis, including antigens of mycobacteria $(3,4)$, Propionibacterium acnes $(P$. acnes) $(5,6)$, vimentin $(7,8)$, metals and silica $(9,10)$. Although all these antigens have shown potential, results demonstrate that sarcoidosis probably has multiple triggers. Importantly, none of the above organic and inorganic antigens have been studied simultaneously in one group of sarcoidosis patients. Identification of triggers in sarcoidosis will allow personalized treatment options, which may include anti-bacterial drugs. In addition, increased knowledge about sensitization to metals and silica can lead to identification of sarcoidosis patients for whom exposure prevention may be more beneficial than increasing immune suppression.

The aim of this study was to examine possible triggers of sarcoidosis in Dutch patients. Correlations between clinical characteristics and immunological response to microbial antigens or metals and silica may result in identification of new clinical phenotypes. Identification of these subgroups can lead the way to clinical trials in the future, to explore more accurate treatment options.

\section{Materials and methods}

\section{Study subjects}

Biopsy proven sarcoidosis patients or Löfgren syndrome patients seen for the first time at the ILD outpatient clinic of the St Antonius Hospital (Nieuwegein, The Netherlands) from 1 May 2016, were asked to participate, until at least 200 patients had been included. The diagnosis of sarcoidosis had been established according to the criteria of the American Thoracic Society/European Respiratory Society (11). Patients with obstructive sleep apnea (OSA) are also seen at the pulmonary outpatient clinic, and this disorder has not been associated with the antigens tested in this study (12). OSA patients were therefore included as a control group. The study was approved by the Medical research Ethics Committees United (MEC-U) of the St Antonius Hospital (R14.023), and written informed consent was obtained from all participants. 


\section{IFN-ץ elispot}

A blood sample was drawn from all participants. Peripheral blood mononuclear cells (PBMCs) were collected and stored at $-150^{\circ} \mathrm{C}$ until time of analysis. IFN-y elispot assays were performed following the manufacturer's instructions (Mabtech, Nacka Strand, Sweden). Briefly, $2 * 10^{5}$ PBMCs were seeded per well, together with $33.33 \mu \mathrm{g} / \mathrm{mL}$ ESAT-6 peptides, $33.33 \mu \mathrm{g} / \mathrm{mL}$ MKatG peptides, $10 \mu \mathrm{g} / \mathrm{mL}$ MKatG protein, $10 \mathrm{ug} / \mathrm{mL} P$. acnes catalase or $20 \mu \mathrm{g} / \mathrm{mL}$ vimentin, in duplicate. Responses were calculated by subtracting the number of spot-forming-cells (SFCs) of the negative control wells from that of the antigen specific wells. Following Drake et al. (13), positive responses were defined as at least 50 SFC per $10^{6}$ PBMCs, at least 3 times higher than the negative control well. Details of PBMC isolation, the antigens used and elispot are provided in the supplement.

\section{Clinical tuberculosis IGRAs}

Medical records of sarcoidosis patients were searched for data of interferon gamma release assays (IGRAs) (TB ELISpot or QuantiFERON tests). When data of those tests were not available, medical records were searched for results of tuberculin skin tests (TSTs).

\section{Cytokine measurements}

Supernatant of elispot plates was collected and stored at $-80^{\circ} \mathrm{C}$ until time of analysis. Concentrations of TNF- $\alpha, \mathrm{II}-2, \mathrm{II}-17 \mathrm{~A}$ and II-1 $\beta$ were measured using Human Magnetic Luminex Assays (Biotechne, Minneapolis, USA) following the manufacturer's instructions. Values beyond the range of the standard curve were given the lowest or highest value the standard curve reached. Baseline cytokine concentrations were subtracted from cytokine concentrations of the antigen stimulated-wells. Negative values were set to zero.

Lymphocyte proliferation tests to determine metal and silica sensitization All sarcoidosis and control patients were asked to provide a second blood sample for lymphocyte proliferation tests (LPTs) on beryllium, aluminum, zirconium and silica. Blood was drawn in citrate tubes and sent within 24 hours to Prohealth Medical, Nederweert, The Netherlands, where the memory lymphocyte immunostimulation assay (MELISA ${ }^{\circledR}$ ) LPT was performed, as described in the supplementary file. Following MELISA ${ }^{\circledR}$ guidelines, a stimulation index $(\mathrm{SI})>2.0$ was considered a weakly positive test result and an $\mathrm{SI}>3.0$ a positive test result. 


\section{HLA-DRB1 genotyping}

Presence of HLA-DRB1*0301 and HLA-DRB1*1501 alleles was determined for sarcoidosis patients of whom residual DNA was available. Tag single nucleotide polymorphisms (SNPs) rs2040410A and rs3135388A were used to capture HLA-DRB1*0301 and HLA-DRB1*1501 respectively, using the methods described by Karakaya et al. (14).

\section{Identification of trigger-related phenotypes}

Scadding stage at diagnosis and follow-up, organ involvement and the use of immunosuppressive medication were collected from medical records. In addition, the clinical outcome status (COS) (15) was determined 2 and 5 years after diagnosis and classified into two groups: group 1: resolved, minimal or persistent disease without treatment ( $\operatorname{COS} 1-6)$ and group 2: persistent disease with need for treatment (COS 7-9). Clinical characteristics and COS were related to elispot and LPT results to explore triggerrelated phenotypes.

\section{Statistical analysis}

Study data was collected and managed using Research Electronic Data Capture (REDCap) tools hosted at St. Antonius Hospital (16). Data was analyzed using IBM SPSS statistics version 24. An unpaired T-test was used to compare numerical data. Non-parametric tests were used for non-normally distributed data (Mann-Whitney $U$ test). Categorical data were compared using the Chi-squared test. If expected cell frequencies were below 5, Fisher's exact test was used for categorical data up to two categories. P-values $<0.05$ were considered significant.

\section{Results}

\section{Patient characteristics}

A total of 205 sarcoidosis patients and 51 control patients were included in the study (Table 1). Control patients were older at inclusion and a higher proportion of control patients were ever smokers compared to the sarcoidosis patients. 
Table 1. Demographics of sarcoidosis and control patients

\begin{tabular}{|c|c|c|c|}
\hline & $\begin{array}{l}\text { Sarcoidosis } \\
(n=205)\end{array}$ & $\begin{array}{l}\text { Controls } \\
(n=51)\end{array}$ & P-value* \\
\hline Sex (Male / Female) (\%) & $53.2 / 46.8$ & $62.7 / 37.3$ & 0.219 \\
\hline Age at diagnosis (Y) & $43.74 \pm 12.48$ & NA & \\
\hline Age at inclusion (Y) & $48.93 \pm 12.21$ & $55.45 \pm 13.71$ & 0.001 \\
\hline Ethnicity (W/NW) (\%) & $89.2 / 10.8$ & $92.2 / 7.8$ & 0.535 \\
\hline $\begin{array}{l}\text { Smoking status } \\
\text { (Never/ former or current) (\%) }\end{array}$ & $51.2 / 48.8$ & $29.4 / 70.6$ & 0.005 \\
\hline $\begin{array}{l}\text { Scadding stage at inclusion } \\
(0 / \mathrm{I} / \mathrm{II} / \mathrm{III} / \mathrm{IV})(\%)\end{array}$ & $\begin{array}{l}19.6 \text { / } 29.4 \text { / } 28.4 \text { / } \\
5.9 \text { / } 16.7\end{array}$ & NA & \\
\hline Extra pulmonary involvement (\%) & 59.5 & NA & \\
\hline
\end{tabular}

Age at diagnosis and age at inclusion are expressed as mean \pm std. deviation.

W: White, NW: Non White; $0=$ Normal chest radiograph; I = Bilateral hilar lymphadenopathy $(\mathrm{BHL}) ; \mathrm{II}=\mathrm{BHL}$ with pulmonary infiltrates; III = pulmonary infiltrates without $\mathrm{BHL}$; IV = fibrosis.

* A P-value regarding sex, ethnicity and smoking status was calculated using Pearson Chi-square test; an independent samples T-test was used to calculate a P-value for differences regarding age at inclusion.

\section{Elispot results}

An elispot assay was performed on PBMCs of 201 sarcoidosis patients and 51 controls. Ninety-one sarcoidosis patients (45.3\%) were using immunosuppressive medication at the time of blood collection. No differences in number of spots upon stimulation with anti-CD3 antibody were observed between sarcoidosis patients with and without immunosuppressive medication, while more controls had a low response (Supplementary Figures 1 and 2). Only 1 control and 2 sarcoidosis patients had a positive elispot for ESAT-6, and neither controls nor patients had a positive elispot for MKatG peptide, although one sarcoidosis patient had a positive elispot for MKatG protein. Eight controls (15.7\%) compared to 7 sarcoidosis patients (3.5\%) had a positive elispot for $P$. acnes catalase $(P=$ 0.003). A vimentin-positive elispot was found for 9 controls (17.6\%) and 18 sarcoidosis patients (9.0\%)(Figure 1). 


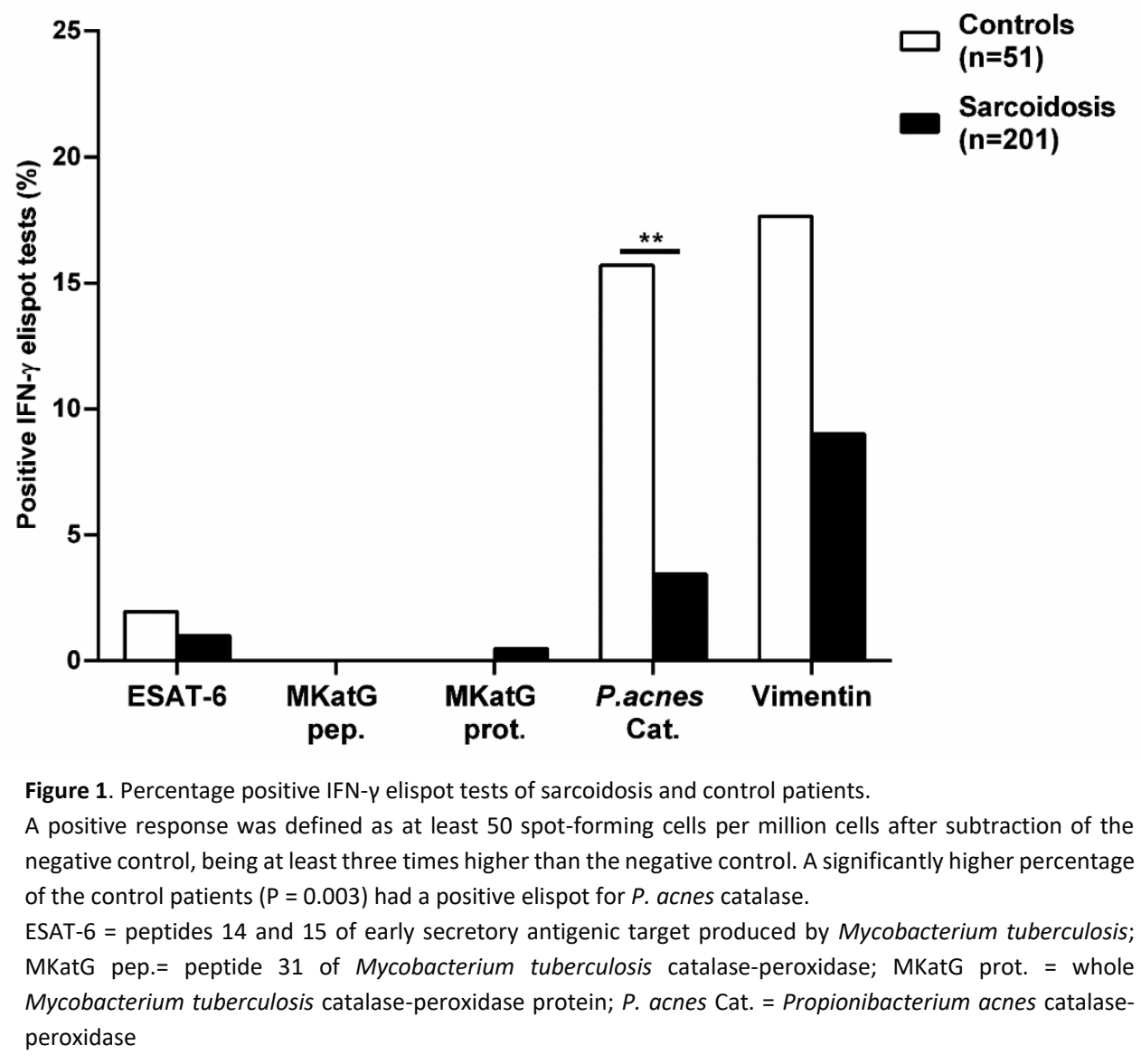

To determine sensitization to mycobacterial antigens, results of our elispot and clinical data of diagnostic IGRAs or TSTs were combined. A total of five sarcoidosis patients had a positive test for mycobacterial antigens.

\section{Antigen-specific cytokine measurements}

Median baseline concentrations of II-1 $\beta, \mathrm{II}-17, \mathrm{II}-2$ and TNF- $\alpha$ were significantly higher in sarcoidosis patients (Supplementary Table 1). Median concentrations of II-1 $\beta$ were significantly higher in sarcoidosis patients after PBMC stimulation with ESAT-6 (Supplementary Figure $3 \mathrm{~A}, \mathrm{P}=0.024)$ ) $P$. acnes catalase (Supplementary Figure 3C, $\mathrm{P}=$ 0.001 ) and vimentin (Supplementary Figure $1 D, P=0.012$ ). 


\section{Metal and silica LPT results}

Of all patients, 24 controls and 105 sarcoidosis patients agreed to provide a second blood sample for an LPT. Fifty-nine sarcoidosis patients (56.2\%) were using immunosuppressive medication at the time of LPT. No differences in the SI upon stimulation with pokeweed (used as positive control) were observed between sarcoidosis patients with and without immunosuppressive medication, or between sarcoidosis patients and controls (Supplementary Figure 4).

Five sarcoidosis and no control patients had a positive LPT. A significantly higher percentage of sarcoidosis patients ( $27.6 \%$ compared to $4.17 \%$ controls, $P=0.014$ ) had a weakly positive LPT (Figure 2 and Table 2). Four sarcoidosis patients had a weakly positive LPT for two antigens (Supplementary Table 2). The single weakly positive control patient had a weakly positive LPT for all the antigens tested. Occupations at time of diagnosis of the 29 sensitized sarcoidosis patients and 1 sensitized control patient are provided in Supplementary Table 5.

A

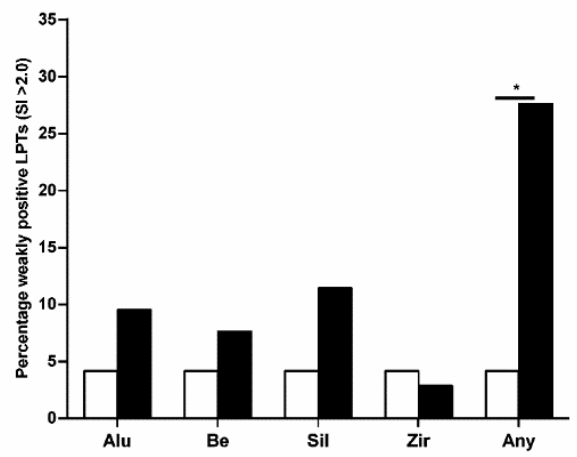

B

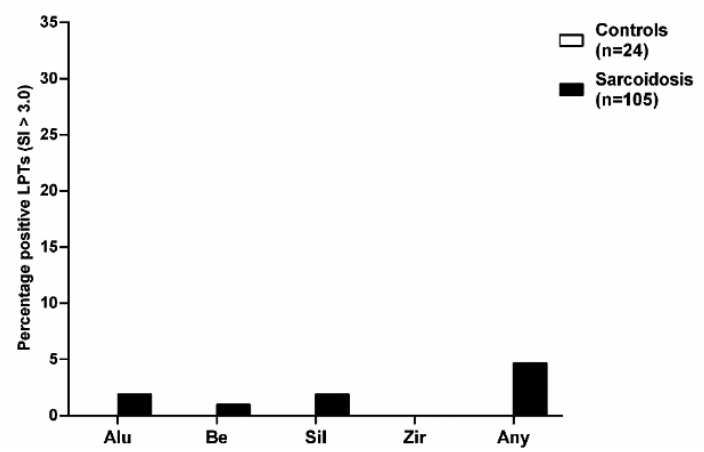

Figure 2. Percentage positive and weakly positive lymphocyte proliferation tests of sarcoidosis and control patients.

A: Percentages of sarcoidosis patients and controls with a weakly positive LPT. A stimulation index $>2.0$ was defined as a weakly positive result. A significantly higher percentage of sarcoidosis patients had a weakly positive LPT ( $P=0.014)$. Four sarcoidosis patients had a weakly positive LPT for two antigens. The only weakly positive control patient had a weakly positive LPT for all the antigens tested. B: Percentages of sarcoidosis patients and controls with positive LPT, which was defined as a stimulation index $>3.0$

Alu: aluminum, Be: beryllium, Sil: silica, Zir: zirconium, LPT: Iymphocyte proliferation test, SI: stimulation index. 
Table 2. Percentage positive and weakly positive lymphocyte proliferation tests of sarcoidosis and control patients

\begin{tabular}{llll}
\hline & Controls $\mathbf{n = 2 4}(\mathbf{\%})$ & Sarcoidosis $\mathbf{n = 1 0 5}$ (\%) & $\mathbf{P}^{*}$ \\
\hline SI $\mathbf{2 . 0}$ & & & \\
\hline Alu & $1(4.17)$ & $10(9.52)$ & 0.688 \\
\hline Be & $1(4.17)$ & $8(7.62)$ & 1.000 \\
\hline Sil & $1(4.17)$ & $12(11.43)$ & 0.460 \\
\hline Zir & $1(4.17)$ & $3(2.86)$ & 0.566 \\
\hline Any & $1(4.17)$ & $29(27.62)$ & 0.014 \\
\hline SI > 3.0 & & & 1.000 \\
\hline Alu & 0 & $2(1.90)$ & 1.000 \\
\hline Be & 0 & $1(0.95)$ & 1.000 \\
\hline Sil & 0 & $2(1.90)$ & NA \\
\hline Zir & 0 & 0 & 0.583 \\
\hline Any & 0 & $5(4.67)$ & \\
\hline
\end{tabular}

A stimulation index $>2.0$ was defined as a weakly positive result. A positive LPT was defined as a stimulation index $>3.0$

Alu: aluminum, BE: beryllium, Sil: silica, Zir: zirconium, LPT: Iymphocyte proliferation test, SI: stimulation index.

* A P-value of any positive LPT SI > 2.0 was calculated using Pearson Chi-square test; the other P-values were calculated using Fisher's exact test. The two silica positive patients were also included in a previous study (19).

\section{Trigger-related phenotypes}

\section{Bacterial antigens}

One sarcoidosis patient with a positive mycobacterial IGRA also had a positive elispot for vimentin (Supplementary Table 3), and two sarcoidosis patients with a positive LPT also had a positive vimentin elispot (Supplementary Table 4). No other overlap between elispot tests or between elispot and LPT was observed. A significantly higher proportion of sarcoidosis patients with a positive response to mycobacterial antigens had cardiac involvement (3/5) compared to sarcoidosis patients without sensitization to mycobacterial antigens (34/196, $P=0.044)$. Although not statistically significant, patients with a positive elispot for $P$. acnes catalase showed a trend towards more skin involvement $(3 / 7$, compared to $27 / 194 P$. acnes catalase negative patients, $P=0.069$ ) (table 3 ). Furthermore, $P$. acnes catalase positive patients were significantly younger at diagnosis than sarcoidosis patients without a positive $P$. acnes catalase elispot (median age 27.94 compared to $42.76, P=0.002$ ). 
Table 3. Organ involvement and elispot

\begin{tabular}{|c|c|c|c|c|c|c|c|c|c|}
\hline & \multicolumn{3}{|c|}{ Mycobacteria } & \multicolumn{3}{|c|}{ P. acnes catalase } & \multicolumn{3}{|c|}{ Vimentin } \\
\hline & $\begin{array}{l}\text { Neg. } \\
n=196\end{array}$ & $\begin{array}{l}\text { Pos. } \\
n=5\end{array}$ & $\mathbf{P}$ & $\begin{array}{l}\text { Neg. } \\
n=194\end{array}$ & $\begin{array}{l}\text { Pos. } \\
n=7\end{array}$ & $\mathbf{P}$ & $\begin{array}{l}\text { Neg. } \\
n=183\end{array}$ & $\begin{array}{l}\text { Pos. } \\
n=18\end{array}$ & $\mathbf{P}$ \\
\hline $\begin{array}{l}\text { Extra } \\
\text { pulm. }\end{array}$ & $\begin{array}{l}116 \\
(59.2)\end{array}$ & $\begin{array}{l}3 \\
(60)\end{array}$ & 1.00 & $\begin{array}{l}113 \\
(58.2)\end{array}$ & $\begin{array}{l}6 \\
(85.7)\end{array}$ & 0.244 & $\begin{array}{l}108 \\
(59)\end{array}$ & $\begin{array}{l}11 \\
(61.1)\end{array}$ & 0.863 \\
\hline Skin & $\begin{array}{l}30 \\
(15.3)\end{array}$ & 0 & 1.00 & $\begin{array}{l}27 \\
(13.9)\end{array}$ & $\begin{array}{l}3 \\
(42.9)\end{array}$ & 0.069 & $\begin{array}{l}27 \\
(14.8)\end{array}$ & $\begin{array}{l}3 \\
(16.7)\end{array}$ & 0.736 \\
\hline Eyes & $\begin{array}{l}24 \\
(12.2)\end{array}$ & 0 & 1.00 & $\begin{array}{l}23 \\
(11.9)\end{array}$ & $\begin{array}{l}1 \\
(14.3)\end{array}$ & 0.595 & $\begin{array}{l}21 \\
(11.5)\end{array}$ & $\begin{array}{l}3 \\
(16.7)\end{array}$ & 0.457 \\
\hline Heart & $\begin{array}{l}34 \\
(17.3)\end{array}$ & $\begin{array}{l}3 \\
(60)\end{array}$ & 0.044 & $\begin{array}{l}36 \\
(18.6)\end{array}$ & $\begin{array}{l}1 \\
(14.3)\end{array}$ & 1.00 & $\begin{array}{l}33 \\
(18)\end{array}$ & $\begin{array}{l}4 \\
(22.2)\end{array}$ & 0.749 \\
\hline
\end{tabular}

Data is shown in absolute numbers with percentages in brackets. P-values were calculated using the Chi-squared test. If expected cell frequencies were below 5, Fisher's exact test was used.

\section{Vimentin}

A higher percentage of Löfgren's syndrome patients were positive for HLA-DRB1*0301 than non-Löfgren patients ( $50 \%$ versus $16.5 \%, P=0.006)$. None of the vimentin-positive sarcoidosis patients were diagnosed with Löfgren's syndrome. No difference in presence of HLA-DRB1*0301 was observed between vimentin positive and vimentin negative patients (11.8\% and $19.7 \%$, respectively, $P=0.75)$. A significantly higher percentage of vimentinpositive patients were positive for HLA-DRB1*1501, than vimentin-negative patients $(47.1 \%$ vs. $23.1 \%, P=0.041$ ) (Figure 3 ).

\section{Inorganic antigens}

No relation was observed between organ involvement and sensitization to metals or silica (data not shown), although a higher percentage of the LPT-positive sarcoidosis patients showed fibrosis on chest X-ray 5 years after the diagnosis, than LPT-negative sarcoidosis patients $(69.2 \%$ vs. $30.3 \%, P=0.016)$. This difference was not observed 2 years after the diagnosis of sarcoidosis (Table 4). No relations were observed between HLA types and LPTpositive sarcoidosis patients (Supplementary Figure 5). 


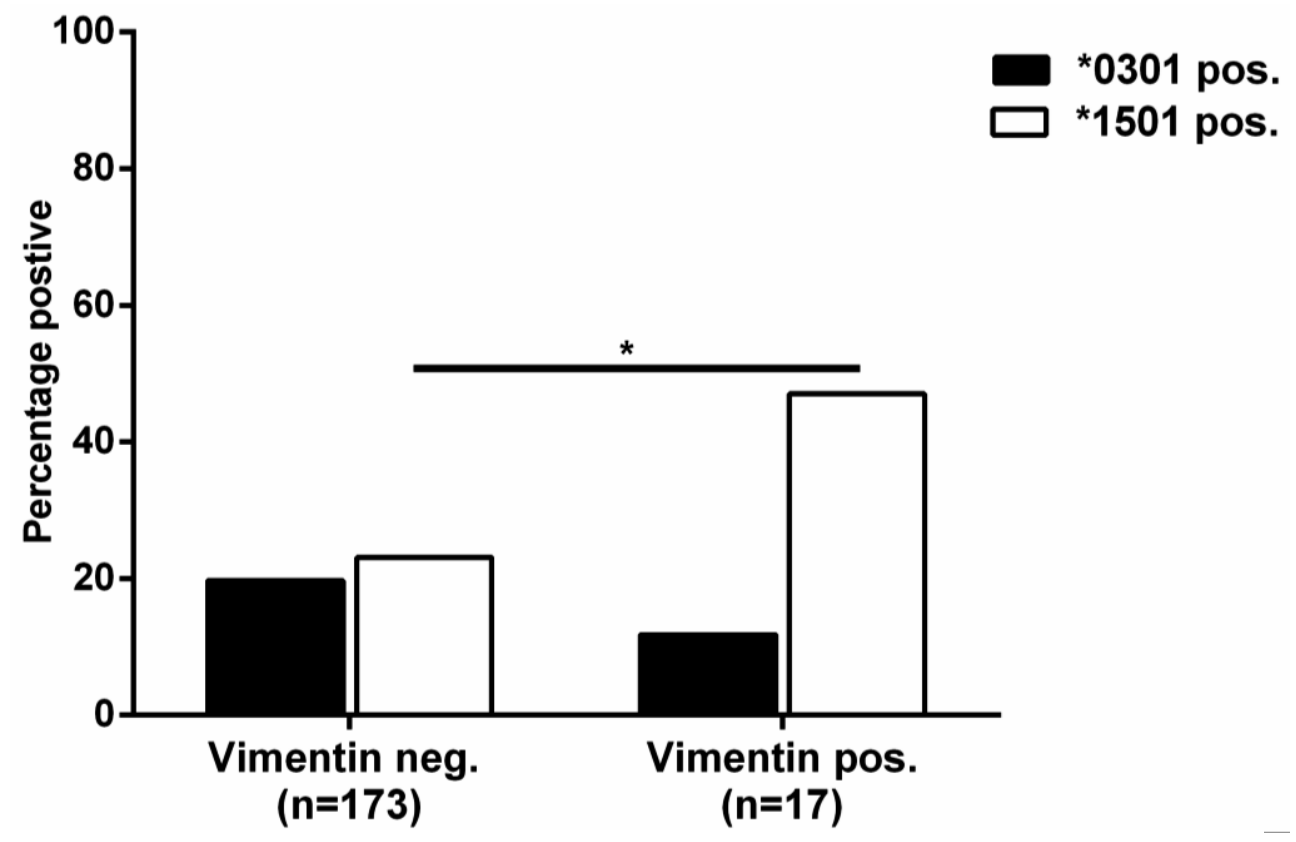

Figure 3. Percentage of vimentin positive patients positive for HLA-DRB1*0301 and HLA-DRB1*1501.

\section{Discussion}

To the best of our knowledge, this is the first study that simultaneously investigated organic and inorganic antigens in the pathogenesis of sarcoidosis within one cohort of patients. We found immunological sensitization, defined by an LPT SI above 3.0, to inorganic antigens in $5 \%$ of sarcoidosis patients. In addition to beryllium, we identified sarcoidosis patients sensitized to aluminum and silica. Even though only observed in a small percentage of patients, these findings imply clinical significance. It makes sense, in our opinion, to carefully re-assess work or home exposure in this subgroup of patients. In patients with chronic beryllium disease (CBD), improved lung function and radiographic findings can be observed when exposure is terminated or decreased $(17,18)$. It seems plausible to assume that this will be the case for other inorganic triggers as well. In a previous paper we showed that occupational exposure to metal / silica determined by a job exposure matrix (JEM) is not predictive for a positive LPT (19). A possible explanation may be that the JEMs are designed to be very specific and will not capture individuals experiencing coincidental high risk exposure while carrying out low-risk jobs. However even very low occasional exposures can be relevant, as bystander beryllium exposure can lead to $\operatorname{CBD}(20,21)$. 


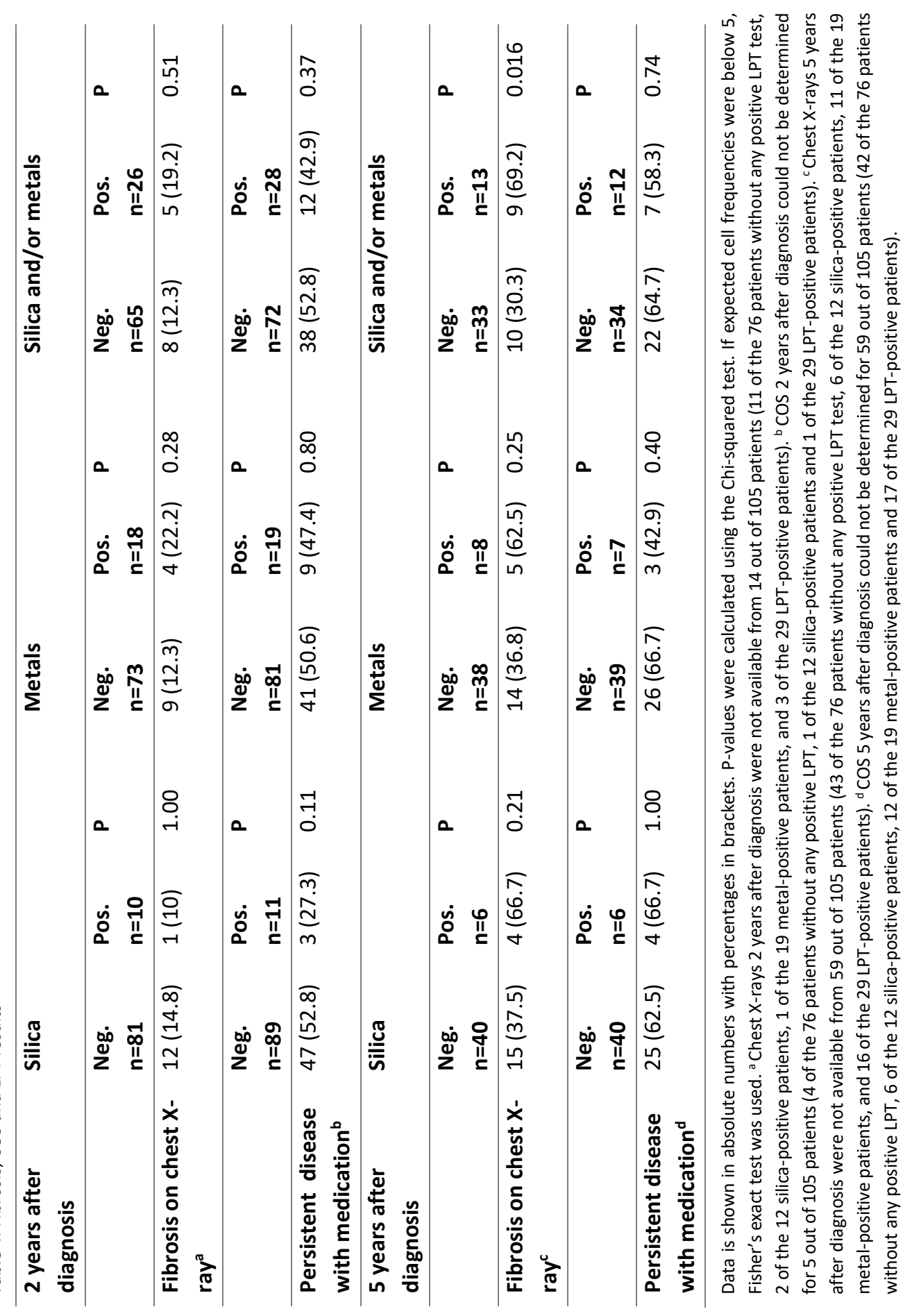


Perhaps a simple occupational history is not detailed enough, and additional (job-specific) questionnaires will be required to identify occasional/recreational exposures that can be sufficient to initiate sarcoidosis in genetic predisposed individuals. Considering above mentioned explanations, in the current study, we decided to test all sarcoidosis patients for metal and silica sensitivity, without determining exposure beforehand.

Regarding the LPT, an SI between 2.0 and 3.0 is considered weakly positive, making interpretation difficult. A weakly positive test does not prove, but rather suggest sensitization. However, when comparing LPT results using an $\mathrm{SI}>2.0$, we found a remarkable difference between patients and controls, with $27.6 \%$ of sarcoidosis patients showing an immunological response compared to only $4.2 \%$ of controls. Clinical relevance is further supported by our finding that sensitization for inorganic triggers, suggested by an $\mathrm{SI}>2.0$, was associated with development of fibrotic sarcoidosis 5 years after diagnosis. An unresolved issue is why some sarcoidosis patients experience spontaneous remission while others develop chronic disease. It has been proposed that difference in antigen clearance could play a role (22). Patients in whom the antigen cannot be cleared are likely to develop chronic disease. Our results of a higher prevalence of fibrotic disease among the subgroup of sarcoidosis patients sensitized to inorganic antigens, fit this hypothesis very well.

Interpretation of our findings regarding $P$. acnes are quite challenging as well. $P$. acnes is a commensal of the human skin but can also be detected in lymph nodes or lung tissue of sarcoidosis as well as non-sarcoidosis patients (23). Unlike T-cells specific for self-antigens, commensal-specific T-cells do not undergo negative selection in the thymus and can be found in healthy individuals (24). Indeed, in our study, a $P$. acnes catalase specific T-cell response was present in approximately $15 \%$ of controls. However, the percentage of sarcoidosis patients with such a T-cell response was significantly lower. Our observations are not in line with previous publications which described an increased response to $P$. acnes in Japanese patients with sarcoidosis $(25,26)$. Differences in ethnicity and genetic susceptibility might explain why an increased $P$. acnes immune response is observed in Japanese but not in Dutch sarcoidosis patients. It seems too early, however, to exclude a role for $P$. acnes in the pathogenesis of sarcoidosis in Dutch patients. First, the lower percentage of $P$. acnes T-cell responses in our sarcoidosis patients could reflect homing of these cells to the lungs. In inflammatory bowel disease it has been demonstrated that circulating microbiota-reactive CD4-positive T-cell frequencies are decreased, which might indeed reflect their selective recruitment to the inflamed gut (27). One may therefore argue that peripheral blood is not the right compartment to study $P$. acnes sensitization in order to the clarify its role in sarcoidosis pathogenesis. Accordingly, in our opinion, future sarcoidosis research should focus either on testing sensitization for $P$. acnes in the alveolar compartment or on detection of $P$. acnes in biopsy material. Second, our results 
demonstrate that sarcoidosis patients sensitized to $P$. acnes catalase are significantly younger at the time of diagnosis and are more likely to have skin involvement. While in theory it seems reasonable to relate $P$. acnes to cutaneous sarcoidosis, more research is needed to confirm this possible association. Finally, it could be that $P$. acnes is a mitogen rather than a specific trigger in sarcoidosis, explaining the relative absence of a specific Tcell response. It has been reported that $P$. acnes has a mitogenic effect on T-lymphocytes, and consequently promotes an inflammatory response, activates specific T-cell subsets and stimulates production of cytokines (28). This way, $P$. acnes may rather serve as an adjuvant, by providing an inflammatory environment during presentation of other antigens to antigen-specific immune cells (29).

Our results suggest that mycobacterial antigens do not play a significant role in sarcoidosis pathogenesis of Dutch patients, which is in line with the fact that the Netherlands is a country with a low tuberculosis incidence: about 5 per 100000 (30). Other studies investigating the role of mycobacterial antigens in sarcoidosis have shown conflicting results. In cohorts of Danish and Japanese sarcoidosis patients no or a very low percentage of latent tuberculosis infection (LTBI) was found ( 0 and $3 \%$, respectively $(31,32)$ ). However, in a study using US and Swedish patients with sarcoidosis, $50 \%$ of patients demonstrated Tcell reactivity against MKatG (33). The contradicting results regarding MKatG between this and our study may be explained by a different definition of a positive elispot result. Whereas we defined it as 50 SFCs per $10^{6}$ PBMCs, being at least 3 times higher than background, Chen et al. used the $95 \%$ confidence interval of the control group as a cut-off, making comparison of results difficult. In our search for trigger-related phenotypes, a remarkable observation was that sarcoidosis patients sensitized to mycobacterial antigens were more likely to have cardiac involvement. Since only 5 sarcoidosis patients were sensitized for mycobacterial antigens, this association requires further investigation as cardiac involvement is a major cause of death in sarcoidosis patients.

We did not observe a significant difference in vimentin-positive elispots between sarcoidosis and control patients, which is in line with an Australian study that found no difference in IFN- $\gamma$ producing cells after stimulation with pooled peptides of vimentin and lysyl tRNA synthethase (34). Based on a previous study reporting a higher number of IFN- $\gamma$ producing cells after vimentin stimulation in DRB1*0301 positive sarcoidosis patients, (35) we also performed HLA-DRB1 genotyping. In contrast to DRB1*0301, we observed a significantly higher percentage of DRB1*1501 carriers among vimentin positive patients. This can be explained by findings of Wahlström et al., who identified by peptide binding predictions, that apart from DRB1*0301, other HLA molecules are also possible binders for vimentin, including DRB1*1501 (35). Where we used the whole protein in elispot assays, Wahlström et al. used a vimentin peptide. The observed association with DRB1*1501 
instead of DRB1*0301 might be caused by difference in vimentin epitopes. Unfortunately, no residual DNA was available from controls, so we were not able to investigate whether sensitization to vimentin in the control group was related to DRB1*1501 as well, or whether this was sarcoidosis-specific.

To study other cytokines as well, concentrations of TNF- $\alpha,\|-2\|-,17 \mathrm{~A}$ and II-1 $\beta$ were measured in supernatant of elispot plates. Higher median II-1 $\beta$ concentrations were found in sarcoidosis patients. However, since higher concentrations were observed after stimulation with vimentin, mycobacterial and $P$. acnes antigens, this seems to be an unspecific inflammatory reaction rather than a specific $\mathrm{T}$-cell response.

There are some limitations to our study. Presence of fibrosis was determined by chest Xray. Only moderate agreement on Scadding stages is reported in literature (36). Furthermore, we are aware that HRCT is preferable to chest X-ray to determine fibrosis. However, follow-up data of HRCT was available only for a proportion of patients, which would have decreased the cohort size and so the power of the analysis. A second limitation was that only half of all patients agreed to provide a second blood sample required for an LPT. Hence, overlap between sensitization to organic and inorganic antigens could not be analyzed for the whole cohort. However, since only a few of the 105 patients demonstrated more than 1 potential trigger, it is unlikely that this would have been the case in the patients not analyzed for inorganic agents.

In conclusion, our study suggests a more prominent role for inorganic triggers such as metals and silica in sarcoidosis pathogenesis than previously thought. Immunological sensitization to inorganic antigens seems related to development of fibrotic sarcoidosis. Future studies including a higher number of patients and controls are warranted to clarify the meaning of a weak positive LPT in sarcoidosis and to definitely confirm the role of metal and silica sensitization in its pathogenesis. We did not find an association between sarcoidosis and an immunological response to bacterial antigens or vimentin. However, our data on LTBI and presence of cardiac sarcoidosis, and the possible relation between sensitization to $P$. acnes and cutaneous involvement, further suggest that trigger-related phenotypes can exist in the heterogeneous population of sarcoidosis patients.

\section{Acknowledgements}

We would like to thank the research group of Y. Eishi (department of Human Pathology, Tokyo Medical and Dental University Graduate school, Tokyo, Japan) who kindly provided P.acnes catalase antigen. 


\section{References}

1. Baughman RP, Teirstein AS, Judson MA, Rossman MD, Yeager Jr H, Bresnitz EA, et al. Clinical characteristics of patients in a case control study of sarcoidosis. Am J Respir Crit Care Med. 2001 Nov 15;164(10 Pt 1):1885-9.

2. Prasse A. The Diagnosis, Differential Diagnosis, and Treatment of Sarcoidosis . Dtsch Arztebl Int. 2016 Aug 22;113(33-34):565-74.

3. Fang $\mathrm{C}$, Huang $\mathrm{H}, \mathrm{Xu} \mathrm{Z}$. Immunological Evidence for the Role of Mycobacteria in Sarcoidosis: A Meta-Analysis . PLoS One. 2016 Aug 1;11(8):e0154716.

4. Gupta D, Agarwal R, Aggarwal AN, Jindal SK. Molecular evidence for the role of mycobacteria in sarcoidosis: a meta-analysis . Eur Respir J. 2007 Sep;30(3):508-16.

5. Eishi Y. Etiologic link between sarcoidosis and Propionibacterium acnes . Respir Investig. 2013 Jun;51(2):56-68.

6. Zhou Y, Hu Y, Li H. Role of propionibacterium acnes in sarcoidosis: A meta-analysis. Vol. 30, Sarcoidosis Vasculitis and Diffuse Lung Diseases. Mattioli 1885 S.p.A.; 2013. p. 262-7.

7. Grunewald J, Kaiser Y, Ostadkarampour M, Rivera N V, Vezzi F, Lotstedt B, et al. Tcell receptor-HLA-DRB1 associations suggest specific antigens in pulmonary sarcoidosis . Eur Respir J. 2016;47(3):898-909.

8. Eberhardt C, Thillai M, Parker R, Siddiqui N, Potiphar L, Goldin R, et al. Proteomic Analysis of Kveim Reagent Identifies Targets of Cellular Immunity in Sarcoidosis . PLoS One. 2017 Jan 23;12(1):e0170285.

9. Fireman E, Shai AB, Alcalay Y, Ophir N, Kivity S, Stejskal V. Identification of metal sensitization in sarcoid-like metal-exposed patients by the MELISA(R) lymphocyte proliferation test - a pilot study . J Occup Med Toxicol. 2016 Apr 12;11:18-016-01011. eCollection 2016.

10. Rafnsson V, Ingimarsson O, Hjalmarsson I, Gunnarsdottir H. Association between exposure to crystalline silica and risk of sarcoidosis . Occup Environ Med. 1998;55(10):657-60.

11. Costabel U, Hunninghake GW. ATS/ERS/WASOG statement on sarcoidosis. Sarcoidosis Statement Committee. American Thoracic Society. European 
Respiratory Society. World Association for Sarcoidosis and Other Granulomatous Disorders. Eur Respir J. 1999;14(4):735-7.

12. Maspero C, Giannini L, Galbiati G, Rosso G, Farronato G. Obstructive sleep apnea syndrome: a literature review. Minerva Stomatol. 64(2):97-109.

13. Drake WP, Dhason MS, Nadaf M, Shepherd BE, Vadivelu S, Hajizadeh R, et al. Cellular recognition of Mycobacterium tuberculosis ESAT-6 and KatG peptides in systemic sarcoidosis. Infect Immun. 2007 Jan;75(1):527-30.

14. Karakaya B, Schimmelpennink MC, Kocourkova L, van der Vis JJ, Meek B, Grutters JC, et al. Bronchoalveolar lavage characteristics correlate with HLA tag SNPs in patients with Löfgren's syndrome and other sarcoidosis. Clin Exp Immunol. 2019 May 1;196(2):249-58.

15. Baughman RP, Nagai S, Balter M, Costabel U, Drent M, Du Bois R, et al. Defining the clinical outcome status (COS) in sarcoidosis: Results of WASOG Task Force. Sarcoidosis Vasc Diffus Lung Dis. 2011;28(1):56-64.

16. Harris PA, Taylor R, Thielke R, Payne J, Gonzalez N, Conde JG. Research electronic data capture (REDCap)--a metadata-driven methodology and workflow process for providing translational research informatics support. J Biomed Inform. 2009 Apr;42(2):377-81.

17. Sood A, Beckett WS, Cullen MR. Variable response to long-term corticosteroid therapy in chronic beryllium disease . Chest. 2004 Dec;126(6):2000-7.

18. Sprince NL, Kanarek DJ, Weber AL, Chamberlin RI, Kazemi H. Reversible respiratory disease in beryllium workers. Am Rev Respir Dis. 1978 Jun;117(6):1011-7.

19. Beijer E, Meek B, Bossuyt X, Peters S, Vermeulen RCH, Kromhout $H$, et al. Immunoreactivity to metal and silica associates with sarcoidosis in Dutch patients. Respir Res. 2020 Jun 8;21(1):141.

20. Infante PF, Newman LS. Beryllium exposure and chronic beryllium disease . Lancet (London, England). 2004 Feb 7;363(9407):415-6.

21. Newman LS, Kreiss K. Nonoccupational beryllium disease masquerading as sarcoidosis: identification by blood lymphocyte proliferative response to beryllium . Am Rev Respir Dis. 1992;145(5):1212-4. 
22. Panselinas E, Judson MA. Acute Pulmonary Exacerbations of Sarcoidosis. Chest. 2012 Oct;142(4):827-36.

23. Ishige I, Eishi Y, Takemura T, Kobayashi I, Nakata K, Tanaka I, et al. Propionibacterium acnes is the most common bacterium commensal in peripheral lung tissue and mediastinal lymph nodes from subjects without sarcoidosis. Sarcoidosis, Vasc Diffus lung Dis Off J WASOG. 2005 Mar;22(1):33-42.

24. Sorini C, Cardoso RF, Gagliani N, Villablanca EJ. Commensal Bacteria-Specific CD4+ T Cell Responses in Health and Disease. Front Immunol. 2018 Nov 20;9.

25. Yorozu P, Furukawa A, Uchida K, Akashi T, Kakegawa T, Ogawa T, et al. Propionibacterium acnes catalase induces increased Th1 immune response in sarcoidosis patients. Respir Investig. 2015 Jul;53(4):161-9.

26. Furusawa H, Suzuki Y, Miyazaki Y, Inase N, Eishi Y. Th1 and Th17 immune responses to viable Propionibacterium acnes in patients with sarcoidosis. Respir Investig. 2012 Sep;50(3):104-9.

27. Hegazy AN, West NR, Stubbington MJT, Wendt E, Suijker KIM, Datsi A, et al. Circulating and Tissue-Resident CD4+ T Cells With Reactivity to Intestinal Microbiota Are Abundant in Healthy Individuals and Function Is Altered During Inflammation. Gastroenterology. 2017 Nov;153(5):1320-1337.e16.

28. Jappe U, Ingham E, Henwood J, Holland KT. Propionibacterium acnes and inflammation in acne; P. acnes has T-cell mitogenic activity. Br J Dermatol. 2002 Feb;146(2):202-9.

29. Wang Z-B, Xu J. Better Adjuvants for Better Vaccines: Progress in Adjuvant Delivery Systems, Modifications, and Adjuvant-Antigen Codelivery. Vaccines. 2020 Mar $13 ; 8(1): 128$.

30. Slump E, Erkens CGM, van Hunen MCJ, Schimmel HJ, van Soolingen D, de Vries G. Tuberculose in Nederland 2018- Surveillancerapport. In: Rijksinstituut voor Volksgezondheid en Millieu. 2019.

31. Milman N, Søborg B, Svendsen CB, Andersen ÅB. Quantiferon test for tuberculosis screening in sarcoidosis patients. Scand J Infect Dis. 2011 Sep 27;43(9):728-35.

32. Inui N, Suda T, Chida K. Use of the QuantiFERON-TB Gold test in Japanese patients 
with sarcoidosis. Respir Med. 2008 Feb;102(2):313-5.

33. Chen ES, Wahlstrom J, Song Z, Willett MH, Wiken M, Yung RC, et al. T cell responses to mycobacterial catalase-peroxidase profile a pathogenic antigen in systemic sarcoidosis. J Immunol (Baltimore, Md 1950). 2008 Dec 15;181(12):8784-96.

34. Ahmadzai H, Cameron B, Chui JJY, Lloyd A, Wakefield D, Thomas PS. Peripheral blood responses to specific antigens and CD28 in sarcoidosis. Respir Med. 2012 May;106(5):701-9.

35. Wahlstrom J, Dengjel J, Winqvist O, Targoff I, Persson B, Duyar H, et al. Autoimmune $T$ cell responses to antigenic peptides presented by bronchoalveolar lavage cell HLADR molecules in sarcoidosis. Clin Immunol. 2009 Dec;133(3):353-63.

36. Baughman RP, Shipley R, Desai S, Drent M, Judson MA, Costabel U, et al. Changes in chest roentgenogram of sarcoidosis patients during a clinical trial of infliximab therapy: Comparison of different methods of evaluation. Chest. 2009 Aug 1;136(2):526-35. 


\section{Supplement}

\section{Methods}

\section{PBMC isolation}

A blood sample $(4 \times 9 \mathrm{~mL}$ ) was drawn from all participants. Peripheral blood mononuclear cells (PBMCs) were collected by the Ficoll-Hypaque density gradient centrifugation method (GE Healthcare) within 24 hours. PBMCs were frozen in RPMI 1640 (Gibco) supplemented with glutamax (Thermo Fisher), 20\% heat-inactivated fetal bovine serum (Gibco) and $20 \%$ dimethylsulfoxide (DMSO) and stored at $-150^{\circ} \mathrm{C}$ until time of analysis. Full details can be found in the online supplement.

\section{Antigens used for PBMC stimulation}

Based on previous findings (1-4), the following antigens and bacteria were used in the enzyme-linked immunospot (elispot) assay:

\section{Mycobacterium tuberculosis}

Mycobacterial $6 \mathrm{kDa}$ early secretory antigenic target (ESAT-6) peptide 14 and 15, sequences NNALQNLARTISEAG and NLARTISEAGQAMAS respectively (purity 90\%), Mycobacterial catalase-peroxidase antigen (MKatG) peptide 31, peptide sequence WTNTPTKWDNSFLEI and the whole MKatG protein (purity 90\%). Peptides and protein were produced at Genscript, Piscataway, USA.

\section{Propionibacterium acnes}

Propionibacterium acnes (P.acnes) catalase antigen was kindly provided by the research group of Y. Eishi from the department of Human Pathology, Tokyo Medical and Dental University Graduate school, Tokyo, Japan.

\section{Vimentin}

Human recombinant vimentin (GF181) was bought from Merck Chemicals B.V., Amsterdam, The Netherlands.

\section{IFN- $\gamma$ elispot}

A blood sample $(4 \times 9 \mathrm{~mL})$ was drawn from all participants. Peripheral blood mononuclear cells (PBMCs) were collected and stored at $-150^{\circ} \mathrm{C}$ until time of analysis. IFN-y elispot assays were performed following the manufactures' instructions (Mabtech, Nacka Strand, Sweden). Briefly, 2*105 PBMCs were seeded per well, together with either $33.33 \mu \mathrm{g} / \mathrm{mL}$ 
ESAT-6 peptides, $33.33 \mu \mathrm{g} / \mathrm{mL}$ MKatG peptides, $10 \mu \mathrm{g} / \mathrm{mL}$ MKatG protein, $10 \mathrm{ug} / \mathrm{mL}$ P.acnes catalase or $20 \mu \mathrm{g} / \mathrm{mL}$ vimentin, in duplicate. As a positive control, PBMCs were seeded together with anti-CD3 mAb (1:50.000 diluted). PBMCs without stimulation served as a negative control. The plates were incubated for 18-22 hours (ESAT-6, MKatG, P.acnes catalase) or $\sim 40$ hours (vimentin) at $37^{\circ} \mathrm{C}$ in $5 \% \mathrm{CO}$. Hereafter, spots were developed following the manufactures protocol. Spots were counted using the AID EliSpot Reader System (Advanced Imaging Devices $\mathrm{GmbH}$, Strassberg, Germany). Responses were calculated by subtracting the spot-forming cells ( $\mathrm{sfc}$ ) of the negative control wells from the antigen specific wells. Following methods of Drake et al. (1), positive responses were defined as at least 50 sfc per 106 PBMCs, being at least 3 times higher than the negative control well.

\section{MELISA ${ }^{\circledR}$}

Blood was drawn in citrate tubes and sent within 24 hours to Prohealth Medical, Nederweert, The Netherlands, where the memory lymphocyte immunostimulation assay $\left(\right.$ MELISA $^{\circledR}$ ) LPT was performed. MELISA ${ }^{\circledR}$ is a clinically validated blood test that detects typeIV allergy (sensitization) to multiple metals $(5,6)$. Furthermore, it can also be used to determine sensitization for silica (7). Lymphocytes were isolated from citrated blood, and $1 * 106$ cells were incubated for 5 days in HEPES-buffered media containing at least two consecutive dilutions of an antigen: aluminium nitrate, beryllium sulphate, silicon dioxide or zirconium dioxide. After cultivating for 5 days, proliferation was measured by incorporation of H3-labelled thymidine. Radioactivity was measured with a scintillation counter (Microbeta, Perkin Elmer). Stimulation indexes (SI) were calculated by dividing the antigen specific counts per minute by the mean counts per minute of the basal controls. Regarding the MELISA ${ }^{\circledR}$ guidelines, a stimulation index $(\mathrm{SI})>2.0$ was considered a weakly positive test result and a $\mathrm{SI}>3.0$ a positive test result. 


\section{Results}

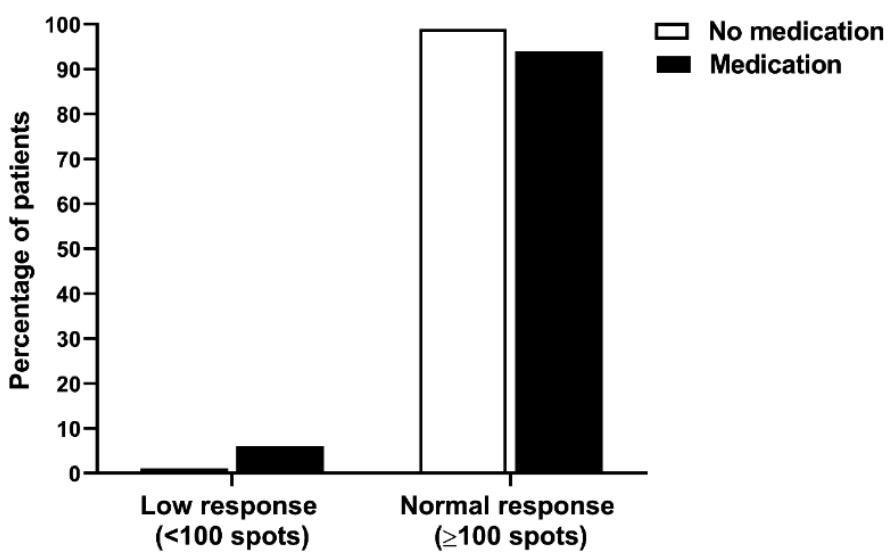

Supplementary Figure 1. Elispot response after stimulation with the positive control (anti-CD3 mAb), compared between sarcoidosis patients with and without immunosuppressive medication at time of PBMC isolation for the elispot assay. No significant differences were observed between patients with and without

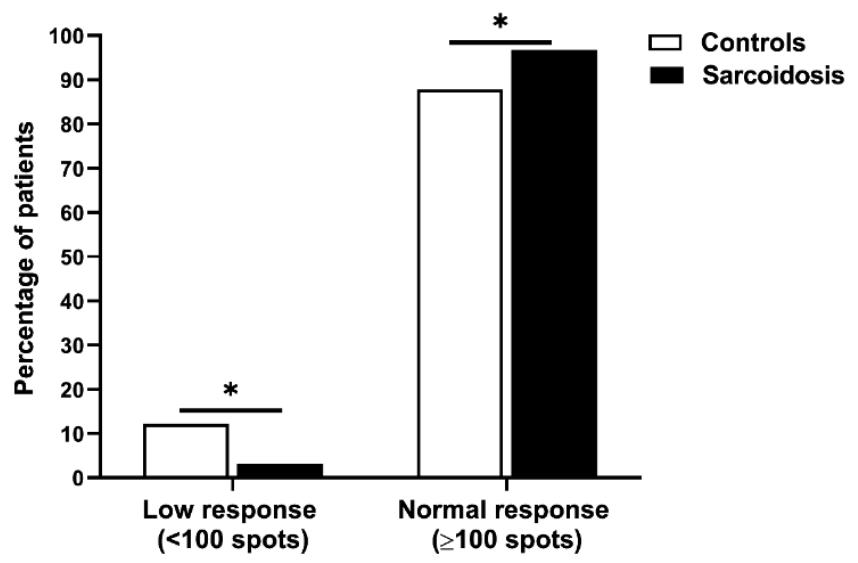

Supplementary Figure 2. Elispot response after stimulation with the positive control (anti-CD3 mAb), compared between sarcoidosis patients and controls. A significant higher percentage of controls had a low response (<100 spots) after stimulation with anti-CD3 $\mathrm{mAb}$ used as a positive control $(\mathrm{P}=0.020)$. 
Supplementary Table 1. Median baseline cytokine levels

\begin{tabular}{|c|c|c|c|}
\hline Cytokine baseline & Controls & Sarcoidosis & $\mathbf{P}^{*}$ \\
\hline \multirow[t]{2}{*}{ II-1 $\beta$ (pg/mL) } & 994.24 (IQR & 2365.65 (IQR & $<0.001$ \\
\hline & 1548.13) & $3080.18)$ & \\
\hline II-17 (pg/mL) & 3.55 (IQR 5.00) & 6.16 (IQR 6.76) & $<0.001$ \\
\hline II-2 (pg/ mL) & 3.10 (IQR 4.15) & 6.95 (IQR 5.46) & $<0.001$ \\
\hline TNF- $\alpha(P g / m L)$ & 133.80 (IQR 215.07) & 322.60 (IQR 438.49) & $<0.001$ \\
\hline
\end{tabular}

$P$ values were calculated using a Mann-Whitney $U$ test. $I Q R=$ interquartile range 
A
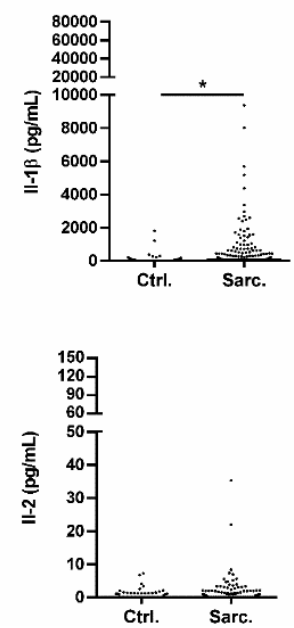

\section{ESAT-6}
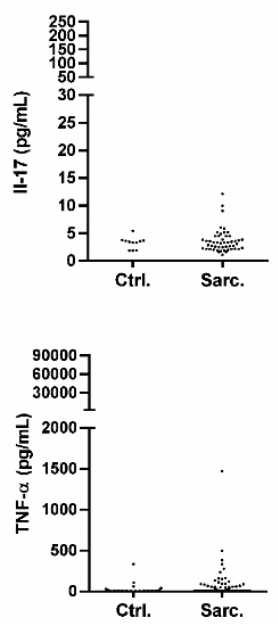

P.acnes catalase
B
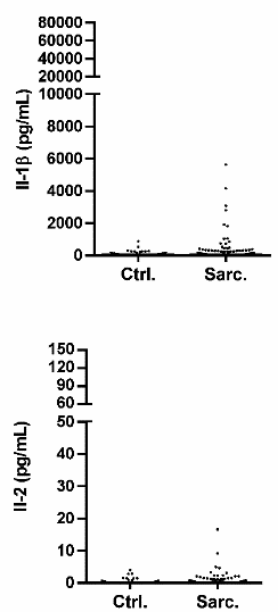

D
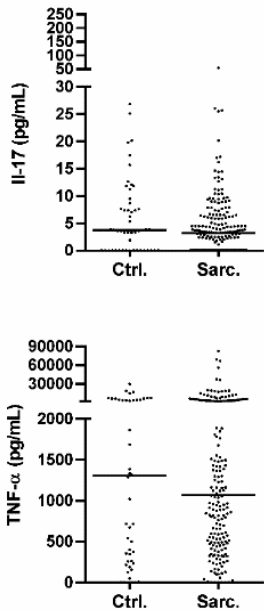

MKatG prot.
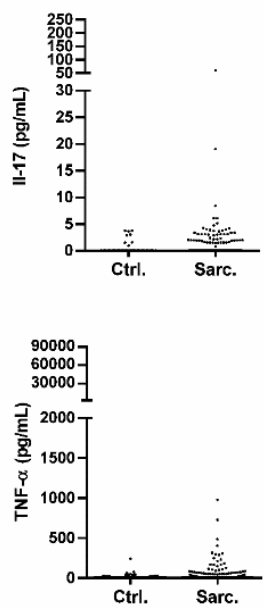

Vimentin
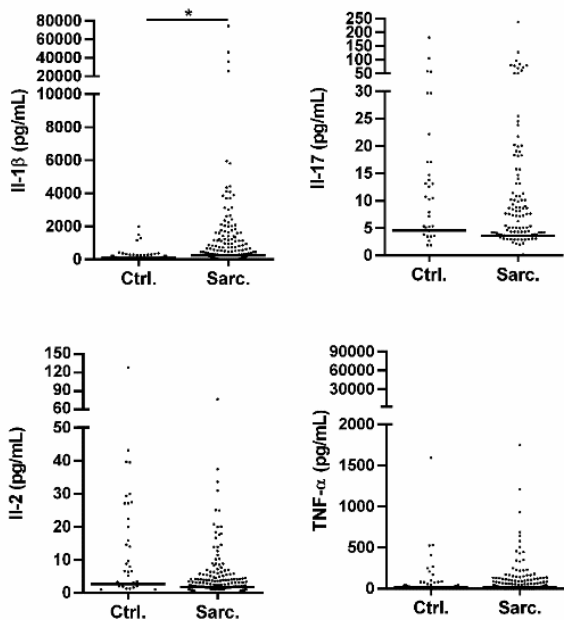

Supplementary Figure 3. Median cytokine concentration in cell supernatant after subtraction of baseline cytokine levels. A: II-1 $\beta,\|-17\|-$,2 and TNF- $\alpha$ concentrations in supernatant after PBMC stimulation with ESAT6. B: II-1 $\beta,\|-17\|-$,2 and TNF- $\alpha$ concentrations in supernatant after PBMC stimulation with the whole MKatG protein. C: II-1 $\beta,\|-17\|-$,2 and TNF- $\alpha$ concentrations in supernatant after PBMC stimulation with P.acnes catalase. D: II-1 $\beta,\|-17\|-$,2 and TNF- $\alpha$ concentrations in supernatant after PBMC stimulation with vimentin 
A

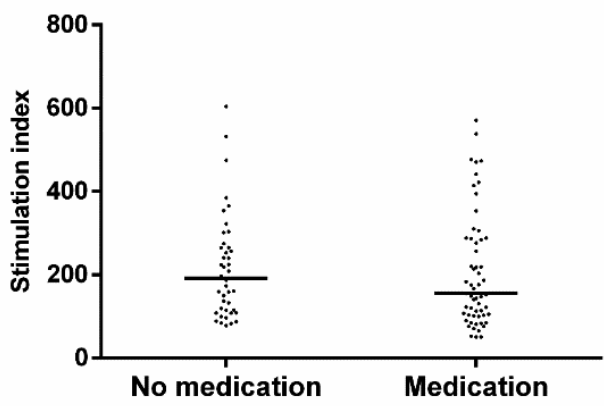

B

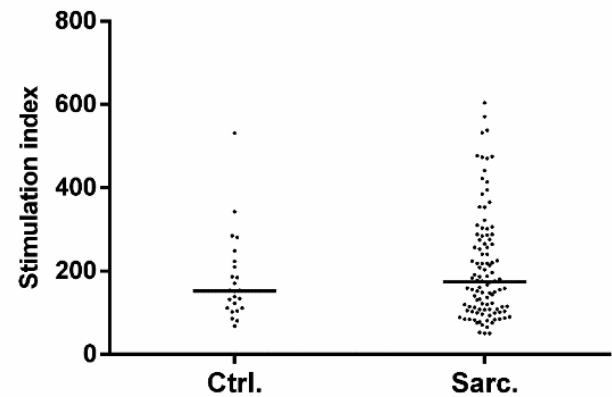

Supplementary Figure 4. Median stimulation index after lymphocyte stimulation with pokeweed, used as a positive control in de LPT

A. No difference was observed in median stimulation index between sarcoidosis patient with and without immunosuppressive medication at time of LPT (191.80 vs $155.40, p=0.344$ ).

B. No difference was observed in median stimulation index between sarcoidosis patients and controls ( 152.45 vs $173.40, p=0.492$ ).

Supplementary Table 2. Overlap in weakly positive LPT results of sarcoidosis patients

\begin{tabular}{lllll}
\hline & $\begin{array}{l}\text { Aluminum } \\
(\mathbf{n}=\mathbf{1 0})\end{array}$ & $\begin{array}{l}\text { Beryllium } \\
(\mathbf{n}=\mathbf{8})\end{array}$ & $\begin{array}{l}\text { Silica } \\
(\mathbf{n}=\mathbf{1 2})\end{array}$ & $\begin{array}{l}\text { Zirconium } \\
(\mathbf{n}=\mathbf{3})\end{array}$ \\
\hline Aluminum & 10 & 1 & 1 & 1 \\
\hline Beryllium & 1 & 8 & 1 & 0 \\
\hline Silica & 1 & 1 & 12 & 0 \\
\hline Zirconium & 1 & 0 & 0 & 3 \\
\hline
\end{tabular}

Supplementary Table 3. Overlap in positive elispot results of sarcoidosis patients

\begin{tabular}{llll}
\hline & Myco. $(n=5)$ & P.ac. cat. $(n=7)$ & $\operatorname{Vim}(n=18)$ \\
\hline Myco & 5 & 0 & 1 \\
\hline P.ac KAT & 0 & 7 & 0 \\
\hline Vim & 1 & 0 & 18 \\
\hline
\end{tabular}

Data is shown as absolute numbers. Myco = positive elispot or IGRA for mycobacterial antigens, P.ac. cat. = positive elispot for P.acnes catalase, $\mathrm{Vim}=$ positive elispot for vimentin. 
Chapter 5. Simultaneous testing of immunological sensitization in sarcoidosis

Supplementary Table 4. Overlap in positive elispots and LPTs of sarcoidosis patients

\begin{tabular}{llll}
\hline & Myco. $(n=2)$ & P.ac cat. $(n=4)$ & Vim $(n=6)$ \\
\hline Sil $(n=12)$ & 0 & 0 & 2 \\
\hline Metal $(n=17)$ & 0 & 0 & 1 \\
\hline LPT $(n=27)$ & 0 & 0 & 2 \\
\hline
\end{tabular}

Data is shown as absolute numbers. Since a LPT was only performed on 105 of the 205 sarcoidosis patients, not all elispot positive patient had a LPT performed. Myco = positive elispot or IGRA for mycobacterial antigens, P.ac. cat. $=$ positive elispot for P.acnes catalase, $\mathrm{Vim}=$ positive elispot for vimentin. Sil = weakly positive LPT for silica, Metal = weakly positive LPT for aluminum, beryllium or zirconium LPT = a weakly positive lymphocyte proliferation test for any of the antigens tested (aluminum, beryllium zirconium or silica). 
Supplementary Table 5. Occupations of the LPT positive and weakly positive sarcoidosis patients and control patient

\begin{tabular}{|c|c|c|c|c|c|}
\hline Patient & $\begin{array}{l}\text { LPT } \\
\text { weak } \\
\text { positive } \\
\text { (SI >2.0) } \\
\text { for }\end{array}$ & $\begin{array}{l}\text { LPT } \\
\text { positive } \\
\text { (SI >3.0) } \\
\text { for }\end{array}$ & Occupation & $\begin{array}{l}\text { Exposure to } \\
\text { metal/silica* } \\
\text { based on } \\
\text { current } \\
\text { occupation }\end{array}$ & $\begin{array}{l}\text { Exposure to } \\
\text { metal/silica } \\
\text { based on all } \\
\text { occupations }\end{array}$ \\
\hline Sarc 15 & Sil & & Civil Engineer & & \\
\hline Sarc 18 & $\mathrm{Be}$ & $\mathrm{Be}$ & $\begin{array}{l}\text { Lorry and Van Driver } \\
\text { (Long-Distance } \\
\text { Transport) }\end{array}$ & & Metal \\
\hline Sarc 43 & $\mathrm{Be}$ & & $\begin{array}{l}\text { Business Services } \\
\text { Salesman }\end{array}$ & & \\
\hline Sarc 63 & Sil & & Office clerk & & \\
\hline Sarc 73 & $\mathrm{Be}, \mathrm{Sil}$ & & $\begin{array}{l}\text { Government } \\
\text { Executive Official }\end{array}$ & & \\
\hline Sarc 74 & $\mathrm{Be}$ & & Cleaner & & \\
\hline Sarc 75 & Zir & & Office clerk & & \\
\hline Sarc 79 & Zir & & Social Worker & & \\
\hline Sarc 85 & Alu & & $\begin{array}{l}\text { Tailor, Made-to- } \\
\text { Measure Garments }\end{array}$ & & \\
\hline Sarc 100 & Sil & & Other Managers & & \\
\hline Sarc 104 & Alu & & Office clerk & & \\
\hline Sarc 113 & Sil & & $\begin{array}{l}\text { Machinery Fitter- } \\
\text { Assembler }\end{array}$ & Metal & Metal \\
\hline Sarc 124 & Sil & Sil & Plasterer, General. & Silica & Silica \\
\hline Sarc 146 & Alu & & Office clerk & & \\
\hline Sarc 159 & Sil & & Roof Thatcher. & & \\
\hline Sarc 166 & Sil & & House builder & Silica & Silica \\
\hline Sarc 167 & $\mathrm{Be}$ & & $\begin{array}{l}\text { Supervisor and } \\
\text { General Foreman } \\
\text { (Construction Work) }\end{array}$ & & \\
\hline Sarc 170 & Alu & Alu & Office clerk & & \\
\hline Sarc 171 & Alu, Be & & Office clerk & & \\
\hline
\end{tabular}


Chapter 5. Simultaneous testing of immunological sensitization in sarcoidosis

\begin{tabular}{llllll}
\hline Sarc 177 & Sil & Sil & Sheet-Metal Worker & Metal & Metal \\
\hline Sarc 178 & Be & Office clerk & & \\
\hline Sarc 186 & Be & $\begin{array}{l}\text { Other Primary } \\
\text { Education Teachers }\end{array}$ & & \\
\hline Sarc 189 & Sil & $\begin{array}{l}\text { Excavating-Machine } \\
\text { Operator }\end{array}$ & Silica & Silica \\
\hline Sarc 193 & Alu & Insurance Salesman & \\
\hline Sarc 194 & Sil & House builder & Silica & \\
\hline Sarc 199 & Alu, Sil & Other Clerical & & \\
& & Supervisors & & \\
\hline Sarc 207 & Alu & General Manager & & \\
\hline Sarc 209 & Alu, Zir & Social Worker & & \\
\hline Sarc 212 & Alu & Alu & Retail Trade & & \\
& & Salesman & & \\
\hline CTRL 38 & Alu, Be, & Concierge & & \\
& Zir, Sil & (Apartment House) & & \\
\hline
\end{tabular}

If patients had no occupation at time of their diagnosis, the most recent performed occupation before the diagnosis is shown. In the last column of the table metal and silica exposure based on all occupations performed before the diagnosis is shown instead of only exposure based on the current occupation.

* Exposure was determined by job exposure matrices (DOM-JEM and ALOHA JEM) coupled to jobs encode by ISCO-

A

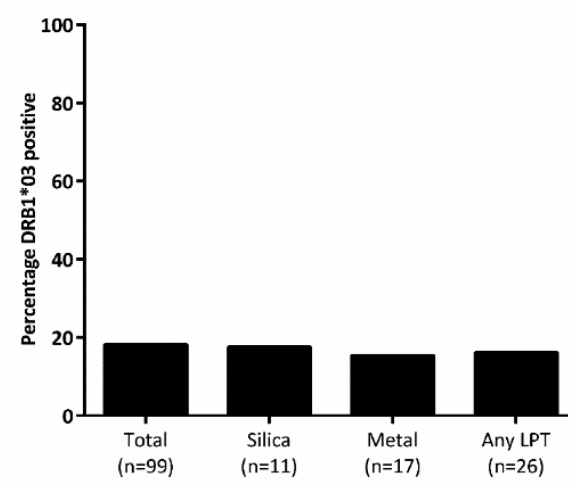

B

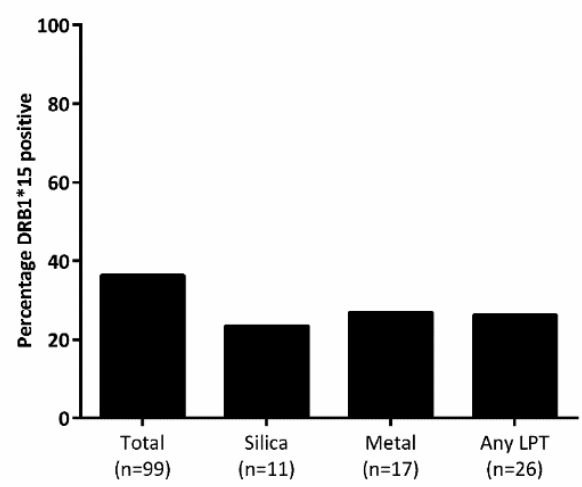

Supplementary Figure 5. Percentage of sarcoidosis patients positive for HLA DRB $1 * 03$ (A) and *15 (B). 


\section{References}

1. Drake WP, Dhason MS, Nadaf M, Shepherd BE, Vadivelu S, Hajizadeh R, et al. Cellular recognition of Mycobacterium tuberculosis ESAT-6 and KatG peptides in systemic sarcoidosis. Infect Immun. 2007 Jan;75(1):527-30.

2. Schupp JC, Tchaptchet S, Lutzen N, Engelhard P, Muller-Quernheim J, Freudenberg $\mathrm{MA}$, et al. Immune response to Propionibacterium acnes in patients with sarcoidosis--in vivo and in vitro. BMC Pulm Med. 2015 Jul 24;15:75-7.

3. Yorozu P, Furukawa A, Uchida K, Akashi T, Kakegawa T, Ogawa T, et al. Propionibacterium acnes catalase induces increased Th1 immune response in sarcoidosis patients. Respir Investig. 2015 Jul;53(4):161-9.

4. Eberhardt C, Thillai M, Parker R, Siddiqui N, Potiphar L, Goldin R, et al. Proteomic Analysis of Kveim Reagent Identifies Targets of Cellular Immunity in Sarcoidosis . PLoS One. 2017 Jan 23;12(1):e0170285.

5. Stejskal VD, Cederbrant K, Lindvall A, Forsbeck M. MELISA-an in vitro tool for the study of metal allergy . Toxicol In Vitro. 1994;8(5):991-1000.

6. Valentine-Thon E, Schiwara H-W. Validity of MELISA for metal sensitivity testing. Neuro Endocrinol Lett. 24(1-2):57-64.

7. Fireman E, Shai AB, Alcalay $Y$, Ophir N, Kivity S, Stejskal V. Identification of metal sensitization in sarcoid-like metal-exposed patients by the MELISA(R) lymphocyte proliferation test - a pilot study . J Occup Med Toxicol. 2016 Apr 12;11:18-016-01011. eCollection 2016.

8. Beijer E, Meek B, Bossuyt X, Peters S, Vermeulen RCH, Kromhout $H$, et al. Immunoreactivity to metal and silica associates with sarcoidosis in Dutch patients. Respir Res. 2020 Jun 8;21(1):141. 

Chapter 6

\section{Latent tuberculosis infection associates with cardiac involvement in patients with sarcoidosis}

Els Beijer

Annelies L. M. Bakker

Raisa Kraaijvanger

Bob Meek

Marco C. Post

Jan C. Grutters

Marcel Veltkamp

Sarcoidosis, Vasc Diffus Lung Dis. 2020;37(3).

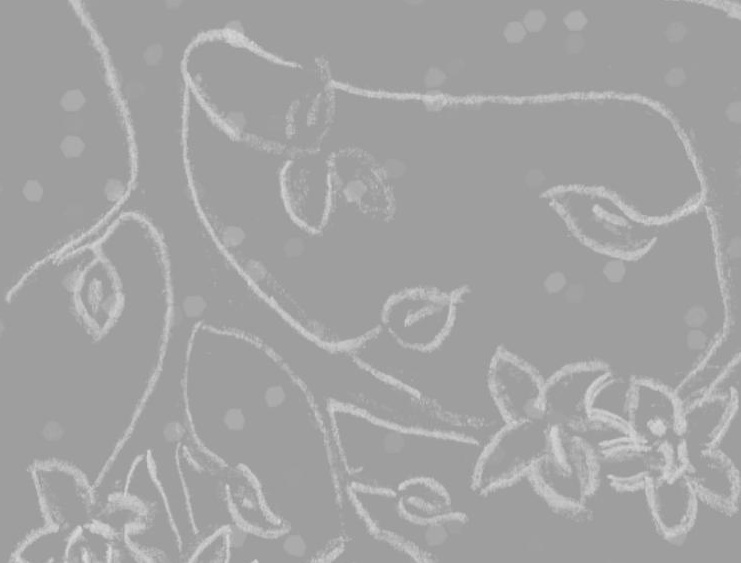




\begin{abstract}
Sarcoidosis is a systemic disease characterized by formation of non-caseating granulomas. About $5 \%$ of patients have symptoms of cardiac sarcoidosis. Identification of cardiac involvement is important since it is a major cause of death. Mycobacterial antigens have been linked to sarcoidosis pathogenesis. Previous findings suggest that a latent tuberculosis infection (LTBI) might associate with development of cardiac involvement in patients with sarcoidosis. The aim of the present study was to further evaluate these findings in another cohort of cardiac sarcoidosis patients.

Interferon release assays (IGRAs) or tuberculin skin tests (TST) were analyzed in a cohort of cardiac sarcoidosis patients $(n=103)$ and compared to non-cardiac sarcoidosis patients ( $n=153)$.

In the cohort of patients with cardiac sarcoidosis, 7 could be diagnoses with an LTBI (6.8\%) compared to only one of the non-cardiac patients $(0.7 \%), p=0.008$.

To conclude, we were able to show an association between an LTBI and cardiac involvement in patients with sarcoidosis. Future research is however required to unravel the mechanism involved in this association.
\end{abstract}

Keywords: Sarcoidosis, Cardiac sarcoidosis, Mycobacteria, Tuberculosis 


\section{Introduction}

Sarcoidosis is a systemic disease characterized by the formation of noncaseating granulomas. Although intrathoracic lymph nodes and the lungs are the most common affected organs, any organ can be involved in this disease (1). About $5 \%$ of sarcoidosis patients have symptoms of cardiac sarcoidosis (CS), although the prevalence of CS is $20-30 \%$ in autopsy and imaging studies (2). Identification of cardiac involvement is important since it is a major cause of death in sarcoidosis patients $(3,4)$.

The etiology of sarcoidosis is not clear do date. However, several antigens have been related to sarcoidosis, including inorganic agents $(5,6)$, auto-antigens (7) and bacteria (8). The two most extensive studied bacteria in relation to sarcoidosis pathogenesis are Propionibacterium acnes (P. acnes) (9) and Mycobacteria (10). Studies regarding $P$. acnes and mycobacteria in relation to sarcoidosis mainly focused on cellular immune responses to antigens of $P$. acnes and mycobacteria $(11,12)$ as well as detecting DNA or antigens in biopsy material of sarcoidosis patients and controls $(13,14)$. Trigger related phenotypes, however, have not been described previously. In recent work from our group (15) sarcoidosis patients were tested for an immunological response towards several antigens related to sarcoidosis pathogenesis. In a total cohort of 201 patients with sarcoidosis, a latent tuberculosis infection (LTBI) was found in 5 patients (2.5\%). Interestingly, when defining trigger-related phenotypes it was found that three of these LTBI patients had cardiac involvement of their sarcoidosis. The aim of the present study was to further evaluate these unexpected results. We used another cohort of CS patients to investigate whether an LTBI associates with cardiac involvement in sarcoidosis.

\section{Methods}

\section{Study subjects}

A cohort of CS patients registered in our hospital was retrospectively studied and included as CS group (approved by the local institutional review board (Z.19.004) of the St Antonius Hospital. Due to the use of clinical data, the need for informed consent was waived). A diagnosis of CS was made after advanced imaging with cardiac resonance imaging (CMR) and fluorodeoxyglucose positron emission tomography (FDG-PET). The likelihood of CS was assessed in a multidisciplinary team consisting of a pulmonologist, cardiologist, radiologist, nuclear specialist and nurse, predominantly based on the diagnostic criteria from the Heart Rhythm Society (HRS) consensus statement (16). Definite and probable CS were the gold standard for the diagnosis of CS.

Biopsy proven sarcoidosis patients or Löfgren syndrome patients without cardiac involvement, seen for the first time at the ILD outpatient clinic of the St Antonius hospital (Nieuwegein, The Netherlands) from May 1st 2016 till December 2017, were also 
retrospectively studied and included in the non-cardiac sarcoidosis (non-CS) group (approved by the Medical research Ethics Committees United (MEC-U) (R14.023), all these patients signed informed consent). The diagnosis of sarcoidosis had been established according to the criteria of the American Thoracic Society/European Respiratory Society (17).

\section{Diagnosis of LTBI}

Following the diagnostic criteria for sarcoidosis to exclude other causes of granulomatous disease, an Interferon Gamma Release Assay (IGRA) or tuberculin skin test (TST is performed in all sarcoidosis patients in the St. Antonius Hospital. Medical records of patients were searched for data of IGRAs (TB ELISpot or QuantiFERON tests). When data of those tests were not available, medical records were searched for results of tuberculin skin tests (TST). If IGRAs or TSTs were not performed in our hospital, available data of referring hospitals were retrieved. If data of IGRAs or TSTs were not available, patients were excluded from the study. Results of IGRAs or TSTs were compared between the CS group and the non-CS group. A diagnosis of LTBI was made when a cellular immune response against antigens of Mycobacterium tuberculosis (MTB) was present without bacterial, radiological or clinical signs of an active tuberculosis infection according to the current guidelines $(18,19)$.

\section{Statistics}

Data were analyzed using IBM SPSS statistics version 24. An unpaired T-test was used to compare numerical data between the non-CS and CS group. Non-parametric tests were used for non-normally distributed data (Mann-Whitney $U$ test). Categorical data were compared using the Chi-squared test. If expected cell frequencies were below 5, Fisher's exact test was used for categorical data up to two categories. Odds ratios were calculated using a binary logistic regression model.

\section{Results}

Retrospective data of IGRAs or TSTs was available from 153 non-CS patients and 103 CS patients, which were included in the study (Table 1). Establishment of the diagnosis of cardiac sarcoidosis is shown in Supplementary Table1. The CS group was significantly older at time of the IGRA or TST and consisted of more men. No difference in ethnicity was observed between the two study groups and also the percentage of patients that originated from another country than the Netherlands did not significantly differ between the non-CS and CS group either (3.9\% vs 7.8\%, $\mathrm{P}=0.189$, Supplementary Table 2 ). 
Table 1. Demographics of study patients

\begin{tabular}{llll}
\hline & Non-CS (n=153) & CS ( $\mathbf{n = 1 0 3 )}$ & $\mathbf{P} *$ \\
\hline IGRA / TST & $149 / 4$ & $96 / 7$ & 0.124 \\
\hline Age (mean \pm SD) & $47.23 \pm 12.64$ & $51.39 \pm 10.87$ & 0.005 \\
\hline Sex (male / female) & $80 / 73$ & $77 / 26$ & $<0.001$ \\
\hline Ethnicity (white / non-white) & $135 / 18$ & $92 / 11$ & 0.788 \\
\hline Organ involvement: & & & \\
\hline$\quad$ Lymph nodes (\%) & $146(96.1)$ & $99(97.1)$ & 0.744 \\
\hline Lungs (\%) & $114(74.5)$ & $78(75.7)$ & 0.825 \\
\hline Nervous system (\%) & $28(18.3)$ & $8(7.8)$ & 0.017 \\
\hline Skin (\%) & $28(18.3)$ & $4(3.9)$ & 0.001 \\
\hline Eyes (\%) & $23(15.0)$ & $8(7.8)$ & 0.081 \\
\hline Bone (\%) & $8(5.2)$ & $8(7.8)$ & 0.411 \\
\hline Liver (\%) & $7(4.6)$ & $7(6.8)$ & 0.443 \\
\hline Spleen (\%) & $5(3.3)$ & $13(12.6)$ & 0.004 \\
\hline
\end{tabular}

Age is age at time of IGRA or TST. * P-values for sex, ethnicity, lung, eye, skin, nervous system, bone, liver and spleen involvement were calculated using Pearson Chi-Square. Statistical differences for IGRA/TST and lymph node involvement were accessed using Fisher's Exact Test. A P-value for age was calculated using an unpaired T-test.

IGRA: Interferon gamma release assay, TST: tuberculin skin test, CS: Cardiac sarcoidosis

In total, 7 CS patients were diagnosed with LTBI (6.8\%) compared to only one patient of the non-CS group ( $0.7 \%), P=0.008$ (Figure 1). When looking at the two different assays, in the CS group 6 of 96 patients had a positive IGRA (6.3\%) compared to 1 of 149 patients of the non-CS group $(0.7 \%)(P=0.016)$. A positive TST was found in 1 of 7 CS patients $(14.3 \%)$ and in none of the 4 non-CS patients $(P=1.000)$. An increased OR of $11.08(\mathrm{Cl}: 1.34 ; 91.49)$ was observed for CS and an LTBI and an increased odds ratio (OR) of 9.87 (Cl: $1.17 ; 83.29$ ) was observed for a positive IGRA and CS. Furthermore, when these ORs were adjusted for age, also significant increased ORs of respectively 10.17 (Cl: 1.23; 84.50) and 9.06 (Cl: 1.06; 77.13) were observed.

Besides cardiac involvement, we also compared other involved organs between the 8 sarcoidosis patients with an LTBI and the other sarcoidosis patients. Prevalence of other involved organs was not different between the patients with an LTBI and the remaining patients (Table 2). 


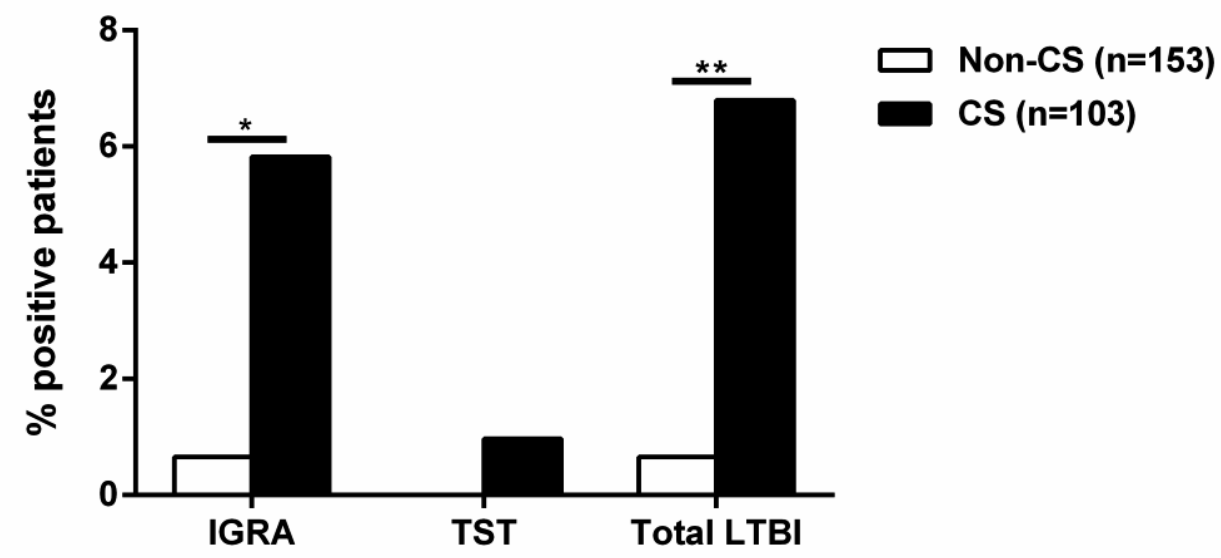

Figure 1. Percentage of patients with a positive IGRA or TST, to determine a latent tuberculosis infection Significant more CS patients had a positive IGRA test compared to the non-CS group (6 versus 1, respectively) $(P=0.016)$. In total, significant more CS patients were diagnosed with a LTBI compared to non-CS patients $(7$ versus 1 , respectively) $(P=0.008)$.

IGRA included a QuantiFERON test or TB elispot.

Non-CS: Non-cardiac sarcoidosis, CS: Cardiac sarcoidosis, IGRA: Interferon gamma release assay, TST: tuberculin skin test, LTBI: latent tuberculosis infection.

Table 2. Organ involvement of LTBI and no LTBI sarcoidosis patients

\begin{tabular}{llll}
\hline Involved organ: & No LTBI $(\mathbf{n}=\mathbf{2 4 8 )}$ & LTBI $(\mathbf{n}=\mathbf{8})$ & P-value* \\
\hline Heart (\%) & $96(38.7)$ & $7(87.5)$ & 0.008 \\
\hline Lymph nodes (\%) & $237(96.3)$ & $8(100)$ & 1.000 \\
\hline Lungs (\%) & $185(74.6)$ & $7(87.5)$ & 0.684 \\
\hline Nervous system (\%) & $36(14.5)$ & $0(0.0)$ & 0.605 \\
\hline Skin (\%) & $32(12.9)$ & $0(0.0)$ & 0.601 \\
\hline Eyes (\%) & $30(12.1)$ & $1(12.5)$ & 1.000 \\
\hline Bone (\%) & $16(6.5)$ & $0(0.0)$ & 1.000 \\
\hline Liver (\%) & $13(5.2)$ & $1(12.5)$ & 0.366 \\
\hline Spleen (\%) & $18(7.3)$ & $0(0.0)$ & 1.000 \\
\hline
\end{tabular}

* P-values were calculated using Fisher's Exact Test

LTBI: Latent tuberculosis infection 


\section{Discussion}

In this study we were able to show that a latent tuberculosis infection is associated with cardiac involvement in patients already diagnosed with sarcoidosis, which is in line with our initial observation (15).

Although the finding that $6.8 \%$ of patients with CS were diagnosed with an LTBI seems low, this is an interesting observation since the Netherlands is a very low tuberculosis incidence country with a tuberculosis incidence of about 5 per 100.000 and an LTBI incidence of about 8 per 100.000 (20).

In previous papers, a possible link between LTBI and sarcoidosis has already been suggested (21). However, to the best of our knowledge, this is the first study to relate LTBI specifically to CS. It is known from literature that myocardial involvement in tuberculosis exists, but this is rare and has been occasionally described in case reports (22). Luk et al. a described a case of CS who underwent heart transplantation, developing recurrent CS in the graft following a mycobacteria tuberculosis infection (23). Since data of IGRAs or TSTs before heart transplantation were not presented, it is unclear whether this patient was suffering from a reactivation of an $\mathrm{LTB}$ already present before heart transplantation, or a newly acquired tuberculosis infection. In a recent study in mice it was demonstrated that after intranasal infection, Mycobacterium avium was able to disseminate into cardiac tissue (24). Interestingly, infection with Mycobacterium avium was able to induce intracardial inflammatory gene expression and induce intracardiac tissue fibrosis. Although quite speculative, if other species of mycobacteria are also capable of inducing such damage to cardiac tissue, this could perhaps trigger a local granulomatous reaction in the heart we define as cardiac sarcoidosis. A possible explanation for our findings, may be molecular mimicry. Molecular mimicry has been described in T cell specific autoimmune diseases including multiple sclerosis and rheumatoid arthritis (RA) but also myocarditis $(25,26)$. Chodisetti et al. identified several $\mathrm{T}$ cell epitopes that are similar to peptides of mycobacterial antigens. Those epitopes may act as molecular mimics and result in an autoimmune response during an infection with $M$. tuberculosis (27). Cross-reactive antibodies with heart tissue were observed in rheumatic carditis patients (28). Further studies should clarify whether such cross reactive antibodies or shared epitopes are also present for mycobacteria and cardiac tissue.

If the association between LTBI and CS can be confirmed in further studies, this could be of interest for clinical management. For instance, it could be relevant to screen sarcoidosis patients with an LTBI for CS, even though symptoms may not be present (yet). Identification of cardiac involvement seems important since it is a major cause of death. Furthermore, in current clinical practice, if a patient is diagnosed with an LTBI they can either choose followup without medication or start LTBI treatment using Isoniazid/Rifampicin (29). One could 
speculate whether it would be beneficial for this group to start LTBI treatment instead of a wait-and-see policy directly after the diagnosis of LTBI is made.

A limitation of this retrospective study design is that the diagnosis of an LTBI was based on a positive result of different assay types (TST or IGRA). So, not all study patients had the same assay performed, although an IGRA was performed in over $95 \%$ of cases and results remained statistical significant when only LTBIs diagnosed by an IGRA were taken into account. A study regarding RA patients showed that results of IGRA tests did not correlate with use of corticosteroids, making these assays useful in RA patients (30), and likewise in sarcoidosis patients (31). Where results of IGRA are not affected by previous BCG vaccination, the TST is. However, no evidence for a previous BCG vaccination was found for the patient with an LTBI based on a positive TST. Moreover, there are several methods to search for an Mycobacterium tuberculosis (MTB) infection, which all have a different sensitivity and specificity. For instance, Masoud et al. showed that purified protein derivative antigens of MTB were present in tissue cells of 3 out of 10 sarcoidosis patients even when MTB DNA could not be detected (14). Based on our retrospective study design, we were not able to examine different methods to search for a MTB infection such as detection of mycobacterial antigens in tissue of patients. It would however be interesting to examine in future studies whether mycobacterial antigens are present in myocardial tissue of cardiac sarcoidosis patients diagnosed with an LTBI.

Another study limitation was that the non-CS and CS group were not similar regarding sex and age. Although tuberculosis is more common in the Netherlands among people with a higher age (32), the OR was still significantly increased after adjustment for age, suggesting that this difference between the groups have not induced a bias in our results. Although patients in the non-CS group did not have symptoms associated with CS, we cannot completely exclude the possibility that there might be some asymptomatic CS patients in this group, since a PET or MRI was not performed for the complete non-CS group.

To conclude, our data suggest that a latent tuberculosis infection associates with cardiac involvement in patients with sarcoidosis. Future research is required to unravel pathways involved in the association between a latent tuberculosis infection and cardiac involvement in sarcoidosis. 


\section{References}

1. Grunewald J, Grutters JC, Arkema E V., Saketkoo LA, Moller DR, Müller-Quernheim J. Sarcoidosis. Nat Rev Dis Prim. 2019 Dec 1;5(1).

2. Kouranos V, Tzelepis GE, Rapti A, Mavrogeni S, Aggeli K, Douskou M, et al. Complementary Role of CMR to Conventional Screening in the Diagnosis and Prognosis of Cardiac Sarcoidosis. JACC Cardiovasc Imaging. 2017 Dec 1;10(12):1437-47.

3. Judson MA. Screening sarcoidosis patients for cardiac sarcoidosis: What the data really show. Vol. 154, Respiratory Medicine. 2019. p. 155-7.

4. Bakker AL, Grutters JC, Keijsers RG, Post MC. Cardiac sarcoidosis: Challenges in clinical practice. Vol. 23, Current Opinion in Pulmonary Medicine. 2017. p. 468-75.

5. Beijer E, Meek B, Bossuyt X, Peters S, Vermeulen RCH, Kromhout $H$, et al. Immunoreactivity to metal and silica associates with sarcoidosis in Dutch patients. Respir Res. 2020 Jun 8;21(1):141.

6. Rafnsson V, Ingimarsson O, Hjalmarsson I, Gunnarsdottir H. Association between exposure to crystalline silica and risk of sarcoidosis . Occup Environ Med. 1998;55(10):657-60.

7. Kinloch AJ, Kaiser $Y$, Wolfgeher D, Ai J, Eklund A, Clark MR, et al. In situ humoral immunity to vimentin in HLA-DRB1*03+ patients with pulmonary sarcoidosis. Front Immunol. 2018 Jul 9;9(JUL).

8. Esteves T, Aparicio G, Garcia-Patos V. Is there any association between Sarcoidosis and infectious agents?: a systematic review and meta-analysis. BMC Pulm Med. 2016 Nov 28;16(1):165.

9. Zhou Y, Hu Y, Li H. Role of propionibacterium acnes in sarcoidosis: A meta-analysis. Vol. 30, Sarcoidosis Vasculitis and Diffuse Lung Diseases. Mattioli 1885 S.p.A.; 2013. p. 262-7.

10. Fang $\mathrm{C}$, Huang $\mathrm{H}, \mathrm{Xu} \mathrm{Z}$. Immunological Evidence for the Role of Mycobacteria in Sarcoidosis: A Meta-Analysis . PLoS One. 2016 Aug 1;11(8):e0154716.

11. Yorozu P, Furukawa A, Uchida K, Akashi T, Kakegawa T, Ogawa T, et al. Propionibacterium acnes catalase induces increased Th1 immune response in sarcoidosis patients. Respir Investig. 2015 Jul;53(4):161-9.

12. Oswald-Richter $K$, Sato $H$, Hajizadeh $R$, Shepherd BE, Sidney J, Sette A, et al. Mycobacterial ESAT- 6 and katG are recognized by sarcoidosis CD4+ T cells when presented by the American sarcoidosis susceptibility allele, DRB1*1101. J Clin Immunol. 2010 Jan;30(1):157-66.

13. Negi M, Takemura T, Guzman J, Uchida K, Furukawa A, Suzuki Y, et al. Localization of propionibacterium acnes in granulomas supports a possible etiologic link 
between sarcoidosis and the bacterium. Mod Pathol. 2012 Sep;25(9):1284-97.

14. Masoud S, Mihan P, Hamed M, Mehdi M, Mohamad RM. The presence of mycobacterial antigens in sarcoidosis associated granulomas. Sarcoidosis, Vasc Diffus lung Dis Off J WASOG. 2017;34(3):236-41.

15. Beijer E, Kraaijvanger R, Eishi Y, Meek B, Veltkamp M. Trigger Related Phenotypes in Sarcoidosis, abstract nr: O3-5. Sci Progr WASOG/JSSOG2019. 2019;38.

16. Birnie DH, Sauer WH, Bogun F, Cooper JM, Culver DA, Duvernoy CS, et al. HRS expert consensus statement on the diagnosis and management of arrhythmias associated with cardiac sarcoidosis. Hear Rhythm. 2014 Jul;11(7):1304-23.

17. Costabel U, Hunninghake GW. ATS/ERS/WASOG statement on sarcoidosis. Sarcoidosis Statement Committee. American Thoracic Society. European Respiratory Society. World Association for Sarcoidosis and Other Granulomatous Disorders. Eur Respir J. 1999;14(4):735-7.

18. Mack U, Migliori GB, Sester M, Rieder HL, Ehlers S, Goletti D, et al. LTBI: Latent tuberculosis infection or lasting immune responses to $M$. tuberculosis? A TBNET consensus statement. In: European Respiratory Journal. Eur Respir J; 2009. p. 95673.

19. Guidelines on the Management of Latent Tuberculosis Infection. Guidelines on the Management of Latent Tuberculosis Infection. World Health Organization; 2015.

20. Slump E, Erkens CGM, van Hunen MCJ, Schimmel HJ, van Soolingen D, de Vries G. Tuberculose in Nederland 2018- Surveillancerapport. In: Rijksinstituut voor Volksgezondheid en Millieu. 2019.

21. Oswald-Richter KA, Beachboard DC, Zhan X, Gaskill CF, Abraham S, Jenkins C, et al. Multiple mycobacterial antigens are targets of the adaptive immune response in pulmonary sarcoidosis. Respir Res. 2010 Nov 23;11:161.

22. Wallis PJW, Branfoot AC, Emerson PA. Sudden death due to myocardial tuberculosis. Thorax. 1984 Feb 1;39(2):155-6.

23. Luk A, Lee A, Ahn E, Soor GS, Ross HJ, Butany J. Cardiac sarcoidosis: Recurrent disease in a heart transplant patient following pulmonary tuberculosis infection. Can J Cardiol. 2010 Aug;26(7):e273-5.

24. Headley CA, Gerberick A, Mehta S, Wu Q, Yu L, Fadda P, et al. Nontuberculous mycobacterium $M$. avium infection predisposes aged mice to cardiac abnormalities and inflammation. Aging Cell. 2019 Jun;18(3):e12926.

25. Rojas $M$, Restrepo-Jiménez $\mathrm{P}$, Monsalve DM, Pacheco $\mathrm{Y}$, Acosta-Ampudia $\mathrm{Y}$, Ramírez-Santana C, et al. Molecular mimicry and autoimmunity. J Autoimmun. 2018 Dec 1;95:100-23.

26. Bracamonte-Baran W, Čiháková D. Cardiac autoimmunity: Myocarditis. In: 
Advances in Experimental Medicine and Biology. 2017. p. 187-221.

27. Chodisetti SB, Rai PK, Gowthaman U, Pahari S, Agrewala JN. Potential T cell epitopes of Mycobacterium tuberculosis that can instigate molecular mimicry against host: implications in autoimmune pathogenesis. BMC Immunol. 2012 Mar 21;13:13.

28. Cunningham MW. Molecular Mimicry, Autoimmunity, and Infection: The CrossReactive Antigens of Group A Streptococci and their Sequelae. Microbiol Spectr. 2019 Jul 5;7(4).

29. Huaman MA, Sterling TR. Treatment of Latent Tuberculosis Infection-An Update. Vol. 40, Clinics in Chest Medicine. W.B. Saunders; 2019. p. 839-48.

30. Sargın G, Şentürk T, Ceylan E, Telli M, Çildağ S, Doğan H. Tst, Quantiferon-tb Gold test and $\mathrm{t}$-spot.Tb test for detecting latent tuberculosis infection in patients with rheumatic disease prior to anti-tnf therapy. Tuberk Toraks. 2018 Jun 30;66(2):13643.

31. Milman N, Søborg B, Svendsen CB, Andersen ÅB. Quantiferon test for tuberculosis screening in sarcoidosis patients. Scand J Infect Dis. 2011 Sep 27;43(9):728-35.

32. de Vries G, Riesmeijer R. Nationaal Plan Tuberculosebestrijding 2016-2020. Op weg naar eliminatie. [National Tuberculosis Control Plan 2016-2020. Moving towards Elimination]. 2016;1-53. 


\section{Supplement}

Supplementary Table 1. Establishment of the diagnosis of cardiac sarcoidosis

\begin{tabular}{lll}
\hline $\begin{array}{l}\text { Total CS } \\
\text { 1.Histological diagnosis from } \\
\text { myocardial tissue }\end{array}$ & $\mathbf{1 0 3}$ & \\
\hline $\mathbf{2 a}+\mathbf{2 b}$ & $\begin{array}{l}\text { Histological diagnosis of } \\
\text { extra-cardiac sarcoidosis } \\
\text { (n=78) }\end{array}$ & $\begin{array}{l}\text { Consensus diagnosis } \\
\text { extra-cardiac } \\
\text { sarcoidosis based on } \\
\text { expert opinion (n=21) }\end{array}$ \\
\hline $\begin{array}{l}\text { Steroid+/- } \\
\text { immunosuppressant } \\
\text { responsive cardiomyopathy } \\
\text { or heart block }\end{array}$ & 1 & 3 \\
\hline $\begin{array}{l}\text { Unexplained reduced LVEF } \\
\text { (<40\%) }\end{array}$ & 11 & 2 \\
\hline $\begin{array}{l}\text { Unexplained sustained } \\
\text { (spontaneous or induced) VT }\end{array}$ & 9 & 4 \\
\hline $\begin{array}{l}\text { Mobitz type II 2nd degree } \\
\text { heart block or 3rd degree } \\
\text { heart block }\end{array}$ & 11 & 9 \\
\hline $\begin{array}{l}\text { Patchy uptake on dedicated } \\
\text { cardiac PET (in a pattern } \\
\text { consistent with CS) }\end{array}$ & 63 & 16 \\
\hline $\begin{array}{l}\text { Late Gadolinium } \\
\text { Enhancement on CMR (in a } \\
\text { pattern consistent with CS) }\end{array}$ & 67 & \\
\hline
\end{tabular}

The likelihood of cardiac sarcoidosis (CS) was assessed in a multidisciplinary team consisting of a pulmonologist, cardiologist, radiologist, nuclear specialist and nurse, predominantly based on the diagnostic criteria from the Heart Rhythm Society (HRS) consensus statement (17). Definite and probable CS were the gold standard for the diagnosis of CS. 
Supplementary Table 2. Country of origin of study patients

\begin{tabular}{lll}
\hline Country of origin & Non-CS $(\mathbf{n}=\mathbf{1 5 3})$ & CS $(\mathbf{n = 1 0 3 )}$ \\
\hline The Netherlands & $146(96.1)$ & $95(92.2)$ \\
\hline Morocco & 0 & $3(2.9)$ \\
\hline Curacao & 0 & $2(1.9)$ \\
\hline Sri Lanka & $2(1.3)$ & 0 \\
\hline Suriname & $1(0.7)$ & $1(1.0)$ \\
\hline Colombia & $1(0.7)$ & 0 \\
\hline Germany & 0 & $1(1.0)$ \\
\hline Grenada & $1(0.7)$ & 0 \\
\hline India & $1(0.7)$ & 0 \\
\hline Syria & 0 & $1(1.0)$ \\
\hline Unknown & $1(0.7)$ & 0 \\
\hline
\end{tabular}

The percentages of patients who originated from another country than the Netherlands did not significantly differ between the CS and non-CS group $(P=0.189)$. 

Chapter 7

\title{
Presence of Propionibacterium acnes in granulomas associates with a chronic disease course in Dutch sarcoidosis patients
}

\author{
Els Beijer \\ Kees A. Seldenrijk \\ Yoshinobu Eishi \\ Keisuke Uchida \\ Jan Damen \\ Jan C. Grutters \\ Marcel Veltkamp
}

ERJ Open Res. 2021 Jan 1;7(1):486-2020. 


\begin{abstract}
Several studies demonstrated that Propionibacterium acnes ( $P$. acnes) may be involved in sarcoidosis pathogenesis. Presence of $P$. acnes was found in granulomas of the majority of Japanese sarcoidosis patients. However, presence of $P$. acnes in tissue has never been related to sarcoidosis phenotypes and clinical outcome. Therefore, the aims of our study were to demonstrate whether $P$. acnes can be detected in granulomas of Dutch sarcoidosis patients and to investigate whether its presence is related to a clinical phenotype and/or course of disease.

Sections of formalin fixed paraffin-embedded tissue blocks of 76 sarcoidosis patients were examined by immunostaining with a $P$. acnes-specific monoclonal antibody (PAB antibody) using a VENTANA BenchMark ULTRA. Clinical outcome status (COS) was determined and classified into two phenotype groups: A: resolved, minimal or persistent disease without treatment (COS 1-6) and B: persistent disease with need for treatment (COS 7-9).

$P$. acnes was detected in samples of 31 patients (41\%) and located within granulomas in samples of 13 patients (17\%). The frequency of $P$. acnes detected in granulomas at diagnosis was significantly higher in patients with phenotype $B$ compared to patients with phenotype A (29\% vs 0\%, P = 0.021).

Presence of $P$. acnes in granulomas can be confirmed in Dutch sarcoidosis patients. It is intriguing that presence of $P$. acnes in granulomas is more frequently found in patients with chronic disease requiring treatment. This adds to the rationale that a subgroup of sarcoidosis patients might benefit from antibiotic therapy.
\end{abstract}




\section{Introduction}

Sarcoidosis is a multisystem inflammatory disorder of unknown etiology that is characterized by the presence of non-caseating granulomas. In over $90 \%$ of patients the lungs are involved (1), but the disease can also affect other organs (2). Patients with symptomatic organ involvement or risk of permanent damage can be treated with immunosuppressive drugs (3), which suppress disease activity but do not cure the disease. The cause of sarcoidosis is still puzzling scientists for more than a century. Several studies demonstrated that specific microorganisms, including mycobacteria and Propionibacterium acnes ( $P$. acnes) could be involved in its disease pathogenesis (4-9). As $P$. acnes is a commensal, Koch's postulates cannot be applied, which makes it difficult to elucidate its etiologic role (10). A higher number of $P$. acnes genomes have been found in tissue from Chinese, Japanese, Italian, English and German sarcoidosis patients compared to tissue of controls, suggesting involvement in disease pathogenesis (11-13). Furthermore, an increased immune response to $P$. acnes among patients with sarcoidosis was found in different studies using Japanese or German patients $(7,8,14)$. Remarkably, in recent work from our own group, we found a lower percentage of Dutch sarcoidosis patients than controls with an immunological response to $P$. acnes (15) which is conflicting with the abovementioned previous papers.

In addition to its role as possible antigen, $P$. acnes can also act as a mitogen which is demonstrated by the fact that $P$. acnes enhances immunogenicity of certain vaccines (16) and enhances cytotoxic activity toward different tumor cells (17-19). A potential mitogenic role of $P$. acnes in sarcoidosis has not previously been studied.

Based on both a possible antigenic as well as mitogenic role for $P$. acnes, we hypothesize that presence of $P$. acnes in tissue could be related to certain clinical phenotypes in sarcoidosis. We therefore examined the presence of $P$. acnes in tissue of Dutch patients with sarcoidosis using an existing $P$. acnes specific monoclonal antibody (PAB antibody) (20) and related results of immunostaining to clinical characteristics such as organ involvement and course of disease.

\section{Methods and materials}

\section{Study patients}

Unstained tissue blocks were requested from two sarcoidosis cohorts previously studied at the St Antonius Hospital (Nieuwegein, The Netherlands) $(15,21)$. The diagnosis of sarcoidosis had been established according to the criteria of the American Thoracic Society/European Respiratory Society (22). Patients were included in the study when enough residual tissue was available and when presence of granulomas could be clearly detected in the hematoxylin and eosin (H\&E) stained tissue sections. The study was 
approved by the Medical research Ethics Committees United (MEC-U) of the St Antonius Hospital (R05-08A) and written consent was obtained from all patients.

\section{Immunostaining}

$4 \mu \mathrm{M}$ thick sections were cut from the formalin-fixed paraffin-embedded tissue sections which were immunohistochemically stained with the PAB antibody; a $P$. acnes specific monoclonal antibody that reacts with cell-membrane bound lipoteichoic acid of the bacterium (20). The PAB antibody was kindly provided by Prof. dr. Eishi and colleagues, Department of Human Pathology, Tokyo Medical and Dental University, Tokyo, Japan. We followed the protocol described by Negi et al. (20), but instead of the original manual procedures the sections were stained by the use of a VENTANA BenchMark ULTRA (Ventana Medical Systems, Inc., Tucson, AZ, USA) using ultraView Universal Alkaline Phosphatase Red Detection Kit (Ventana Medical Systems, Inc.). We modified the original protocol to optimize the sensitivity and specificity of the staining results for the VENTANA BenchMark ULTRA. Shortly, sections were de-paraffinized and rehydrated followed by antigen retrieval using the hot plate heating system of the machine instead of antigen retrieval by microwave. Because mineral oil (Liquid Coverslip, Ventana Medical Systems, Inc.) covering the tissue slides was found to inhibit the reaction with $P A B$ antibody, before the primary antibody reaction with the PAB antibody, a washing step ( 3 times for 5 minutes each) in the EZ Prep buffer (Roche Nederland B.V, Woerden) was added under the Antibody Titration program selected, followed by washing 5 minutes with tap water and 5 minutes with reaction buffer (Roche Nederland B.V, Woerden, The Netherlands). The PAB antibody (crude mouse ascites fluid) was used in a concentration of 1:30.000 (diluted with DAKO REAL antibody diluent, S2022, DAKO, Glostrup, Denmark) and incubated for 16 minutes at room temperature. Instead of using peroxidase substrate diaminobenzidine (DAB) to develop the signal, ultraView Universal Alkaline Phosphatase Red Detection Kit (Ventana Medical Systems, Inc.) was used. Sections were counterstained with Mayer's hematoxylin. Detection of $P$. acnes in tissue was analyzed by a pulmonary pathologist (KS). The staining was considered positive when small round/dot like structures were seen. If such structures were detected, it was determined whether positive PAB staining was present in or outside the granulomas.

\section{Identification of $\boldsymbol{P}$. acnes related phenotypes}

To determine possible $P$. acnes related phenotypes, organ involvement, age at diagnosis and Scadding stage at diagnosis and follow up was collected from medical records of sarcoidosis patients. 
The Clinical outcome status (COS), a definition of clinical outcome in sarcoidosis established by The World Association of Sarcoidosis and Other Granulomatous disease (WASOG) (23), was determined 2 and 5 years after diagnosis. The disease status of patients was retrospectively examined and classified into resolved, minimal or persistent disease. Resolved was classified as patients showing no signs of disease anymore, so normalization of chest x-ray, pulmonary function test, laboratory tests etc. Minimal disease is defined as a disease burden of $25 \%$ or less compared to the maximum disease burden experienced by patients measured by for example pulmonary function test, Chest X-ray, biomarkers and skin lesions. For example, the worst pulmonary function test had to be improved by at least $75 \%$ to be considered minimal disease.

Furthermore, it was examined whether patients were ever treated, and if so whether they were still using medication or not (defined as no medication > one year). Patients in whom medication was increased the last year were considered worsening. Medication included all immunosuppressive systemic therapies used for sarcoidosis, including corticosteroids, DMARDS and anti-TNF $\alpha$ antibodies, except for non-steroid anti-inflammatory drugs. This results in 9 cOS scores:

1: Resolved disease, never treated

2: Resolved diseases, no treatment > one year

3: Minimal disease, never treated

4: Minimal disease, no therapy > one year

5: Persistent disease, never treated

6: Persistent disease, no therapy > one year

7: Persistent disease, current therapy but no worsening in prior year and asymptomatic

8: Persistent disease, current therapy but no worsening in prior year and symptomatic

9: persistent disease, current therapy which worsened in the prior year

Patients who died in the period over which the COS was determined were placed in COS 9. To analyze whether there was a correlation between presence of $P$. acnes and COS, we classified the COS scores into two phenotype groups: A: resolved, minimal or persistent disease without treatment ( $\operatorname{COS} 1-6)$ and B: persistent disease with need for treatment (COS 7-9).

\section{Statistical analysis}

Data was analyzed using IBM SPSS statistics version 24. An unpaired T-test was used to compare numerical data. Non-parametric tests were used for non-normally distributed data (Mann-Whitney $U$ test). Categorical data were compared using the Chi-squared test. If 
expected cell frequencies were below 5, Fisher's exact test was used for categorical data up to two categories. P-values $<0.05$ were considered significant.

\section{Results}

Characteristics of study patients and tissue samples

Formalin-fixed paraffin-embedded tissue blocks were available from 76 patients. Mean age of included patients was 44 years, $84 \%$ was Caucasian and $71 \%$ had extra pulmonary involvement. $68 \%$ and $67 \%$ were classified in phenotype group B 2 and 5 years after diagnosis respectively (Table 1 ).

Table 1. Characteristics of study patients

\begin{tabular}{|c|c|}
\hline & Sarcoidosis $(\mathrm{n}=76)$ \\
\hline Age $^{a}$ & $43.98 \pm 12.22$ \\
\hline Male sex & $42(55)$ \\
\hline Ever smoker & $43(59)$ \\
\hline Caucasian & $64(84)$ \\
\hline Medication at time of biopsy & $6(8)$ \\
\hline Third-line therapy ${ }^{b}$ & $27(36)$ \\
\hline COS group A/B ( 2 years follow up) & $23 / 49(32 / 68)$ \\
\hline COS group A/B (5 years follow up) & $15 / 31(33 / 67)$ \\
\hline $\begin{array}{l}\text { Scadding stage at time biopsy } \\
\text { (0/I/II/III/IV/unknown) }\end{array}$ & $\begin{array}{l}5 / 19 / 28 / 9 / 10 / 5 \\
(7 / 25 / 37 / 12 / 13 / 7)\end{array}$ \\
\hline Extra pulmonary involvement & $54(71)$ \\
\hline Skin & $18(24)$ \\
\hline Eyes & $7 \quad(9)$ \\
\hline Liver & $8 \quad(11)$ \\
\hline Heart & $13(17)$ \\
\hline Spleen & $3(4)$ \\
\hline Bones & $4 \quad(5)$ \\
\hline Nerve system & $15(20)$ \\
\hline Central & $6 \quad(8)$ \\
\hline Peripheral & $1(1)$ \\
\hline SFN & $10(13)$ \\
\hline
\end{tabular}

Data is shown as absolute numbers with percentage in brackets.

${ }^{a}$ Age is age at time of biopsy and is shown as mean \pm SD. ${ }^{b}$ Third-line therapy consisted of infliximab use at follow up. COS: Clinical outcome status, SFN: Small fiber neuropathy, Scadding stages: $0=$ Normal chest radiograph; I = Bilateral hilar lymphadenopathy $(\mathrm{BHL}) ; \mathrm{II}=\mathrm{BHL}$ with pulmonarv infiltrates; III = pulmonary infiltrates without $\mathrm{BHL}$; IV = fibrosis. 


\section{$P$. acnes can be detected in tissue samples of Dutch patient with sarcoidosis}

Most tissue sections used for staining originated from the lung, followed by lymph node and skin samples. $P$. acnes was detected in tissue samples from 31 of the 76 sarcoidosis patients $(41 \%)$ and was located in the granulomas in 13 samples of all patients (17\%) (Table 2, Figure 1 and Figure 2). When $P$. acnes was not detected inside granulomas, it was mostly located directly adjacent to granulomas in histiocytes and in a few cases in granuloma-free areas of the tissue. Besides lung, lymph node and skin tissue, we also found presence of $P$. acnes in bone marrow and liver tissue.

Table 2. Detection of $P$. acnes and origin of tissue used

\begin{tabular}{|c|c|c|c|}
\hline & \multirow[t]{2}{*}{$\mathbf{n}$} & \multicolumn{2}{|c|}{ Detection of $P$. acnes in: } \\
\hline & & Tissue & Granulomas \\
\hline Total number of patients ${ }^{a}$ & 76 & $31(41)$ & $13(17)$ \\
\hline Total number of tissue sections & 80 & $32(40)$ & $14(18)$ \\
\hline Lung & 32 & $10(31)$ & $7(22)$ \\
\hline VATS & 7 & $3(43)$ & $3(43)$ \\
\hline TBLB & 25 & $7(28)$ & $4(16)$ \\
\hline Lymph node & 25 & $12(48)$ & $2(8)$ \\
\hline lymphadenectomy & 14 & $9(64)$ & $1(7)$ \\
\hline mediastinoscopy & 5 & $1(20)$ & 0 \\
\hline EBUS-TBNA/needle & 6 & $2(33)$ & $1(17)$ \\
\hline Skin & 17 & $7(41)$ & $4(24)$ \\
\hline Other & 6 & $3(50)$ & $1(17)$ \\
\hline Bone marrow & 2 & $2(100)$ & 0 \\
\hline Liver & 2 & $1(50)$ & $1(50)$ \\
\hline Nasal concha & 1 & 0 & 0 \\
\hline Salivary gland & 1 & 0 & 0 \\
\hline
\end{tabular}

Data is shown as number of samples with percentages in brackets

a Of 4 of 76 patients, 2 tissue sections of different organs were stained namely: Lymph node (negative) and lung ( $P$. acnes positive in tissue and granulomas, liver (negative) and lymph node ( $P$. acnes positive in tissue), skin ( $P$. acnes positive in tissue and granulomas) and lung (negative), skin ( $P$. acnes positive in tissue and granulomas) and lung ( $P$. acnes positive in tissue and granulomas).

VATS: Video-assisted thoracoscopic surgery, TBLB: transbronchial lung biopsy, EBUS-TBNA: endobronchial ultrasound- transbronchial needle aspiration 

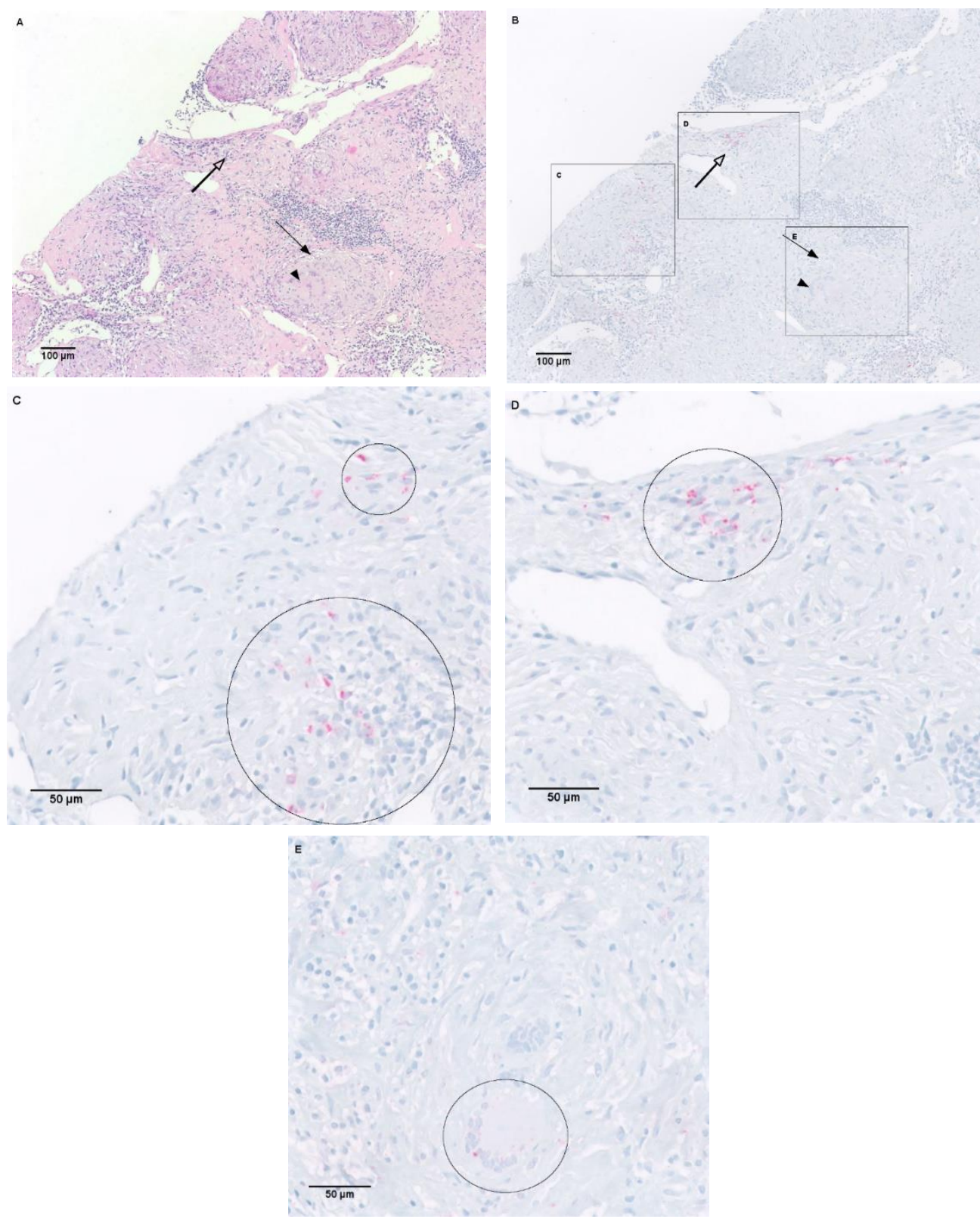

Figure 1. Presence of $P$. acnes in and around an immature granuloma of the lymph node

A. Hematoxylin and eosin (H\&E) staining of a needle lymph node biopsy including several mature granulomas. Arrow: a mature granuloma including a multinucleated giant cell (arrow head). Open arrow: an immature granuloma. B. PAB staining corresponding with the area in picture $\mathbf{A}$, including several areas with $P$. acnes-positive red signals (rectangle $\mathrm{C}$ and $\mathrm{D}$ ) and a mature granuloma negative for $P$. acnes (rectangle E). C. Higher magnification of positive $P$. acnes staining (circles) around granulomas. D. Higher magnification of positive $P$. acnes staining (circle) in an immature granuloma. E. Higher magnification of another area including a multinucleated giant cell positive for $P$. acnes. 

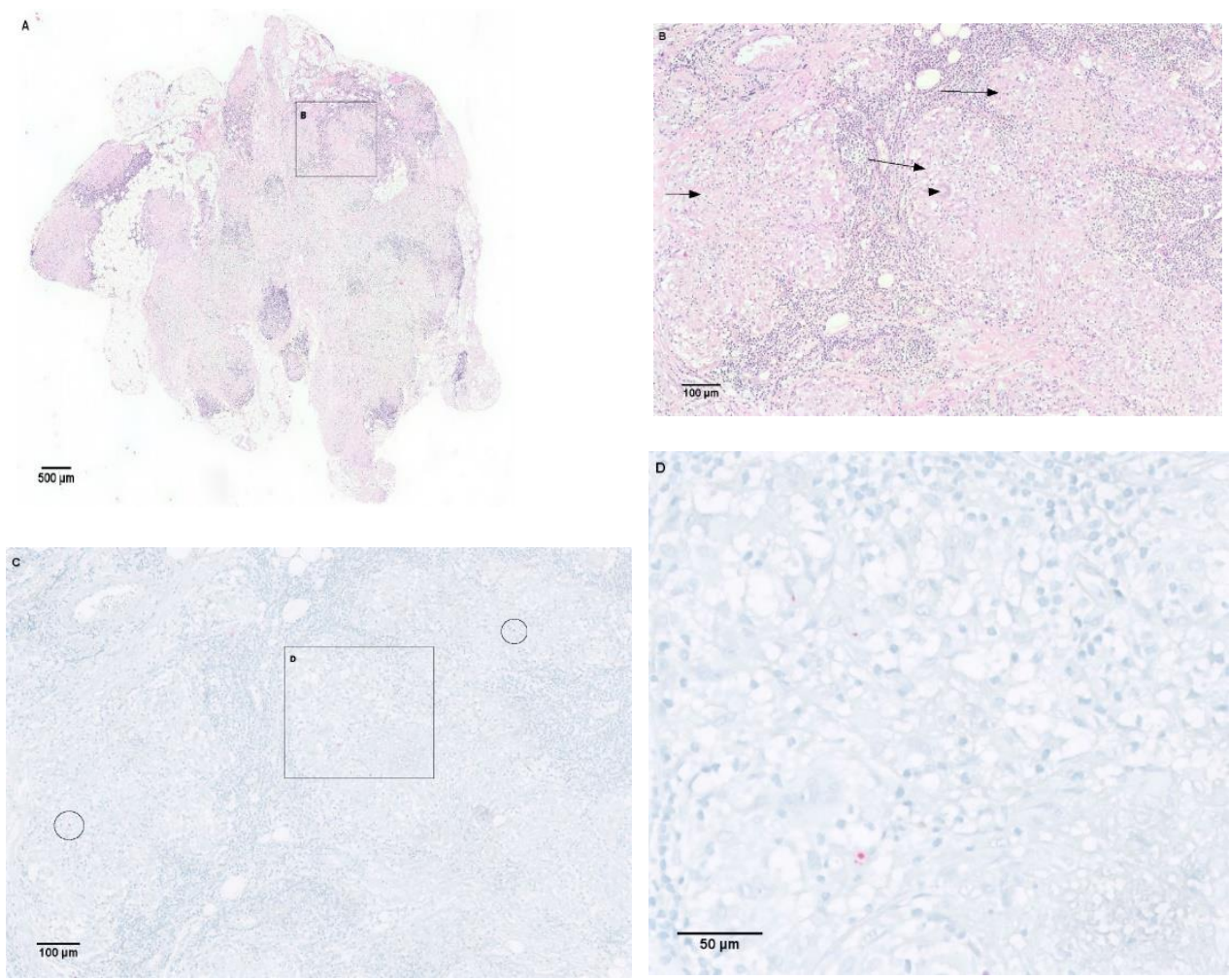

Figure 2. Presence of $P$. acnes in a mature granuloma in subcutaneous tissue of the lower eyelid

A. Overview of hematoxylin and eosin (H\&E) staining of subcutaneous tissue of the lower eyelid. B. Higher magnification of area $B$ from picture $A$, including mature granulomas (arrows) and multinucleated giant cells (arrow head). C. PAB staining of corresponding area of picture B, including several areas of $P$. acnes-positive signals (circles and rectangle D), in mature granulomas. D. Higher magnification of area D from picture $C$, with positive $P$. acnes staining in a mature granuloma.

No significant difference was observed in the frequency of $P$. acnes detected in tissue or granulomas between the different organs used in the study $(P=0.583$ and $p=0.490$, respectively). $P$. acnes was detected in tissue or granulomas in $3(43 \%)$ and $3(43 \%)$ respectively, of the 7 lung samples obtained by video-assisted thoracic surgery (VATS), and in $7(28 \%)$ and $4(16 \%)$ respectively, of the lung samples obtained by transbronchial lung biopsy (TBLB). No significant difference in presence of $P$. acnes in tissue or granulomas was observed between the different biopsy methods used for the lung samples $(P=0.648$ and $P$ $=0.157$, respectively) and lymph node samples $(P=0.167$ and $P=0.588$, respectively). 


\section{Presence of $\boldsymbol{P}$. acnes does not correlate with organ involvement}

When relating positive $P$. acnes staining results to clinical characteristics, no relation with age, sex, ethnicity, organ involvement or Scadding stage was observed (Table 3A and 3B).

\section{Presence of $\boldsymbol{P}$. acnes correlates with clinical outcome}

Presence of $P$. acnes in tissue was compared between the two COS groups defined two and five years after diagnosis. Two years after diagnosis, a trend $(P=0.093)$ towards a higher prevalence of $P$. acnes in tissue was seen in COS group B $(47 \%, 23 / 49)$ compared to COS group $A(26 \%, 6 / 23)$. When comparing presence of $P$. acnes specifically inside granulomas, also a trend $(P=0.050)$ towards a higher prevalence was seen in COS group $B$ patients $(25 \%$, 12/49) compared to COS group A patients (4\%, 1/23) (Figure 3A). COS defined after 5 years revealed a trend $(P=0.072)$ towards a higher prevalence of $P$. acnes in tissue in COS group B $(55 \%, 17 / 31)$ compared to COS group A $(27 \%, 4 / 15)$. A significantly higher percentage of patients within COS group B $(29 \%, 9 / 31)$ were positively stained for $P$. acnes inside granulomas compared to $\operatorname{COS}$ group $A$ patients $(0,0 / 15)(P=0.021$, Figure $3 B)$.
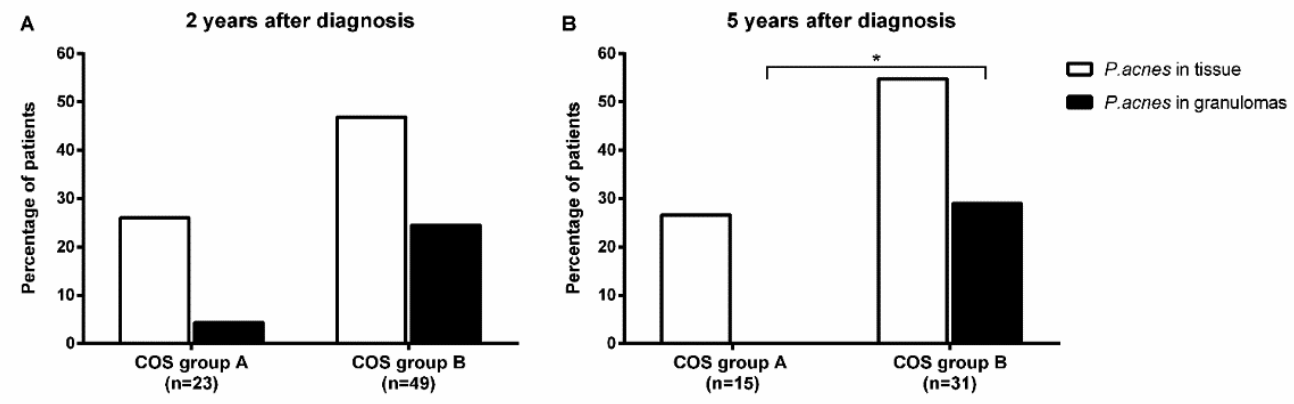

Figure 3. Frequency of $P$. acnes detected in tissue samples from sarcoidosis patients with a different clinical outcome status 2 years $(A)$ and 5 years $(B)$ after diagnosis

$\operatorname{COS}$ group $A=$ Resolved, minimal or persistent disease without treatment (COS 1-6).

$\operatorname{COS}$ group $B=$ Persistent disease with need for treatment (COS 7-9).

PAB: $P$. acnes-specific monoclonal antibodies that react with cell-membrane-bound lipoteichoic acid

Since COS group B can be a very heterogeneous group of patients, ranging from patients with remission of symptoms due to long-term corticosteroid treatment to severe therapy refractory patients requiring third-line medication, we also determined whether presence of $P$. acnes in tissue and granulomas was specifically related to patients requiring third-line medication at follow up. In a significant higher percentage of patients using infliximab, $P$. acnes was present in granulomas compared to non-third-line therapy requiring patients (33\% vs. $8 \%, P=0.009$ ) (Figure 4 ). 
Table 3A. Presence of P.acnes in tissue related to organ involvement and Scadding stage

\begin{tabular}{|c|c|c|c|}
\hline & \multicolumn{3}{|l|}{ PAB staining } \\
\hline & $\begin{array}{l}\text { Negative } \\
(\mathrm{n}=45)\end{array}$ & $\begin{array}{l}\text { Positive } \\
(n=31)\end{array}$ & $\mathrm{P}^{*}$ \\
\hline Age & $44.59 \pm 12.51$ & $43.08 \pm 11.94$ & 0.601 \\
\hline Male sex & $23(51)$ & $19(61)$ & 0.380 \\
\hline White & $38(84)$ & $26(84)$ & 1.000 \\
\hline $\begin{array}{l}\text { Extra pulmonary } \\
\text { involvement }\end{array}$ & $32(71)$ & $22(71)$ & 0.989 \\
\hline Skin & $12(27)$ & $6(19)$ & 0.461 \\
\hline Eyes & $4(9)$ & $3(10)$ & 1.000 \\
\hline Liver & $2(4)$ & $6(19)$ & 0.057 \\
\hline Heart & $8(18)$ & $5(16)$ & 0.851 \\
\hline Spleen & $2(4)$ & $1(3)$ & 1.000 \\
\hline Bones & $3(7)$ & $1(3)$ & 0.641 \\
\hline Nerve system & $11(24)$ & $4(13)$ & 0.214 \\
\hline Central & $5(11)$ & $1(3)$ & 0.391 \\
\hline Peripheral & $1(2)$ & 0 & 1.000 \\
\hline SFN & $7(16)$ & $3(10)$ & 0.514 \\
\hline $\begin{array}{l}\text { Scadding stage } \\
\text { at diagnosis }\end{array}$ & $(n=44)$ & $(n=29)$ & \\
\hline $\begin{array}{l}\text { (0/I/II/III/IV) } \\
(\%)\end{array}$ & $\begin{array}{l}3 / 13 / 19 / 5 / 4 \\
(7 / 30 / 43 / 11 / 9)\end{array}$ & $\begin{array}{l}0 / 10 / 13 / 2 / 4 \\
(0 / 35 / 45 / 7 / 14)\end{array}$ & 0.585 \\
\hline $\begin{array}{l}\text { Scadding stage } \\
\text { after } 2 \text { years }\end{array}$ & $(n=39)$ & $(n=24)$ & \\
\hline $\begin{array}{l}\text { (0/I/II/III/IV) } \\
(\%)\end{array}$ & $\begin{array}{l}11 / 4 / 12 / 5 / 7 \\
(28 / 10 / 31 / 13 / 18)\end{array}$ & $\begin{array}{l}6 / 3 / 8 / 1 / 6 \\
(25 / 13 / 33 / 4 / 25)\end{array}$ & 0.794 \\
\hline $\begin{array}{l}\text { Scadding stage } \\
\text { after } 5 \text { years }\end{array}$ & $(n=25)$ & $(n=16)$ & \\
\hline $\begin{array}{l}\text { (0/I/II/III/IV) } \\
(\%)\end{array}$ & $\begin{array}{l}5 / 2 / 4 / 6 / 8 \\
(20 / 8 / 16 / 24 / 32)\end{array}$ & $\begin{array}{l}3 / 1 / 4 / 2 / 6 \\
(19 / 6 / 25 / 13 / 38)\end{array}$ & 0.878 \\
\hline
\end{tabular}

Age is age at time of biopsy and shown as mean \pm SD

Chest $X$-rays to determine Scadding stages were missing from 3 sarcoidosis patients at diagnosis, from 13 patients 2 years after diagnosis and from 35 patients 5 years after diagnosis. Scadding stages: $0=$ Normal chest radiograph; I = Bilateral hilar lymphadenopathy $(\mathrm{BHL}) ; \mathrm{II}=\mathrm{BHL}$ with pulmonary infiltrates; III = pulmonary infiltrates without BHL; IV = fibrosis.

SFN: Small fiber neuropathy, PAB: $P$. acnes-specific monoclonal antibodies that react with cellmembrane-bound lipoteichoic acid

* A P-value regarding age was calculated using an independent samples T-test. Other P-values were calculated by the use of a Fisher's exact test, except for sex (both p-values), extra pulmonary involvement in the $P$. acnes score group, skin, heart and nerve system involvement in the $P$. acnes score group and Scadding stages 
Table 3B. Presence of P.acnes in granulomas related to organ involvement and Scadding stage

\begin{tabular}{|c|c|c|c|}
\hline & \multicolumn{3}{|c|}{ PAB staining present in granulomas } \\
\hline & $\begin{array}{l}\text { No } \\
(n=63)\end{array}$ & $\begin{array}{l}\text { Yes } \\
(n=13)\end{array}$ & $\mathrm{P}^{*}$ \\
\hline Age & $44.76 \pm 12.17$ & $40.18 \pm 12.26$ & 0.222 \\
\hline Male sex & $33(52)$ & $9(69)$ & 0.266 \\
\hline White & $52(83)$ & $12(92)$ & 0.679 \\
\hline $\begin{array}{l}\text { Extra pulmonary } \\
\text { involvement }\end{array}$ & $46(73)$ & $8(62)$ & 0.504 \\
\hline Skin & $15(24)$ & $3(23)$ & 1.000 \\
\hline Eyes & $6(10)$ & $1(8)$ & 1.000 \\
\hline Liver & $6(10)$ & $2(15)$ & 0.619 \\
\hline Heart & $12(19)$ & $1(8)$ & 0.446 \\
\hline Spleen & $2(3)$ & $1(8)$ & 0.435 \\
\hline Bones & $4(6)$ & 0 & 1.000 \\
\hline Nerve system & $14(22)$ & $1(8)$ & 0.444 \\
\hline Central & $6(10)$ & 0 & 0.582 \\
\hline Peripheral & $1(2)$ & 0 & 1.000 \\
\hline SFN & $9(14)$ & $1(8)$ & 1.000 \\
\hline $\begin{array}{l}\text { Scadding stage } \\
\text { at diagnosis }\end{array}$ & $(n=61)$ & $(n=12)$ & \\
\hline $\begin{array}{l}(0 / I / I I / I I I / I V) \\
(\%)\end{array}$ & $\begin{array}{l}3 / 19 / 29 / 5 / 5 \\
(5 / 31 / 48 / 8 / 8)\end{array}$ & $\begin{array}{l}0 / 4 / 3 / 2 / 3 \\
(0 / 33 / 25 / 17 / 25)\end{array}$ & 0.277 \\
\hline $\begin{array}{l}\text { Scadding stage } \\
\text { after } 2 \text { years }\end{array}$ & $(n=53)$ & $(n=10)$ & \\
\hline $\begin{array}{l}\text { (0/I/II/III/IV) } \\
(\%)\end{array}$ & $\begin{array}{l}14 / 6 / 19 / 5 / 9 \\
(26 / 11 / 36 / 9 / 17)\end{array}$ & $\begin{array}{l}3 / 1 / 1 / 1 / 4 \\
(30 / 10 / 10 / 10 / 40)\end{array}$ & 0.408 \\
\hline $\begin{array}{l}\text { Scadding stage } \\
\text { after } 5 \text { years }\end{array}$ & $(n=34)$ & $(n=7)$ & \\
\hline (0/I/II/III/IV) & $7 / 2 / 8 / 7 / 10$ & 1/1/0/1/4 & 0.441 \\
\hline (\%) & $(21 / 6 / 24 / 21 / 29)$ & $14 / 14 / 0 / 14 / 57$ & \\
\hline
\end{tabular}

Age is age at time of biopsy and shown as mean $\pm S D$

Chest X-rays to determine Scadding stages were missing from 3 sarcoidosis patients at diagnosis, from 13 patients 2 years after diagnosis and from 35 patients 5 years after diagnosis. Scadding stages: $0=$ Normal chest radiograph; I = Bilateral hilar lymphadenopathy $(\mathrm{BHL}) ; \mathrm{II}=\mathrm{BHL}$ with pulmonary infiltrates; III = pulmonary infiltrates without $\mathrm{BHL}$; IV = fibrosis.

SFN: Small fiber neuropathy, PAB: $P$. acnes-specific monoclonal antibodies that react with cellmembrane-bound lipoteichoic acid

* A P-value regarding age was calculated using an independent samples T-test. Other P-values were calculated by the use of a Fisher's exact test, except for sex (both p-values), extra pulmonary involvement in the $P$. acnes score group, skin, heart and nerve system involvement in the $P$. acnes score group and Scadding stages 


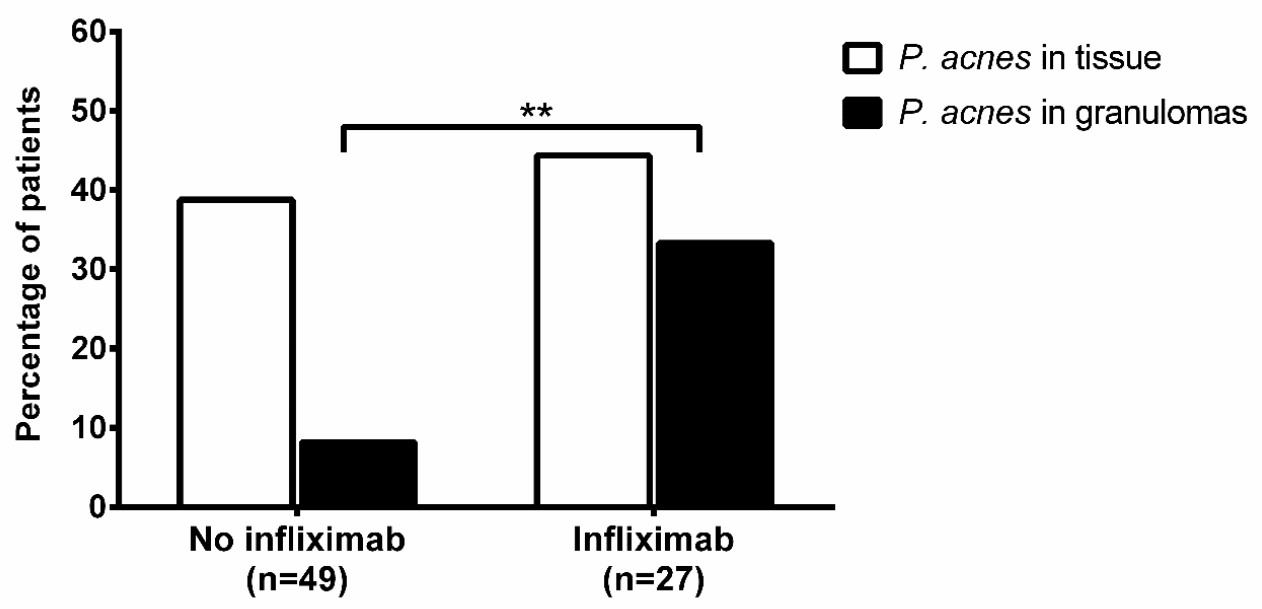

Figure 4. Frequency of $P$. acnes detected in biopsy samples from sarcoidosis patients with or without third-line therapy (infliximab) during follow up.

A significantly higher percentage of third-line therapy requiring patients (all using infliximab) showed presence of $P$. acnes in granulomas than patients who did not require third-line therapy $(P=0.009)$.

PAB: $P$. acnes-specific monoclonal antibodies that react with cell-membrane-bound lipoteichoic acid.

\section{Discussion}

In this study we demonstrated that $P$. acnes is present in granulomas of Dutch patients with sarcoidosis, which is in line with previous studies in Japanese and German sarcoidosis patients (20). Furthermore, to the best of our knowledge, our study is the first to show a relation between presence of $P$. acnes and clinical outcome in sarcoidosis. Regardless of whether the role of $P$. acnes might be antigenic or mitogenic, this data adds to the rational that $P$. acnes might be involved in the disease pathogenesis of sarcoidosis.

Negi et al. (20) previously examined the presence of $P$. acnes in tissue samples from sarcoidosis patients, using the same $P A B$ antibody as used in the current study. A remarkable difference was found in percentage of $P$. acnes positive sarcoidosis patients. They found $P$. acnes in granulomas in $57 \%$ of the 77 lung samples from Japanese sarcoidosis patients whereas we found $P$. acnes in granulomas in $22 \%$ of the 32 lung samples from Dutch sarcoidosis patients. This difference could be partially explained by the lower proportion of VATS samples (35\% in their study compared to $22 \%$ in our study). Negi et al. described that $P$. acnes in granulomas was more frequent detected in VATS samples compared to TBLB samples, probably due to the larger size of VATS samples. Similar to the 
lung samples, the percentage of Dutch patients with presence of $P$. acnes in granulomas of lymph node samples ( $8 \%$ ) was lower compared to Japanese and German patients ( $88 \%$ and $89 \%$ respectively). Although the difference between Japanese and Dutch patients may be explained by difference in ethnicity, this is not a plausible explanation for the difference between German and Dutch patients. The difference in the detection frequency of $P$. acnes in granulomas can possible be caused by a lower sensitivity of immunostaining method used in our study. Therefore, future studies will have to compare the detection sensitivity of $P$. acnes in granulomas using the different immunostaining methods. It is however important to state that the localization and pattern of $P$. acnes within and outside granulomas was comparable with the study of Negi et al. Specifically, we observed that presence of $P$. acnes outside granulomas was most frequently detected directly adjacent to granulomas but also in granuloma-free parts of the tissue in a few cases. Furthermore, the pattern within granulomas was comparable, with more intense dot like structures in immature granulomas and more sparsely- distributed staining or even no staining in mature granulomas.

A new and clinical relevant finding, in our opinion, is the fact that this is the first study that shows an association between presence of $P$. acnes and clinical outcome in patients with sarcoidosis. We observed that presence of $P$. acnes in tissue and in granulomas is more frequently found in patients with a chronic disease course requiring chronic treatment. Several studies demonstrated the mitogenic properties of $P$. acnes on different immune cells $(16,24,25)$. Our study was not aimed to prove that $P$. acnes has a specific etiologic role in sarcoidosis. However, in our opinion, the results do suggest that at least a potential mitogenic role of $P$. acnes may contribute to sarcoidosis disease pathogenesis. It is tempting to speculate that presence of $P$. acnes in or around granulomas can enhance an ongoing inflammatory reaction in sarcoidosis, contributing to perpetuation of the inflammatory granulomatous response seen in some patients. If this holds true, it is interesting to see whether decreasing the bacterial load of $P$. acnes using antibiotics can be beneficial in a subgroup of patients with sarcoidosis.

A case report already described a good effect of clarithromycin on fever, joint pain, FDG uptake on PET-CT, CRP and S-IL2R levels in a sarcoidosis patient in whom $P$. acnes was present in granulomas (26). Moreover, a retrospective study described good responses on treatment with minocycline in $P$. acnes positive cutaneous sarcoidosis patients (27). When we examined severe therapy refractory patients for presence of $P$. acnes, we observed that patients requiring infliximab treatment at follow up, had more often presence of $P$. acnes in granulomas at diagnosis compared to patients without treatment or treated with first or second line treatment. If antibacterial treatment in sarcoidosis patients with presence of $P$. acnes in tissue and granulomas is beneficial, the requirement of $3^{\text {rd }}$ line treatments (e.g. infliximab) may be prevented. 
Currently, in a randomized controlled clinical trial (J-ACNES ), the effect of antibacterial drugs in addition to standard corticosteroid therapy in cardiac sarcoidosis patients is examined (28). However, in this trial presence of $P$. acnes in myocardial tissue was not an inclusion criterion. Therefore, in future studies it would be interesting to have information on the presence or absence of $P$. acnes in these patients while investigating the effect of antibiotic therapy.

A limitation of the study was that the COS after five years could not be determined in all patients. However, since the proportion of patients within COS group A and B was quite similar after two and five years and the results regarding association with $P$. acnes staining as well, we assume that this analysis on a smaller group of patients has not introduced a bias. A disadvantage of using COS is the fact that disease status and medication use have been retrospectively assessed. Since we only scored whether medication was used or not, we have no information on patients who declined the use of medication while they actually needed it.

Another limitation is that we probably have a more severe patient group than other general hospitals, since the Antonius Hospital is an national referral center for ILD and Sarcoidosis. As a consequence we had very few patients in the resolved and minimal disease COS groups. For this reason we had not enough patients in every group to adequately analyze whether disease status alone, irrespective of use of medication, was associated with presence of $P$. acnes in tissue and granulomas. However, instead of disease status we think that need for treatment could be of more value regarding presence of $P$. acnes. If we want to further explore the use of antibacterial therapy, in our opinion, it is more relevant to focus on patients who actually need treatment.

In future studies, it would be interesting to add a second detection method, such as PCR, to the immunostaining. To accurately compare the results, development and use of a primer specific to LTA of the $P$. acnes bacteria would be valuable.

To conclude, this study confirms the presence of $P$. acnes in tissue and granulomas of respectively $40 \%$ and $17 \%$ of Dutch patients with sarcoidosis. Interestingly, the presence of $P$. acnes inside granulomas of Dutch sarcoidosis patients was associated with a chronic disease phenotype and requirement of treatment. Regardless of whether the role of $P$. acnes is antigenic or mitogenic, our data contribute to the premise that it is relevant to further explore antibacterial therapy as a treatment option for a subset of sarcoidosis patients. 


\section{References}

1. Ramachandraiah V, Aronow W, Chandy D. Pulmonary sarcoidosis: an update. Postgrad Med. 2017 Jan 2;129(1):149-58.

2. Spagnolo P, Rossi G, Trisolini R, Sverzellati N, Baughman RP, Wells AU. Pulmonary sarcoidosis. Lancet Respir Med. 2018;

3. Baughman RP, Lower EE. Treatment of Sarcoidosis. Clin Rev Allergy Immunol. 2015 Aug 22;49(1):79-92.

4. Esteves T, Aparicio G, Garcia-Patos V. Is there any association between Sarcoidosis and infectious agents?: a systematic review and meta-analysis. BMC Pulm Med. 2016 Nov 28;16(1):165.

5. Zhou Y, Wei YR, Zhang Y, Du SS, Baughman RP, Li HP. Real-time quantitative reverse transcription-polymerase chain reaction to detect propionibacterial ribosomal RNA in the lymph nodes of Chinese patients with sarcoidosis. Clin Exp Immunol. 2015 Sep;181(3):511-7.

6. Ebe Y, Ikushima S, Yamaguchi T, Kohno K, Azuma A, Sato K, et al. Proliferative response of peripheral blood mononuclear cells and levels of antibody to recombinant protein from Propionibacterium acnes DNA expression library in Japanese patients with sarcoidosis. Sarcoidosis Vasc Diffuse Lung Dis. 2000;17(3):256-65.

7. Yorozu P, Furukawa A, Uchida K, Akashi T, Kakegawa T, Ogawa T, et al. Propionibacterium acnes catalase induces increased Th1 immune response in sarcoidosis patients. Respir Investig. 2015 Jul;53(4):161-9.

8. Schupp JC, Tchaptchet S, Lutzen N, Engelhard P, Muller-Quernheim J, Freudenberg $M A$, et al. Immune response to Propionibacterium acnes in patients with sarcoidosis--in vivo and in vitro. BMC Pulm Med. 2015 Jul 24;15:75-7.

9. Eishi Y. Etiologic link between sarcoidosis and Propionibacterium acnes. Respir Investig. 2013 Jun;51(2):56-68.

10. Ishige I, Eishi Y, Takemura T, Kobayashi I, Nakata K, Tanaka I, et al. Propionibacterium acnes is the most common bacterium commensal in peripheral lung tissue and mediastinal lymph nodes from subjects without sarcoidosis. Sarcoidosis, Vasc Diffus lung Dis Off J WASOG. 2005 Mar;22(1):33-42. 
11. Zhao MM, Du SS, Li QH, Chen T, Qiu H, Wu Q, et al. High throughput 16SrRNA gene sequencing reveals the correlation between Propionibacterium acnes and sarcoidosis. Respir Res. 2017 Feb 1;18(1).

12. Ishige I, Usui Y, Takemura T, Eishi Y. Quantitative PCR of mycobacterial and propionibacterial DNA in lymph nodes of Japanese patients with sarcoidosis. Lancet. 1999 Jul 10;354(9173):120-3.

13. Eishi $Y$, Suga M, Ishige I, Kobayashi D, Yamada T, Takemura T, et al. Quantitative analysis of mycobacterial and propionibacterial DNA in lymph nodes of Japanese and European patients with sarcoidosis. J Clin Microbiol. 2002;40(1):198-204.

14. Furusawa H, Suzuki Y, Miyazaki Y, Inase N, Eishi Y. Th1 and Th17 immune responses to viable Propionibacterium acnes in patients with sarcoidosis. Respir Investig. 2012 Sep;50(3):104-9.

15. Beijer E, Kraaijvanger R, Eishi Y, Meek B, Veltkamp M. Trigger Related Phenotypes in Sarcoidosis, abstract nr: O3-5. Sci Progr WASOG/JSSOG2019. 2019;38.

16. Teixeira D, Ishimura ME, Apostólico J de S, Viel JM, Passarelli VC, Cunha-Neto E, et al. Propionibacterium acnes enhances the immunogenicity of hivbr18 human immunodeficiency virus-1 vaccine. Front Immunol. 2018 Feb 7;9(FEB).

17. Ghaffar A, Cullen RT, Woodruff MFA. Further analysis of the anti-tumour effect in vitro of peritoneal Exudate cells from mice treated with corynebacterium parvum. Br J Cancer. 1975;31(1):15-24.

18. Keller R, Keist R, van der Meide PH. Modulation of tumoricidal activity, induced in bone-marrow-derived mononuclear phagocytes by interferon $\gamma$ or Corynebacterium parvum, by interferon $\beta$, tumor necrosis factor, prostaglandin E2, and transforming growth factor $\beta$. Int J Cancer. 1991;49(5):796-800.

19. Ananias RZ, Rodrigues EG, Braga EG, Squaiella CC, Mussalem JS, Longhini ALF, et al. Modulatory effect of killed Propionibacterium acnes and its purified soluble polysaccharide on peritoneal exudate cells from C57BI/6 mice: Major NKT cell recruitment and increased cytotoxicity. Scand J Immunol. 2007 Jun;65(6):538-48.

20. Negi M, Takemura T, Guzman J, Uchida K, Furukawa A, Suzuki Y, et al. Localization of propionibacterium acnes in granulomas supports a possible etiologic link between sarcoidosis and the bacterium. Mod Pathol. 2012 Sep;25(9):1284-97. 
21. Vorselaars AD, Crommelin HA, Deneer VH, Meek B, Claessen AM, Keijsers RG, et al. Effectiveness of infliximab in refractory FDG PET-positive sarcoidosis . Eur Respir J. 2015 Jul;46(1):175-85.

22. Costabel U, Hunninghake GW. ATS/ERS/WASOG statement on sarcoidosis. Sarcoidosis Statement Committee. American Thoracic Society. European Respiratory Society. World Association for Sarcoidosis and Other Granulomatous Disorders. Eur Respir J. 1999;14(4):735-7.

23. Baughman RP, Nagai S, Balter M, Costabel U, Drent M, Du Bois R, et al. Defining the clinical outcome status (COS) in sarcoidosis: Results of WASOG Task Force. Sarcoidosis Vasc Diffus Lung Dis. 2011;28(1):56-64.

24. Yeon SJ, Matsumoto SE, Yamashita M, Tomimatsu K, Teruya K, Katakura Y, et al. Propionibacterium acnes acts as an adjuvant in in vitro immunization of human peripheral blood mononuclear cells. Biosci Biotechnol Biochem. 2007;71(8):19639.

25. Mussalem JS, Squaiella-Baptistão CC, Teixeira D, Yendo TM, Thies FG, Popi AF, et al. Adjuvant effect of killed propionibacterium acnes on mouse peritoneal B-1 lymphocytes and their early phagocyte differentiation. PLoS One. 2012 Mar 20;7(3).

26. Takemori N, Nakamura M, Kojima M, Eishi Y. Successful treatment in a case of Propionibacterium acnes-associated sarcoidosis with clarithromycin administration: a case report . J Med Case Rep. 2014 Jan 15;8:15.

27. Inoue $Y$, Teraki Y. Association of Propionibacterium acnes with the efficacy of minocycline therapy for cutaneous sarcoidosis. Int J Dermatol. 2020;

28. Ishibashi K, Eishi Y, Tahara N, Asakura M, Sakamoto N, Nakamura K, et al. Japanese antibacterial drug management for cardiac Sarcoidosis (J-ACNES): A multicenter, open-label, randomized controlled study. J Arrhythmia. 2018;34(5):520-6. 


Chapter 8

Detection of Propionibacterium acnes in granulomas of patients with either hypersensitivity pneumonitis or vasculitis reveals that its presence is not unique for sarcoidosis

\author{
Els Beijer \\ Kees A. Seldenrijk \\ Bob Meek \\ Jan Damen \\ Marian J.R. Quanjel \\ Jan C. Grutters \\ Marcel Veltkamp
}

This chapter was accepted as a letter in ERJ open research, 2021 Jan 1;930-2020 


\section{Introduction}

Granulomas are compact organized structures of different immune cells including macrophages, lymphocytes and plasma cells, thought to be formed when (foreign) antigens cannot be cleared. The differential diagnosis of a granulomatous lesion is broad and includes infectious etiologies, malignancy and inflammatory disorders like vasculitis, hypersensitivity pneumonitis and sarcoidosis (1).

Propionibacterium acnes ( $P$. acnes) is a gram positive bacteria that is a commensal of the skin (2). Studies have demonstrated that $P$. acnes is also able to induce granulomas (3). Furthermore, $P$. acnes is suggested to be involved in the pathogenesis of sarcoidosis, a complex inflammatory disease mainly involving the lungs and lymph nodes, characterized by non-caseating granulomas (4).

Although presence of $P$. acnes has already been shown in granulomas of sarcoidosis patients (5), it is unknown whether this bacterium can also be found in granulomatous disorders with frequent involvement of the lungs other than sarcoidosis such as hypersensitivity pneumonitis (HP), Granulomatosis with polyangiitis (GPA) and Eosinophilic granulomatosis with polyangiitis (EGPA).

To investigate whether presence of $P$. acnes in granulomas is specific for sarcoidosis we examined granulomatous tissue of HP, GPA and EGPA patients for presence of $P$. acnes.

\section{Methods}

Tissue blocks were collected from patients with HP, GPA and EGPA who participated in our biobank study. Patients were included in the study when enough residual tissue was available and when granulomas could be detected in the haematoxylin stained tissue sections. Tissue blocks of 35 patients with HP and of 13 patients with (E)GPA were collected. Tissue blocks of all HP and 9 (E)GPA patients showed granulomas and had enough tissue left to be included in the study. The study was approved by the Medical research Ethics Committees United (MEC-U) of the St. Antonius Hospital (R05-08A) and written consent was obtained from all patients. Formalin fixed, paraffin embedded tissue sections were immunohistochemically stained with the PAB antibody; a $P$. acnes specific monoclonal antibody that reacts with cell-membrane bound lipoteichoic acid (LTA) of the bacterium (5). Full methods are described elsewhere (6). Difference in presence of $P$. acnes between the patients groups was compared using the Chi-squared test. An independent sample T-test was used to compare BAL lymphocytes between HP patients. Fisher's exact test was used to compare presence of $P$. acnes in granulomas of HP patients with and without an known inducing agent. P-values $<0.05$ were considered significant. 


\section{Results}

In total, 35 patients with HP and 9 patients with (E)GPA were included in the study (Table 1.) Presence of $P$. acnes in tissue was found in $57.1 \%$ of HP patients $(20 / 35)$ and in $33.3 \%$ of (E)GPA patients (3/9). More specifically, presence of $P$. acnes was observed inside granulomas of $25.7 \%$ HP patients (9/35) and of 11.1\% (E)GPA patients (1/9). (Figure 1 and Figure 2). Results between the diagnostic groups were not statistically significant $(P=0.272$ and $\mathrm{P}=0.659$ for presence of $P$. acnes in tissue and granulomas respectively). Moreover, the percentages of patients with presence of $P$. acnes in tissue or granulomas was comparable with a previously described Dutch sarcoidosis cohort (Figure 3).

Table 1. Characteristics of study patients

\begin{tabular}{cll}
\hline & HP $(\mathbf{n}=\mathbf{3 5})$ & (E)GPA $(\mathbf{n}=9)$ \\
\hline Age (mean \pm SD) & $58.2 \pm 9.2$ & $51.6 \pm 14.7$ \\
\hline Male sex & $17(48.6)$ & $6(66.7)$ \\
\hline Origin of tissue & & $6(66.7)$ \\
\hline Lung & $34(97.1)$ & 0 \\
\hline Lymph node & $1(2.9)$ & $1(11.1)$ \\
\hline Skin & 0 & $2(22.2$ \\
\hline Nose & 0 & NA \\
\hline Inducing agent & $14(40.0)$ & NA \\
\hline Birds & $3(8.6)$ & NA
\end{tabular}

Data is shown as absolute values with percentages in brackets. HP: hypersensitivity pneumonitis, (E)GPA:

(Eosinophilic) granulomatosis with polyangiitis, NA: not applicable 

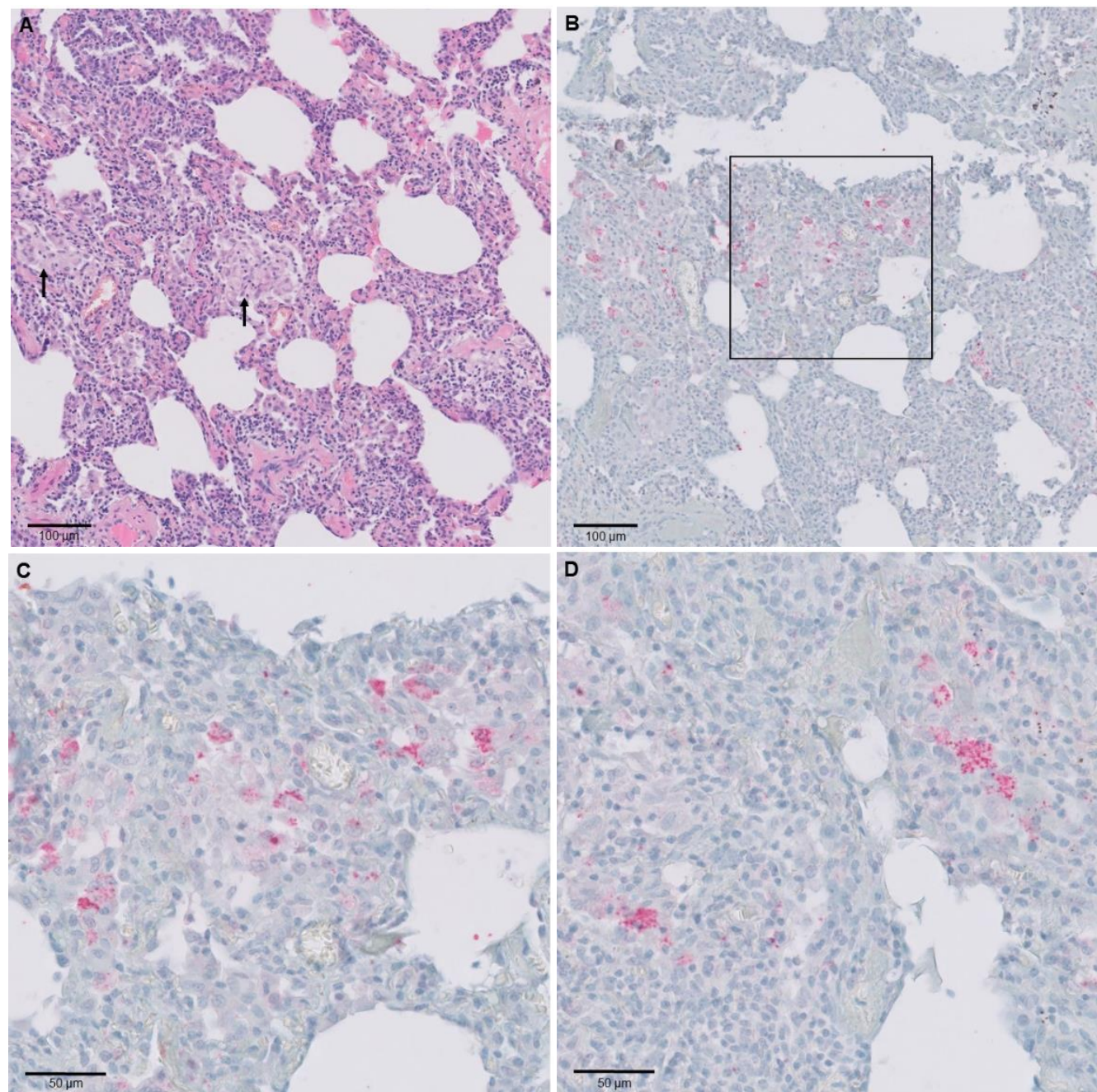

Figure 1. Presence of $P$. acnes in tissue and granulomas of an HP patient.

A. Hematoxylin and eosin stain (HE) stain of lung tissue. The black arrows show granulomas. B. Positive PAB staining (in red) in the granulomas corresponding with picture A. C. Higher magnification corresponding with the square in picture B. D. Area of positive PAB staining outside granulomas. HP: hypersensitivity pneumonitis, PAB: P. acnes specific monoclonal antibody that reacts with cell-membrane bound lipoteichoic acid (LTA) of the bacterium. 

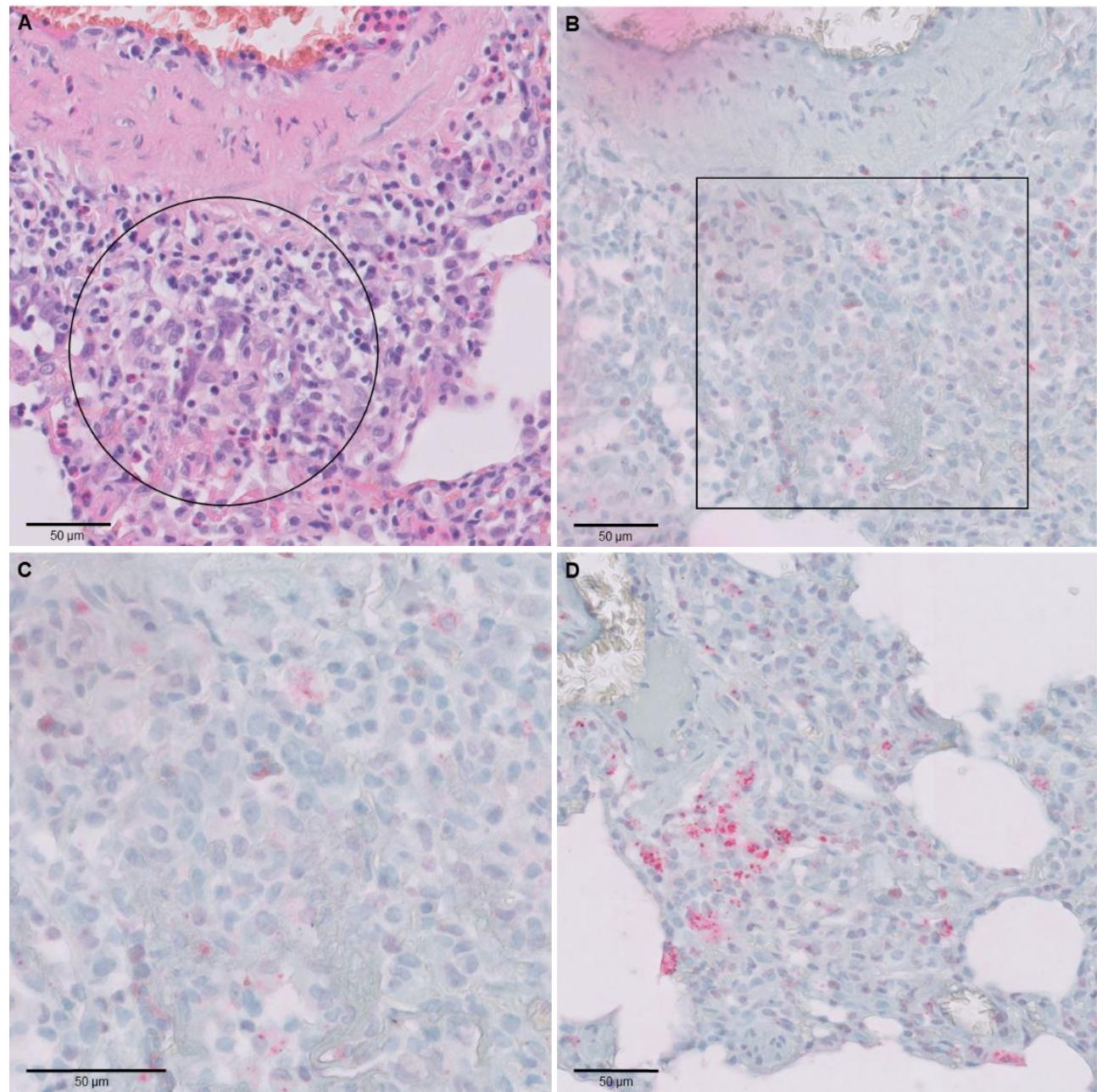

Figure 2. Presence of $P$. acnes in tissue and granulomas of an EGPA patient.

A. Hematoxylin and eosin stain (HE) stain of lung tissue, with an immature granuloma indicated by the circle. B. Positive $P A B$ staining (in red) in the granuloma corresponding with picture A. C. Higher magnification corresponding with the square in picture B. D. Area of positive PAB staining outside granulomas.

EGPA: Eosinophilic granulomatosis with polyangiitis, PAB: $P$. acnes specific monoclonal antibody that reacts with cell-membrane bound lipoteichoic acid (LTA) of the bacterium. 


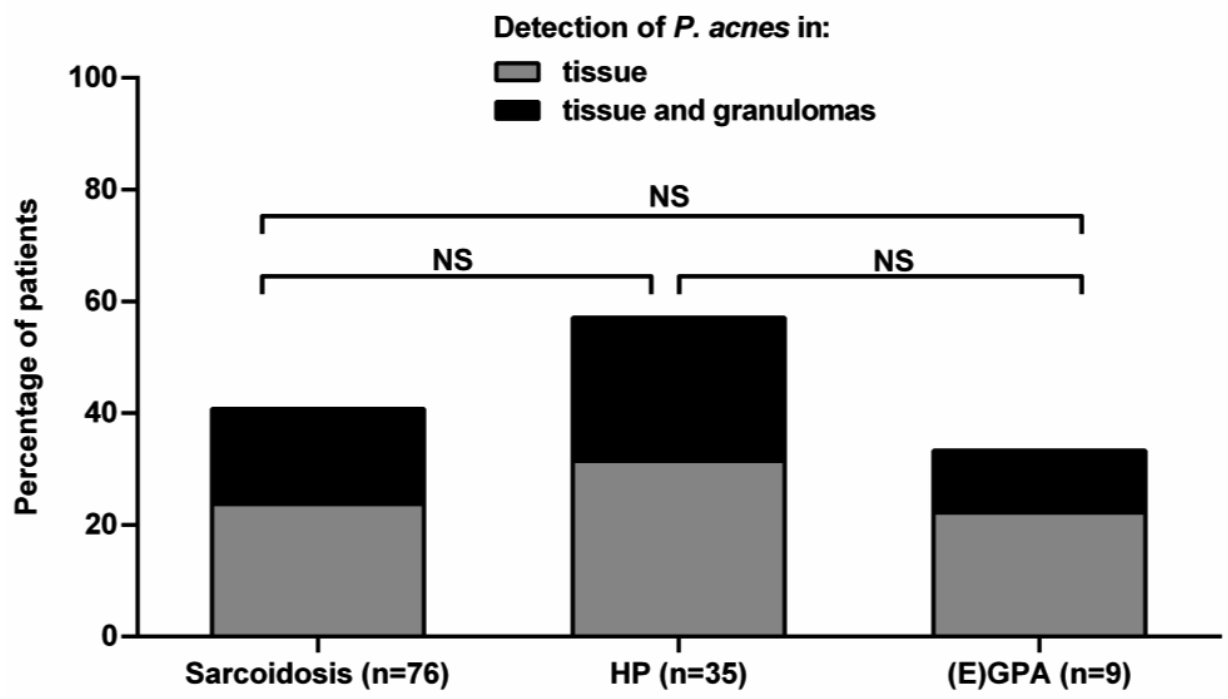

Figure 3. Percentage of patients with presence of $P$. acnes in tissue or in tissue and granulomas.

The sarcoidosis group was previously described (6). No significant difference was observed between the three groups regarding $P$. acnes in tissue or $P$. acnes in granulomas $(P=0.210$ and $P=0.460$ respectively).

HP: hypersensitivity pneumonitis, (E)GPA: (Eosinophilic) granulomatosis with polyangiitis, PAB: P. acnes specific monoclonal antibody that reacts with cell-membrane bound lipoteichoic acid (LTA) of the bacterium, NS: non-significant.

As presence of $P$. acnes appeared not to be specific to sarcoidosis and considering the known attributed mitogenic properties of this bacteria (7), we further explored such a role for $P$. acnes in our study by assessing BAL lymphocytosis in the patients with HP. Interestingly, a higher percentage of lymphocytes was indeed observed in HP patients stained positively for $P$. acnes in granulomas compared to HP patients without $P$. acnes staining in granulomas $(70.3 \%$ vs $41.3 \%, P=0.018)$ (Figure 4$)$. The percentage of patients with presence of $P$. acnes in granulomas did not significantly differ between the HP group in which an inducing agent was known compared to the HP group in which the inducing agent was unknown $(35.3 \%$ vs $16.7 \%, \mathrm{P}=0.264)$. 


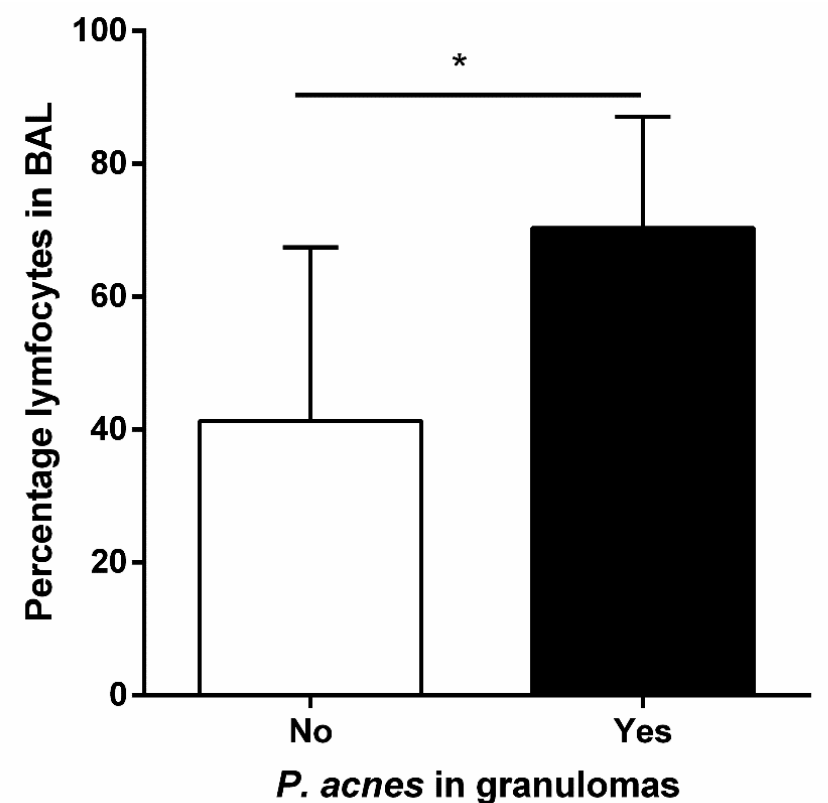

Figure 4. Lymphocyte percentage in BAL of HP patients with and without presence of $P$. acnes in granulomas.

A significantly higher percentage of lymphocytes was observed in HP patients stained positively for $P$. acnes in granulomas compared to HP patients without $P$. acnes staining in granulomas $(70.3 \%$ vs $41.3 \%, P=$ 0.018).

BAL: Bronchoalveolar lavage, HP: hypersensitivity pneumonitis

\section{Discussion}

Up to now, considering granulomatous diseases, $P$. acnes has solely been related to the pathogenesis of sarcoidosis (8). Presence of $P$. acnes has been demonstrated in tissue and granulomas of Japanese, German and Dutch sarcoidosis patients $(5,6)$. To the best of our knowledge, this is the first study that demonstrates that $P$. acnes can also be detected in tissue and granulomas of patients with HP and vasculitis. If presence of $P$. acnes is not disease specific, as our data suggests, one can debate whether $P$. acnes has an antigenic role in sarcoidosis pathogenesis. Regarding HP and (E)GPA pathogenesis no data is available suggesting an antigenic role for $P$. acnes. However, data on a possible mitogenic role for $P$. acnes have been described $(7,9)$. The higher percentage of lymphocytes observed in BAL of HP patients with presence of $P$. acnes in granulomas, supports the hypothesis that $P$. acnes may indeed act as an mitogen by enhancing lymphocyte proliferation. Moreover, since we 
observed presence of $P$. acnes in granulomas of HP patients in which a causal agent was previously identified it is unlikely that $P$. acnes act as a specific agent in HP.

The PAB antibody that has been used in this study reacts with cell-membrane bound lipoteichoic acid (LTA) of the $P$. acnes bacteria. LTA is a cell wall polymer of gram-positive bacteria and plays a role in bacterial growth, membrane homeostasis and virulence (10). Furthermore, LTAs have shown to be immunogenic (11) and activate the innate immune system via toll-like receptor 2 (TLR2) and NOD-like receptor family pyrin domain containing 6 (NLRP6) $(12,13)$, key receptor families involved in the innate immune defense against invading pathogens. Interleukin-18 production can be stimulated following activation of NLRP6 (13). Results of several papers suggest that TLR2 and interleukin-18 are at least partly involved in granuloma formation $(14,15)$ and in vitro and in vivo models have indeed shown that $P$. acnes is able to induce granulomas (3). It is therefore possible that $P$. acnes is not a specific trigger of sarcoidosis, HP and (E)GPA, but that its LTA contributes to inflammation and granuloma formation.

A limitation of the study is that no control group with healthy individuals was included in the study. It is however difficult to include an appropriate control group in the study, as healthy controls would usually not show granulomas in tissue. Another limitation was that we have not been able to analyze the disease course in HP patients due to the small sample size in combination with too much missing follow-up data. Furthermore, also the sample size of vasculitis patients from whom suitable tissue was available was too small to perform sub analysis on disease course or BAL. Consequently, we were unable to examine whether $P$. acnes is related to a chronic disease course in (E)GPA and HP as well. Due to the low samples sizes of the HP and EGPA group, the power to detect a difference with the sarcoidosis group was too small to conclude that those diseases and HP patients with and without a known inducing agent, do not really differ regarding presence of $P$. acnes in granulomas. Although the percentages of $P$. acnes in granulomas of the non-sarcoidosis group were quite comparable to the sarcoidosis group, further studies using a higher number of patients are needed to clarify whether there is really no difference in presence of $P$. acnes between those diseases. Last, in this study we only examined LTA of the $P$. acnes bacteria. It is plausible that LTAs of other gram positive bacteria can also be found in granulomas. Future studies will have to determine whether granulomas are uniquely related to LTAs of $P$. acnes or can be attributed to LTAs in general.

To conclude, we have shown that presence of $P$. acnes in granulomas is not unique for sarcoidosis but can also be found in patients with HP and EGPA. We hypothesize that $P$. acnes may be involved in the disease pathogenesis of those granulomatous diseases in a mitogenic way. Future studies are needed to determine the precise role of $P$. acnes and other LTAs in those granulomatous diseases. 


\section{Acknowledgements}

We would like to thank the research group of Y. Eishi (department of Human Pathology, Tokyo Medical and Dental University Graduate school, Tokyo, Japan) who kindly provided the PAB antibody. 


\section{References}

1. Shah KK, Pritt BS, Alexander MP. Histopathologic review of granulomatous inflammation. Vol. 7, Journal of Clinical Tuberculosis and Other Mycobacterial Diseases. Elsevier Ltd; 2017. p. 1-12.

2. Leheste JR, Ruvolo KE, Chrostowski JE, Rivera K, Husko C, Miceli A, et al. P. acnesdriven disease pathology: Current knowledge and future directions. Vol. 7, Frontiers in Cellular and Infection Microbiology. Frontiers Media S.A.; 2017.

3. lio $\mathrm{K}$, lio $\mathrm{T}$, Okui $\mathrm{Y}$, Ichikawa $\mathrm{H}$, Tanimoto $\mathrm{Y}$, Miyahara $\mathrm{N}$, et al. Experimental Pulmonary Granuloma Mimicking Sarcoidosis Induced by Propionibacterium Acnes in Mice. Acta Med Okayama. 2010;64(2).

4. Grunewald J, Grutters JC, Arkema E V., Saketkoo LA, Moller DR, Müller-Quernheim J. Sarcoidosis. Nat Rev Dis Prim. 2019 Dec 1;5(1).

5. Negi M, Takemura T, Guzman J, Uchida K, Furukawa A, Suzuki Y, et al. Localization of propionibacterium acnes in granulomas supports a possible etiologic link between sarcoidosis and the bacterium. Mod Pathol. 2012 Sep;25(9):1284-97.

6. Beijer E, Seldenrijk K, Eishi Y, Uchida K, Damen J, Grutters JC, et al. Presence of Propionibacterium acnes in granulomas associates with a chronic disease course in Dutch sarcoidosis patients. ERJ Open Res. 2020 Jan 1;486-2020.

7. Jappe U, Ingham E, Henwood J, Holland KT. Propionibacterium acnes and inflammation in acne; P. acnes has T-cell mitogenic activity. Br J Dermatol. 2002 Feb;146(2):202-9.

8. Eishi Y. Etiologic link between sarcoidosis and Propionibacterium acnes . Respir Investig. 2013 Jun;51(2):56-68.

9. Yeon SJ, Matsumoto SE, Yamashita M, Tomimatsu K, Teruya K, Katakura Y, et al. Propionibacterium acnes acts as an adjuvant in in vitro immunization of human peripheral blood mononuclear cells. Biosci Biotechnol Biochem. 2007;71(8):19639.

10. Percy MG, Gründling A. Lipoteichoic Acid Synthesis and Function in Gram-Positive Bacteria. Annu Rev Microbiol. 2014 Sep 8;68(1):81-100.

11. Knox KW, Wicken AJ. Immunological properties of teichoic acids. Vol. 37, 
Bacteriological Reviews. American Society for Microbiology (ASM); 1973. p. 215-57.

12. Mitchell JA, Paul-Clark MJ, Clarke GW, McMaster SK, Cartwright N. Critical role of toll-like receptors and nucleotide oligomerisation domain in the regulation of health and disease. Vol. 193, Journal of Endocrinology. J Endocrinol; 2007. p. 323-30.

13. Hara H, Seregin SS, Yang D, Fukase K, Chamaillard M, Alnemri ES, et al. The NLRP6 Inflammasome Recognizes Lipoteichoic Acid and Regulates Gram-Positive Pathogen Infection. Cell. 2018 Nov 29;175(6):1651-1664.e14.

14. Hu W, Yang S, Shimada Y, Münch M, Marín-Juez R, Meijer AH, et al. Infection and RNA-seq analysis of a zebrafish t/r2 mutant shows a broad function of this toll-like receptor in transcriptional and metabolic control and defense to Mycobacterium marinum infection. BMC Genomics. 2019 Nov 20;20(1).

15. Volkman DJ. Sarcoidosis and IL18. Vol. 101, Clinical Immunology. Academic Press Inc.; 2001. p. 1-2. 

Chapter 9

\title{
Elevated Serum amyloid A levels are not
} specific for sarcoidosis but associate with a

\section{fibrotic pulmonary phenotype}

\author{
Els Beijer \\ Claudia Roodenburg \\ Milou C. Schimmelpennink \\ Jan C. Grutters \\ Bob Meek \\ Marcel Veltkamp
}

Cells. 2021; 10(3):585

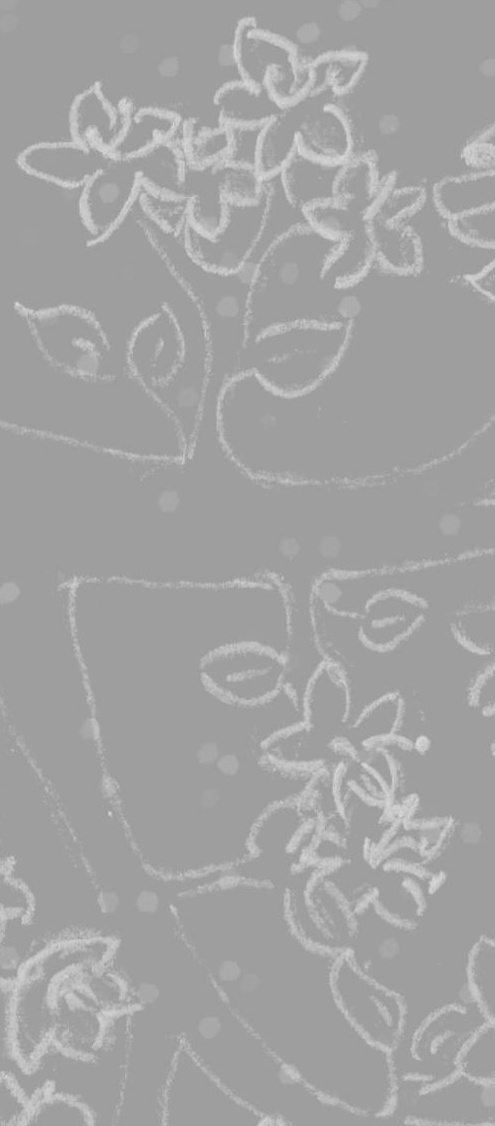




\begin{abstract}
Elevated SAA levels have been found in several inflammatory diseases, including sarcoidosis. SAA is suggested to be involved in sarcoidosis pathogenesis by involvement in granuloma formation and maintenance. We hypothesized that SAA serum levels would be higher in sarcoidosis compared to other non-infectious granulomatous and nongranulomatous diseases.

SAA levels were measured in serum from sarcoidosis, Hypersensitivity pneumonitis (HP) and (eosinophilic) granulomatosis with polyangiitis ((E)GPA) patients. Idiopathic pulmonary fibrosis (IPF) patients were included as non-granulomatous disease group.

SAA levels of patients with sarcoidosis $(31.0 \mu \mathrm{g} / \mathrm{mL}), \mathrm{HP}(23.4 \mu \mathrm{g} / \mathrm{mL}),(\mathrm{E}) \mathrm{GPA}(36.9 \mu \mathrm{g} / \mathrm{mL})$ and IPF $(22.1 \mu \mathrm{g} / \mathrm{mL})$ were all higher than SAA levels of healthy controls $(10.1 \mu \mathrm{g} / \mathrm{mL})$. SAA levels did not differ between the diagnostic groups. When SAA serum levels were analyzed in sarcoidosis subgroups, fibrotic sarcoidosis patients showed higher SAA levels than sarcoidosis patients without fibrosis $(47.8 \mu \mathrm{g} / \mathrm{mL}$ vs $29.4 \mu \mathrm{g} / \mathrm{mL}, \mathrm{P}=0.005)$.

To conclude, the observation that fibrotic sarcoidosis patients have higher SAA levels, together with our finding that SAA levels were also increased in IPF patients, suggests that SAA may next to granulomatous processes also reflect the process of fibrogenesis. Further studies should clarify the exact role of SAA in fibrosis and the underlying mechanisms involved.
\end{abstract}

Keywords: Sarcoidosis, SAA, fibrosis 


\section{Introduction}

Serum amyloid A (SAA) is produced by the liver during the acute phase reaction (APR) which serves to eliminate foreign pathogens in a way that has not fully been elucidated yet (1). Elevated SAA levels have also been found in several inflammatory diseases, including rheumatoid arthritis, diabetes type II, Crohn's disease (2) and sarcoidosis (3-5). Sarcoidosis is a systemic disease which is characterized by formation of non-caseating granulomas through a complex immunological process. Lymph nodes, skin, eyes and lungs are the most frequent involved organs (6). The etiology of the disease is currently not completely clear, but probably results from the complex interplay between different etiologic agents and the immune system in predisposed individuals (7).

Multiple effects of SAA may relate to its contribution in sarcoidosis pathogenesis. First, SAA was found to contribute to Th17-cell proliferation and Th17 cytokine production (8). Th17cells have been found to contribute in sarcoidosis pathogenesis $(9,10)$ and in granuloma formation (11,12). Second, Chen et al. (13) studied the role of SAA in the regulation of granulomatous inflammation in sarcoidosis and found significant presence of SAA in granulomas of sarcoidosis patients which exceeded the intensity of SAA staining found in tissue from patients with tuberculosis, granulomatous polyangiitis or hypersensitivity pneumonitis (13). They therefore proposed that SAA might contribute to granuloma formation in sarcoidosis due to SAA overproduction as result of the intensity of the immune response in this disease. This accumulation of SAA might result in misfolding or aggregation of this protein and formation of complexes with other matrix proteins, leading to granuloma formation and entrapment of microbial antigens or autoantigens (13).

In our previous work we identified trigger related phenotypes in sarcoidosis based on immunological sensitization for mycobacterial antigens and presence of Propionibacterial antigens in granulomas $(14,15)$. Based on its function as an acute phase protein upregulated by infections and contribution in bacterial clearance $(1,16,17)$ together with its considered role as a biomarker in sarcoidosis, increased SAA levels may reflect underlying microbial antigens or autoantigens as triggers in a subgroup of sarcoidosis patients. This prompted us to further investigate the role of SAA in this heterogeneous disease. Based on the study of Chen et al. (13) we hypothesize that SAA serum levels will be higher in sarcoidosis compared to other non-infectious granulomatous and non-granulomatous diseases. Furthermore, we hypothesize that SAA levels in sarcoidosis patients with immunological sensitization for bacterial and auto-antigens will be higher compared to patients with immunological sensitization for inorganic triggers like metals or silica. 


\section{Material and methods}

\section{Study population}

Two sarcoidosis cohorts previously studied in the St. Antonius hospital were included in the study $(14,18)$. Sarcoidosis was diagnosed according to the criteria of the American Thoracic Society/European Respiratory Society (6). Hypersensitivity pneumonitis (HP) and (eosinophilic) granulomatosis with polyangiitis ((E)GPA) patients participating in our biobank study were included as granulomatous disease groups other than sarcoidosis. $A$ cohort of patients with IPF (19) were included as non-granulomatous disease group. SAA levels of the granulomatous disease and non-granulomatous disease group were compared to a healthy control group.

Written consent was obtained from all patients and healthy controls. The study was approved by the Medical research Ethics Committees United (MEC-U) of the Antonius hospital (R05-08A).

\section{SAA serum measurements and correlations}

SAA levels were determined in serum from patients and controls through a SAA human ELISA kit (KHA0012, Invitrogen, Camarillo, CA) following the manufactures protocol. Data of C-reactive protein (CRP) and lung function at time of serum collection for SAA measurements were retrospectively collected from medical records. Correlations between SAA and CRP and lung function were determined for patients of whom data was available at time of serum collection used for SAA measurements.

\section{Sarcoidosis patients with immunological sensitization to either bacterial, inorganic or autoantigens}

Immunological sensitization to mycobacterial antigens, Propopionibacterium acnes ( $P$. acnes) catalase, vimentin and metals and silica were previously determined (14). Sarcoidosis patients in which sensitization was determined were divided in the following sub-groups: Bacterial sensitization (sensitization to mycobacterial antigens or $P$. acnes catalase), autoantigen sensitization (sensitization to vimentin) and inorganic sensitization (sensitization to aluminum, beryllium, zirconium or silica). SAA serum levels of sarcoidosis patients with immunological sensitization to bacterial and autoantigens were compared to SAA levels of sarcoidosis patients with immunological sensitization to inorganic antigens.

\section{Statistics}

Study data were collected and managed using REDCap electronic data capture tools hosted at St. Antonius hospital. Data were analyzed using IBM SPSS statistics version 24. An unpaired T-test was used to compare numerical data between the groups. Non-parametric 
tests were used for non-normally distributed data (Mann-Whitney $U$ test). Categorical data were compared between the groups using the Chi-squared test. If expected cell frequencies were below 5, Fisher's exact test was used for categorical data up to two categories. Correlation between SAA and other variables was determined with Spearman's rho correlation. P-values $<0.05$ were considered significant.

\section{Results}

\section{Demographics of study patients}

SAA serum levels were measured in 215 sarcoidosis patients, 30 HP patients, 11 (E)GPA patients, 68 IPF patients and 200 healthy controls. Demographics can be found in Table 1.

SAA serum levels do not differ between patients with granulomatous and nongranulomatous diseases but are higher in general compared to healthy controls

Median SAA levels of sarcoidosis, HP, (E)GPA and IPF patients were all higher than the median SAA level of healthy controls. No differences in median SAA levels were observed between the different patient groups (Figure 1). When comparing the granulomatous diseases (sarcoidosis, HP, EAA, (E)GPA) with the non-granulomatous disease patients (IPF), no difference in median SAA levels was observed either (median 30.5 IQR 55.3 vs 22.1 IQR 55.5, $P=0.737)$.

\section{SAA correlates with CRP and lung function}

Significant moderate positive correlations were found between SAA and CRP serum levels. Significant weak negative correlations were observed between SAA and FEV1 percentage of predicted (Table 2). When analyzing the correlations per diagnostic group, only in sarcoidosis and IPF patients the correlation between SAA and CRP remained significant $(R=$ 0.384 and $R=0.598$ respectively, both $P<0.001)$. FEV1 showed only a weak negative correlation with SAA in sarcoidosis patients $(R=-0.191, P=0.012)$. Although no overall correlation was observed between SAA and DLCO, the sub analysis revealed a weak negative correlation in sarcoidosis patients $(R=-0.223, P=0.005)$ and a trend in IPF patients $(R=-0.265, P=0.050)$. 
Chapter 9. Elevated SAA levels associate with a fibrotic pulmonary phenotype

Table 1. Demographics of study patients

\begin{tabular}{|c|c|c|c|c|c|}
\hline & $H C(n=200)$ & Sar $(n=215)$ & HP $(n=30)$ & (E)GPA (n=11) & IPF (n=68) \\
\hline Age $^{a}$ & $46.6 \pm 9.2$ & $48.2 \pm 11.8$ & $59.6 \pm 9.5$ & $54.7 \pm 13.9$ & $69.5 \pm 8.9$ \\
\hline Sex (male) & $92(46)$ & $117(54)$ & $15(50)$ & $7(64)$ & $60(88)$ \\
\hline $\begin{array}{l}\text { Ethnicity } \\
\text { (White) }\end{array}$ & & $190(89)$ & $30(100)$ & $11(100)$ & 67 (99) \\
\hline $\begin{array}{l}\text { Smoker } \\
\text { (Never) }\end{array}$ & & 105 (49) & $13(43)$ & $4(36)$ & $16(24)$ \\
\hline Medication & 0 & $101(47)$ & $12(40)$ & $6(55)$ & 0 \\
\hline CRP (mg/L) & & 2.0 IQR 4.0 & 2.0 IQR 4.0 & 2.0 IQR 23.0 & 3.5 IQR 5.0 \\
\hline $\begin{array}{l}\text { FVC } \\
\% \text { predicted }\end{array}$ & & $94.3 \pm 20.3$ & $78.5 \pm 21.7$ & $90.0 \pm 21.2$ & $80.1 \pm 20.1$ \\
\hline $\begin{array}{l}\text { FEV1 } \\
\text { \% predicted }\end{array}$ & & $84.9 \pm 21.5$ & $81.2 \pm 22.0$ & $86.2 \pm 20.1$ & $82.9 \pm 18.3$ \\
\hline $\begin{array}{l}\text { DLCO } \\
\% \text { predicted }\end{array}$ & & $73.5 \pm 17.4$ & $46.8 \pm 13.8$ & $58.9 \pm 20.2$ & $41.5 \pm 11.4$ \\
\hline $\begin{array}{l}\text { Scadding } \\
\text { stage }\end{array}$ & & $44(21)$ & NA & NA & NA \\
\hline 0 & & $45(21)$ & & & \\
\hline I & & $50(23)$ & & & \\
\hline II & & $32(15)$ & & & \\
\hline III & & 40 (19) & & & \\
\hline IV & & $4(2)$ & & & \\
\hline Unknown & & & & & \\
\hline
\end{tabular}

Values are shown as absolute numbers with percentages in brackets.

${ }^{a}$ Age, FVC \% predicted, FEV1 \% predicted and DLCO \% predicted are shown as mean \pm std. CRP, is shown as median IQR. Medication consisted of immunosuppressive medication including prednisone, methotrexate, azathioprine, infliximab, leflunomide, adalumimab, hydroxychloroquine and cellcept. CRP was available from 207 sarcoidosis patients, 27 HP patients, 9 (E)GPA patients and 68 IPF patients. FVC was available from 166 sarcoidosis patients, $27 \mathrm{HP}$ patients, 11 (E)GPA patients and 59 IPF patients. FEV1 was available from 174 sarcoidosis patients, $26 \mathrm{HP}$ patients, 11 (E)GPA patients and 60 IPF patents. DLCO was available from 160 sarcoidosis patients, $25 \mathrm{HP}$ patients, 7 (E)GPA patients and 55 IPF patients.

HC: healthy control, Sar: sarcoidosis, HP: hypersensitivity pneumonitis, (E)GPA: (eosinophilic) granulomatosis with polyangiitis ((E)GPA), IPF: idiopathic pulmonary fibrosis, CRP: C-reactive protein, FVC: Forced vital capacity, FEV1: Forced expiratory volume in 1 second, DLCO: Diffusing capacity 


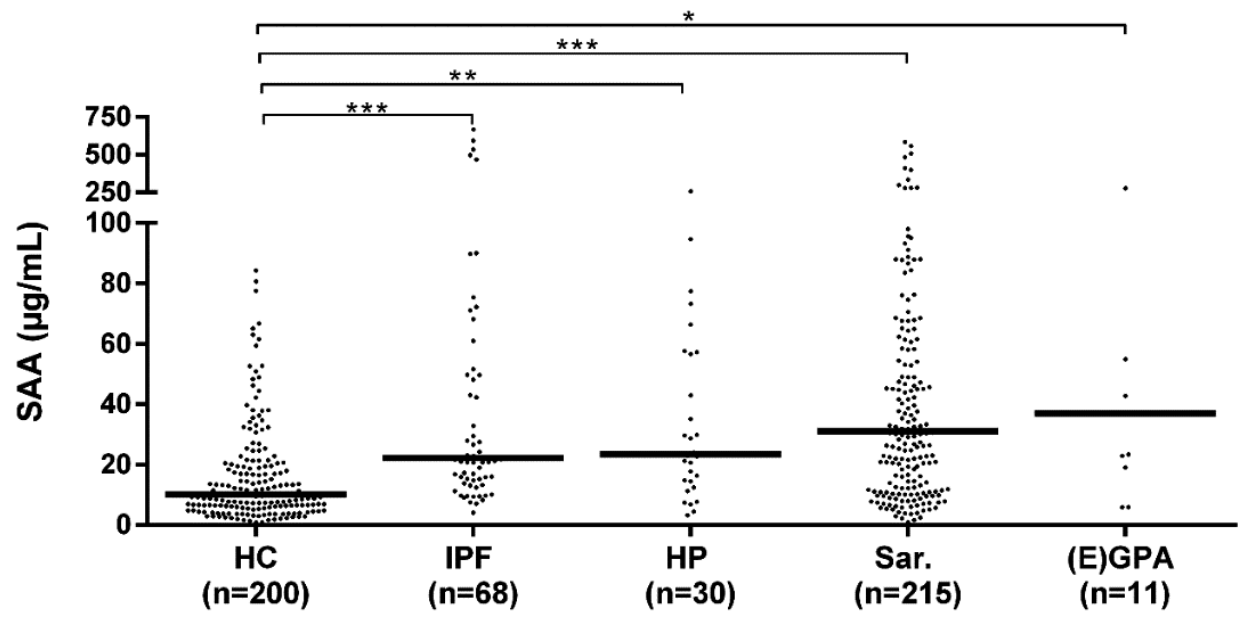

Figure 1. Serum SAA levels in patients and healthy controls.

Median SAA levels of IPF (22.1 IQR 55.5), HP (23.4 IQR 43.4), sarcoidosis (31.0 IQR 56.3) and (E)GPA patients (36.9 IQR 123.7) were all higher than the median SAA level of healthy controls (10.1 IQR 15.6). Median SAA levels did not significantly differ between the diagnostic groups.

HC: healthy control, Sar: sarcoidosis, HP: hypersensitivity pneumonitis, (E)GPA: (eosinophilic) granulomatosis with polyangiitis ((E)GPA), IPF: idiopathic pulmonary fibrosis.

P-values were calculated using Kruskal-Wallis test including pairwise comparisons

Table 2. Spearmans's rho correlations with SAA

\begin{tabular}{lll}
\hline & R & P \\
\hline CRP $(\mathbf{m g} / \mathbf{L})(\mathbf{n = 3 1 1})$ & 0.408 & $<0.001$ \\
\hline FVC \% predicted $(\mathbf{n}=\mathbf{2 6 3})$ & -0.084 & 0.173 \\
\hline FEV1 \% predicted $(\mathbf{n}=\mathbf{2 7 1})$ & -0.154 & 0.011 \\
\hline DLCO \% predicted $(\mathbf{n}=\mathbf{2 4 5})$ & -0.111 & 0.082 \\
\hline
\end{tabular}

Correlations and P-values were determined by Spearmans's rho CRP: C-reactive protein, FVC: Forced vital capacity, FEV1: Forced expiratory volume in 1 second, DLCO: Diffusing capacity 


\section{SAA levels are higher in patients using immunosuppressive medication}

As part of the patients with sarcoidosis, HP and (E)GPA was using medication at time of SAA determination, we analyzed whether SAA levels differed between patients with and without medication. Overall, patients using immunosuppressive medication showed higher SAA levels than patients without medication. When considering the type of medication used, we only observed significant higher SAA levels in patients using prednisone (Table 3). When we compared the different diagnostic groups for SAA levels and the use of medication, we only observed significantly higher median SAA levels in sarcoidosis patients with medication compared to sarcoidosis patients without medication ( $44.4 \mu \mathrm{g} / \mathrm{mL}$ vs $26.3 \mu \mathrm{g} / \mathrm{mL}, \mathrm{P}=0.001$ ). When we compared SAA levels per type of medication used, we again found significant higher SAA levels in sarcoidosis patients using prednisone. No difference was observed for the other types of medication used or for CRP levels.

Table 3. Median SAA levels in Sarcoidosis, HP and (E)GPA patients with and without immunosuppressive medication

\begin{tabular}{|c|c|c|c|}
\hline $\begin{array}{l}\text { Use of immunosuppressive } \\
\text { mediation }\end{array}$ & No $(n=404)$ & Yes $(n=119)$ & $\mathbf{P}$ \\
\hline SAA ( $\mu \mathrm{g} / \mathrm{mL})$ & 16.9 IQR 30.2 & 43.8 IQR 72.5 & $<0.001$ \\
\hline \multirow[t]{2}{*}{ Prednisone } & No $(n=430)$ & Yes $(n=93)$ & \\
\hline & 16.9 IQR 30.7 & 49.0 IQR 93.10 & $<0.001$ \\
\hline MTX & No $(n=488)$ & Yes $(n=35)$ & \\
\hline SAA ( $\mu \mathrm{g} / \mathrm{mL})$ & 20.6 IQR 40.0 & 25.9 IQR 56.4 & 0.536 \\
\hline \multirow[t]{2}{*}{ Aza } & No $(n=515)$ & Yes $(n=8)$ & \\
\hline & 20.6 IQR 40.0 & 32.2 IQR 32.7 & 0.232 \\
\hline Inf & No $(n=516)$ & Yes $(n=7)$ & \\
\hline SAA ( $\mu \mathrm{g} / \mathrm{mL})$ & 20.7 IQR 40.0 & 35.0 IQR 87.6 & 0.531 \\
\hline
\end{tabular}

MTX: Methotrexate, Aza: Azathioprine, Inf: infliximab

Sub analysis were performed only for medications used by 5 or more patients .

Leflunomide and hydroxychloroquine was used by 1 patient and adalimumab and cellcept by 2 patients

SAA levels do not differ between sarcoidosis patients with immunological sensitization to bacterial and autoantigens or inorganic antigens

The median SAA level of patients sensitized to bacterial and/or auto-antigens was 30.4 IQR 68.7 and to inorganic antigens 32.1 IQR 81.6 (Figure 2). SAA levels did not significantly differ between the groups $(P=0.719)$. 


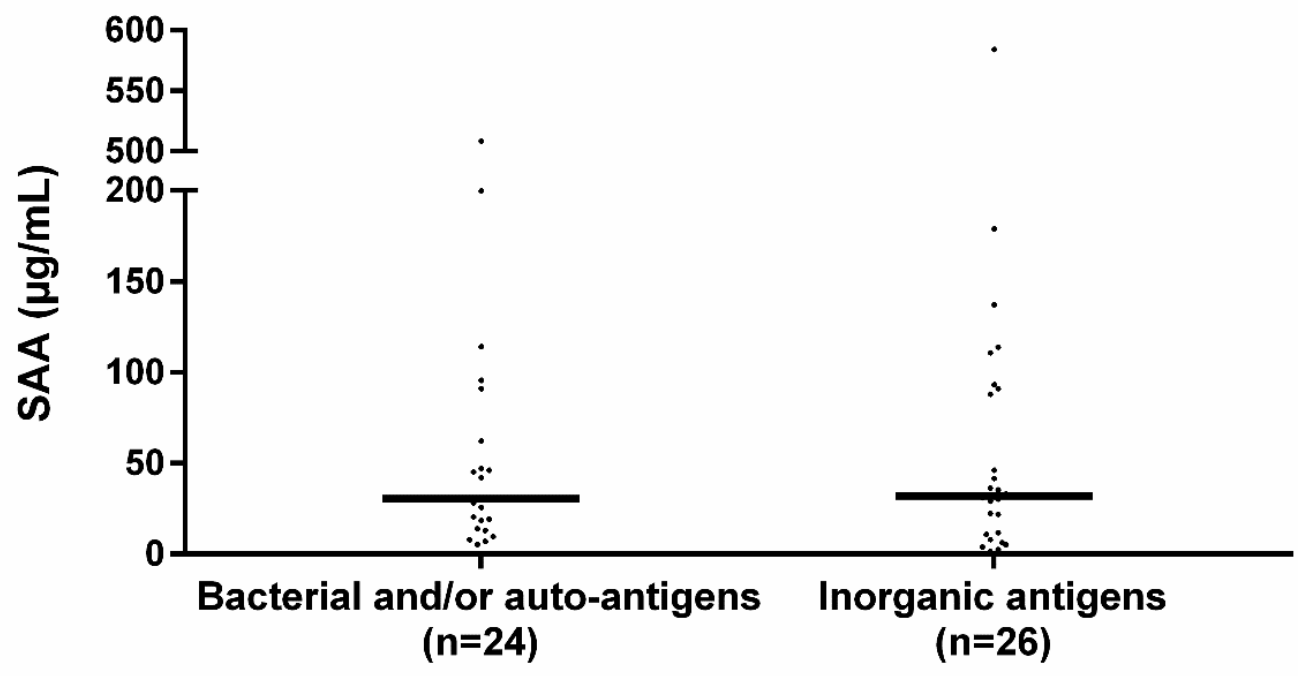

Figure 2. Serum SAA levels in sensitized sarcoidosis sub-groups.

Median SAA levels between bacterial sensitized and/or auto-antigen sensitized and inorganic agent sensitized sarcoidosis patients did not significantly differ.

Bacterial: sensitization to mycobacterial antigens or $P$. acnes catalase, Auto-antigen: sensitization to vimentin, Inorganic: sensitization to aluminum, beryllium, zirconium or silica.

$\mathrm{P}$-values were calculated using Mann-Whitney $\mathrm{U}$ test.

\section{SAA serum levels are higher in sarcoidosis patients with parenchymal fibrosis}

Median SAA levels were compared between sarcoidosis patients with different Scadding stages. Comparing SAA levels between all Scadding stages showed a significant differences in median SAA levels between the 5 Scadding stages $(P=0.025$, Table 4). Pairwise comparisons showed that Scadding stage IV patients had significantly higher median SAA levels compared to Scadding stage III patients (adj. P = 0.012). Furthermore, when SAA serum levels of Scadding stage IV (fibrosis) patients were compared with all other Scadding stages together (no fibrosis), significant higher median SAA levels were observed in the fibrotic group $(P=0.005)$. When we only examined sarcoidosis patients without use of immunosuppressive medication, median SAA levels were still significantly higher in the fibrotic group (48.9 vs $22.3, \mathrm{P}=0.020$ ). No differences in median CRP levels were found between any of the Scadding stages. 
Table 4. SAA levels among sarcoidosis patients with different Scadding stages

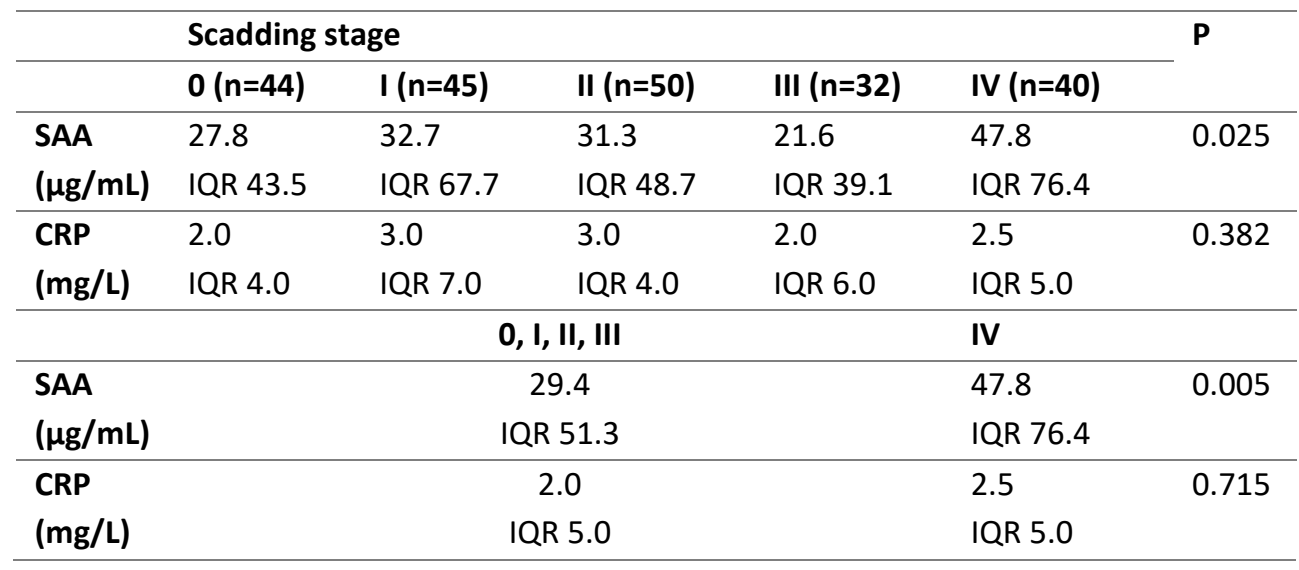

Values are shown as median IQR. CRP was missing from 2 Scadding stage II patients, 3 Scadding stage III patients and 2 Scadding stage IV patients.

P- values for multiple comparisons were calculated using Kruskal-Wallis test. Multiple comparisons were adjusted by the Bonferroni correction. P-values comparing 2 groups were defined by the Mann-Whitney $U$ test.

\section{Discussion}

Although previous studies have suggested a possible role for SAA in the pathogenesis of sarcoidosis, our study shows this is not reflected by differences in serum levels between sarcoidosis and other pulmonary (granulomatous) diseases. SAA levels were elevated in patients with sarcoidosis, HP, (E)GPA and IPF compared to healthy controls. Within the group of sarcoidosis patients, SAA levels did not differ between patients with immunological sensitization to either bacterial and auto-antigens, or inorganic antigens. Important findings from our study are the increased SAA levels in patients with IPF and in sarcoidosis patients with pulmonary fibrosis compared to sarcoidosis patient without parenchymal fibrosis.

Even though in vitro activated monocyte/macrophages are capable of producing SAA (20) and sarcoidosis is a monocyte/macrophage driven disease (21), this did not result in an overall increase in circulating SAA when compared to other inflammatory diseases. It may be that SAA produced in tissue does not necessarily contribute to the circulatory levels of SAA and vice versa. For instance, SAA was not observed in granulomas of GPA patients, while expression and serum levels were increased $(13,22)$. Likewise, we observed elevated SAA levels in serum of HP patients while results of Chen et al. demonstrated limited to no SAA staining in granulomas of HP patients (13). 
Chen et al. did observe that SAA patterns within granulomas of sarcoidosis patients were different from patients with other granulomatous diseases including chronic beryllium disease (CBD) and Crohn's disease. However, a lymph node of a patient infected with Mycobacteria Tuberculosis demonstrated patchy expression of SAA, localized mostly around the periphery of necrotizing granulomas (13). For this reason, combined with the fact that SAA is an acute phase protein upregulated by infections (1) and may have a role in clearance of bacterial antigens $(16,17)$, we hypothesized that sarcoidosis patients sensitized to bacterial antigens had higher SAA levels than sarcoidosis patients sensitized to inorganic antigens such as metals and silica. The results of our study do not support this hypothesis. It is possible that blood is not the correct compartment to answer this question, and that immunohistochemical staining of SAA in granulomas may be required to determine whether there are different patterns between those subgroups of sarcoidosis patients and between sarcoidosis and other granulomatous disease patients.

Interestingly, we observed that sarcoidosis patients with a pulmonary fibrotic phenotype, had higher serum SAA levels than sarcoidosis patient without pulmonary fibrosis. Chen et al. showed that the extent of SAA staining correlated with the degree of collagen deposition (13). This suggests that SAA serum levels and tissue expression is associated with chronic inflammation and fibrosis. In line with the association between SAA and fibrosis, we observed a correlation between SAA and DLCO \% predicted in sarcoidosis. In patients with systemic sclerosis (SSc), SAA was found to associate with pulmonary involvement and a negative correlation between SAA and DLCO was observed as well. Moreover, within SSC patients with different HRCT patterns, SSc patients with reticulation or honeycombing on $\mathrm{HRCT}$, indicative for pulmonary fibrosis, had the highest serum SAA levels (23).

Comparable to our results, Vietri et al. showed that SAA levels in serum were higher in IPF patients than in healthy controls (24). They hypothesized that SAA is overproduced in response to fibrotic and hypoxic stimuli, since increased SAA levels are also observed in chronic obstructive pulmonary disease (COPD) (25) and obstructive sleep apnea (OSA) (26). Another possible explanation for the association between increased SAA levels and fibrosis may be that fibrosis is often accompanied by low-grade inflammation and tissue-barrier disruption (27). Since SAA contributes to (bacterial) antigen clearance, its production may be upregulated in response to the barrier disruption of fibrotic areas. A distinct, contrasting explanation is perhaps an anti-fibrogenic effect of SAA. This was observed in a mouse model of $\mathrm{CCl}_{4}$-induced hepatic fibrogenesis in which liver fibrosis was enhanced after treatment with anti-SAA antibodies (28). Hypothetically, SAA production may be induced in response to fibrogenesis, to prevent further fibrosis formation.

We observed an overall correlation between CRP and SAA. After performing analysis in the diagnostic groups we only observed a significant correlation in sarcoidosis and IPF patients, 
probably explained by the larger sample size of these patients groups. Although acute phase proteins such as CRP and SAA correlate quite well in several diseases (29-31), in our study SAA levels are higher in sarcoidosis patients with an pulmonary fibrotic phenotype compared to sarcoidosis patients without fibrosis, while CRP levels do not differ between these groups. This observation shows that determining SAA levels next to CRP levels can be meaningful in sarcoidosis patients, since those two acute phase proteins reflect different phases of disease.

An intriguing observation was the higher SAA level in patients using immunosuppressive medication at time of serum collection for SAA measurement. This effect was specifically seen in sarcoidosis patients using prednisone. Comparable to our observation, Yamada et al. also observed higher SAA levels in rheumatoid arthritis patients receiving oral prednisolone (32). An inducing effect of prednisolone on SAA production of HepG2 cells have been found (33). Interestingly, a major increase in SAA expression in human monocytes and macrophages was found after a combined treatment with lipopolysaccharide (LPS) and dexamethasone or methylprednisolone (20). In a previous study, we showed the presence of $C$. acnes lipoteichoic acid (LTA) in granulomas of sarcoidosis patients (15). Comparable to LPS of gram-negative bacteria, is LTA a cell wall polymer of gram-positive bacteria and plays a role in bacterial growth, membrane homeostasis and virulence (34). Furthermore, LTAs have shown to be immunogenic and activate the innate immune system via TLR2 and NLRP6 $(35,36)$. It is possible that bacterial molecules including LPS and LTA together with glucocorticoids stimulate macrophages within granulomas to produce SAA, explaining the higher SAA levels observed in sarcoidosis patients using prednisone.

Based on the results of our study, it is not possible to determine whether medication itself has an effect on SAA levels or that SAA levels are increased in the more severe patient group needing immunosuppressive therapy. However, since we observed higher SAA levels in fibrotic sarcoidosis patients who did not use medication, there have to be other factors that determine the higher SAA levels we observed in fibrotic sarcoidosis patients compared to non-fibrotic sarcoidosis patients. It has been suggested that SAA is useful as biomarker in sarcoidosis, since it is not dramatically affected by immunosuppressive therapy (37). Further studies will have to clarify the association between immunosuppressive therapy and SAA, for example by performing SAA measurements before, during and after treatment.

Our study has some limitations. First, SAA levels were not measured at time of diagnosis for all patients. For this reason, we were not able to analyze whether increased SAA levels were predictive for disease course. We were not able to measure SAA levels of all patients at time of diagnosis since we made use of existing patient cohorts from which serum at time of diagnosis was not available. However, by making use of these patient cohorts, we were able 
to analyze SAA levels between sensitization subgroups within the sarcoidosis patients, which had never been performed before. A second limitation was that a proportion of the patients were using immunosuppressive medication at time of SAA measurements. We were not able to track down whether increased SAA levels observed in the patients using medication was due to the mediation itself or rather due to the more severe disease course of these patients. Further studies will have to reveal the effect of immunosuppressive medication on disease course, for instance by measuring SAA levels at diagnosis and during follow-up in one cohort of patients.

To conclude, increased SAA levels in serum is not specifically associated with sarcoidosis but can also be found in other granulomatous diseases such as HP and (E)GPA. In patients with sarcoidosis, the level of serum SAA is associated with the concomitant use of glucocorticoids. The fact that elevated SAA levels were observed in patients with IPF and were significantly higher in sarcoidosis patients with pulmonary fibrosis compared to patients without parenchymal fibrosis, suggests that SAA may also reflect the process of fibrogenesis. Further studies should clarify the exact role of SAA in fibrosis and the underlying mechanisms involved in the effects of glucocorticoids on SAA levels in sarcoidosis. 


\section{References}

1. Buck M, Gouwy M, Wang J, Snick J, Opdenakker G, Struyf S, et al. Structure and Expression of Different Serum Amyloid A (SAA) Variants and their ConcentrationDependent Functions During Host Insults. Curr Med Chem. 2016 Apr 20;23(17):1725-55.

2. Ye RD, Sun L. Emerging functions of serum amyloid $A$ in inflammation. J Leukoc Biol. 2015 Dec;98(6):923-9.

3. Ivanisevic J, Kotur-Stevuljevic J, Stefanovic A, Spasic S, Vucinic Mihailovic V, Videnovic Ivanov J, et al. Association of serum amyloid $A$ and oxidative stress with paraoxonase 1 in sarcoidosis patients . Eur J Clin Invest. 2016;46(5):418-24.

4. Gungor S, Ozseker F, Yalcinsoy M, Akkaya E, Can G, Eroglu H, et al. Conventional markers in determination of activity of sarcoidosis. Int Immunopharmacol. 2015;25(1):174-9.

5. Bargagli E, Magi B, Olivieri C, Bianchi N, Landi C, Rottoli P. Analysis of serum amyloid A in sarcoidosis patients. Respir Med. 2011;105(5):775-80.

6. Costabel U, Hunninghake GW. ATS/ERS/WASOG statement on sarcoidosis. Sarcoidosis Statement Committee. American Thoracic Society. European Respiratory Society. World Association for Sarcoidosis and Other Granulomatous Disorders. Eur Respir J. 1999;14(4):735-7.

7. Beijer E, Veltkamp M, Meek B, Moller DR. Etiology and Immunopathogenesis of Sarcoidosis: Novel Insights. Semin Respir Crit Care Med. 2017 Aug;38(4):404-16.

8. Sano T, Huang W, Hall JA, Yang Y, Chen A, Gavzy SJ, et al. An IL-23R/IL-22 Circuit Regulates Epithelial Serum Amyloid A to Promote Local Effector Th17 Responses. Cell. 2015 Oct 8;163(2):381-93.

9. Zissel G, Muller-Quernheim J. Cellular Players in the Immunopathogenesis of Sarcoidosis . Clin Chest Med. 2015 Dec;36(4):549-60.

10. Mortaz Rezayat, F., Amani, D., Kiani, A., Garssen, J., Adcock, I., Velayati,A. E. The Roles of T Helper 1, T Helper 17 and Regulatory T Cells in the Pathogenesis of Sarcoidosis. Iran J Allergy, Asthma Immunol. 2016;15(4).

11. Pacheco Y, Lim CX, Weichhart T, Valeyre D, Bentaher A, Calender A. Sarcoidosis and 
the mTOR, Rac1, and Autophagy Triad. Vol. 41, Trends in Immunology. Elsevier Ltd; 2020. p. 286-99.

12. Song J, Zhao M, Li Q, Lu L, Zhou Y, Zhang $\mathrm{Y}$, et al. IL-17A can promote Propionibacterium acnes-induced sarcoidosis-like granulomatosis in mice. Front Immunol. 2019;10(AUG).

13. Chen ES, Song Z, Willett MH, Heine S, Yung RC, Liu MC, et al. Serum amyloid A regulates granulomatous inflammation in sarcoidosis through Toll-like receptor-2. Am J Respir Crit Care Med. 2010 Feb 15;181(4):360-73.

14. Beijer E, Kraaijvanger R, Roodenburg C, Grutters JC, Meek B, Veltkamp M. Simultaneous testing of immunological sensitization to multiple antigens in sarcoidosis reveals an association with inorganic antigens specifically related to a fibrotic phenotype. Clin Exp Immunol. 2020 Sep 17; cei.13519.

15. Beijer E, Seldenrijk K, Eishi Y, Uchida K, Damen J, Grutters JC, et al. Presence of Propionibacterium acnes in granulomas associates with a chronic disease course in Dutch sarcoidosis patients. ERJ Open Res. 2020 Jan 1;486-2020.

16. Shah C, Hari-Dass R, Raynes JG. Serum amyloid A is an innate immune opsonin for Gram-negative bacteria. Blood. 2006 Sep 1;108(5):1751-7.

17. Derebe MG, Zlatkov CM, Gattu S, Ruhn KA, Vaishnava S, Diehl GE, et al. Serum amyloid $A$ is a retinol binding protein that transports retinol during bacterial infection. Elife. 2014 Jul 29;3(July2014):1-18.

18. Vorselaars AD, Crommelin HA, Deneer VH, Meek B, Claessen AM, Keijsers RG, et al. Effectiveness of infliximab in refractory FDG PET-positive sarcoidosis . Eur Respir J. 2015 Jul;46(1):175-85.

19. Schimmelpennink MC, Quanjel M, Vorselaars ADM, Wiertz I, Veltkamp M, Van Moorsel CHM, et al. Value of serum soluble interleukin-2 receptor as a diagnostic and predictive biomarker in sarcoidosis. Expert Rev Respir Med. 2020 Jul 2;14(7):749-56.

20. Jumeau C, Awad F, Assrawi E, Cobret L, Duquesnoy P, Giurgea I, et al. Expression of SAA1, SAA2 and SAA4 genes in human primary monocytes and monocyte-derived macrophages. PLoS One. 2019 May 1;14(5). 
21. Cinetto F, Scarpa R, Dell'Edera A, Jones MG. Immunology of sarcoidosis: old companions, new relationships. Curr Opin Pulm Med. 2020 Sep;26(5):535-43.

22. Bijl M, Bootsma H, Van Der Geld Y, Limburg PC, Kallenberg CGM, Van Rijswijk MH. Serum amyloid $\mathrm{P}$ component levels are not decreased in patients with systemic lupus erythematosus and do not rise during an acute phase reaction. Ann Rheum Dis. 2004 Jul;63(7):831-5.

23. Lakota K, Carns M, Podlusky S, Mrak-Poljsak K, Hinchcliff M, Lee J, et al. Serum amyloid $a$ is a marker for pulmonary involvement in systemic sclerosis. PLoS One. 2015 Jan 28;10(1).

24. Vietri L, Bennett D, Cameli P, Bergantini L, Cillis G, Sestini P, et al. Serum amyloid A in patients with idiopathic pulmonary fibrosis. Respir Investig. 2019 Sep 1;57(5):430-4.

25. Bozinovski S, Hutchinson A, Thompson M, MacGregor L, Black J, Giannakis E, et al. Serum amyloid $A$ is a biomarker of acute exacerbations of chronic obstructive pulmonary disease. Am J Respir Crit Care Med. 2008 Feb 1;177(3):269-78.

26. Svatikova A, Wolk R, Shamsuzzaman AS, Kara T, Olson EJ, Somers VK. Serum amyloid a in obstructive sleep apnea. Circulation. 2003 Sep 23;108(12):1451-4.

27. Leonard-Duke J, Evans S, Hannan RT, Barker TH, Bates JHT, Bonham CA, et al. Multiscale models of lung fibrosis. Matrix Biol. 2020 Sep 1;91-92:35-50.

28. Wang $Y$, Huang $H$, Sun R, Chen B, Han F, Li Q, et al. Serum amyloid a induces M2blike macrophage polarization during liver inflammation. Oncotarget. 2017;8(65):109238-46.

29. Wang CM, Deng JH, Mao GF, He YL, Shi X. Serum Amyloid A: A Potential Biomarker Assessing Disease Activity in Systemic Lupus Erythematosus. Med Sci Monit. 2020 Jun 25;26:e923290.

30. Yuan ZY, Zhang XX, Wu YJ, Zeng ZP, She WM, Chen SY, et al. Serum amyloid A levels in patients with liver diseases. World J Gastroenterol. 2019 Nov 21;25(43):6440-50.

31. Dev S, Singh A. Study of role of serum amyloid A (SAA) as a marker of disease activity in juvenile idiopathic arthritis. J Fam Med Prim Care. 2019;8(6):2129. 
32. Yamada T, Okuda $\mathrm{Y}$, Takasugi $\mathrm{K}$, Itoh $\mathrm{K}$, Igari J. Relative serum amyloid A (SAA) values: The influence of SAA1 genotypes and corticosteroid treatment in Japanese patients with rheumatoid arthritis. Ann Rheum Dis. 2001;60(2):124-7.

33. Smith JW, McDonald TL. Production of serum amyloid A and C-reactive protein by HepG2 cells: Stimulated with combinations of cytokines or monocyte conditioned media: The effects of prednisolone. Clin Exp Immunol. 1992;90(2):293-9.

34. Percy MG, Gründling A. Lipoteichoic Acid Synthesis and Function in Gram-Positive Bacteria. Annu Rev Microbiol. 2014 Sep 8;68(1):81-100.

35. Mitchell JA, Paul-Clark MJ, Clarke GW, McMaster SK, Cartwright N. Critical role of toll-like receptors and nucleotide oligomerisation domain in the regulation of health and disease. Vol. 193, Journal of Endocrinology. J Endocrinol; 2007. p. 323-30.

36. Hara H, Seregin SS, Yang D, Fukase K, Chamaillard M, Alnemri ES, et al. The NLRP6 Inflammasome Recognizes Lipoteichoic Acid and Regulates Gram-Positive Pathogen Infection. Cell. 2018 Nov 29;175(6):1651-1664.e14.

37. Rothkrantz-Kos S, Van Dieijen-Visser MP, Mulder PGH, Drent M. Potential usefulness of inflammatory markers to monitor respiratory functional impairment in sarcoidosis. Clin Chem. 2003 Sep 1;49(9):1510-7. 

Chapter 10

Summary and general discussion
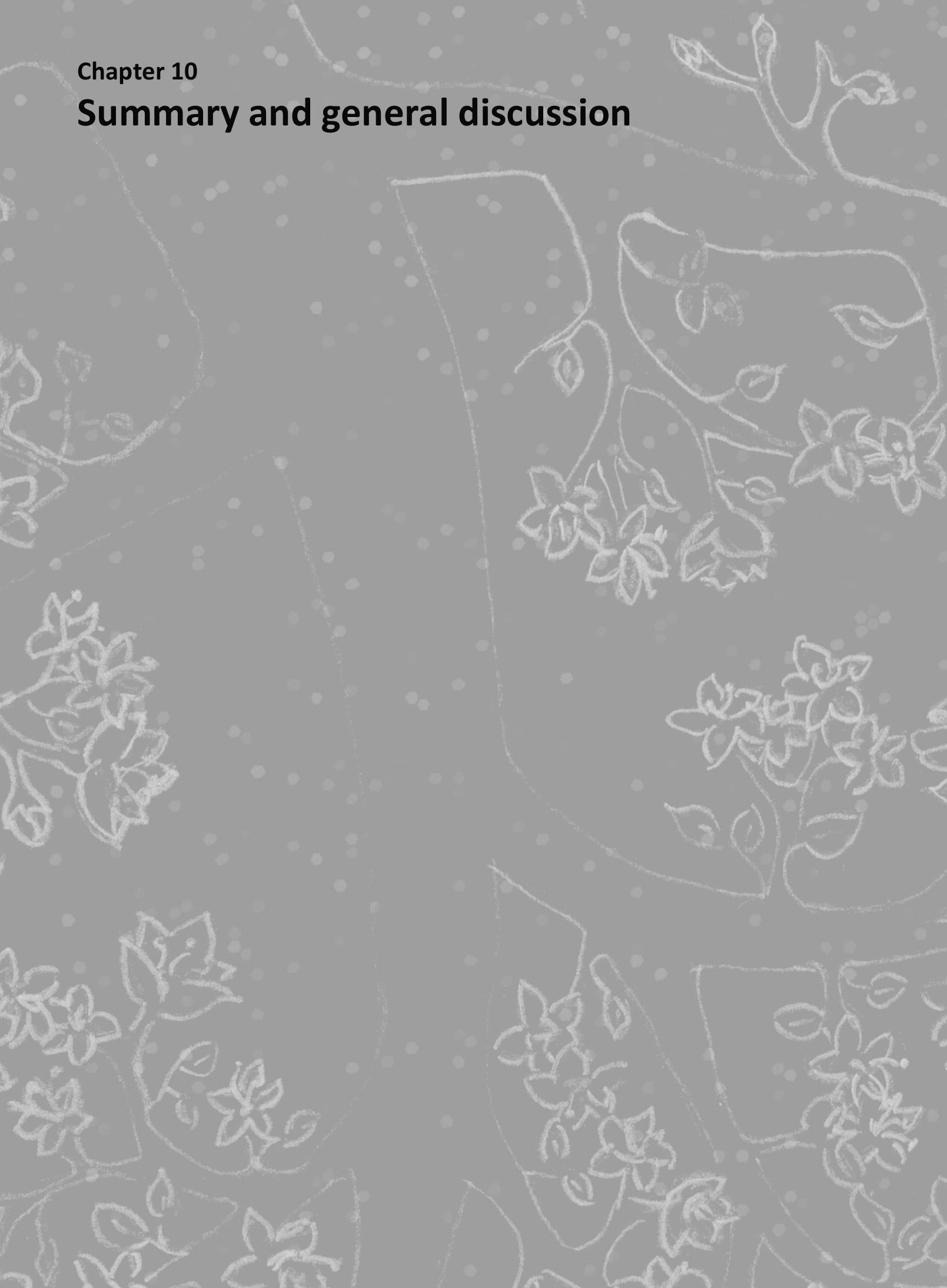
The hallmark of sarcoidosis is the formation of non-caseating granulomas (1), which are compact organized structures of mature macrophages accompanied by other immune cells including lymphocytes and plasma cells. They are thought to be formed when phagocytes are not able to destroy certain particles. Granulomas are not specific for sarcoidosis since granulomas can be formed in response to infectious agents, foreign bodies, many inflammatory and autoimmune conditions (2). The diagnosis of sarcoidosis is therefore based on exclusion of granulomatous infectious diseases or other causes of granulomas (3). The presentation of sarcoidosis can be very heterogeneous and virtually any organ can be affected. The lungs and hilar and mediastinal lymph nodes are the most frequently involved (in about $90 \%$ of cases), followed by involvement of the skin, eyes and liver (4). Moreover, the course of the disease is unpredictable, meaning that it may either spontaneously resolve or become chronic (5). Due to the fact that various antigens are able to stimulate granuloma formation together with the heterogeneous presentation observed among sarcoidosis patients, it seems plausible that multiple antigens are able to trigger sarcoidosis development. This thesis addresses the question whether multiple potential triggers relate to different presentations or disease course of sarcoidosis, and aimed to identify triggerrelated phenotypes.

\section{Summary}

Sarcoidosis has a complex disease pathogenesis, with involvement of both innate and adaptive immune responses. Several innate immune system receptors including NOD-like receptors and Toll-like receptors appear to be involved in the development of sarcoidosis as well as cellular players such as dendritic cells and macrophages. Furthermore, lymphocytes from the adaptive immune system including Th1, Th17, regulatory T cells, and $B$ cells are likely to play a role in sarcoidosis pathogenesis as well. It is likely that sarcoidosis does not have one single cause but rather results from the complex interplay between different etiologic agents and the immune system in predisposed individuals. Chapter 2 provides an overview of possible etiologic agents of sarcoidosis. Although sarcoidosis is a systemic disease, the intrathoracic lymph nodes and lungs are the most frequently involved organs. This has led to the hypothesis that the etiologic agent might be airborne. Both exogenous organic, including mycobacterial antigens and propionibacterial antigens, and inorganic components, like metals and silica, are potential candidates triggering the disease. More recent data also suggest that self-antigens, such as vimentin and serum amyloid $A$ (SAA), could be involved in triggering sarcoidosis pathogenesis.

Chapter 3 describes in detail three patients in which the combination of exposure to inorganic substances and related immunological sensitization is, in our opinion, highly 
suggestive for a causal relationship. These observations made in the ILD-clinic prompted us to further investigate the possibility of trigger-related phenotypes in sarcoidosis.

In chapter 4 both occupational exposure and immunoreactivity to metals and silica was characterized in a group of sarcoidosis patients and controls. Standardized assessment of in-depth occupational exposure is not included in the current diagnostic work-up of sarcoidosis. When beryllium exposure is clinically suspected in patients with sarcoidosis, chronic beryllium disease (CBD) can be excluded by testing for beryllium immunoreactivity using a Lymphocyte Proliferation Test (LPT). This is important since CBD can be histopathological and clinical indistinguishable from sarcoidosis (6). Also other inorganic antigens such as aluminum, zirconium and silica are suggested to play a role in the pathogenesis of sarcoidosis (7-9). At present, however, a causal relationship between these antigens and sarcoidosis has not been established. First because studies using a control group are lacking and second because exposure is difficult to assess. Identification of possible etiologic antigens in sarcoidosis is important since it may lead to a more personalized treatment regime. For instance, avoiding exposure might be the first step in the treatment of sarcoidosis patients in whom metal or silica might trigger the disease pathogenesis. In patients with $\mathrm{CBD}$, improved lung function and radiographic findings can indeed be observed when exposure is terminated or decreased $(10,11)$.

We observed no differences in occupational groups or occupational exposure to metals and silica between the sarcoidosis and control patients. However, sensitization to the metals tested (aluminum, beryllium and zirconium) and silica was only observed in sarcoidosis patients. Taken together, significantly more sarcoidosis patients than controls had immunological sensitization to any of the antigens tested. This observation supports the concept that metals and silica might indeed be involved in the pathogenesis of sarcoidosis in a subgroup of patients. The finding of sarcoidosis patients with beryllium sensitization demonstrates that also in the Netherlands, patients with CBD can be identified within a group of biopsy proven sarcoidosis patients. Since immunological sensitivity to metal and silica, but not occupational exposure, differed between patients and controls, genetic variants may be involved in the ability to respond to the substances addressed in this study. This has already been shown in CBD were a Glu at position 69 in the HLA-DPB1 gene is found in approximately $90 \%$ of patients compared to about $40 \%$ of healthy controls $(12,13)$. Moreover, occupational exposure was not associated with sensitization in our study. A possible explanation for this observation may be that even very low occasional exposures to potentially immune sensitizing substances can be relevant in genetic predisposed individuals $(14,15)$ and that a simple occupational history is not detailed enough to identify these exposures. 
Considerable research effort has focused on identification of triggers of sarcoidosis, including antigens of mycobacteria $(16,17)$, Propionibacterium acnes (P. acnes) $(18,19)$, vimentin $(20,21)$, metals and silica $(9,22)$. Although all these antigens can elicit noncaseating granulomas, results demonstrate that sarcoidosis probably has multiple triggers. Importantly, however, none of the above organic and inorganic antigens have been studied simultaneously in one group of sarcoidosis patients. In chapter $\mathbf{5}$ we therefore describe peripheral T-cell responses to organic and inorganic antigens, simultaneously studied in one cohort of sarcoidosis patients. Antigen sensitization was analyzed in relation to clinical characteristics for identification of possible trigger-related phenotypes. We found no association between immunological sensitization towards the organic antigens and sarcoidosis. Quite unexpectedly, we found immunological sensitization towards propionibacterial antigens in a significantly lower percentage of sarcoidosis patients than controls. Sarcoidosis patients sensitized to antigens of $P$. acnes, were younger at diagnosis and showed a trend towards more often skin involvement than sarcoidosis patients without propionibacterial antigen sensitization. Immunological sensitization towards mycobacterial antigens was also found in a low percentage of patients with sarcoidosis suggesting that this is not a major causative antigen in Dutch patients. However, sarcoidosis patients sensitized for mycobacterial antigens had more often cardiac involvement than sarcoidosis patients without mycobacterial sensitization. Significant more sarcoidosis patients than control patients showed sensitization to metals and silica. Finally, we observed that sensitization to metals and silica is associated with development of fibrotic sarcoidosis 5 years after diagnosis. Our study therefore suggests a more prominent role for inorganic triggers such as metals and silica in sarcoidosis pathogenesis than previously thought. The data on mycobacteria and presence of cardiac sarcoidosis, the possible relation between sensitization to $P$. acnes and cutaneous involvement, and the association of fibrosis with metal and silica sensitization, also suggest that trigger-related phenotypes do exist in the heterogeneous population of sarcoidosis patients.

In chapter 6 the possible association between a latent tuberculosis infection (LTBI) and cardiac involvement in sarcoidosis was further evaluated based on the data presented in chapter 5 . About $5 \%$ of sarcoidosis patients have symptoms of cardiac sarcoidosis (CS), although the prevalence of CS is estimated to be $20-30 \%$ in autopsy and imaging studies (23). Identification of cardiac involvement is important since it is a major cause of death among sarcoidosis patients $(24,25)$. Interestingly, in chapter 5 it was found that three of the five LTBI patients had cardiac involvement of their sarcoidosis. In the current chapter we used another cohort of CS patients to investigate whether an LTBI associates with cardiac 
involvement in sarcoidosis. We observed that significant more CS patients had an LTBI compared to non-CS patients. This is in concordance with the preliminary findings of chapter 5 where we observed that sarcoidosis patients sensitized for mycobacterial antigens had more often cardiac involvement compared to sarcoidosis patients without mycobacterial sensitization. If the association between LTBI and CS can be confirmed in future research, this could be of interest for clinical management. For instance, it could be relevant to screen sarcoidosis patients with an LTBI for CS, even though symptoms may not be present (yet).

In chapter 7 the presence of $P$. acnes in granulomas of Dutch sarcoidosis patients was demonstrated using immunohistochemistry. Results of the staining were studied in relation to disease course. As $P$. acnes is a commensal, Koch's postulates cannot be applied, which makes it difficult to prove its etiologic role in sarcoidosis beyond doubt (26). However, a higher number of $P$. acnes genomes have been found in tissue from Chinese, Japanese, Italian, English and German sarcoidosis patients compared to tissue of controls, suggesting involvement in disease pathogenesis (27-29). Furthermore, an increased immune response to $P$. acnes among patients with sarcoidosis was found in different studies using Japanese or German patients (30-32). In addition to its role as possible antigen, $P$. acnes can also act as a mitogen which is demonstrated by the fact that $P$. acnes enhances immunogenicity of certain vaccines (33) and enhances cytotoxic activity toward different tumor cells (34-36). We showed in this chapter that $P$. acnes could be detected in tissue samples of a subgroup of Dutch patient with sarcoidosis. Moreover, the presence of $P$. acnes inside granulomas was associated with a chronic disease phenotype and requirement of treatment. Regardless of whether the role of $P$. acnes is antigenic or mitogenic, our data contribute to the premise that it is relevant to further explore antibacterial therapy and therapy against specific bacterial antigens as treatment options for a subset of sarcoidosis patients.

To further explore whether presence of $P$. acnes is unique for sarcoidosis, in chapter $\mathbf{8}$ we examined granulomatous tissue of Granulomatosis with polyangiitis (GPA), Eosinophilic granulomatosis with polyangiitis (EGPA) and hypersensitivity pneumonitis (HP) patients for presence of $P$. acnes. Several studies have demonstrated that $P$. acnes is able to induce granulomas (37). Furthermore, $P$. acnes is suggested to be involved in the pathogenesis of sarcoidosis. Granulomas are however not specific for sarcoidosis, but are also observed in other diseases (38). More specifically, granulomas are seen in diseases other than sarcoidosis in which the lungs are frequently involved, including HP, GPA and EGPA (39). Although presence of $P$. acnes has already been shown in granulomas of sarcoidosis patients 
$(40,41)$, it is unknown whether this bacterium can be found in granulomas of those above mentioned granulomatous diseases.

Interestingly we found presence of $P$. acnes in tissue of HP and (E)GPA patients. More specifically, presence of $P$. acnes was also observed in granulomas of HP and (E)GPA patients. The percentage of patients with presence of $P$. acnes in tissue or granulomas was not different from the sarcoidosis cohort studied in chapter 7 . These data suggest that presence of $P$. acnes in tissue and granulomas is not disease specific and the role of $P$. acnes as a specific antigenic trigger in sarcoidosis could therefore be questioned. Regarding the possible mitogenic effect of $P$. acnes observed among sarcoidosis patients in chapter 7 , we wondered whether features pointing to a mitogenic effect of $P$. acnes could be observed in other inflammatory diseases as well. We therefore examined whether bronchoalveolar lavage (BAL) cell subsets differed between HP patients with and HP patients without presence of $P$. acnes in granulomas. Interestingly, HP patients who had presence of $P$. acnes in granulomas showed a higher percentage of lymphocytes in BAL than HP patients in whom presence of $P$. acnes was not detected in granulomas. This observation supports the rational that antigens of $P$. acnes might act as a mitogen by enhancing lymphocyte proliferation in HP. It is therefore possible that $P$. acnes is not a specific trigger of sarcoidosis, HP and (E)GPA, but that it contributes to granuloma formation and maintenance in a mitogenic way.

In Chapter 9 SAA levels in serum of granulomatous diseases including sarcoidosis, HP, (E)GPA were compared with SAA serum levels of patients with idiopathic pulmonary fibrosis (IPF), as non-granulomatous group, and healthy controls. Serum amyloid $A(S A A)$ is produced by the liver during the acute phase reaction (APR) which serves to eliminate foreign pathogens. Elevated SAA levels have also been found in several inflammatory diseases, including rheumatoid arthritis, diabetes type II, Crohn's disease (42) and sarcoidosis (43-45). Chen et al. (46) studied the role of SAA in the regulation of granulomatous inflammation in sarcoidosis and found presence of SAA in granulomas of sarcoidosis patients. They proposed that SAA might contribute to granuloma formation in sarcoidosis due to SAA overproduction as result of the intensity of the immune response in this disease. These abundant SAA levels likely result in misfolding or aggregation of SAA which could serve as a seed for further amyloid-like, protein aggregation leading to entrapment of microbial antigens or autoantigens resulting in granuloma formation (46). Moreover, being a TLR2 ligand $(47,48)$, SAA might function as a feed forward loop to conserve granuloma formation. Although we observed higher serum SAA levels in serum of sarcoidosis, HP and (E)GPA patients than in serum of healthy controls, we did not observe a difference in SAA levels between the diagnostic groups. Moreover, we did also not observe 
differences in SAA levels between the granulomatous and non-granulomatous diseases. Interestingly, however, we observed that sarcoidosis patients with a pulmonary fibrotic phenotype, had higher serum SAA levels than sarcoidosis patients without pulmonary fibrosis and that SAA levels negatively correlated with DLCO \% predicted. This observation, together with our finding that SAA levels were not increased solely in granulomatous diseases but also in IPF patients, suggests that SAA can play a role in both granuloma formation as well as in fibrogenesis.

\section{General discussion}

Sarcoidosis is hallmarked by non-caseating granulomas (1) which are compact organized structure of immune cells thought to be formed in response to inability of phagocytes to destroy certain particles (2). Granulomas are not specific for sarcoidosis and in several other granulomatous diseases the underlying cause of the granulomas can be established. For instance, granulomas are observed in some infectious diseases including tuberculosis and histoplasmosis (49). When the cause of granulomas remains unknown, and the clinical and radiological features are compatible with sarcoidosis, the diagnosis of sarcoidosis is made based on exclusion of known granulomatous infectious diseases. Since sarcoidosis has a very heterogeneous presentation and multiple agents have been related to granuloma formation, it is plausible that the disease is rather a collection of several granulomatous diseases induced by different granuloma stimulating triggers. The cause of sarcoidosis is puzzling scientists for more than a century and considerable research effort has focused on the identification of triggers of sarcoidosis. However, multiple organic, inorganic and selfantigens have not been studied before in the same cohort of sarcoidosis patients. Moreover, relations between possible triggers and clinical data for the identification of new clinical phenotypes have not been described. In this thesis we therefore aimed to study the association between organic as well as inorganic antigens and sarcoidosis, and searched for disease phenotypes that correlated with the antigens studied.

\section{Inorganic triggers}

So far, the possible antigenic role of metal and silica in the disease pathogenesis of sarcoidosis was merely based on case reports and epidemiological studies. We were able to show that an immunological response to metals and silica associated with sarcoidosis in a study involving over 100 sarcoidosis patients and a non-sarcoidosis control group. Furthermore, we observed that immunological sensitization to metals or silica in sarcoidosis patients was associated with development of pulmonary fibrosis at follow up. This is in concordance with patients we do observe in clinical practice. Some of them are diagnosed with sarcoidosis and had high occupational exposure to metal or silica, such as workers in 
metal industrial or plasterers. These subjects usually present with some a-typical clinical as well as radiological features of sarcoidosis. This may include digital clubbing and pulmonary crackles on auscultation, indicative for the development of pulmonary fibrosis. Based on our findings it may now be informative to perform an LPT on different metals and silica, to examine the possible contributing agents of this clinical presentation of sarcoidosis. Since fibrosis is irreversible and extensive fibrosis will lead to a decline in lung function and a decreased diffusion capacity (50), it is of great importance that the fibrotic process will not be stimulated further. Moreover, it was indeed shown in patients with CBD that termination of exposure is beneficial in the context of disease progression $(10,11)$. The avoidance of further exposure to the antigens for which sensitization is found, may therefore be relevant to prevent chronicity and/or further disease progression. Of note, we also showed that a positive LPT was present in patients without occupational metal and silica exposure, based on the job exposure matrices used. Several factors may be responsible for this observation. First, relevant exposures to initiate sarcoidosis may be originated from other sources than occupations (15), for instance certain recreational activities (51), living in an environment high in metal fumes $(52,53)$ or wearing certain prosthetic implants $(54)$. Second, it is possible that even very low amounts of exposures, which are not detected by the occupational questionnaire coupled to the job exposure matrix, are able to induce immunological sensitization and trigger sarcoidosis in genetic predisposed individuals. Genetic susceptibility has already been shown in CBD. Individuals expressing HLA-DPB1 alleles that are characterized by the presence of a glutamic acid at position 69 of the beta chain, are thought to develop beryllium sensitization upon beryllium exposure due to a conformational change in the HLA-DP/peptide complex induced by the $\mathrm{Be}^{2}$ cation (55). Peptides of the plexin A protein may be the self-peptide present in the HLA-DP binding groove which after interaction with the beryllium cation are conformational changed and seen as foreign by HLA-DP specific CD4 T-cells $(56,57)$.

It is possible that sensitization to other inorganic agents, including aluminum, silica and zirconium, are also induced by conformational changes in the MHCll-peptide binding complex. To study such immunological mechanisms, a larger group of patients with a positive LPT for these antigens is needed. Although it might be difficult to accurately screen all sarcoidosis patients on relevant exposure, it may be important in light of the disease course, to identify the source of exposure as soon as sensitization is determined.

Regarding the LPT, a stimulation index between 2.0 and 3.0 is considered weakly positive, making interpretation difficult. A weakly positive test does not prove, but rather suggests sensitization. However, when comparing LPT results using a stimulation index $>2.0$, we found a remarkable difference between patients and controls, with $27.6 \%$ of sarcoidosis patients showing an immunological response compared to only $4.2 \%$ of controls. Moreover, 
we showed a significant correlation between the MELISA ${ }^{\circledR}$ LPT on beryllium and the official beryllium LPT following the ATS guidelines. It was shown that the specificity of this latter assay was quite high (0.969) (58), making the presence of false positive results less likely. A larger sarcoidosis and control cohort investigated for metal and silica sensitization is warranted to clarify the meaning of a weak positive LPT in sarcoidosis and to determine the specificity of the MELISA ${ }^{\circledR}$ LPT for metals and silica in sarcoidosis.

\section{Propionibacterium acnes}

Although we were able to show an association between sensitization to inorganic agents and sarcoidosis, we found no evidence for an association between sensitization to antigens of mycobacteria, vimentin or P. acnes and sarcoidosis in Dutch patients. Interestingly, we even observed that significant less sarcoidosis patients than control patients had a positive elispot test for $P$. acnes catalase. Since $P$. acnes is a commensal of the skin in the majority of the population (59) it is not surprising that sensitization to antigens of this bacterium can be found in healthy individuals. The finding that less sarcoidosis patients than controls showed sensitization to a specific antigen of this bacterium might have different explanations. First, in sarcoidosis patients a decreased peripheral cellular T-cell function to common recall antigens has been described, a phenomenon called T-cell exhausting and anergy (60). The appearance of peripheral T-cell anergy to common recall antigens at one hand and a prominent T-cell inflammatory reaction at affected sites at the other hand, is described as the immune paradox in sarcoidosis (61). This immune paradox might be caused by an unbalance in regulatory T-cells and memory T-cells, whereby the abundant presence of regulatory $\mathrm{T}$-cells excessively suppress memory T-cell proliferation in response to recall antigens. Those regulatory T-cells were, on the other hand, found to ineffectively suppress TNF- $\alpha$ production. Since TNF- $\alpha$ is a major player in granuloma formation, this inability to effectively inhibit abundant TNF- $\alpha$ production may explain the granulomatous inflammation observed at diseased organs in sarcoidosis (60). Second, in addition to T-cell anergy in peripheral blood, it might be that $P$. acnes catalase specific T-cells are homed to inflammatory sites such as the lungs, lymph nodes and skin. In this scenario, blood may not the most suitable compartment to study sensitization to $P$. acnes. It is however more invasive to study T-cell responses to $P$. acnes in other compartments, since this will require performance of bronchoalveolar lavages (BALs) or lymph node punctures. For this reason, we used immunostaining to examine whether $P$. acnes could be detected in tissue and granulomas of sarcoidosis patients.

Although presence of $P$. acnes was already shown in tissue and granulomas of Japanese and German patients with sarcoidosis (40), we showed for the first time that $P$. acnes is also present in tissue and granulomas of Dutch patients with sarcoidosis. In addition, we 
observed that sarcoidosis patients in which $P$. acnes was detected in granulomas had a more chronic and severe disease course than sarcoidosis patients in which $P$. acnes was not demonstrated in granulomas. We however also observed that this $P$. acnes antigen was present in granulomas of patients with other diseases. Studies investigating the lung microbiome in sarcoidosis patients did not observe a difference in the microbiome composition and microbiome diversity between sarcoidosis and other ILD patients (62-64). Second, no difference in the abundance of $P$. acnes was found between sarcoidosis and other ILD patients (63). It could therefore be expected to find tissue presence of $P$. acnes not solely in sarcoidosis but in other ILDs as well.

Finally, our observation that a specific T-cell response to an antigen of $P$. acnes is not common in peripheral blood of sarcoidosis patients, and the finding that antigens of $P$. acnes are not unique for granulomas of sarcoidosis patients, do not support a role of $P$. acnes as specific antigenic trigger in sarcoidosis. Together with our observation that $P$. acnes in granulomas associated with a chronic disease course in sarcoidosis and with a higher lymphocyte percentage in BAL of HP patients, it seems likely to assume that lipoteichoic acids (LTAs) of $P$. acnes acts as a mitogen. Indeed, a mitogenic effect of $P$. acnes has been described previously (65).

\section{Bacterial mitogenic effects}

Although immunomodulatory effects have been found for $P$. acnes $(33,36,66)$ it is plausible that such properties are not specially related to the $P$. acnes bacteria but that other commensal bacteria could exert similar effects. For example, Corynebacterium pyruviciproducens was found to have immunomodulatory effects since it enhanced macrophage proliferation, maturation and differentiation. Those effects on differentiation and maturation were especially found for macrophages with high levels of $\mathrm{MHCI}$ and costimulatory factors, which indicates that Corynebacterium pyruviciproducens promotes antigen presentation and interaction of macrophages with T- lymphocytes (67).

The PAB antibody that was used in our study reacts with cell-membrane bound LTA of the $P$. acnes bacteria. LTA is a cell wall polymer of gram-positive bacteria and plays a role in bacterial growth, membrane homeostasis and virulence (68). Furthermore, LTAs have shown to be immunogenic (69) and activates the innate immune system via TLR2 and NLRP6 $(70,71)$. Interleukin-18 (IL-18) production can be stimulated following activation of NLRP6 (71). Interestingly, several papers have showed increased IL-18 levels in BAL and blood of sarcoidosis patients compared to controls (72) and it was shown that IL-18 plasma levels were significantly higher in sarcoidosis patients with disease progression and/or need of steroid treatment (73). As we observed that $P$. acnes was present in granulomas of patients 
with a chronic disease course and need for treatment, it is plausible that LTAs cause an inflammatory response resulting in this chronic disease course.

Results of several papers suggest that TLR2 is at least partly involved in granuloma formation $(46,74-77)$. It is possible that LTAs of other gram-positive bacteria are also able to stimulate the immune system via NLRP6 and TLR-2 and therefore contribute in inflammation and granuloma formation as well. First, Corynebacterium tuberculostearicum and Staphylococcus epidermidis, both commensals of the human skin (78), were indeed found to induce immune responses via TLR2 $(79,80)$. Second, Corynebacteria have been associated with granulomatous diseases $(81,82)$. It is therefore plausible that besides LTAs of the $P$. acnes bacteria also LTAs of other gram-positive bacteria can be found in granulomas of varying diseases. Future studies using antibodies against LTA of other grampositive bacteria should indicate whether this is indeed the case.

Concluding, although our results suggest that $P$. acnes is rather a mitogen and not a specific antigen for sarcoidosis, identification of this bacterium in granulomas of sarcoidosis patients may be of importance. Since presence of antigens of this bacterium in granulomas was found to associate with a chronic medication requiring phenotype, and more specific, with the need for $3^{\text {rd }}$ line medication, it seems valuable to evaluate whether this specific subgroup of patients can benefit from the use of antibacterial therapy or more specific therapy against bacterial LTAs.

\section{Trigger-related phenotypes}

The main aim of this thesis was to identify trigger-related phenotypes. In a heterogeneous group of sarcoidosis patients, which was studied simultaneously for sensitization to different antigens, we indeed observed trigger-related phenotypes. Two trigger-related phenotypes, namely pulmonary fibrosis related to inorganic agent sensitization, and a chronic disease course in patients with granulomas positive for $P$. acnes, are described extensively in the previous paragraphs. These 2 trigger-related phenotypes could possibly be explained by difficult clearance of inorganic agents leading to an ongoing inflammatory granulomatous reaction resulting in fibrosis (83), and the fact that $P$. acnes might act as a mitogen (65) resulting in an ongoing inflammatory reaction, contributing to perpetuation of the inflammatory granulomatous response.

We observed a third, more surprising, trigger-related phenotype, namely the association between a latent tuberculosis infection (LTBI) and cardiac involvement in sarcoidosis. An explanation for this trigger-related phenotype is more difficult to find. An interesting observation from literature however is that HLA-DQB1*0601 is both associated with cardiac involvement of sarcoidosis as well as susceptibility to Tuberculosis among Asian patients $(84,85)$. It would be interesting to study whether such gene polymorphisms could also relate 
an infection with Mycobacterium tuberculosis to cardiac involvement of sarcoidosis in Caucasian sarcoidosis patients.

The existence of molecular mimicry may be the underlying mechanisms explaining this association, and in more general, may underlie in the existence of trigger-related phenotypes. Molecular mimicry means that similar epitopes are shared on different proteins. For instance, bacteria and viruses can contain epitopes similar to epitopes present on the host's major histocompatibility complex (MHC). When an immune response is initiated to microbial antigens, tolerance to self-antigens can be broken and a cross-reaction to similar host proteins may develop, which could lead to tissue injury and auto-immune disease (86).

Tuberculosis reactive T-cells have indeed been found to recognize self-antigens $(87,88)$. Moreover, an association between a historical mycobacterial infection and the development of auto-immune diseases have been observed in several studies $(89,90)$. Molecular mimicry between mycobacterial heat shock proteins (HSPs) and host HSPs have been thought to play a role in the pathogenesis of sarcoidosis (91) and increased levels of anti-HSP antibodies were found in sera from sarcoidosis patients (92). Interestingly, Naruse et al. suggested that, among other genes, HSP70 may be a candidate gene for the development of cardiac sarcoidosis (84).

The cross-reactivity between pathogenic epitopes and host epitopes could be an explanation for the associations observed in this study including the association between cardiac involvement and an LTBI, and the possible association between skin involvement and sensitization to antigens of $P$. acnes catalase.

\section{Serum amyloid $\mathrm{A}$}

The acute phase protein SAA was proposed to contribute to granuloma formation in sarcoidosis by overproduction resulting in misfolding or aggregation of SAA which could serve as a seed for further amyloid-like protein aggregation and entrapment of microbial antigens or auto-antigens. Based on its contribution to granuloma formation, we hypothesized that SAA levels would be higher in serum from patients with granulomatous diseases compared to patients with non-granulomatous diseases.

First, we observed that SAA levels were not significantly different between the patients with granulomatous diseases and patients with IPF, while both patient groups showed significant higher SAA levels than the healthy control group. Second, we observed that sarcoidosis patients with Scadding stage IV showed higher SAA levels than sarcoidosis patients without pulmonary fibrosis.

An association between SAA and fibrosis have been observed in other cases (93-95) in which the underlying cause of the elevated SAA levels can be related to an underlying 
inflammatory process. However, we observed elevated SAA levels in IPF patients, a disease which not seems to be initiated in response to a primary immunopathogenic mechanism (96). Possibly, elevated SAA levels could be caused by, or could contribute to fibrotic processes as well. Indeed, SAA have been found to induce the production of matrix metalloproteases (97) which are thought to be critical players in the pathogenesis of lung fibrosis (98). Moreover, SAA was found to induce IL-6 production by human fibroblasts and monocytes $(99,100)$. IL- 6 seems to be involved in a fibrotic process by inducing production of collagen I (101) and blockage of IL-6 showed indeed attenuated collagen production and fibrosis in a cardiac rat model (102). Although IPF may not be initiated by a primary immunopathogenic mechanism, secondary inflammation may contribute in its pathogenesis (96). So possibly, SAA is involved in or contributes to a fibrotic process in several ways.

Due to the recruiting effect of microbial antigens on SAA production, we expected that SAA levels were higher in sarcoidosis patients with bacterial sensitization compared to sarcoidosis patients with inorganic sensitization. We were however not able to show that there was a difference between these subgroups of sarcoidosis patients. Multiple reason may explain the absence of an association between SAA levels and sensitization for bacterial agents in our study. First it could be that the subgroups studied were too small to detect a difference between the groups. Second, as previously mentioned, we showed that sensitization to inorganic agents was related to a fibrotic phenotype in sarcoidosis. Since we observed that SAA levels were also increased in IPF patients, it is possible that SAA is involved in fibrotic processes. For this reason SAA levels can be elevated in sarcoidosis patients with inorganic sensitization, but regarding its role as an acute phase protein, also in sarcoidosis patients sensitized for bacterial antigens.

\section{Autophagy}

As already mentioned, this thesis mainly focused on the identification of trigger-related phenotypes in sarcoidosis. The possible triggers studied in this thesis were, except for vimentin and SAA, all exogenous antigens. Beside specific antigens also genetic factors and cellular pathways are considered to be of at least equal importance regarding sarcoidosis pathogenesis. For instance, it is possible that granulomas are formed in response to antigens that not have been cleared due to a defect in underlying clearance mechanisms. Autophagy is an intracellular process whereby cytosolic components are degraded to maintain homeostasis and to provide substrates for energy generation. Autophagy is activated in response to several stimuli, including stress and nutrient shortage. It regulates various processes including metabolism and development, but also infection removal and antigen presentation (103). Autophagy is therefore involved in host defense as well as in 
the regulation of inflammation (104) and contributes to sufficient elimination of exogenous substances including microbial antigens (105) metals and nanoparticles (106). Autophagy consist of multiple phases, with involvement of several genes such as mechanistic target of rapamycin (mTOR), NOD1 and NOD2 $(103,107)$. Impaired autophagy processes have been related to multiple diseases including, but not limited to, liver diseases, diabetes, heart diseases, inflammatory bowel diseases and cancer (108).

Familial cases of sarcoidosis carrying variants in the NOD2 gene and other autophagy related genes have been described $(109,110)$. However, also an unaffected familial member carried the NOD2 variant (109), suggesting that other factors such as epigenetics, or specific antigens have indeed to be present before sarcoidosis will develop.

Xenophagy is a specific type of autophagy used for the elimination of invading pathogens (104). Xenophagy was found to be involved in the clearance of several bacteria including mycobacteria and $P$. acnes (111). Interestingly, vimentin, another suspected antigen in the pathogenesis of sarcoidosis, is an essential contributor in the xenophagy process (111). Moreover, both surface-located vimentin as well as extracellular vimentin may be involved in the innate immune response to eliminate microbial infections and is a ligand for pattern recognition receptors (112). Adaptive Th17 immune responses to vimentin have been observed in peripheral blood of healthy individuals (113). It is possible that increased vimentin expression levels, for example induced by un-cleared microbial infections, lead to increased exposure and Th17 mediated pathologies. Th17-cells have been found to produce IFN- $\nu(114)$ and contribute in sarcoidosis pathogenesis $(115,116)$.

The fact that vimentin is involved in the autophagy process and that both microbial antigens as well as metals and nanoparticles may induce autophagy, may explain our finding that some sarcoidosis patients were sensitized for vimentin as well as for bacterial or inorganic antigens. Possibly, vimentin is not a specific trigger in sarcoidosis, but vimentin-specific Tcells are rather a consequence of other processes such as infection or tissue damage, which may lead to expansion of auto-immune T-cells (117). This may also explain why vimentin reactive T-cells and auto-antibodies are not specific for sarcoidosis, but are also found in patients with IPF and systemic lupus erythematous (118).

Besides bacterial and inorganic antigens, also SAA has found to be an inducer of autophagy (119). Taken together, all the antigens and proteins studied in this thesis for their possible relation in sarcoidosis pathogenesis, have been described in literature as inducers or contributors of autophagy. Several pathways are thought to be altered in sarcoidosis, of which many interact with autophagy (104). This shows once more that sarcoidosis is a multifactorial disease, which probably results from the interplay between genetic susceptibility, immunity and exposure to particular antigens. More specifically, it is possible that sarcoidosis will develop only when there is a coincidence of exposure to a particular 
antigen in combination with specific variants in certain genes involved in pathways including both autophagy as well as immunity. In the absence of either the specific antigen exposure or the genetic variants, disease will probably never develop.

\section{Future directions}

Based on the results described in this thesis, it might be important to aim at future incorporation of screening for immunological sensitization to possible triggers in the diagnostic work-up of sarcoidosis patients. In view of this it is important to further investigate whether the possible trigger-related phenotypes described in this thesis have clinical relevance. In other words, we should bridge the step from identification of triggerrelated phenotype to actual phenotype-based therapy in sarcoidosis. The new insights and hypotheses resulting from this thesis are summarized in Figure 1.

We observed that even sarcoidosis patients without JEM based metal and silica exposure demonstrated metal and silica sensitization. If low amounts of inorganic exposures are indeed able to initiate sensitization and sarcoidosis, it is difficult to determine based on exposure which patients should be further evaluated with an LPT. For this reason it seems more relevant to screen sarcoidosis patients for sensitization without determination of exposure beforehand. Moreover, since this will probably lead to a larger group of patients with a positive LPT, studies investigation genetic variants, including HLA-DPB1-Glu69, in inorganic agent sensitized patients can be initiated. The LPT is a complex test, which has some limitation since samples have to be fresh and both lymphocyte numbers as well as lymphocyte responses may be inhibited by the use of immunosuppressive medication. If certain genetic variants can be linked to metal and silica sensitization, genetic tests would be a more convenient way to screen sarcoidosis patients since such tests require only limited amounts of blood, immunosuppressive medication does not influence the results and DNA can be extracted from stored samples.

Since presence of $P$. acnes in granulomas was linked to the most severe clinical outcomes as defined by the COS-score, it could be relevant to evaluate the use of antibacterial therapy in this subgroup of patients. Some Japanese case reports already showed promising results of anti-bacterial therapy in sarcoidosis patients $(120,121)$ and a trial with clarithromycin and doxycycline hydrochloride in Japanese cardiac sarcoidosis patients is ongoing (122). In this trial, treatment regimen was not based on the presence or absence of $P$. acnes in tissue or granulomas of patients. In future studies it would therefore be interesting to study the use of antibacterial therapy in sarcoidosis patients with and without presence of $P$. acnes in granulomas, to explore whether the identification of this subgroup, in light of treatment 


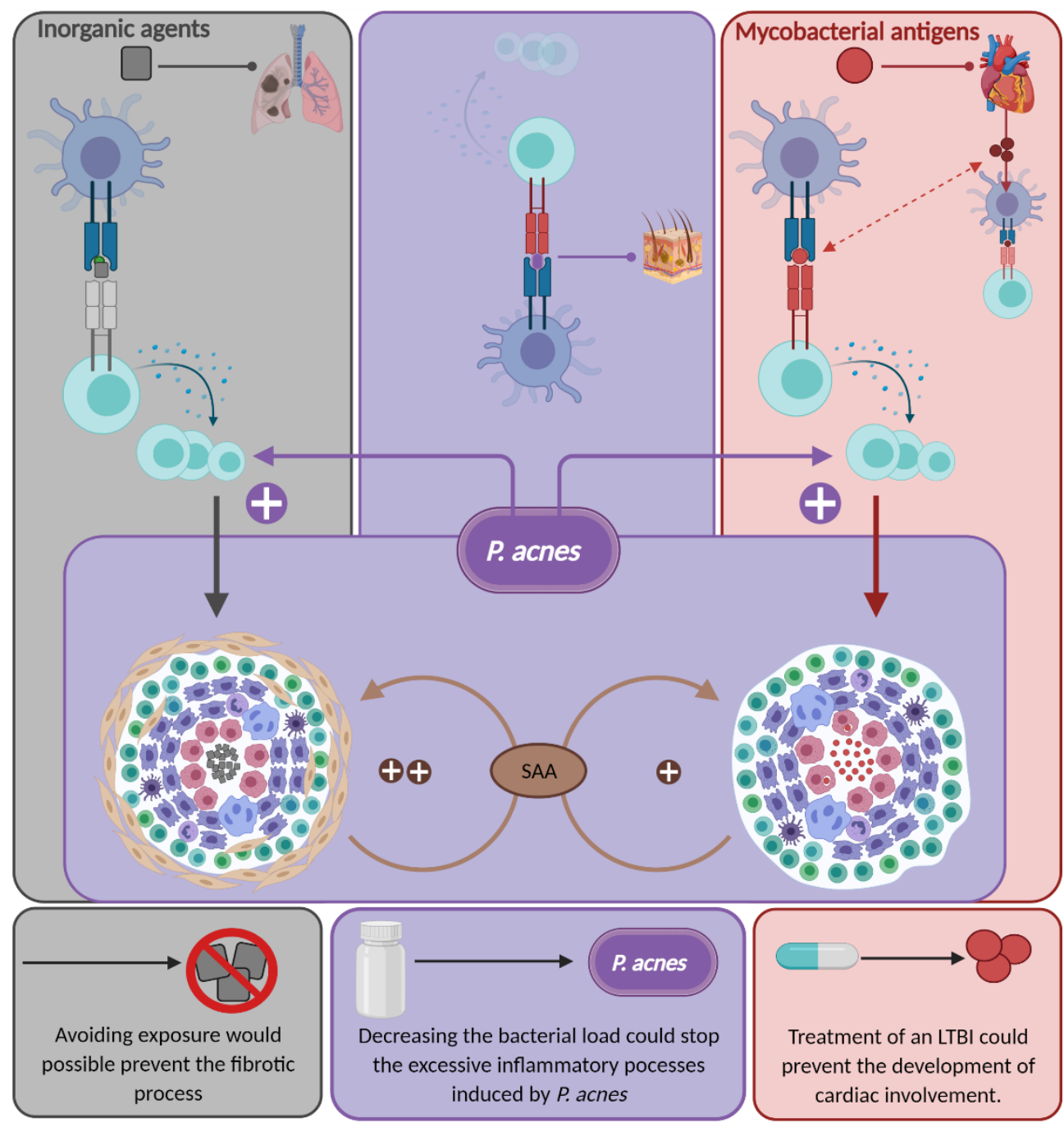

Figure 1. Schematic overview of the trigger related phenotypes observed in this thesis and possible future treatment options.

Inorganic agents that are not able to be cleared may, in susceptible individuals, lead to chronic inflammation and tissue damage resulting in fibrosis. Searching for certain genetic variants, including HLA-DPB1-Glu69, in inorganic agent sensitized patients could lead to identification of patients who could benefit from inorganic agent exposure avoidance. Mitogenic effects executed by $P$. acnes may increase the inflammatory and granulomas process by enhancing lymphocyte proliferation and cytokine secretion. Decreasing the bacterial load could decrease these excessive inflammatory processes observed in sarcoidosis. Cardiac sarcoidosis may be developed due to molecular mimicry between Tuberculosis antigens and cardiac proteins. Treatment of an LTBI may possible prevent the development of cardiac involvement in sarcoidosis. 
responses, is valuable. At least in $P$. acnes induced granulomatous mice models, reduction of $P$. acnes by the use of anti-bacterial treatment showed improvement in the pulmonary lesions, including decreased granulomas and BAL cell counts (123).

Regarding the association found between an LBTI and presence of cardiac involvement in sarcoidosis, it could be considered to systematically explore cardiac involvement extensively in each patient with sarcoidosis and an LTBI, even though symptoms of cardiac involvement may not be present (yet). Furthermore, in current clinical practice, if a patient is diagnosed with an LTBI they can either choose follow-up without medication or start LTBI treatment using Isoniazid/Rifampicin. It could be beneficial for this group to start LTBI treatment instead of a wait-and-see policy directly after the diagnosis of LTBI is made.

In our study, we were not able to show that increased SAA serum levels were specifically associated with sarcoidosis or granulomatous diseases. SAA levels in serum can be increased due to the contribution of SAA in the acute phase response. Increased serum SAA levels can therefore be found in patients with several diseases. It would be interesting to examine the role of SAA in sarcoidosis pathogenesis in more detail. Antibodies to vimentin, another self-protein suspected to act as an auto-antigen in sarcoidosis, have been observed in bronchoalveolar lavage fluid (BALF) of a subgroup of sarcoidosis patients (124). If SAA act as an auto-antigen in sarcoidosis, it is plausible that antibodies against SAA in serum or BALF of sarcoidosis patients can be observed as well. Future studies should determine whether this is indeed the case.

In this thesis we focused solely on possible triggers of sarcoidosis. Although we studied multiple antigens simultaneously in one cohort of patients, we did not examine if it is a combination of particular antigens that together will trigger the development of sarcoidosis. Moreover, it is possible that sarcoidosis will develop only when there is a coincidence of exposure to particular antigens in combination with genetic variants in specific genes involved in pathways including autophagy and immunity. To thoroughly explore such hypotheses, a study should be conducted which combines different aspects thought to contribute in sarcoidosis pathogenesis, including triggers, auto-antibody analysis and whole exome sequencing. Stratification of patients will demand a large cohort with different genetic backgrounds, heterogeneous disease presentations and diverse disease outcomes and therefore requires international collaborations.

If such future studies reveal that genetic variants associate with particular antigens, personalized treatment options can be further explored. For instance, antibiotic treatment in combination with mTOR inhibitors such as rapamycin, could be effective in sarcoidosis 
patients with a bacterial inducing antigen in combination with genetic variants in the autophagy process. Moreover, non-affected family members of sarcoidosis patients carrying the same genetic variants may be advised to avoid exposure to particular antigens, to prevent disease development.

To conclude, sarcoidosis is a complex and heterogeneous granulomatous disease that seems the result of an interplay between genetic variants in immune and non-immune related processes and specific antigens. The results of this thesis strengthen the hypothesis that the disease can develop in response to a variety of antigens, which can differ from patient to patient. Studying both inducing antigens as well as defects in underlying pathways and genetic variants in MHC and other immune related genes, especially those involved in autophagy, innate as well as adaptive immunity, could probably lead to the identification of more personalized based treatments and better prediction of disease course and dangerous phenotypes. 


\section{References}

1. Shaikh F, Abtin FG, Lau R, Saggar R, Belperio JA, Lynch JP. Radiographic and Histopathologic Features in Sarcoidosis: A Pictorial Display. Semin Respir Crit Care Med. 2020 Oct 10;41(05):758-84.

2. Pagán AJ, Ramakrishnan L. The Formation and Function of Granulomas. Annu Rev Immunol. 2018 Apr 26;36(1).

3. James DG. A clinicopathological classification of granulomatous disorders. Vol. 76, Postgraduate Medical Journal. Postgrad Med J; 2000. p. 457-65.

4. Grunewald J, Grutters JC, Arkema E V., Saketkoo LA, Moller DR, Müller-Quernheim J. Sarcoidosis. Nat Rev Dis Prim. 2019 Dec 1;5(1).

5. Prasse A. The Diagnosis, Differential Diagnosis, and Treatment of Sarcoidosis . Dtsch Arztebl Int. 2016 Aug 22;113(33-34):565-74.

6. Mayer AS, Hamzeh N, Maier LA. Sarcoidosis and chronic beryllium disease: similarities and differences . Semin Respir Crit Care Med. 2014 Jun;35(3):316-29.

7. Cai HR, Cao M, Meng FQ, Wei JY. Pulmonary sarcoid-like granulomatosis induced by aluminum dust: report of a case and literature review . Chin Med J (Engl). 2007 Sep 5;120(17):1556-60.

8. Werfel U, Schneider J, Rodelsperger K, Kotter J, Popp W, Woitowitz HJ, et al. Sarcoid granulomatosis after zirconium exposure with multiple organ involvement. Eur Respir J. 1998 Sep;12(3):750.

9. Rafnsson V, Ingimarsson O, Hjalmarsson I, Gunnarsdottir H. Association between exposure to crystalline silica and risk of sarcoidosis. Occup Environ Med. 1998;55(10):657-60.

10. Sood A, Beckett WS, Cullen MR. Variable response to long-term corticosteroid therapy in chronic beryllium disease . Chest. 2004 Dec;126(6):2000-7.

11. Sprince NL, Kanarek DJ, Weber AL, Chamberlin RI, Kazemi H. Reversible respiratory disease in beryllium workers. Am Rev Respir Dis. 1978 Jun;117(6):1011-7.

12. Richeldi L, Sorrentino R, Saltini C. HLA-DPB1 glutamate 69: a genetic marker of beryllium disease. Science. 1993;262(5131):242-4.

13. McCanlies EC, Kreiss K, Andrew M, Weston A. HLA-DPB1 and chronic beryllium disease: a HuGE review . Am J Epidemiol. 2003;157(5):388-98.

14. Infante PF, Newman LS. Beryllium exposure and chronic beryllium disease . Lancet (London, England). 2004 Feb 7;363(9407):415-6.

15. Newman LS, Kreiss K. Nonoccupational beryllium disease masquerading as sarcoidosis: identification by blood lymphocyte proliferative response to beryllium . Am Rev Respir Dis. 1992;145(5):1212-4.

16. Fang $\mathrm{C}$, Huang $\mathrm{H}, \mathrm{Xu}$ Z. Immunological Evidence for the Role of Mycobacteria in 
Sarcoidosis: A Meta-Analysis . PLoS One. 2016 Aug 1;11(8):e0154716.

17. Gupta D, Agarwal R, Aggarwal AN, Jindal SK. Molecular evidence for the role of mycobacteria in sarcoidosis: a meta-analysis . Eur Respir J. 2007 Sep;30(3):508-16.

18. Eishi Y. Etiologic link between sarcoidosis and Propionibacterium acnes. Respir Investig. 2013 Jun;51(2):56-68.

19. Zhou Y, Hu Y, Li H. Role of propionibacterium acnes in sarcoidosis: A meta-analysis. Vol. 30, Sarcoidosis Vasculitis and Diffuse Lung Diseases. Mattioli 1885 S.p.A.; 2013. p. 262-7.

20. Grunewald J, Kaiser Y, Ostadkarampour M, Rivera N V, Vezzi F, Lotstedt B, et al. Tcell receptor-HLA-DRB1 associations suggest specific antigens in pulmonary sarcoidosis . Eur Respir J. 2016;47(3):898-909.

21. Eberhardt C, Thillai M, Parker R, Siddiqui N, Potiphar L, Goldin R, et al. Proteomic Analysis of Kveim Reagent Identifies Targets of Cellular Immunity in Sarcoidosis . PLoS One. 2017 Jan 23;12(1):e0170285.

22. Fireman E, Shai AB, Alcalay $Y$, Ophir N, Kivity S, Stejskal V. Identification of metal sensitization in sarcoid-like metal-exposed patients by the MELISA(R) lymphocyte proliferation test - a pilot study . J Occup Med Toxicol. 2016 Apr 12;11:18-016-01011. eCollection 2016.

23. Kouranos V, Tzelepis GE, Rapti A, Mavrogeni S, Aggeli K, Douskou M, et al. Complementary Role of CMR to Conventional Screening in the Diagnosis and Prognosis of Cardiac Sarcoidosis. JACC Cardiovasc Imaging. 2017 Dec 1;10(12):1437-47.

24. Judson MA. Screening sarcoidosis patients for cardiac sarcoidosis: What the data really show. Vol. 154, Respiratory Medicine. 2019. p. 155-7.

25. Bakker AL, Grutters JC, Keijsers RG, Post MC. Cardiac sarcoidosis: Challenges in clinical practice. Vol. 23, Current Opinion in Pulmonary Medicine. 2017. p. 468-75.

26. Ishige I, Eishi Y, Takemura T, Kobayashi I, Nakata K, Tanaka I, et al. Propionibacterium acnes is the most common bacterium commensal in peripheral lung tissue and mediastinal lymph nodes from subjects without sarcoidosis. Sarcoidosis, Vasc Diffus lung Dis Off J WASOG. 2005 Mar;22(1):33-42.

27. Zhao MM, Du SS, Li QH, Chen T, Qiu H, Wu Q, et al. High throughput 16SrRNA gene sequencing reveals the correlation between Propionibacterium acnes and sarcoidosis. Respir Res. 2017 Feb 1;18(1).

28. Ishige I, Usui Y, Takemura T, Eishi Y. Quantitative PCR of mycobacterial and propionibacterial DNA in lymph nodes of Japanese patients with sarcoidosis. Lancet. 1999 Jul 10;354(9173):120-3.

29. Eishi Y, Suga M, Ishige I, Kobayashi D, Yamada T, Takemura T, et al. Quantitative 
analysis of mycobacterial and propionibacterial DNA in lymph nodes of Japanese and European patients with sarcoidosis. J Clin Microbiol. 2002;40(1):198-204.

30. Yorozu P, Furukawa A, Uchida K, Akashi T, Kakegawa T, Ogawa T, et al. Propionibacterium acnes catalase induces increased Th1 immune response in sarcoidosis patients. Respir Investig. 2015 Jul;53(4):161-9.

31. Furusawa H, Suzuki Y, Miyazaki Y, Inase N, Eishi Y. Th1 and Th17 immune responses to viable Propionibacterium acnes in patients with sarcoidosis. Respir Investig. 2012 Sep;50(3):104-9.

32. Schupp JC, Tchaptchet S, Lutzen N, Engelhard P, Muller-Quernheim J, Freudenberg $\mathrm{MA}$, et al. Immune response to Propionibacterium acnes in patients with sarcoidosis--in vivo and in vitro. BMC Pulm Med. 2015 Jul 24;15:75-7.

33. Teixeira D, Ishimura ME, Apostólico J de S, Viel JM, Passarelli VC, Cunha-Neto E, et al. Propionibacterium acnes enhances the immunogenicity of hivbr18 human immunodeficiency virus-1 vaccine. Front Immunol. 2018 Feb 7;9(FEB).

34. Ghaffar A, Cullen RT, Woodruff MFA. Further analysis of the anti-tumour effect in vitro of peritoneal Exudate cells from mice treated with corynebacterium parvum. Br J Cancer. 1975;31(1):15-24.

35. Keller R, Keist R, van der Meide PH. Modulation of tumoricidal activity, induced in bone-marrow-derived mononuclear phagocytes by interferon $\gamma$ or Corynebacterium parvum, by interferon $\beta$, tumor necrosis factor, prostaglandin E2, and transforming growth factor $\beta$. Int J Cancer. 1991;49(5):796-800.

36. Ananias RZ, Rodrigues EG, Braga EG, Squaiella CC, Mussalem JS, Longhini ALF, et al. Modulatory effect of killed Propionibacterium acnes and its purified soluble polysaccharide on peritoneal exudate cells from C57BI/6 mice: Major NKT cell recruitment and increased cytotoxicity. Scand J Immunol. 2007 Jun;65(6):538-48.

37. lio $K$, lio $T$, Okui $Y$, Ichikawa $H$, Tanimoto $Y$, Miyahara $N$, et al. Experimental Pulmonary Granuloma Mimicking Sarcoidosis Induced by Propionibacterium Acnes in Mice. Acta Med Okayama. 2010;64(2).

38. Shah KK, Pritt BS, Alexander MP. Histopathologic review of granulomatous inflammation. Vol. 7, Journal of Clinical Tuberculosis and Other Mycobacterial Diseases. Elsevier Ltd; 2017. p. 1-12.

39. Naeem M, Ballard DH, Jawad H, Raptis C, Bhalla S. Noninfectious Granulomatous Diseases of the Chest. RadioGraphics. 2020 Jun 5;190180.

40. Negi M, Takemura T, Guzman J, Uchida K, Furukawa A, Suzuki Y, et al. Localization of propionibacterium acnes in granulomas supports a possible etiologic link between sarcoidosis and the bacterium. Mod Pathol. 2012 Sep;25(9):1284-97.

41. Beijer E, Seldenrijk K, Eishi Y, Uchida K, Damen J, Grutters JC, et al. Presence of 
Propionibacterium acnes in granulomas associates with a chronic disease course in Dutch sarcoidosis patients. ERJ Open Res. 2020 Jan 1;486-2020.

42. Ye RD, Sun L. Emerging functions of serum amyloid A in inflammation. J Leukoc Biol. 2015 Dec;98(6):923-9.

43. Ivanisevic J, Kotur-Stevuljevic J, Stefanovic A, Spasic S, Vucinic Mihailovic V, Videnovic Ivanov J, et al. Association of serum amyloid $A$ and oxidative stress with paraoxonase 1 in sarcoidosis patients . Eur J Clin Invest. 2016;46(5):418-24.

44. Gungor S, Ozseker F, Yalcinsoy M, Akkaya E, Can G, Eroglu H, et al. Conventional markers in determination of activity of sarcoidosis. Int Immunopharmacol. 2015;25(1):174-9.

45. Bargagli E, Magi B, Olivieri C, Bianchi N, Landi C, Rottoli P. Analysis of serum amyloid A in sarcoidosis patients. Respir Med. 2011;105(5):775-80.

46. Chen ES, Song Z, Willett MH, Heine S, Yung RC, Liu MC, et al. Serum amyloid A regulates granulomatous inflammation in sarcoidosis through Toll-like receptor-2. Am J Respir Crit Care Med. 2010 Feb 15;181(4):360-73.

47. Cheng N, He R, Tian J, Ye PP, Ye RD. Cutting edge: TLR2 is a functional receptor for acute-phase serum amyloid A. J Immunol (Baltimore, Md 1950). 2008 Jul 1;181(1):22-6.

48. He RL, Zhou J, Hanson CZ, Chen J, Cheng N, Ye RD. Serum amyloid A induces G-CSF expression and neutrophilia via Toll-like receptor 2 . Blood. 2009 Jan 8;113(2):42937.

49. Santosham R, Deslauriers J. Tuberculosis and Other Granulomatous Diseases of the Airway. Vol. 28, Thoracic surgery clinics. Thorac Surg Clin; 2018. p. 155-61.

50. Cottin V, Wollin L, Fischer A, Quaresma M, Stowasser S, Harari S. Fibrosing interstitial lung diseases: Knowns and unknowns. Vol. 28, European Respiratory Review. European Respiratory Society; 2019.

51. Catinon M, Chemarin C, Assaad S, Vuillermoz-Blas S, Roux E, Traverse-Glehen A, et al. Wire brushing wood furniture, granulomatosis and microscopic mineralogical analysis. Sarcoidosis Vasc Diffus Lung Dis. 2014 Oct 20;31(3 SE-Letter to Editor):2624.

52. Deubelbeiss U, Gemperli A, Schindler C, Baty F, Brutsche MH. Prevalence of sarcoidosis in Switzerland is associated with environmental factors . Eur Respir J. 2010;35(5):1088-97.

53. Frye BC, Quartucci C, Rakete S, Grubanovic A, Höhne K, Mangold F, et al. A Cluster of Beryllium Sensitization Traced to the Presence of Beryllium in Concrete Dust. Chest. 2020 Sep;

54. Balbouzis T, Georgiadis T, Grigoris P. Granulomatous Lung Disease: A Novel 
Complication following Metallosis from Hip Arthroplasty. Hip Pelvis. 2016;28(4):249.

55. Clayton GM, Wang Y, Crawford F, Novikov A, Wimberly BT, Kieft JS, et al. Structural basis of chronic beryllium disease: linking allergic hypersensitivity and autoimmunity. Cell. 2014 Jul 3;158(1):132-42.

56. Petukh M, Wu B, Stefl S, Smith N, Hyde-Volpe D, Wang L, et al. Chronic Beryllium Disease: revealing the role of beryllium ion and small peptides binding to HLA-DP2 . PLoS One. 2014 Nov 4;9(11):e111604.

57. Falta MT, Pinilla C, Mack DG, Tinega AN, Crawford F, Giulianotti $M$, et al. Identification of beryllium-dependent peptides recognized by CD4+ $T$ cells in chronic beryllium disease . J Exp Med. 2013 Jul 1;210(7):1403-18.

58. Stange AW, Furman FJ, Hilmas DE. The beryllium lymphocyte proliferation test: Relevant issues in beryllium health surveillance. Am J Ind Med. 2004 Nov;46(5):45362.

59. Xu H, Li H. Acne, the Skin Microbiome, and Antibiotic Treatment. Am J Clin Dermatol. 2019 Jun 10;20(3):335-44.

60. Miyara M, Amoura Z, Parizot C, Badoual C, Dorgham K, Trad S, et al. The immune paradox of sarcoidosis and regulatory T cells . J Exp Med. 2006 Feb 20;203(2):35970.

61. Loke WSJ, Freeman A, Garthwaite L, Prazakova S, Park M, Hsu K, et al. T-bet and interleukin-27: possible TH1 immunomodulators of sarcoidosis. Inflammopharmacology. 2015 Oct 22;23(5):283-90.

62. Garzoni C, Brugger SD, Qi W, Wasmer S, Cusini A, Dumont P, et al. Microbial communities in the respiratory tract of patients with interstitial lung disease. Thorax. 2013 Dec;68(12):1150-6.

63. Becker A, Vella G, Galata V, Rentz K, Beisswenger C, Herr C, et al. The composition of the pulmonary microbiota in sarcoidosis - An observational study. Respir Res. 2019 Feb 28;20(1).

64. D’Argenio V, Casaburi G, Precone V, Moccia LG, Postiglione I, Bocchino M, et al. A common microbial signature is present in the lower airways of interstitial lung diseases including sarcoidosis. Sarcoidosis Vasc Diffus Lung Dis. 2018 Dec 5;35(4):354-62.

65. Jappe U, Ingham E, Henwood J, Holland KT. Propionibacterium acnes and inflammation in acne; P. acnes has T-cell mitogenic activity. Br J Dermatol. 2002 Feb;146(2):202-9.

66. Yeon SJ, Matsumoto SE, Yamashita M, Tomimatsu K, Teruya K, Katakura Y, et al. Propionibacterium acnes acts as an adjuvant in in vitro immunization of human 
peripheral blood mononuclear cells. Biosci Biotechnol Biochem. 2007;71(8):19639.

67. Tong J, Han Q, Wang S, Su Z, Zheng D, Shen P, et al. Corynebacterium pyruviciproducens, as an immune modulator, can promote the activity of macrophages and up-regulate antibody response to particulate antigen. Exp Biol Med. 2012 Nov 1;237(11):1322-30.

68. Percy MG, Gründling A. Lipoteichoic Acid Synthesis and Function in Gram-Positive Bacteria. Annu Rev Microbiol. 2014 Sep 8;68(1):81-100.

69. Knox KW, Wicken AJ. Immunological properties of teichoic acids. Vol. 37, Bacteriological Reviews. American Society for Microbiology (ASM); 1973. p. 215-57.

70. Mitchell JA, Paul-Clark MJ, Clarke GW, McMaster SK, Cartwright N. Critical role of toll-like receptors and nucleotide oligomerisation domain in the regulation of health and disease. Vol. 193, Journal of Endocrinology. J Endocrinol; 2007. p. 323-30.

71. Hara H, Seregin SS, Yang D, Fukase K, Chamaillard M, Alnemri ES, et al. The NLRP6 Inflammasome Recognizes Lipoteichoic Acid and Regulates Gram-Positive Pathogen Infection. Cell. 2018 Nov 29;175(6):1651-1664.e14.

72. Liu DH, Yao YT, Cui W, Chen K. The association between interleukin-18 and pulmonary sarcoidosis: A meta-analysis. Scand J Clin Lab Invest. 2010 Oct;70(6):428-32.

73. Kieszko R, Krawczyk P, Jankowska O, Chocholska S, Król A, Milanowski J. The clinical significance of interleukin 18 assessment in sarcoidosis patients. Respir Med. 2007 Apr;101(4):722-8.

74. Magalhães KG, Almeida PE, Atella GC, Maya-Monteiro CM, Castro-Faria-Neto HC, Pelajo-Machado $M$, et al. Schistosomal-Derived Lysophosphatidylcholine Are Involved in Eosinophil Activation and Recruitment through Toll-Like Receptor-2Dependent Mechanisms. J Infect Dis. 2010 Nov;202(9):1369-79.

75. Puissegur M-P, Lay G, Gilleron M, Botella L, Nigou J, Marrakchi H, et al. Mycobacterial Lipomannan Induces Granuloma Macrophage Fusion via a TLR2Dependent, ADAM9- and $\beta 1$ Integrin-Mediated Pathway . J Immunol. 2007 Mar 1;178(5):3161-9.

76. Hu W, Yang S, Shimada Y, Münch M, Marín-Juez R, Meijer AH, et al. Infection and RNA-seq analysis of a zebrafish t/r2 mutant shows a broad function of this toll-like receptor in transcriptional and metabolic control and defense to Mycobacterium marinum infection. BMC Genomics. 2019 Nov 20;20(1).

77. Gong $W$, Huang $F$, Sun $L, Y u A$, Zhang $X, X u Y$, et al. Toll-like receptor-2 regulates macrophage polarization induced by excretory-secretory antigens from Schistosoma japonicum eggs and promotes liver pathology in murine 
schistosomiasis. PLoS NegI Trop Dis. 2018 Dec 1;12(12).

78. Byrd AL, Belkaid Y, Segre JA. The human skin microbiome. Vol. 16, Nature Reviews Microbiology. Nature Publishing Group; 2018. p. 143-55.

79. Altonsy MO, Kurwa HA, Lauzon GJ, Amrein M, Gerber AN, Almishri W, et al. Corynebacterium tuberculostearicum, a human skin colonizer, induces the canonical nuclear factor-kB inflammatory signaling pathway in human skin cells. Immunity, Inflamm Dis. 2020 Mar 1;8(1):62-79.

80. Lai Y, Cogen AL, Radek KA, Park HJ, MacLeod DT, Leichtle A, et al. Activation of TLR2 by a small molecule produced by staphylococcus epidermidis increases antimicrobial defense against bacterial skin infections. J Invest Dermatol. 2010;130(9):2211-21.

81. Mathelin C, Riegel P, Chenard MP, Brettes JP. Association of corynebacteria with granulomatous mastitis. Vol. 119, European Journal of Obstetrics and Gynecology and Reproductive Biology. Elsevier Ireland Ltd; 2005. p. 260-1.

82. Nureki SI, Miyazaki E, Matsuno O, Takenaka R, Ando M, Kumamoto T, et al. Corynebacterium ulcerans infection of the lung mimicking the histology of ChurgStrauss syndrome. Chest. 2007;131(4):1237-9.

83. Panselinas E, Judson MA. Acute Pulmonary Exacerbations of Sarcoidosis. Chest. 2012 Oct;142(4):827-36.

84. Naruse TK, Matsuzawa Y, Ota M, Katsuyama Y, Matsumori A, Hara M, et al. HLADQB1*0601 is primarily associated with the susceptibility to cardiac sarcoidosis. Tissue Antigens. 2000;56(1):52-7.

85. Wu F, Zhang W, Zhang L, Wu J, Li C, Meng X, et al. NRAMP1, VDR, HLA-DRB1, and HLA-DQB1 gene polymorphisms in susceptibility to tuberculosis among the chinese kazakh population: A case-control study. Biomed Res Int. 2013;2013.

86. Nickerson C, Luthra H, David C. Antigenic mimicry and autoimmune diseases. Int Rev Immunol. 1991;7(3):205-24.

87. Mor F, Cohen IR. $T$ cells in the lesion of experimental autoimmune encephalomyelitis. Enrichment for reactivities to myelin basic protein and to heat shock proteins. J Clin Invest. 1992;90(6):2447-55.

88. van Eden W, Holoshitz J, Nevo Z, Frenkel A, Klajman A, Cohen IR. Arthritis induced by a T-lymphocyte clone that responds to Mycobacterium tuberculosis and to cartilage proteoglycans. Proc Natl Acad Sci U S A. 1985;82(15):5117-20.

89. Lin YC, Liang SJ, Liu YH, Hsu WH, Shih CM, Sung FC, et al. Tuberculosis as a risk factor for systemic lupus erythematosus: Results of a nationwide study in Taiwan. Rheumatol Int. 2012 Jun;32(6):1669-73.

90. Chao WC, Lin CH, Liao TL, Chen YM, Chen DY, Chen HH. Association between a 
history of mycobacterial infection and the risk of newly diagnosed Sjögren's syndrome: A nationwide, population-based case-control study. PLoS One. 2017 May $1 ; 12(5)$.

91. Dubaniewicz A. Mycobacterium tuberculosis heat shock proteins and autoimmunity in sarcoidosis. Vol. 9, Autoimmunity Reviews. Autoimmun Rev; 2010. p. 419-24.

92. Dubaniewicz A, Kämpfer S, Singh M. Serum anti-mycobacterial heat shock proteins antibodies in sarcoidosis and tuberculosis. Tuberculosis. 2006 Jan;86(1):60-7.

93. Hosaka N, Ito M, Taki Y, Iwai H, Toki J, Ikehara S. Amyloid A gastrointestinal amyloidosis associated with idiopathic retroperitoneal fibrosis: Report of a rare autopsy case and review of the literature. Arch Pathol Lab Med. 2003;127(6):7358.

94. Lakota K, Carns M, Podlusky S, Mrak-Poljsak K, Hinchcliff M, Lee J, et al. Serum amyloid a is a marker for pulmonary involvement in systemic sclerosis. PLoS One. 2015 Jan 28;10(1).

95. Ooms V, Decupere M, Lerut E, Vanrenterghem Y, Kuypers DRJ. Secondary renal amyloidosis due to long-standing tubulointerstitial nephritis in a patient with Sjögren syndrome. Am J Kidney Dis. 2005 Nov;46(5).

96. Desai O, Winkler J, Minasyan M, Herzog EL. The role of immune and inflammatory cells in idiopathic pulmonary fibrosis. Vol. 5, Frontiers in Medicine. Frontiers Media S.A.; 2018.

97. Connolly M, Mullan RH, McCormick J, Matthews C, Sullivan O, Kennedy A, et al. Acute-phase serum amyloid $A$ regulates tumor necrosis factor $\alpha$ and matrix turnover and predicts disease progression in patients with inflammatory arthritis before and after biologic therapy. Arthritis Rheum. 2012;64(4):1035-45.

98. Pardo A, Cabrera S, Maldonado M, Selman M. Role of matrix metalloproteinases in the pathogenesis of idiopathic pulmonary fibrosis. Vol. 17, Respiratory Research. BioMed Central Ltd.; 2016.

99. O’Reilly S, Cant R, Ciechomska M, Finnigan J, Oakley F, Hambleton S, et al. Serum amyloid $A$ induces interleukin-6 in dermal fibroblasts via Toll-like receptor 2, interleukin-1 receptor-associated kinase 4 and nuclear factor-kB. Immunology. 2014;143(3):331-40.

100. Anthony D, McQualter JL, Bishara M, Lim EX, Yatmaz S, Seow HJ, et al. SAA drives proinflammatory heterotypic macrophage differentiation in the lung via CSF-1Rdependent signaling. FASEB J. 2014 Sep 1;28(9):3867-77.

101. Hügle T, O’Reilly S, Simpson R, Kraaij MD, Bigley V, Collin M, et al. Tumor necrosis factor-costimulated $T$ lymphocytes from patients with systemic sclerosis trigger collagen production in fibroblasts. Arthritis Rheum. 2013 Feb;65(2):481-91. 
102. Mir SA, Chatterjee A, Mitra A, Pathak K, Mahata SK, Sarkar S. Inhibition of Signal Transducer and Activator of Transcription 3 (STAT3) attenuates interleukin-6 (IL-6)induced collagen synthesis and resultant hypertrophy in rat heart. J Biol Chem. 2012 Jan 20;287(4):2666-77.

103. Wang X, Xu Z, Cai Y, Zeng S, Peng B, Ren X, et al. Rheostatic Balance of Circadian Rhythm and Autophagy in Metabolism and Disease. Front Cell Dev Biol. 2020 Nov $24 ; 8$.

104. Pacheco Y, Lim CX, Weichhart T, Valeyre D, Bentaher A, Calender A. Sarcoidosis and the mTOR, Rac1, and Autophagy Triad. Vol. 41, Trends in Immunology. Elsevier Ltd; 2020. p. 286-99.

105. Keller MD, Torres VJ, Cadwell K. Autophagy and microbial pathogenesis. Vol. 27, Cell Death and Differentiation. Springer Nature; 2020. p. 872-86.

106. Chatterjee S, Sarkar S, Bhattacharya S. Toxic metals and autophagy. Vol. 27, Chemical Research in Toxicology. American Chemical Society; 2014. p. 1887-900.

107. Travassos LH, Carneiro LAM, Ramjeet M, Hussey S, Kim YG, Magalhes JG, et al. Nod1 and Nod2 direct autophagy by recruiting ATG16L1 to the plasma membrane at the site of bacterial entry. Nat Immunol. 2010 Jan;11(1):55-62.

108. Ichimiya T, Yamakawa T, Hirano T, Yokoyama Y, Hayashi Y, Hirayama D, et al. Autophagy and autophagy-related diseases: A review. Vol. 21, International Journal of Molecular Sciences. MDPI AG; 2020. p. 1-21.

109. Besnard V, Calender A, Bouvry D, Pacheco Y, Chapelon-Abric C, Jeny F, et al. G908R NOD2 variant in a family with sarcoidosis. Respir Res. 2018 Mar 20;19(1).

110. Calender A, Rollat Farnier PA, Buisson A, Pinson S, Bentaher A, Lebecque S, et al. Whole exome sequencing in three families segregating a pediatric case of sarcoidosis. BMC Med Genomics. 2018 Mar 6;11(1).

111. Berthelot JM, Puéchal X. Impaired intracellular pathogen clearance and inflammatory joint disease: Is Whipple's disease a guiding light? Vol. 85, Joint Bone Spine. Elsevier Masson SAS; 2018. p. 531-6.

112. Mak TN, Bruggemann H. Vimentin in Bacterial Infections. Cells. $2016 \mathrm{Apr}$ 18;5(2):10.3390/cells5020018.

113. Sullivan JA, Jankowska-Gan E, Hegde S, Pestrak MA, Agashe V V., Park AC, et al. Th17 Responses to Collagen Type V, ka1-Tubulin, and Vimentin Are Present Early in Human Development and Persist Throughout Life. Am J Transplant. 2017 Apr 1;17(4):944-56.

114. Annunziato F, Cosmi L, Santarlasci V, Maggi L, Liotta F, Mazzinghi B, et al. Phenotypic and functional features of human Th17 cells. J Exp Med. 2007 Aug 6;204(8):184961. 
115. Zissel G, Muller-Quernheim J. Cellular Players in the Immunopathogenesis of Sarcoidosis . Clin Chest Med. 2015 Dec;36(4):549-60.

116. Mortaz Rezayat, F., Amani, D., Kiani, A., Garssen, J., Adcock, I., Velayati,A. E. The Roles of T Helper 1, T Helper 17 and Regulatory T Cells in the Pathogenesis of Sarcoidosis. Iran J Allergy, Asthma Immunol. 2016;15(4).

117. Li FJ, Surolia R, Li H, Wang Z, Kulkarni T, Liu G, et al. Autoimmunity to Vimentin Is Associated with Outcomes of Patients with Idiopathic Pulmonary Fibrosis. J Immunol. 2017 Sep 1;199(5):1596-605.

118. Musaelyan A, Lapin S, Nazarov V, Tkachenko O, Gilburd B, Mazing A, et al. Vimentin as antigenic target in autoimmunity: A comprehensive review. Vol. 17, Autoimmunity Reviews. Elsevier B.V.; 2018. p. 926-34.

119. Zhu S, Wang Y, Chen W, Li W, Wang A, Wong S, et al. High-density lipoprotein (HDL) counter- regulates serum amyloid A (SAA)-induced SPLA2-IIE and SPLA2-V expression in macrophages. PLoS One. 2016 Nov 1;11(11).

120. Takemori N, Nakamura M, Kojima M, Eishi Y. Successful treatment in a case of Propionibacterium acnes-associated sarcoidosis with clarithromycin administration: a case report . J Med Case Rep. 2014 Jan 15;8:15.

121. Inoue Y, Teraki Y. Association of Propionibacterium acnes with the efficacy of minocycline therapy for cutaneous sarcoidosis. Int J Dermatol. 2020;

122. Ishibashi K, Eishi Y, Tahara N, Asakura M, Sakamoto N, Nakamura K, et al. Japanese antibacterial drug management for cardiac Sarcoidosis (J-ACNES): A multicenter, open-label, randomized controlled study. J Arrhythmia. 2018;34(5):520-6.

123. Nishiwaki T, Yoneyama H, Eishi Y, Matsuo N, Tatsumi K, Kimura H, et al. Indigenous pulmonary Propionibacterium acnes primes the host in the development of sarcoidlike pulmonary granulomatosis in mice. Am J Pathol. 2004;165(2):631-9.

124. Kinloch AJ, Kaiser $Y$, Wolfgeher D, Ai J, Eklund A, Clark MR, et al. In situ humoral immunity to vimentin in HLA-DRB ${ }^{*} 03+$ patients with pulmonary sarcoidosis. Front Immunol. 2018 Jul 9;9(JUL). 


\section{Appendix}

Nederlandse samenvatting

Affiliations of the authors

Dankwoord

List of publications

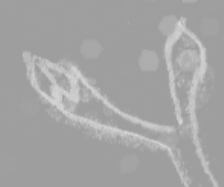

Curriculum Vitae 


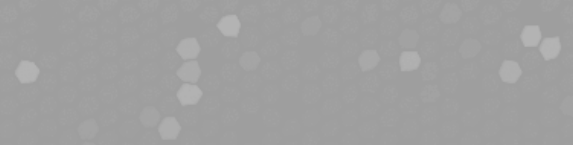

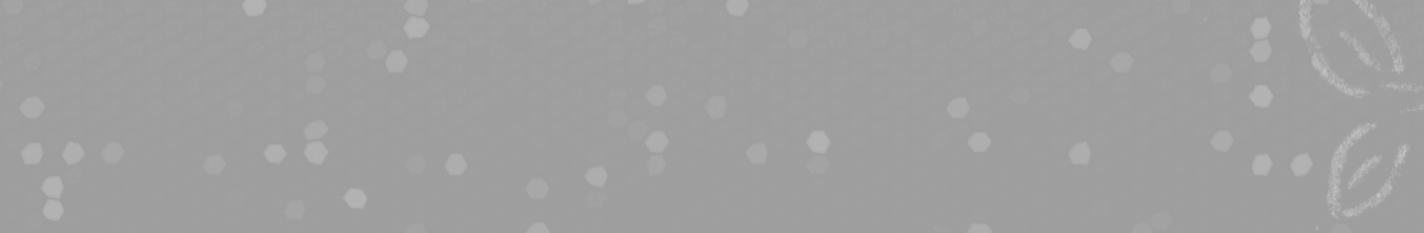<smiles>C1CCCC1</smiles>

$\therefore \%$

0.0<smiles>COCO</smiles>

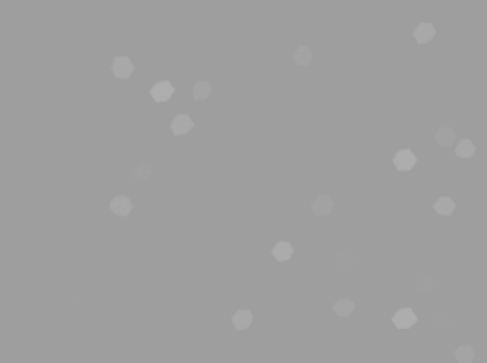

$0+0$

no

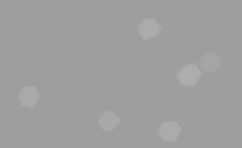<smiles>O=CCO</smiles>

80

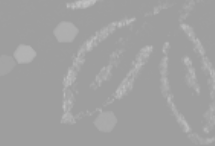

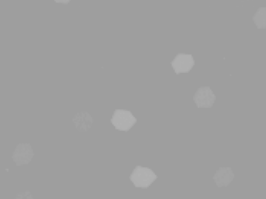

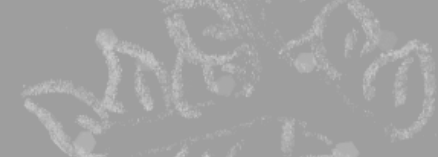

है $2(f)(3)+2)^{2}=$<smiles>O=C1CC(=O)C1</smiles>

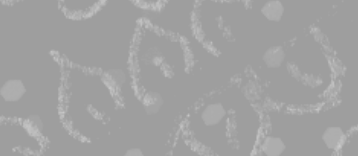

$(8)$

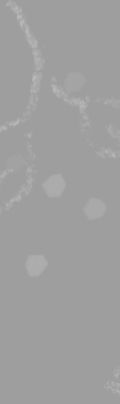

$\int_{0}^{2} y^{2}$

-

a
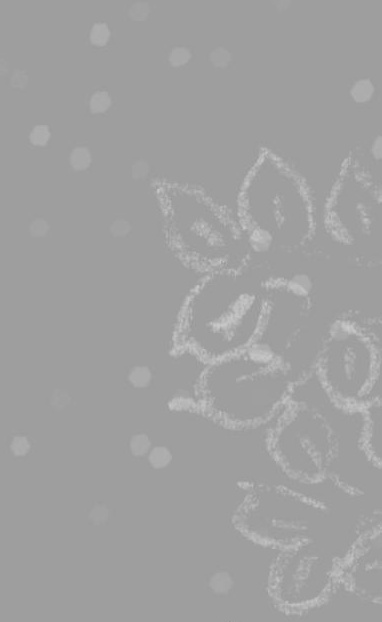

○

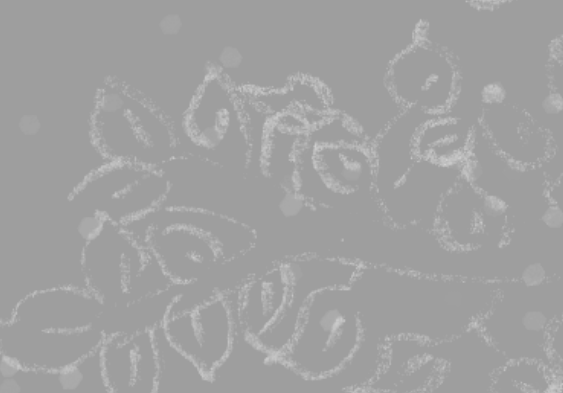


Nederlandse samenvatting 


\section{Inleiding}

Sarcoïdose is een systemische ziekte die gekenmerkt wordt door de vorming van granulomen; opeenhopingen van verschillende witte bloedcellen welke betrokken zijn bij ons afweersysteem. De granulomen die gezien worden bij sarcoïdose zijn meestal nietverkazend, wat betekend dat er geen necrose (weefsel afsterving) plaats vindt in het granuloom. Granulomen worden doorgaans gevormd wanneer het witte bloedcellen niet lukt bepaalde onderdelen van bijvoorbeeld bacteriën of lichaamsvreemde stoffen op te ruimen. Een granuloom bakent deze deeltjes dan af zodat verdere verspreiding voorkomen wordt.

Sarcoïdose ontstaat meestal bij mannen met een leeftijd tussen de 30 en 50 jaar en bij vrouwen met een leeftijd tussen de 40 en 60 jaar. Het is een zeldzame ziekte waarvan wordt geschat dat er in Nederland om en nabij 7000 mensen aan lijden (ongeveer 40 per 100.000 mensen). Sarcoïdose kan zich per patiënt anders presenteren. De longen en intra thoracale lymfeklieren (klieren in de borstholte) zijn het vaakst aangedaan, maar eigenlijk kan elk orgaan betrokken raken in de ziekte. Sarcoïdose patiënten kunnen geclassificeerd worden op basis van de mate van betrokkenheid van de longen en intra thoracale lymfeklieren middels de Scadding stadia. Deze Scadding stadia worden bepaald middels een Röntgen foto van de longen en rijken van 0 tot en met 5, waarbij er bij stadium 0 geen betrokkenheid is van de intra thoracale lymfeklieren en longen, bij Scadding stage 1 zijn de intra thoracale lymfeklieren aangedaan maar de longen niet, Scadding stage 2 geeft aan dat zowel de intra thoracale lymfeklieren als de longen aangedaan zijn, bij Scadding stage 3 zijn de intra thoracale lymfeklieren niet aangedaan maar de longen wel, en bij Scadding stage 4 is er sprake van littekenvorming in de longen, ook wel fibrose genoemd. Naast de heterogene presentatie die sarcoïdose kent, kan ook het beloop van de ziekte per patiënt verschillen. Een scoringssysteem dat het beloop van de ziekte aangeeft is de zogenaamde clinical outcome status (COS). Deze wordt doorgaans bepaald 5 jaar nadat de diagnose gesteld is en geeft onder andere aan of de ziekte verdwenen of nog steeds actief is, of de patiënt medicatie gebruikt of ooit een medicamenteuze behandeling heeft gehad. Deze status zegt dus niet alleen iets over de lymfeklier en long betrokkenheid, maar geeft een algemeen uitkomst beeld van de ziekte weer.

De oorzaak van sarcoïdose is nog niet geheel bekend. Er wordt gedacht dat een samenspel tussen veranderingen in onze eigen genen (erfelijk materiaal), het afweersysteem en deeltjes die granuloomvorming kunnen initiëren kan resulteren in sarcoïdose. Omdat het beeld dat bij sarcoïdose gezien wordt kan lijken op infectieuze granulomateuze ziekten zoals lepra en tuberculose, wordt gesuggereerd dat bepaalde bacteriën, waaronder 
mycobacteriën en Propionibacterium acnes ( $P$. acnes), een oorzaak van sarcoïdose kunnen zijn. Omdat de longen vaak aangedaan zijn in sarcoïdose, wordt ook vermoed dat het inademen van anorganische deeltjes, bestaande uit bijvoorbeeld metaal of silica, sarcoïdose zou kunnen veroorzaken. Daarnaast wordt in recentere studies gesuggereerd dat sarcoïdose het resultaat is van een auto-immuun reactie tegen lichaamseigen eiwitten, waaronder vimentine, een eiwit dat onderdeel is van het cytoskelet verantwoordelijk voor de vorm en stevigheid van onze cellen. Ook serum amyloïde $A$ (SAA), een eiwit dat door het lichaam geproduceerd wordt als reactie op infecties en andere ontstekingsprocessen, zou een rol kunnen spelen bij de granuloom vorming in sarcoïdose. Deze bacteriën, metaal en silica deeltjes en lichaamseigen eiwitten zouden een granulomateuze reactie kunnen uitlokken, wat in samenspel met andere factoren uiteindelijk kan resulteren in sarcoïdose. Deze granuloom initiërende deeltjes worden daarom ook wel "triggers" van sarcoïdose genoemd.

\section{Doel van dit proefschrift}

Omdat sarcoïdose een erg heterogene presentatie kent en meerdere stoffen (ook wel antigenen genoemd) granulomen kunnen veroorzaken, is het mogelijk dat sarcoïdose niet één enkele homogene ziekte is, maar eerder een verzameling van meerdere granulomateuze ziekten geïnduceerd door verschillende granuloom stimulerende antigenen. Zoals hierboven beschreven zijn er afgelopen jaren al verschillende mogelijke triggers van sarcoïdose onderzocht. Een relatie tussen anorganische stoffen en sarcoïdose is tot op heden enkel gebaseerd op case reports en epidemiologische studies waarbij enkel naar blootstelling is gekeken. In dit proefschrift hebben we daarom een groep sarcoïdose patiënten onderzocht op zowel blootstelling als immuunreacties tegen anorganische stoffen waaronder metalen en silica.

Ondanks dat er al veel onderzoek gedaan is naar mogelijke triggers van sarcoïdose, zijn mogelijke bacteriële, auto-immuun en anorganische triggers van sarcoïdose nog nooit tegelijkertijd in hetzelfde cohort van sarcoïdose patiënten onderzocht. Daarnaast is er nog nooit onderzoek gedaan naar een relatie tussen mogelijke triggers en ziekteverschijnselen zoals orgaan betrokkenheid, Scadding stage en COS. In dit proefschrift hebben we daarom in dezelfde patiëntengroep onderzoek gedaan naar de mycobacterie, $P$. acnes bacterie, vimentine, metalen en silica. Daarnaast hebben we gekeken of er een verband is tussen deze mogelijke triggers en ziekte verschijnselen, om zogenoemde trigger-gerelateerde fenotypes te ontdekken.

Momenteel is er nog geen genezende behandeling voor sarcoïdose. Patiënten die vanwege het risico op orgaan beschadiging medicatie nodig hebben worden behandeld met immuun 
onderdrukkende middelen om zo de ontsteking te onderdrukken en symptomen te verminderen. Meer inzicht in triggers van sarcoïdose en mogelijke trigger-gerelateerde fenotypes is daarom van belang. Deze kennis zou namelijk kunnen leiden tot een meer gepersonaliseerde behandeling van de ziekte. Patiënten bij wie bacteriën een mogelijke rol spelen in het ziekte proces kunnen bijvoorbeeld baat hebben bij antibacteriële therapie, terwijl het vermijden van relevante blootstelling meer effect zal hebben bij patiënten waarbij metalen en silica sarcoïdose hebben getriggered. Het identificeren van triggergerelateerde-fenotypes zou er daarnaast voor kunnen zorgen dat het ziekteverloop beter te voorspellen is, en dat er wellicht ook beter voorspeld kan worden welke patiënten behandeld zouden moeten worden en bij wie het minder noodzakelijk is.

Hoofdstuk 2: Etiologie en immuun gerelateerde pathologie van sarcoïdose: Nieuwe inzichten.

In dit review wordt een overzicht gegeven van belangrijke spelers van het afweersysteem, ook wel immuunsysteem genoemd, die mogelijk betrokken zijn in de pathogenese van sarcoïdose. Daarnaast wordt een overzicht gegeven van tot op heden gesuggereerde triggers van sarcoïdose, die ook genoemd worden in de inleiding van deze samenvatting. Het aangeboren immuunsysteem zorgt voor de eerste verdedigingen tegen pathogenen. Micro-organismen bevatten een groot scala aan moleculaire patronen waardoor ze te onderscheiden zijn van lichaamseigen cellen. Deze moleculaire patronen worden pathogenassociated molecular patterns (PAMPs) genoemd. Naast deze PAMPs kunnen eiwitten die geproduceerd en uitgescheiden worden tijdens weefselschade, herkend worden door het aangeboren immuunsysteem. Deze eiwitten worden ook wel danger-associated molecular patterns (DAMPs) genoemd. Het aangeboren immuunsysteem herkend deze DAMPs en PAMPs door middel van pattern recognition receptors (PRRs), zoals bijvoorbeeld toll-like receptors (TLRs) en nucleotide-binding oligomerization domain (NOD) like receptors (NLRs). Wanneer deze receptoren geactiveerd worden zal er een immuun respons geïnitieerd worden. Meerdere studies hebben afwijkingen in TLRs en NLRs gevonden in sarcoïdose patiënten. Aangetaste capaciteit om PAMPs te kunnen herkennen kan resulteren in een verminderde verdediging tegen pathogenen. Dit zou granuloomvorming kunnen triggeren en zo kunnen leiden tot een verhoogde sarcoïdose vatbaarheid. In tegenstelling tot het aangeboren immuunsysteem, is het verworven immuunsysteem erg specifiek. Het omvat antigeen presenterende cellen (APCs), T-cellen en B-cellen met het vermogen om antilichamen te produceren. Elke T-cel heeft een specifieke T-cel receptor die in staat is om verwerkte antigenen, gepresenteerd in major histocompatibility complex ( $\mathrm{MHC}$ ) moleculen 
op APCs, te herkennen. Als reactie op herkende lichaamsvreemde antigenen, zullen T-cellen zich delen en cytokines produceren, die bijdragen aan het doden van de indringers. Door de blijvende immuun stimulatie in sarcoïdose, hopen T-cellen zich op rond de granulomen. Het is niet geheel bekend waarom een overactieve T-cel reactie plaats vindt in sarcoïdose, maar het zou zo kunnen zijn dat T-cellen reageren op antigenen maar dat signalen, moleculen en cellen die dit proces na verloop van tijd weer af moeten remmen ontbreken of inefficiënt zijn in sarcoïdose.

Hoofdstuk 3: Klinische observaties: is metaal of silica geassocieerde sarcoïdose een nieuw trigger-gerelateerd fenotype?

Voor sommige anorganische stoffen, zoals bepaalde metalen, is al beschreven dat zij granuloom vorming kunnen veroorzaken. Het meest beschreven metaal in deze context is beryllium. Chronische beryllium ziekte of berylliose is een granulomateuze ziekte die gerelateerd is aan beryllium blootstelling, en die klinisch vaak niet te onderscheiden is van sarcoïdose. Wanneer iemand die hier genetisch gevoelig voor is in aanraking komt met beryllium, zal er een immuunrespons volgen waarbij er beryllium geheugen cellen gevormd worden. Deze aanwezigheid van zulke geheugencellen kan vastgesteld worden door witte bloedcellen buiten het lichaam bloot te stellen aan beryllium. Wanneer er geheugen cellen aanwezig zijn, zullen deze na blootstelling aan beryllium delen en cytokines produceren. Dit fenomeen wordt immunologische sensibilisatie genoemd aan kan aangetoond worden met verschillende laboratorium testen zoals een elispot test of een lymfocyten proliferatie test (LPT). De diagnose chronische beryllium ziekte wordt gesteld wanneer er aanwezigheid is van beryllium blootstelling, niet-verkazende granulomen en beryllium sensibilisatie. In dit hoofdstuk hebben wij een patiënt beschreven bij wie de diagnose sarcoïdose gewijzigd kon worden in chronische beryllium ziekte op basis van werkzaamheden in een ijzergieterij, niet verkazende granulomen en een positieve beryllium LPT. Daarnaast hebben wij 2 patiënten beschreven die zich presenteerden met een radiologisch beeld niet geheel typerend voor sarcoïdose. Op basis van de longbiopten die niet verkazende granulomen lieten zien werd toch de diagnose sarcoïdose gesteld. Bij beide patiënten werd in het longbiopt lichaamsvreemd materiaal gevonden, mogelijk veroorzaakt door werkzaamheden als, respectievelijk, logistiek medewerker in de haven van een staalfabriek en stukadoor, met daarbij blootstelling aan metaal en silica. Een LPT toonde bij de ene patiënt aluminium sensibilisatie en bij de andere sensibilisatie voor silica. Wanneer de diagnostische criteria om chronische beryllium ziekte vast te stellen gevolgd worden, is het aannemelijk (maar 
niet bewezen) dat aluminium dan wel silica een rol hebben gespeeld bij het ontstaan van sarcoïdose bij deze laatste twee patiënten.

Hoofdstuk 4: Sensibilisatie tegen metalen en silica is geassocieerd met sarcoïdose in Nederlandse patiënten.

De relatie tussen anorganische stoffen en sarcoïdose is tot op heden enkel beschreven in epidemiologische studies die alleen naar blootstelling hebben gekeken, of in beschrijvingen van enkele patiënten zoals in hoofdstuk 3 . Om deze reden hebben we in hoofdstuk 4 zowel metaal en silica blootstelling als metaal en silica sensibilisatie onderzocht in een groep sarcoïdose patiënten en dit vergeleken met een controlegroep. Metaal en silica blootstelling werd in 256 sarcoïdose patiënten en in 73 controles bepaald middels een complete beroepsgeschiedenis gekoppeld aan een job exposure matrix (JEM). Een JEM is een soort schema dat per beroepstitel aangeeft of er in dat beroep blootstelling plaats vindt aan bepaalde stoffen. Met een LPT werd een deel van deze patiënten $(n=33)$ en controles $(n=19)$ onderzocht op sensibilisatie tegen aluminium, beryllium, zirkonium en silica. We zagen geen verschil tussen het percentage sarcoïdose patiënten en controles dat blootstelling had aan metalen of silica o.b.v. de resultaten van de vragenlijsten gekoppeld aan de JEM. Echter, sensibilisatie tegen metalen of silica werd alleen gevonden in sarcoïdose patiënten en niet in de controles, wat met $21.2 \%$ tegenover $0 \%$ een significant verschil was. Deze observatie ondersteunt de hypothese dat metalen en silica bijdragend zijn in de ontwikkeling van sarcoïdose in een subgroep van de patiënten.

Omdat sensibilisatie wel verschilde tussen de sarcoïdose en controlegroep, maar blootstelling niet, is het goed mogelijk dat veranderingen in bepaalde genen in sarcoïdose patiënten er toe leidt dat sensibilisatie tegen metalen en silica ontstaat. Zulke genetische veranderingen zijn al aangetoond in chronische beryllium ziekte, waarbij $90 \%$ van de patiënten met chronische beryllium ziekte een specifieke verandering had in een aminozuur van het HLA-DPB1 gen, terwijl dit in ongeveer $40 \%$ gezonde controles gezien werd.

Een opvallende bevinding in onze studie was dat er ook sarcoïdose patiënten waren die op basis van onze vragenlijst gekoppeld aan de JEM geen blootstelling hadden aan metalen en silica, maar wel sensibilisatie lieten zien. Het zou kunnen zijn dat door genetische vatbaarheid, een hele kleine mate van blootstelling die door deze JEM niet opgepikt wordt, al kan leiden tot sensibilisatie en uiteindelijk sarcoïdose. 
Hoofdstuk 5: Uit het gelijktijdig testen van sarcoïdose patiënten op sensibilisatie tegen verschillende antigenen blijkt een associatie met anorganische antigenen gerelateerd aan een fibrotisch fenotype van sarcoïdose.

In dit hoofdstuk hebben we in een cohort van 201 sarcoïdose patiënten en 51 controles sensibilisatie tegen antigenen van de Mycobacterie, de $P$. acnes bacterie en vimentine onderzocht. In 105 van deze sarcoïdose patiënten en in 24 van de controles hebben we ook naar sensibilisatie tegen metalen en silica gekeken. Daarna hebben we gekeken of sensibilisatie voor bepaalde antigenen gerelateerd was aan bepaalde ziekteverschijnselen, om zo trigger-gerelateerde fenotypes te identificeren.

We vonden geen verschil in het percentage sarcoïdose patiënten en controles dat gesensibiliseerd was voor mycobacteriële antigenen of vimentine. Opvallend was dat 3 van de 5 sarcoïdose patiënten die gesensibiliseerd waren voor mycobacteriële antigenen betrokkenheid van het hart hadden, zogenaamde cardiale sarcoïdose. Een verrassende bevinding was dat een lager percentage van de sarcoïdose patiënten sensibilisatie voor $P$. acnes antigenen liet zien (3.5\% vergeleken met $15.7 \%$ van de controles). Sarcoïdose patiënten met $P$. acnes sensibilisatie waren jonger ten tijde van diagnose dan sarcoïdose patiënten zonder $P$. acnes sensibilisatie. Daarnaast leek het zo te zijn dat deze patiëntengroep vaker huid betrokkenheid had, al was dit net niet significant verschillend van de groep zonder $P$. acnes sensibilisatie. In tegenstelling tot deze organische antigenen, zagen we wel een associatie tussen de geteste anorganische antigenen en sarcoïdose. Een hoger percentage van de sarcoïdose patiënten liet namelijk sensibilisatie zien tegen aluminium, beryllium, silica of zirkonium in vergelijking met de controlegroep ( $27.6 \%$ versus 4.2\%). Daarnaast hadden sarcoïdose patiënten met sensibilisatie tegen een van deze anorganische stoffen vaker longfibrose ontwikkeld 5 jaar na de diagnose dan sarcoïdose patiënten zonder sensibilisatie tegen de geteste anorganische stoffen. De resultaten van deze studie suggereren dat anorganische triggers zoals metalen en silica een grotere rol spelen in sarcoïdose dan tot op heden is gedacht. Daarnaast blijkt uit de relaties tussen mycobacteriële antigenen en cardiale betrokkenheid, $P$. acnes antigenen en huid betrokkenheid en anorganische antigenen en fibrose, dat het inderdaad mogelijk is om trigger-gerelateerde fenotypes te identificeren in een heterogene groep sarcoïdose patiënten. 
Hoofdstuk 6: Een latente tuberculose infectie is geassocieerd met cardiale betrokkenheid in patiënten met sarcoïdose

In dit hoofdstuk hebben we de mogelijke associatie tussen mycobacteriële antigen en cardiale betrokkenheid in sarcoïdose uit hoofdstuk 5 verder onderzocht. Cardiale betrokkenheid komt bij ongeveer $5 \%$ van de sarcoïdose patiënten voor, hoewel uit autopsies en radiologische studies blijkt dat dit een onderschatting kan zijn en dat het werkelijke percentage waarschijnlijk tussen de 20 en $30 \%$ ligt. Identificatie van cardiale betrokkenheid is belangrijk omdat dit een belangrijke doodsoorzaak is bij sarcoïdose. In dit hoofdstuk hebben we gekeken naar een latente tuberculose infectie (LTBI). Bij een LTBI is iemand in het verleden ooit besmet met Mycobacterium tuberculosis, hetgeen blijkt uit sensibilisatie in het bloed, zonder dat tekenen te tonen van een actieve tuberculose infectie. Een groep cardiale sarcoïdose patiënten $(n=103)$ werd onderzocht op het hebben van een LTBI en vergeleken met sarcoïdose patiënten zonder cardiale betrokkenheid $(n=153)$. We zagen dat een significant hoger percentage van de cardiale sarcoïdose patiënten een LTBI had dan de niet-cardiale sarcoïdose patiënten (6.8\% vergeleken met $0.7 \%$ ). Als toekomstige studies deze associatie kunnen bevestigen, kan dat van klinisch belang zijn. Het kan bijvoorbeeld relevant zijn om sarcoïdose patiënten bij wie een LTBI vastgesteld wordt, direct te screenen op cardiale betrokkenheid, ook al zijn er nog geen signalen die wijzen op cardiale sarcoïdose. Daarnaast zou het behandelen van de LTBI wellicht kunnen voorkomen dat er cardiale betrokkenheid op treedt.

Hoofdstuk 7: Aanwezigheid van P. acnes in granulomen associeert met een chronisch ziekte beloop in Nederlandse sarcoïdose patiënten

In dit hoofdstuk hebben we onderzocht of we $P$. acnes kunnen detecteren in weefsel en granulomen van Nederlandse sarcoïdose patiënten. Daarnaast hebben we gekeken of aanwezigheid van $P$. acnes in weefsel en granulomen gerelateerd is aan het ziekteverloop van sarcoïdose.

Het is lastig om een etiologische rol van $P$. acnes in sarcoïdose aan te tonen omdat deze bacterie bij de meeste mensen als commensaal op de huid voorkomt. Echter, DNA van de $P$. acnes bacterie is vaker gevonden in weefsel van Chinese, Japanse, Italiaanse, Engelse en Duitse sarcoïdose patiënten dan in controles. Dit suggereert dat $P$. acnes op $z^{\prime} n$ minst betrokken is in het ziekteproces. Daarnaast is er een verhoogde immuunrespons tegen $P$. acnes gevonden in verschillende studies met Japanse en Duitse sarcoïdose patiënten. In hoofdstuk 5 konden wij dit echter niet aantonen in ons cohort van sarcoïdose patiënten uit 
Nederland. Wellicht is bloed niet de juiste plek om te zoeken naar een mogelijke rol van $P$. acnes in het ontstaan van sarcoïdose. Daarom hebben wij in dit huidige hoofdstuk weefsel van sarcoïdose patiënten gebruikt om door middel van een andere methode naar de rol van $P$. acnes in sarcoïdose te kijken. Granulomateus weefsel van 76 sarcoïdose patiënten werd gekleurd met een antilichaam tegen een deeltje van de celwand van de $P$. acnes bacterie, om zo de aanwezigheid van deze bacterie zichtbaar te maken. Daarna hebben we gekeken of de sarcoïdose patiënten bij wie $P$. acnes gedetecteerd was een ander ziektebeloop hadden dan de sarcoïdose patiënten zonder $P$. acnes in het weefsel of granulomen. We zagen dat bij een subgroep van deze Nederlandse sarcoïdose patiënten (41\%) $P$. acnes aanwezig was in het onderzochte weefsel. Bij $17 \%$ van de sarcoïdose groep was $P$. acnes ook specifiek aantoonbaar in granulomen. Daarnaast zagen we dat sarcoïdose patiënten met $P$. acnes in granulomen vaker een chronisch ziekteloop en noodzaak voor immunosuppressieve behandeling hadden, dan de patiënten waar $P$. acnes niet detecteerbaar was in granulomen. Een mogelijke verklaring voor de relatie tussen aanwezigheid van $P$. acnes en een chronisch ziektebeloop kan zijn dat $P$. acnes mitogene effecten heeft, hetgeen ook beschreven is in andere studies. Een mitogeen is een deeltje of stof die cellen aspecifiek aanzet tot delen. Dus naast dat $P$. acnes sarcoïdose zou kunnen initiëren, zou het ook als een mitogeen in brede context kunnen werken en zo een inflammatoire reactie en de presentatie van antigenen aan T-cellen in stand kunnen houden.

Hoofdstuk 8: Detectie van $P$. acnes in granulomen van patiënten met hypersensitiviteits pneumonitis of vasculitis onthult dat $P$. acnes niet specifiek is voor granulomen van patiënten met sarcoïdose.

Omdat we in hoofdstuk 7 veronderstelden dat $P$. acnes een mitogene rol zou kunnen hebben en wellicht geen specifieke trigger is van sarcoïdose, hebben we in hoofdstuk 8 verder onderzocht of de aanwezigheid van $P$. acnes in granulomen specifiek is voor sarcoïdose.

Verschillende studies hebben al laten zien dat $P$. acnes granuloom vorming kan triggeren. Bovendien wordt er gesuggereerd dat de $P$. acnes bacterie betrokken is bij de pathogenese van sarcoïdose. Granulomen zijn echter niet specifiek voor sarcoïdose en komen ook voor bij andere ziektes. $P$. acnes is al aangetoond in granulomen van sarcoïdose patiënten maar het is niet bekend of deze bacterie ook aanwezig is in granulomen van patiënten met andere granulomateuze ziekten zoals hypersensitiviteits pneumonitis (HP), Granulomatose met polyangiitis (GPA) en Eosinofiele Granulomatose met Polyangiitis (EGPA). Granulomateus 
weefsel van patiënten met HP, GPA en EGPA werd daarom onderzocht op de aanwezigheid van de $P$. acnes bacterie door gebruik te maken van dezelfde methode als in hoofdstuk 7 . We zagen aanwezigheid van de $P$. acnes bacterie ook in weefsel en granulomen van een deel van de HP, GPA en EGPA patiënten. Het percentage van de patiënten waarbij aanwezigheid van de $P$. acnes bacterie gevonden werd in weefsel of granulomen verschilden niet van het percentage sarcoïdose patiënten uit hoofdstuk 7 waarbij $P$. acnes in weefsel of granulomen gevonden werd. Deze resultaten suggereren dat aanwezigheid van $P$. acnes in weefsel en granulomen niet ziekte specifiek is en maken de rol van $P$. acnes als specifieke trigger in sarcoïdose twijfelachtig. Met betrekking tot het mitogene effect van de $P$. acnes bacterie, waargenomen in hoofdstuk 7, vroegen we ons af of er in andere inflammatoire ziekten ook kenmerken te zien waren die konden wijzen op een mogelijk mitogeen effect van de $P$. acnes bacterie. Om deze reden hebben we gekeken naar subgroepen van immuuncellen in bronchoalveolaire lavage (BAL) van HP patiënten met en zonder aanwezigheid van $P$. acnes in granulomen. We zagen dat HP patiënten met aanwezigheid van $P$. acnes in granulomen een hoger lymfocyten percentage in de BAL hadden dan HP patiënten zonder $P$. acnes in granulomen. Deze bevinding ondersteunt de hypothese dat $P$. acnes kan werken als een mitogeen, waardoor ook in HP proliferatie van lymfocyten versterkt wordt. Het is daarom mogelijk dat $P$. acnes geen specifieke trigger is in sarcoïdose, HP en (E)GPA maar dat het als mitogeen bijdraagt in de vorming en in stand houding van granulomen.

Hoofdstuk 9: Serum Amyloïde A bloed waardes zijn verhoogd in patiënten met granulomateuze en fibrotische ziektes

In dit hoofdstuk hebben we Serum Amyloïde A (SAA) waardes in bloed van patiënten met granulomateuze ziektes waaronder sarcoïdose, HP en (E)GPA vergeleken met SAA bloed waardes van patiënten met idiopathische pulmonaire fibrose (IPF), een niet granulomateuze ziekte.

Verhoogde waardes van het acute fase eiwit SAA zijn gevonden in verscheidene inflammatoire ziekten zoals reumatoïde artritis, ziekte van Crohn en ook in sarcoïdose. Daarnaast wordt in de literatuur gesuggereerd dat SAA een regulerende rol heeft in de vorming en in stand houding van granulomen in sarcoïdose.

Ondanks dat we hogere SAA concentraties vonden in bloed van sarcoïdose, HP en (E)GPA patiënten in vergelijking met gezonde controles, zagen we tussen de verschillende granulomateuze ziektes geen verschillen in SAA concentraties. Bovendien werd geen verschil gevonden in SAA concentraties tussen de patiënten met granulomateuze ziekten 
enerzijds en patiënten met IPF anderzijds. Daarnaast zagen we dat sarcoïdose patiënten met pulmonale fibrose (Scadding stadium IV) hogere SAA concentraties bloed hadden dan sarcoïdose patiënten zonder pulmonale fibrose. Deze observatie, samen met de bevinding dat SAA waardes niet alleen verhoogd zijn in granulomateuze ziektes maar ook in patiënten met IPF, doet vermoeden dat SAA naast granulomateuze processen ook betrokken is in fibrotische processen.

\section{Conclusies}

De oorzaak van sarcoïdose houdt wetenschappers al meer dan een eeuw bezig. Sarcoïdose wordt gekarakteriseerd door granulomen, echter granulomen zijn niet specifiek voor sarcoïdose maar ook te vinden bij andere ziekten zoals tuberculose, Hypersensitiviteits Pneumonitis (HP), Granulomatose met Polyangiitis (GPA) en Eosinofiele Granulomatose met Polyangiitis (EGPA). Wanneer de oorzaak van aanwezige granulomen niet bekend is en het radiologische en klinische beeld past bij sarcoïdose, wordt de diagnose sarcoïdose gesteld door andere ziekten uit te sluiten (per exclusionem). Omdat sarcoïdose een heterogene presentatie kent en verscheidene antigenen in relatie zijn gebracht met granuloom vorming, is het mogelijk dat sarcoïdose niet een enkele homogene ziekte is maar eerder een verzameling van meerdere granulomateuze ziektes geïnduceerd door verschillende triggers.

Het doel van dit proefschrift was om zowel organische als anorganische antigenen te onderzoeken in hetzelfde cohort, en daarnaast te onderzoeken of er trigger-gerelateerde fenotypes van sarcoïdose te identificeren zijn.

De suggestie dat metalen en silica een rol spelen in de pathogenese van sarcoïdose was tot dusver gebaseerd op epidemiologische studies en casus beschrijvingen. In hoofdstuk 4 en 5 hebben we aangetoond dat immunologische sensibilisatie tegen metalen en silica geassocieerd is met sarcoïdose op basis van onderzoek in een grote groep sarcoïdose patiënten die vergeleken werd met een controle groep. Daarnaast zagen we dat sensibilisatie tegen metalen en silica gerelateerd was aan het ontwikkelen pulmonale fibrose in sarcoïdose patiënten 5 jaar na de diagnose. Omdat fibrose onomkeerbaar is en grote mate van fibrose kan leiden tot een verlaagde longfunctie en diffusie capaciteit, is het belangrijk dat een fibrotisch proces niet verder gestimuleerd wordt. In patiënten met chronische beryllium ziekte is het inderdaad aangetoond dat het stoppen van blootstelling aan beryllium bevorderlijk kan zijn met het oog op voorkomen van verdere ziekteprogressie. Het vermijden van verdere blootstelling aan metalen en silica zal daarom ook een chronisch 
beloop en progressie kunnen voorkomen in sarcoïdose patiënten die metaal of silica gesensibiliseerd zijn.

We hebben aan de andere kant ook laten zien dat sarcoïdose patiënten met metaal en silica sensibilisatie niet altijd blootstelling aan metalen en silica hebben op basis van de vragenlijsten gekoppeld aan de JEM. Meerdere oorzaken kunnen ten grondslag liggen aan deze bevinding. Ten eerste kan relevante blootstelling aan metalen en silica plaats hebben gevonden op basis van niet werk-gerelateerde activiteiten, zoals bepaalde hobby's, het wonen in een omgeving met een hoge mate van metaal gassen of het hebben van bepaalde implantaten. Daarnaast is het mogelijk dat zelfs een hele lage mate van blootstelling, die niet opgepikt wordt door de JEM, al kan leiden tot sensibilisatie en sarcoïdose bij genetisch vatbare patiënten. Zulke genetische vatbaarheid is al beschreven bij CBD. Het is mogelijk dat bepaalde genetische veranderingen ook een rol spelen bij sensibilisatie tegen andere anorganische antigenen zoals aluminium, silica en zirkonium. Verder onderzoek zal dit uit moeten wijzen.

Ondanks dat we een associatie aan konden tonen tussen anorganische antigenen en sarcoïdose, hebben we geen associatie gevonden tussen sensibilisatie tegen antigenen van de $P$. acnes bacterie, de mycobacterie en vimentine en sarcoïdose in een Nederlandse patiëntengroep. We vonden zelfs dat een lager percentage sarcoïdose patiënten dan controles gesensibiliseerd was voor $P$. acnes antigenen. Omdat de $P$. acnes bacterie als commensaal voorkomt op de huid bij het merendeel van de mensen, is het niet verassend dat sensibilisatie tegen deze bacterie bij gezonde personen gevonden kan worden. Het lage percentage sarcoïdose patiënten dat sensibilisatie tegen de $P$. acnes bacterie liet zien, kan mogelijk verklaard worden door de verlaagde perifere T-cel functionaliteit tegen vaak terugkerende antigenen welke is beschreven in sarcoïdose. Deze verminderde T-cel functionaliteit in bloed enerzijds en een buitensporige T-cel inflammatie in aangedane organen anderzijds is beschreven als de immuun paradox in sarcoïdose. Daarnaast zou het zo kunnen zijn dat $P$. acnes specifieke T-cellen vanuit het bloed naar aangedane weefsels zijn getrokken waardoor er geen sensibilisatie in bloed gevonden wordt. Bloed lijkt daarom niet het meest geschikt om sensibilisatie tegen de $P$. acnes bacterie te onderzoeken. Echter, het is vrij invasief om sensibilisatie tegen $P$. acnes in andere organen te onderzoeken omdat dit verrichting van bijvoorbeeld een BAL of lymfeklier punctie zou vereisen. Om deze reden hebben we met een immunohistochemische kleuring gekeken of we $P$. acnes konden aantonen in reeds aanwezig weefsel en granulomen van sarcoïdose patiënten. We hebben in hoofdstuk 7 voor de eerste keer laten zien dat de $P$. acnes bacterie aanwezig is in weefsel en granulomen van Nederlandse sarcoïdose patiënten. Daarnaast bleek de subgroep van de sarcoïdose patiënten waarbij $P$. acnes aangetoond kon worden in granulomen een 
chronischer en ernstiger ziektebeloop te hebben dan de sarcoïdose patiënten waarbij we $P$. acnes niet hebben gedetecteerd in granulomen. in hoofdstuk 8 zagen we dat aanwezigheid van $P$. acnes in granulomen niet specifiek is voor sarcoïdose en dat dit ook gevonden kan worden bij patiënten met andere granulomateuze ziektes. Deze bevinding, samen met de afwezigheid van sensibilisatie tegen $P$. acnes antigenen in bloed, is niet ondersteunend voor een rol van $P$. acnes als specifieke trigger in sarcoïdose. De observatie dat $P$. acnes in granulomen van sarcoïdose patiënten associeerde met een chronisch ziektebeloop en de observatie dat HP patiënten met $P$. acnes in granulomen een hoger lymfocyten percentage hebben in de BAL duiden meer op een mitogene rol van $P$. acnes, zoals al eerder is beschreven in de literatuur. Ondanks dat onze resultaten meer wijzen op een mitogene rol van $P$. acnes dan op een rol als specifieke trigger in sarcoïdose zou het identificeren van $P$. acnes in granulomen van sarcoïdose patiënten van belang kunnen zijn. Er kan dan bijvoorbeeld onderzocht worden of deze subgroep van sarcoïdose patiënten gebaat is bij het gebruik van antibacteriële therapie.

Het voornaamste doel van dit proefschrift was om te onderzoeken of er triggergerelateerde fenotypes van sarcoïdose te identificeren zijn. In een heterogene groep sarcoïdose patiënten zagen we inderdaad dat bepaalde antigenen gerelateerd waren aan de betrokkenheid van organen of aan een ander ziektebeloop. Twee van deze triggergerelateerde fenotypes, namelijk $P$. acnes en een chronisch ziekte beloop, en anorganische antigenen en pulmonale fibrose, zijn hierboven al uitgebreid beschreven. Een verklaring voor de relaties tussen deze triggers en fenotypes zou verklaard kunnen worden door de mitogene werking van $P$. acnes waardoor een inflammatoire reactie aan houdt, en het door het lichaam moeilijk kunnen verwijderen van anorganische deeltjes waardoor inflammatie, schade en fibrose zou kunnen ontstaan. We zagen in hoofdstuk 5 een derde, meer verassend, trigger-gerelateerd fenotype namelijk de relatie tussen een LTBI en cardiale betrokkenheid in sarcoïdose. Sarcoïdose patiënten waarbij een LTBI gevonden wordt zouden mogelijk baat kunnen hebben bij een Tuberculose behandeling, om zo cardiale betrokkenheid te voorkomen. Een verklaring voor de associatie tussen een LTBI en cardiale sarcoïdose zou moleculaire mimicry kunnen zijn. Moleculaire mimicry houdt in dat dezelfde epitopen aanwezig kunnen zijn op meerdere eiwitten. Een epitoop is het gedeelte van een molecuul of antigen, dat door cellen van het immunsysteem herkend wordt. Bacteriën en virussen kunnen bijvoorbeeld dezelfde epitopen bevatten als epitopen die voorkomen op onze eigen immuun cellen. Wanneer een immuunreactie tegen deze microbiële antigenen in gang wordt gezet kan door een kruis reactie de tolerantie tegen onze eigen epitopen verbroken worden waardoor een auto-immuun reactie ontstaat. Een voorbeeld hiervan is reumatische hart ziekte als gevolg van acute reuma. Hierbij ontstaat een auto-immune 
reactie als vervolg op infectie met de Streptococcus pyogenes bacterie, waarbij T-cellen zowel streptokokken peptiden als peptiden in ons eigen hart herkennen en aanvallen. Zulke cross-reacties zouden ook aanwezig kunnen zijn tussen de mycobacterie en hart weefsel. Verder onderzoek is nodig om dit aan te kunnen tonen.

Gebaseerd op de resultaten beschreven in dit proefschrift lijkt het belangrijk om het vaststellen van immunologische sensibilisatie tegen mogelijk triggers van sarcoïdose op te nemen in de work-up van toekomstige sarcoïdose patiënten. Het is van belang om verder te onderzoeken of de trigger-gerelateerde fenotypes beschreven in dit proefschrift klinisch relevant zijn. In andere woorden, we zullen een brug moeten slaan tussen de identificatie van trigger-gerelateerde fenotypes en een op fenotype gebaseerde behandeling van sarcoïdose. De nieuwe inzichten en hypothesen gebaseerd op de bevindingen in dit proefschrift zijn samengevat in Figuur 1.

Concluderend, sarcoïdose is een complexe ziekte en mogelijk het resultaat van de wisselwerking tussen genetische varianten in immuun cellen en andere processen enerzijds en specifieke antigenen anderzijds. De resultaten beschreven in dit proefschrift versterken de hypothese dat sarcoïdose kan ontstaan als reactie op verscheidene antigenen welke van patiënt tot patiënt kunnen verschillen, en zijn mogelijk een eerste stap in de richting van antigeen gerelateerde behandeling in subgroepen van sarcoïdose patiënten. 


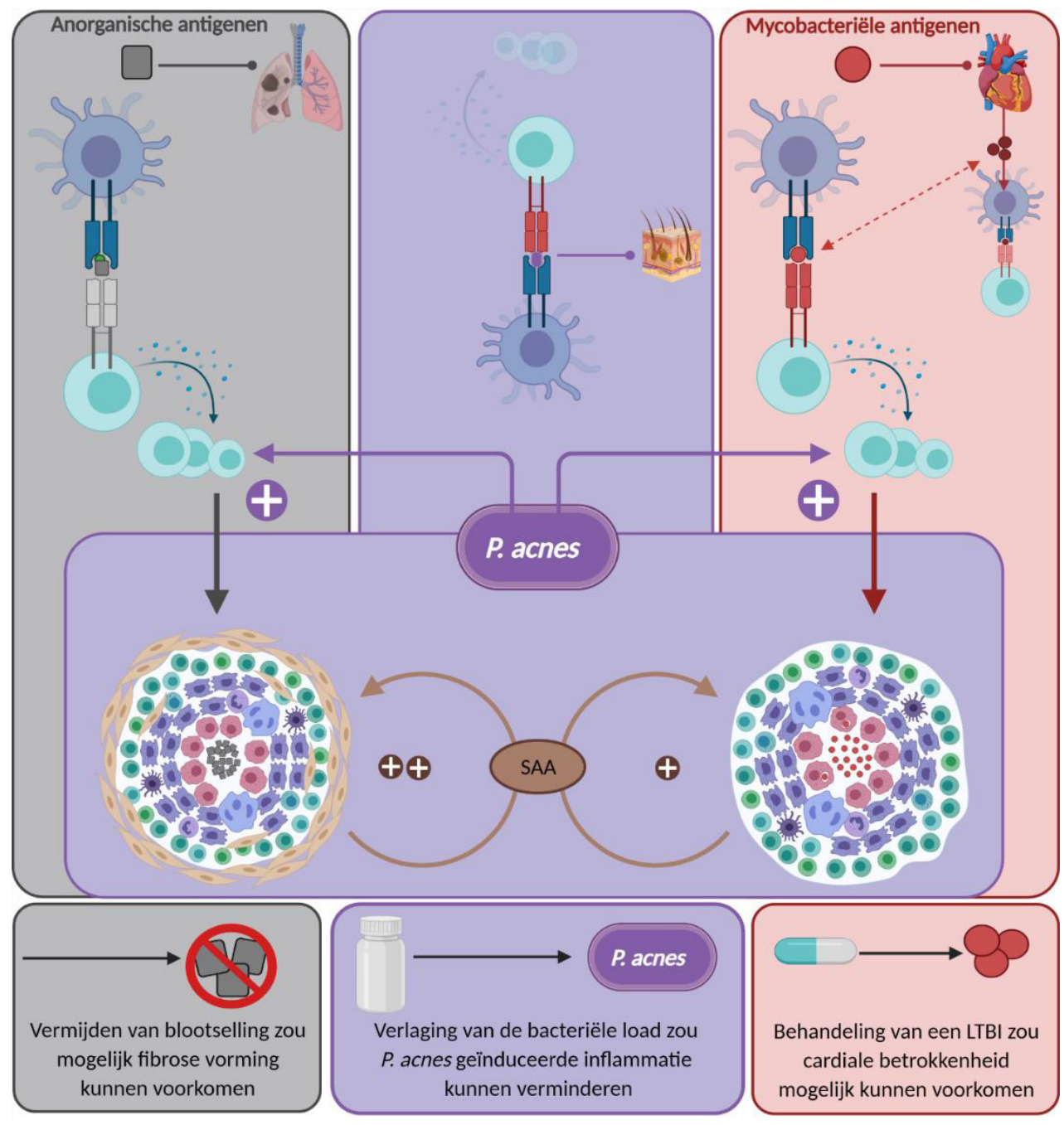

Figuur 1 geeft een schematisch overzicht van de trigger-gerelateerde fenotypes waargenomen in dit proefschrift en bijbehorende toekomstige behandel opties.

Anorganische antigenen die niet geklaard kunnen worden zouden, in genetisch vatbare patiënten, kunnen leiden tot chronische ontsteking en weefselschade, wat kan resulteren in fibrose. Het vermijden van blootstelling zou voor deze patiënten meer baad kunnen hebben dan het ophogen van immuun suppressieve medicatie. Mitogene effecten van de $P$. acnes bacterie, zoals het versterken van lymfocyten proliferatie en cytokine productie, zouden inflammatie en granuloomvorming in stand kunnen houden. Het verlagen van de bacteriële load zou deze extensieve ontstekingsprocessen kunnen verminderen. Cardiale betrokkenheid zou kunnen ontstaan door mimicry tussen tuberculose antigenen en cardiale eiwitten. Behandeling van een latente tuberculose infectie zou mogelijk cardiale betrokkenheid kunnen voorkomen. 


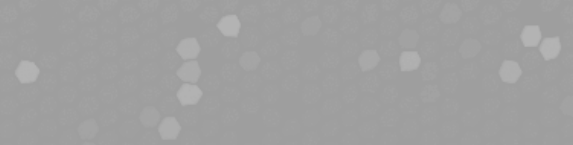

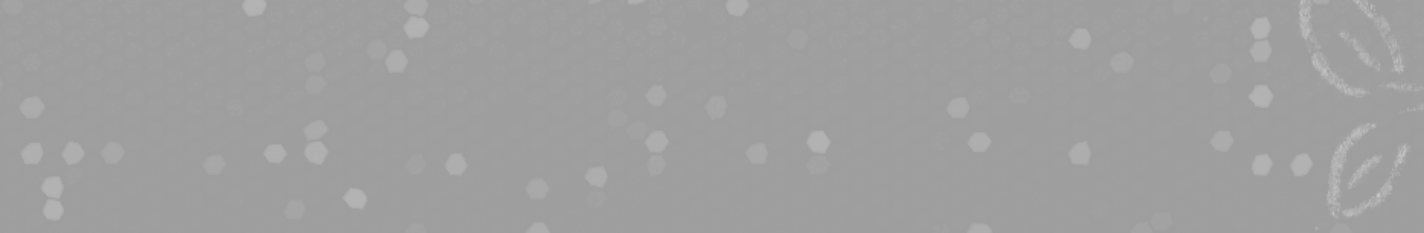<smiles>C1CCCC1</smiles>

$\therefore \%$

0.0<smiles>COCO</smiles>

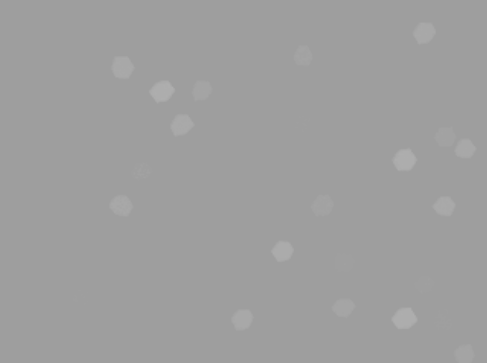

$0+0$

no

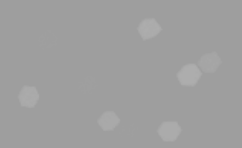<smiles>O=CCO</smiles>

80

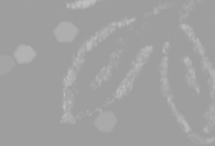

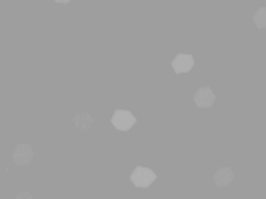

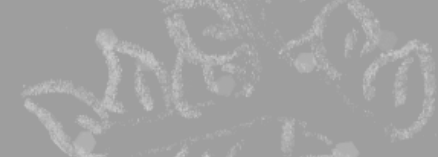

है $2(f)(3)+2)^{2}=$<smiles>O=C1CC(=O)C1</smiles>

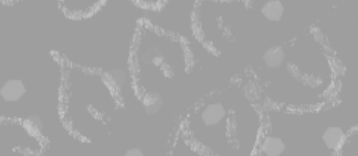

$(8)$

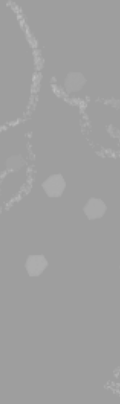

$\int_{0}^{2} y^{2}$

-

a
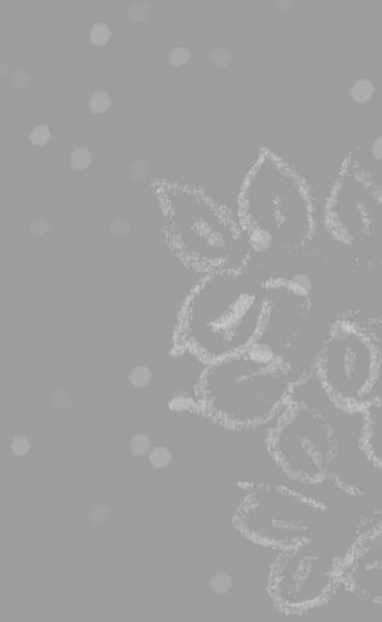

○

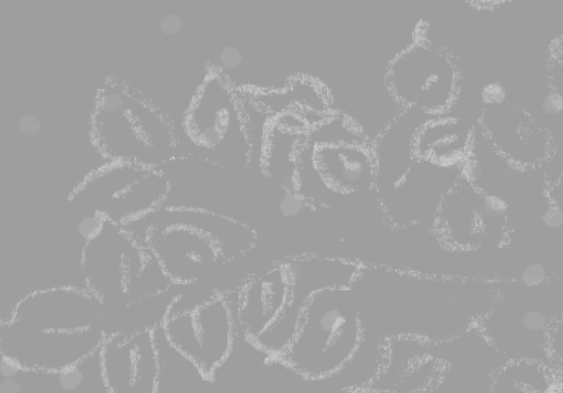


Affiliations of the authors 
In order of appearance in the manuscript:

\section{Els Beijer}

Interstitial Lung Diseases Centre of Excellence, Department of Pulmonology, St. Antonius Hospital, Nieuwegein, The Netherlands

\section{Marcel Veltkamp}

Interstitial Lung Diseases Centre of Excellence, Department of Pulmonology, St. Antonius Hospital, Nieuwegein, The Netherlands

Division of Heart and Lungs, University Medical Centre, Utrecht, The Netherlands

\section{Bob Meek}

Department of Medical Microbiology and Immunology, St. Antonius Hospital, Nieuwegein, The Netherlands

\section{David R. Moller}

Division of Pulmonary and Critical Care Medicine, Johns Hopkins University School of Medicine, Baltimore Maryland, USA

\section{Raisa Kraaijvanger}

Interstitial Lung Diseases Centre of Excellence, Department of Pulmonology, St. Antonius Hospital, Nieuwegein, The Netherlands

\section{Hans Kromhout}

Institute for Risk Assessment Sciences, Utrecht University, The Netherlands

\section{Wouter H. van Es}

Department of Radiology, St. Antonius Hospital, Nieuwegein, The Netherlands

\section{Kees A. Seldenrijk}

Pathology DNA, Department of Pathology, St. Antonius Hospital, Nieuwegein, The Netherlands

\section{Marjolein Drent}

Interstitial Lung Diseases Centre of Excellence, Department of Pulmonology, St. Antonius Hospital, Nieuwegein, The Netherlands 
Department of Pharmacology and Toxicology, FHML, Maastricht University, Maastricht, The Netherlands

Jos M. Rooijackers

Netherlands Expertise Center for Occupational Respiratory Disorders, Utrecht, The Netherlands

\section{Xavier Bossuyt}

Laboratory Medicine, University Hospital Leuven, Leuven, Belgium

Department of Microbiology and Immunology, KU Leuven, Leuven, Belgium

\section{Susan Peters}

Institute for Risk Assessment Sciences, Utrecht University, The Netherlands

\section{Roel C.H. Vermeulen}

Institute for Risk Assessment Sciences, Utrecht University, The Netherlands

\section{Claudia Roodenburg}

Interstitial Lung Diseases Centre of Excellence, Department of Pulmonology, St. Antonius Hospital, Nieuwegein, The Netherlands

Department of Medical Microbiology and Immunology, St. Antonius Hospital, Nieuwegein, The Netherlands

\section{Jan C. Grutters}

Interstitial Lung Diseases Centre of Excellence, Department of Pulmonology, St. Antonius Hospital, Nieuwegein, The Netherlands

Division of Heart and Lungs, University Medical Centre, Utrecht, The Netherlands

\section{Annelies L. M. Bakker}

Department of Cardiology, St. Antonius Hospital, Nieuwegein, The Netherlands

\section{Marco C. Post}

Department of Cardiology, St. Antonius Hospital, Nieuwegein, The Netherlands

\section{Yoshinobu Eishi}

Department of Human Pathology, Tokyo Medical and Dental University, Tokyo, Japan 


\section{Keisuke Uchida}

Department of Human Pathology, Tokyo Medical and Dental University, Tokyo, Japan

\section{Jan Damen}

Pathology DNA, Department of Pathology, Jeroen Bosch Hospital, 's-Hertogenbosch, The Netherlands

\section{Marian J.R. Quanjel}

Interstitial Lung Diseases Centre of Excellence, Department of Pulmonology, St. Antonius Hospital, Nieuwegein, The Netherlands

\section{Milou C. Schimmelpennink}

Interstitial Lung Diseases Centre of Excellence, Department of Pulmonology, St. Antonius Hospital, Nieuwegein, The Netherlands 


\section{Dankwoord}


Met het schrijven van dit dankwoord is er officieel een einde gekomen aan dit proefschrift en aan mijn tijd als promovendus. Opgelucht dat dit proefschrift er nu ligt, vind ik het ook jammer dat mijn tijd in het Antonius hiermee ten einde komt. Zonder de hulp van velen, op alle mogelijke vlakken, zou dit proefschrift hier nu niet hebben gelegen.

Allereerst wil ik daarom alle patiënten bedanken die mee hebben gedaan aan wetenschappelijk onderzoek. Zonder deze bijdrage zou onderzoek zoals beschreven in dit proefschrift onmogelijk zijn.

Daarnaast wil ik een aantal mensen in het bijzonder bedanken. Te beginnen bij:

Dr. Veltkamp, beste Marcel, ik wil je ontzettend bedanken voor al je aanstekelijke enthousiasme en je prettige begeleiding! Bewonderingswaardig hoe je in je overvolle agenda altijd tijd maakte om te overleggen. Ik heb ervan genoten om samen over de data en manuscripten te sparren waarbij altijd ruimte was voor eigen inbreng. Uitspraken als: "We gaan er eens even een klap op geven", "Leuk stuk!", en "Submitten die hap", zullen me nog lang bij blijven. En nu gaan we bier drinken!

Dr. Meek, beste Bob, bedankt dat ik altijd bij je aan kon kloppen met immunologische vragen, praktische tips voor in het lab, en je connecties zodat ik in meerdere ziekenhuis labs mee heb kunnen kijken. Zonder deze begeleiding waren de elispot resultaten er niet gekomen. Daarnaast ook bedankt voor alle tijd die je genomen heb om de manuscripten van scherpe en gedetailleerde feedback te voorzien!

Prof. Dr. Grutters, beste Jan, ook jou wil bedanken voor je begeleiding, je scherpe opmerkingen en vragen tijdens presentaties en suggesties om verder te onderzoeken. Bedankt dat je altijd tijd maakte en voor je waardevolle input en feedback op alle delen van dit proefschrift.

Dr. van Moorsel, beste Coline, ook al ben ik denk ik een van de weinige promovendi die je niet direct begeleid hebt, toch wil ik je bedanken voor de begeleiding die hebt gegeven tijdens project besprekingen. Je voelde altijd haarfijn aan waar het project, en vooral ik, op bijgestuurd moest worden om de vaart erin te houden. Het viel soms wat rauw op m'n dak, maar zonder jouw directe woorden lag dit proefschrift er nu waarschijnlijk nog steeds niet.

Jan, Marcel en Coline, bedankt dat ik onderdeel mocht zijn van deze fantastische onderzoeksgroep, ik heb een ontzettend leuke en leerzame tijd gehad! Daarnaast ben ik enorm dankbaar dat ik zoveel binnen en vooral ook buitenlandse congressen heb mogen 
bezoeken. Ik realiseer me dat het heel bijzonder is en voel me bevoorrecht dat ik afgelopen jaren zoveel gave plekken heb kunnen zien!

Dr. Seldenrijk, beste Kees, bedankt voor alle tijd die je, zelfs na je pensioen, in het $P$. acnes onderzoek hebt gestoken. Ik heb genoten van alle leerzame uren achter de microscoop en je oprechte interesse. Het was je nooit teveel om "even" naar het Antonius te komen om weer een lading coupes te beoordelen. Daarnaast is de week met de Japanners iets wat ik waarschijnlijk nooit zal vergeten. Bedankt ook voor je gastvrijheid en gezelligheid die week!

Graag wil ik ook alle andere co-auteurs bedanken voor hun bijdrage aan het onderzoek en de manuscripten!

Jan Damen, bedankt voor je hulp en doorzettingsvermogen bij het opzetten van de $P$. acnes kleuring! Bedankt dat ik altijd langs mocht komen in het JBZ en je begeleiding in de "plons chemie". Dankzij jou hebben we de kleuring tóch machinaal draaiend weten te krijgen. Daarnaast ook bedankt voor alle kleuringen die hebt gedraaid en je bijdrage aan de 2 manuscripten die hieruit voort zijn gekomen.

Analisten van het pathologie lab, bedankt voor jullie hulp bij de eerste stapjes in het opzetten van de $P$. acnes kleuring en jullie inhoudelijke bijdrage in de week met de Japanners.

Medewerkers van het pathologie secretariaat, bedankt voor al het materiaal dat jullie voor me hebben opgevraagd en hebben verzonden.

Dear Prof. Dr. Eishi, I would like to thank you, Keisuke and other colleagues for providing the $\mathrm{PAB}$ antibody and $P$. acnes catalase antigen and for the fruitful collaboration. Thank you for receiving us in your pathology lab in Tokyo, for visiting the St. Antonius hospital and your help with the immunohistochemical $P$. acnes staining. "Never give up!"

Prof. dr. ir. J. Kromhout, beste Hans, bedankt voor je hulp bij het coderen van de beroepsgeschiedenis, en voor het koppelen van metaal en silica blootstelling aan al deze beroepen.

Claudia, bedankt voor al je hulp bij het bij elkaar pipeteren van dit proefschrift! Nooit was iets je teveel en nergens draai jij je hand voor om, en dat altijd met een uitbundige lach! 
Raisa, ook jij ontzettend bedankt voor al je hulp bij alle elispots en luminexen. Tijdens je sollicitatie gesprek vertelde je dat je gek bent op labwerk, nou.. dat heb je geweten! Dankzij de hulp van jou en Claudia heeft het project een enorme sprint gemaakt. Ik ben jullie ontzettend dankbaar voor al het pipeteer werk!

Analisten van de $\mathrm{MMI}$, bedankt voor het aannemen, registreren en doorgeven van alle "IGRASAR bloedjes". Bedankt dat ik gebruik heb mogen maken van jullie praktische kennis en laboratorium.

Amina, bedankt voor het benaderen, nogmaals benaderen en nógmaals benaderen van al die patiënten voor een bloedafname. Ook dit heeft ervoor gezorgd dat ik opeens een bak met resultaten had waaruit een mooi artikel voort gekomen is!

ILD-verpleegkundigen en ILD-artsen, ik wil jullie ontzettend bedanken voor jullie hulp bij het includeren van de sarcoïdose patiënten! Zonder jullie hulp en inzet hadden we die 200 inclusies nooit gehaald.

Annette en Aernoud, Annette ten eerste bedankt voor het bepalen van een aantal SNPs, en Aernoud voor het verschaffen van data in je nieuwe Redcap functie. Daarnaast vooral bedankt voor alle fietstochtjes, terrasjes, film avonden, etentjes, potjes rummikub, gezelligheid en jullie humor! Collega's zoals jullie hebben mede gemaakt dat ik zo'n leuke tijd heb gehad in het Antonius. Veel dank dat jullie mijn paranimfen willen zijn!

Alle andere collega's en (ex) collega's van de onderzoeksgroep, Lisette, Annelies, Michelle, Dymph, Sofia, Milou, Montse, Mark, Karlijn, Karin, Kim, Helmi, Yvonne, Sanne, Inge, Ivo, Thijs, Heleen, Nynke, Marjolein en alle anderen, bedankt voor jullie hulp bij inhoudelijke en praktische zaken, alle grappen \& grollen, koffie \& taart, uitjes, borrels, pubquizen, gezelligheid op congressen en gezelligheid in het algemeen!

Ilse, Sofie, Loes, Brigitte, Manou, Lisanne, Liesan en Marlin, wat hebben wij al veel meegemaakt met elkaar. Naast een eerste bruiloft, baby, eigen bedrijf en emigratie, nu ook een eerste proefschrift. Ik ben jullie ontzettend dankbaar voor jullie onvoorwaardelijke vriendschap, inmiddels al zólang dat ik wel durf te beweren dat deze voor altijd is. Ik wil jullie bedanken voor al jullie interesse en enthousiaste reacties als ik weer eens vertelde dat er een artikel gepubliceerd was, maar meer nog voor alle fantastische weekendjes weg, $3^{\mathrm{e}}$ kerstdagen, borrels, etentjes en ga zo maar door. Zonder al deze momenten van ontspanning was het onmogelijk geweest gemotiveerd dit proefschrift af te ronden! 
Heike, Melanie, Lisa en Claudia, wat ben ik blij dat wij elkaar tijdens onze studie hebben leren kennen! Leuk hoe wij allen een ander pad in zijn geslagen, en toch met elkaar kunnen sparren over nieuwe banen, eten, en vele andere dingen. Jullie ook bedankt voor de weekendjes weg, etentjes, wandelingen, vriendschap en gezelligheid!

Rob en Cilka, en overige schoonfamilie, bedankt voor jullie interesse en dat ik aan mocht haken bij veel etentjes, wandelingen en vakanties! Zulke momenten van ontspanning doen het altijd goed!

Papa, Mama en Jan, ook al begrepen jullie misschien niet altijd wat ik daar nou precies aan het doen was in Nieuwegein, bedankt dat jullie wel altijd geïnteresseerd waren en vroegen of dat artikel nou al gepubliceerd was.

Papa \& Mama, bedankt voor het meegeven van jullie positiviteit, nuchterheid, doorzettingsvermogen en alle andere eigenschappen die bij hebben gedragen aan de afronding van dit promotie traject. Jullie allen bedankt dat ik altijd aan mag komen schuiven, mee mag rijden en dat het altijd zo gezellig is met jullie!

Lieve Quint, allereerst bedankt voor al je relativerende woorden als ik me weer eens veel te druk maakte om vele dingen die bij een promotie traject komen kijken. Jouw lach en steun maakte dat ik het zelf ook kon relativeren en in zag dat het allemaal vast wel goed zou komen. Heel erg fijn dat jij me voor bent gegaan in deze wereld van het promoveren en me daardoor met een aantal dingen kon helpen. Maar het allermeest wil ik je natuurlijk bedanken dat je bent wie je bent, je humor, nuchterheid, dat we al zo lang samen het leven delen maar elkaar ook vrij laten! Ook al zijn we momenteel fysiek gescheiden door een aantal kilometers, we slaan ons hier ook wel weer door heen. Ik hoop dat we samen nog vele mooie reizen mogen maken, concerten en festivals mogen bezoeken, maar vooral nog heel veel lachen samen! 


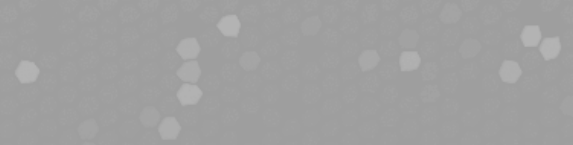

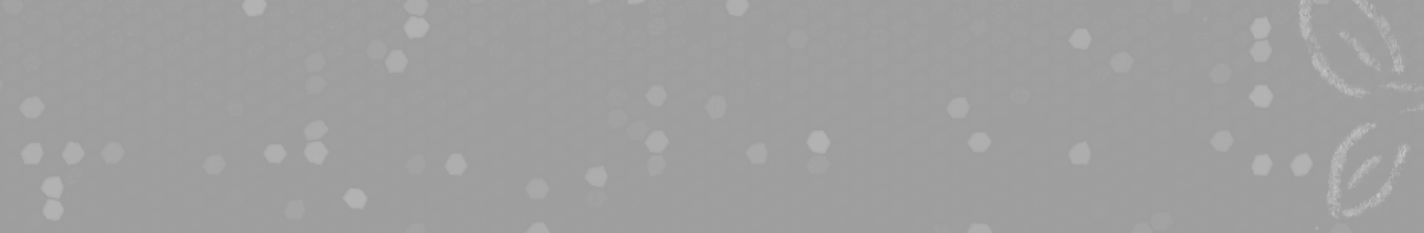<smiles>C1CCCC1</smiles>

$\therefore \%$

0.0<smiles>COCO</smiles>

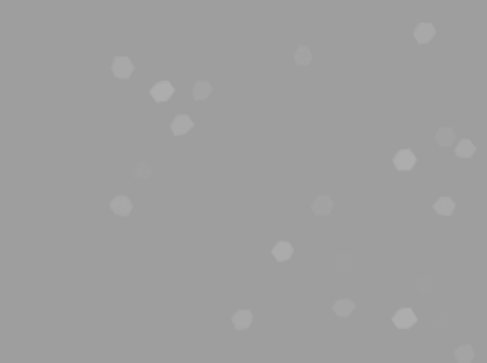

$0+0$

no

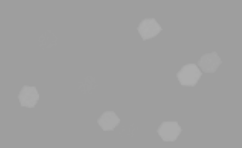<smiles>O=CCO</smiles>

80

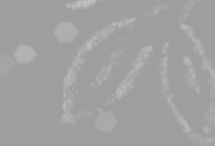

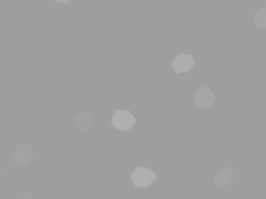

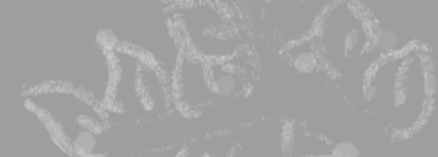

है $2(f)(3)+2)^{2}=$<smiles>O=C1CC(=O)C1</smiles>

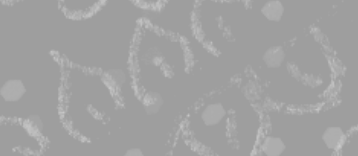

$(8)$

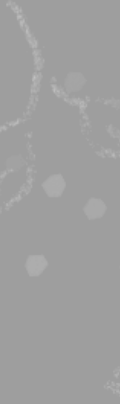

$\int_{0}^{2} y^{2}$

-

a
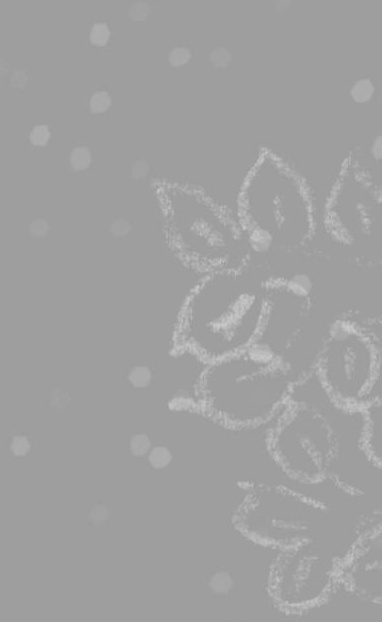

○

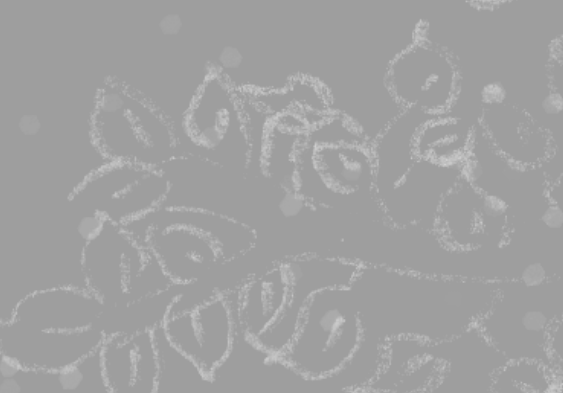




\section{List of publications}

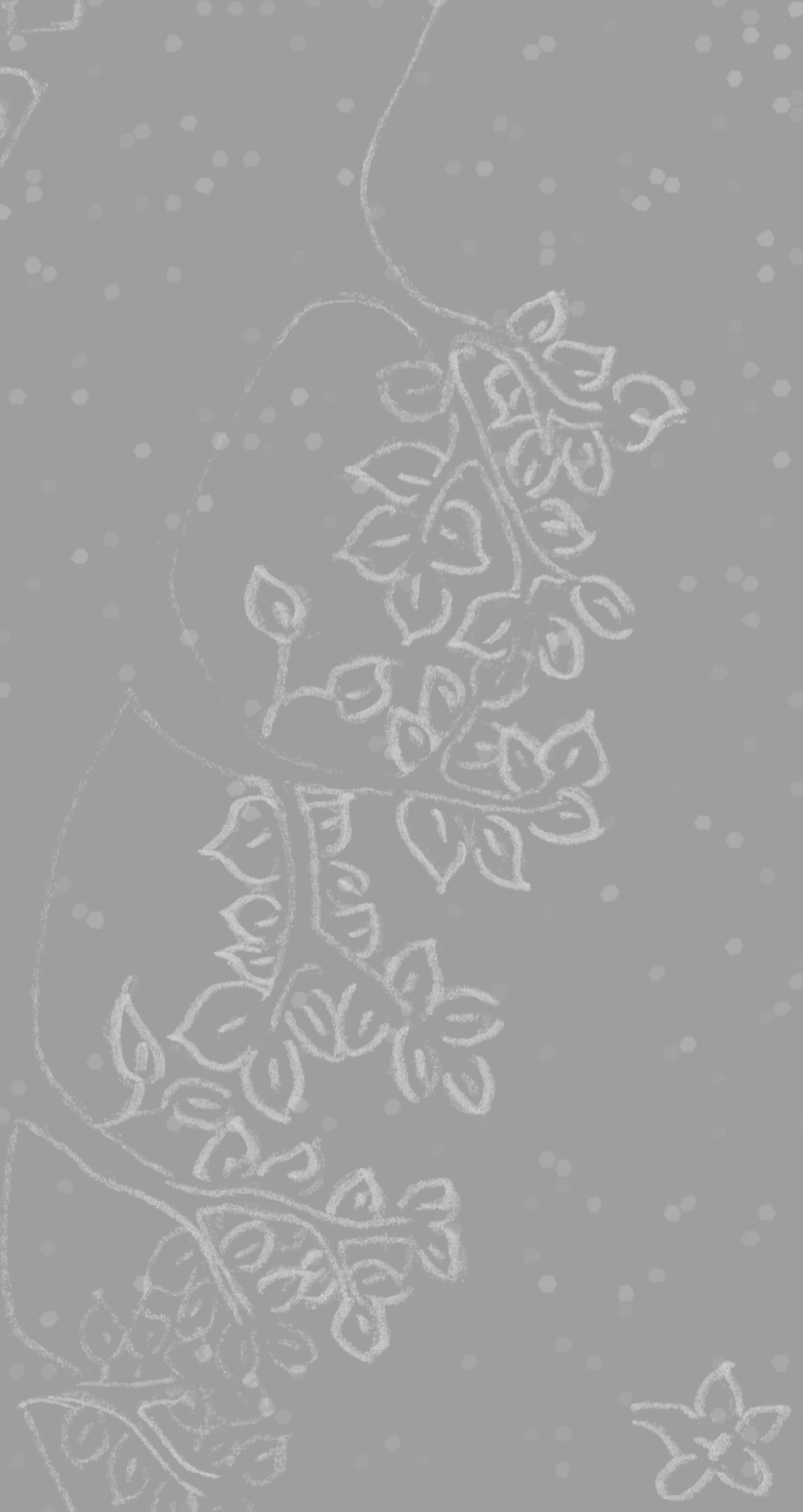


Beijer E, Roodenburg C, Schimmelpennink MC, Grutters JC, Meek B, Veltkamp M. Elevated Serum amyloid A levels are not specific for sarcoidosis but associate with a fibrotic pulmonary phenotype. Cells. 2021; 10(3):585.

Beijer E, Seldenrijk K, Meek B, Damen J, Quanjel MJR, Grutters JC, Veltkamp M. Detection of $C$. acnes in granulomas of patients with either hypersensitivity pneumonitis or vasculitis reveals that its presence is not unique for sarcoidosis. ERJ Open Res. 2021 Jan 1;930-2020.

Beijer E, Seldenrijk K, Eishi Y, Uchida K, Damen J, Grutters JC, Veltkamp M. Presence of Propionibacterium acnes in granulomas associates with a chronic disease course in Dutch sarcoidosis patients. ERJ Open Res. 2021 Jan 1;7(1):486-2020.

Beijer E, Bakker A, Kraaijvanger R, Meek B, Post M, Grutters J, Veltkamp M. Latent tuberculosis infection associates with cardiac involvement in patients with sarcoidosis. Sarcoidosis, Vasc Diffus Lung Dis. 2020;37(3).

Beijer E, Kraaijvanger R, Roodenburg C, Grutters JC, Meek B, Veltkamp M. Simultaneous testing of immunological sensitization to multiple antigens in sarcoidosis reveals an association with inorganic antigens specifically related to a fibrotic phenotype. Clin Exp Immunol. 2020 Sep 17; cei.13519.

Beijer E, Meek B, Bossuyt X, Peters S, Vermeulen RCH, Kromhout H, Veltkamp M. Immunoreactivity to metal and silica associates with sarcoidosis in Dutch patients. Respir Res. 2020 Jun 8;21(1):141.

Beijer E, Meek B, Kromhout H, van Es HW, Seldenrijk K, Drent M, Rooijackers JM, Veltkamp $M$. Sarcoidosis in a patient clinically diagnosed with silicosis; is silica associated sarcoidosis a new phenotype? Respir Med Case Reports. 2019 Jan 1;28:100906.

Beijer E, Veltkamp M, Meek B, Moller DR. Etiology and Immunopathogenesis of Sarcoidosis: Novel Insights . Semin Respir Crit Care Med. 2017 Aug;38(4):404-16. 


\section{Curriculum Vitae}

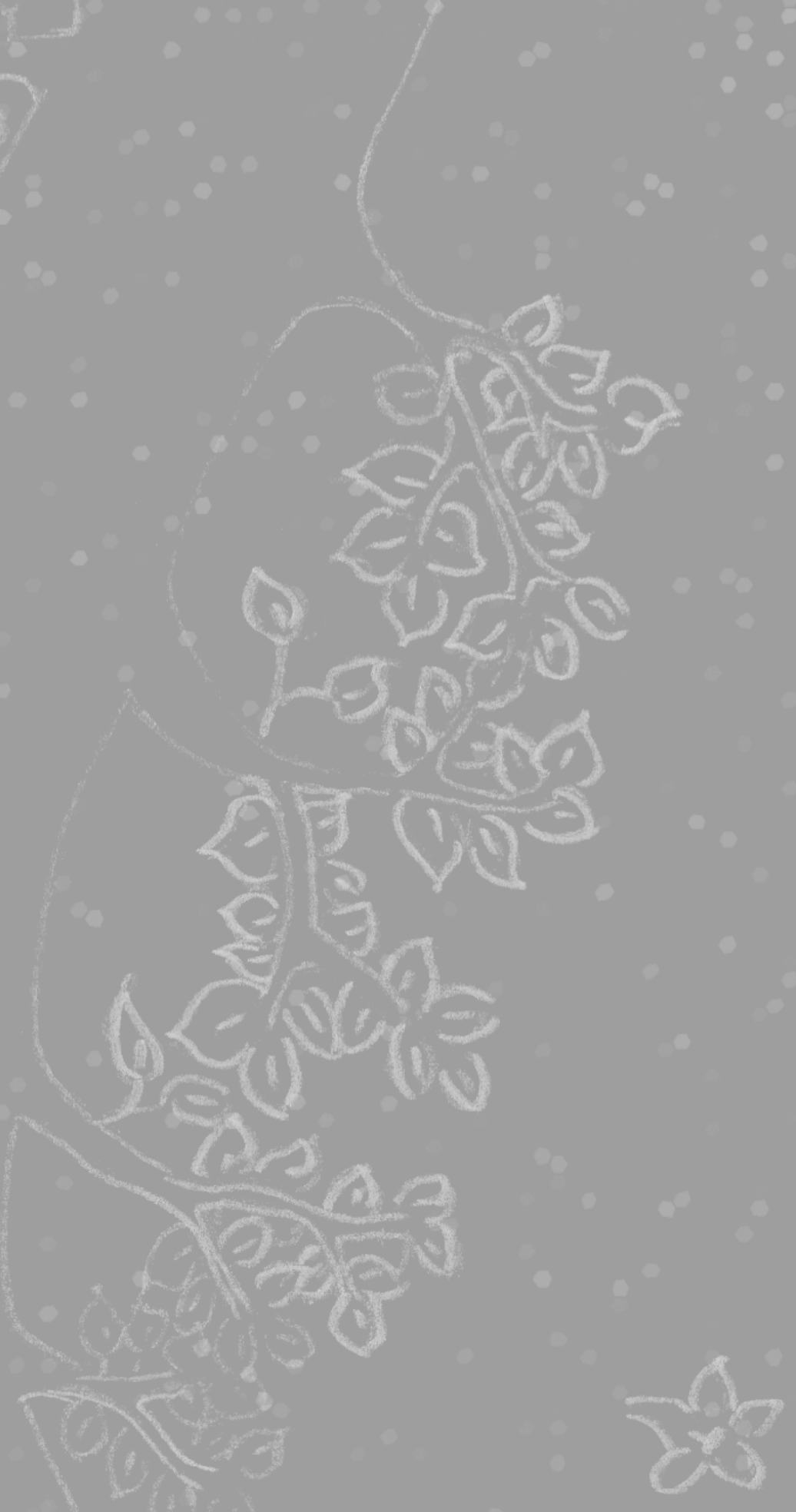


Elsje Dinanda Beijer was born on May 8th 1991 in Zutphen. She finished high school at Stedelijk Dalton college Zutphen in 2009. In this year she started studying Nutrition \& Health at the Wageningen University and obtained her bachelor degree in 2012. She continued with the master specialization Molecular nutrition and Toxicology at the Wageningen University in 2012. During her master she performed research in the department of Nutrition \& Pharmacology on receptor(s) possible involved in the anti-inflammatory effects of the fatty acid ethanol-amide DHEA. Thereafter she moved from Wageningen to Utrecht for an internship at the Utrecht institute of pharmaceutical sciences about the effects of probiotics on the allergic/immune response in a co-culture model consisting of intestinal epithelial cells and PBMCs. In 2014 she received her master's degree (MSc). A triggered interest for the immune system and research lead to the start of this PhD project at the Interstitial Lung Diseases Centre of Excellence at the St Antonius Hospital in Nieuwegein. Parts of her research were awarded with a best presentation and a young investigator award at the annual WASOG conferences in 2018 and 2019. 
